\title{
HOW SCIENTIFIC INSTRUMENTS SPEAK
}

A HERMENEUTICS OF TECHNOLOGICAL MEDIATIONS IN (NEURO-)SCIENTIFIC PRACTICE

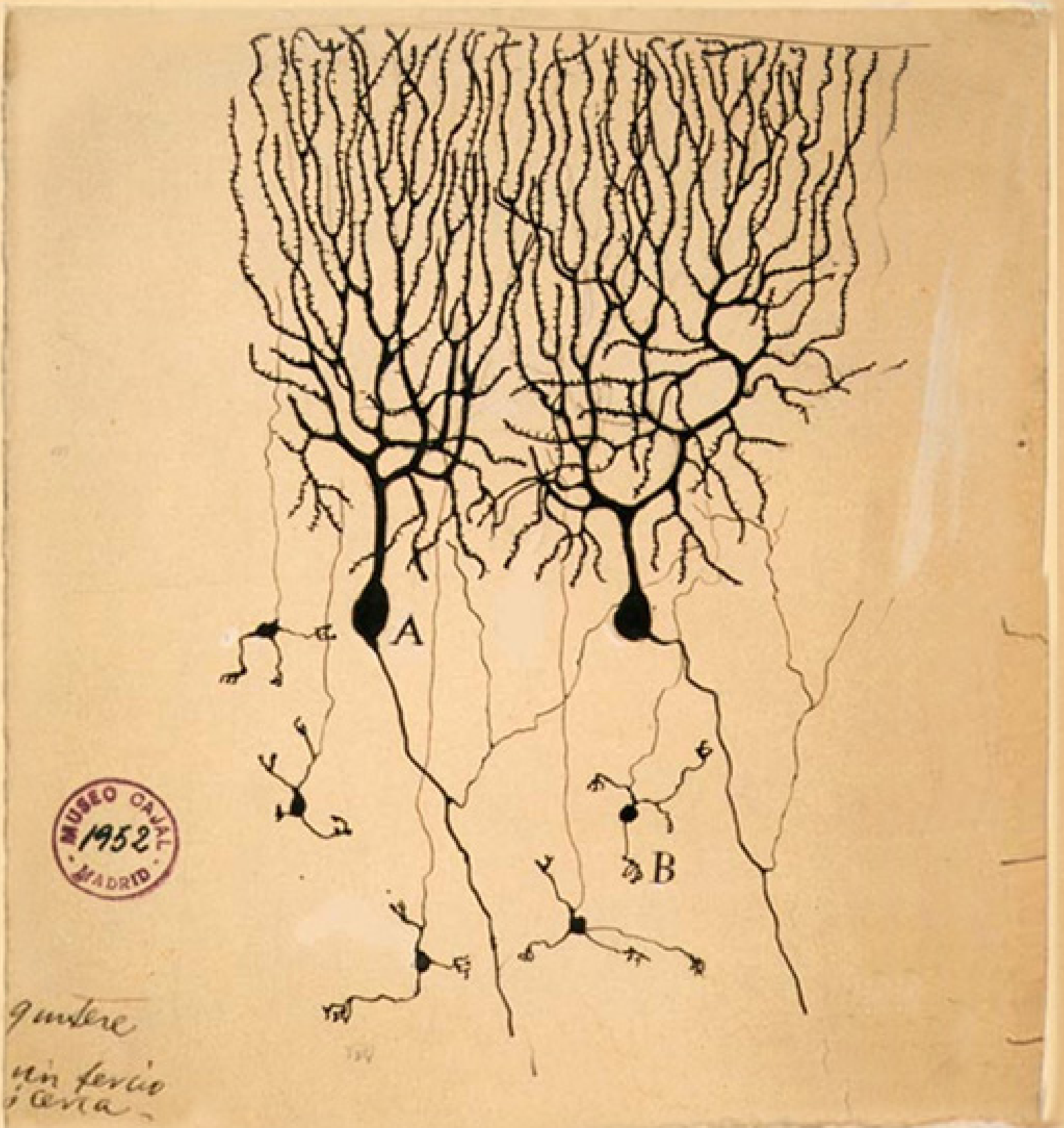


HOW SCIENTIFIC INSTRUMENTS SPEAK

A HERMENEUTICS OF TECHNOLOGICAL MEDIATIONS IN

(NEURO-)SCIENTIFIC PRACTICE

Bas de Boer 
HOW SCIENTIFIC INSTRUMENTS SPEAK

A HERMENEUTICS OF TECHNOLOGICAL MEDIATIONS IN

(NEURO-)SCIENTIFIC PRACTICE

DISSERTATION

to obtain

the degree of doctor at the University of Twente, on the authority of the rector magnificus, prof.dr. T.T.M. Palstra,

on account of the decision of the Doctorate Board, to be publicly defended

on Thursday the $17^{\text {th }}$ of October 2019 at 12:45 hours

Sebastiaan Oege Mathijs de Boer

born on the $28^{\text {th }}$ of November 1989

in 's-Hertogenbosch, The Netherlands 
Supervisors:

Prof. dr. ir. P.P.C.C. Verbeek

Prof. dr. H.F.M. Te Molder

Cover design: Ilse Modder, www.ilsemodder.nl

Printed by: Gildeprint - Enschede, www.gildeprint.nl

Lay-out: Ilse Modder, www.ilsemodder.nl

ISBN: $\quad$ 978-90-365-4838-0

DOI: $\quad 10.3990 / 1.9789036548380$

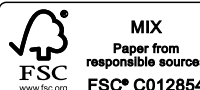

(C) 2019 Bas de Boer, The Netherlands. All rights reserved. No parts of this thesis may be reproduced, stored in a retrieval system or transmitted in any form or by any means without permission of the author. Alle rechten voorbehouden. Niets uit deze uitgave mag worden vermenigvuldigd, in enige vorm of op enige wijze, zonder voorafgaande schriftelijke toestemming van de auteur.

\section{GRADUATION COMMITTEE}

Chairman/secretary Prof. dr. Th.A.J. Toonen

Supervisor

Supervisor

Committee Members
Prof. dr. ir. P.P.C.C. Verbeek

Prof. dr. H.F.M. te Molder

Prof. dr. H.W. de Regt

Dr. F. Russo

Prof. dr. A. Sissel Hoe

Prof. dr. Ir. M. Boon

Prof. dr. C. Aydin
University of Twente University of Twente Wageningen University Radboud University

University of Amsterdam NTNU

University of Twente

University of Twente 
This work is financed by the Dutch National Science Foundation (NWO) VICI grant (grant number: 227-20-006) for the project "Theorizing Technological Mediation: Toward an Empirical-Philosophical Theory of Technology,” led by Prof. dr. ir. P.P.C.C. Verbeek. 


\section{Contents}

Introduction: Technological Mediations and (Neuro-)Scientific Practice

The Context of Discovery and the Context of Justification in Philosophy of Science

Instruments in the Philosophy of Science: Three Perspectives

The Technological Mediation Approach Applied to Scientific Practice

Scientific Instruments in Neuroscientific Practice

Structure of the Book

Part I: Towards a Theory Of Technological Mediations In Scientific Practice

Chapter 1: The Perspective of the Instruments: Mediating Collectivity

Introduction: Science and Scientific Collectives

\$1.1 Scientific Instruments as Solidified Knowledge

\$1.2 Scientific Instruments as Offering Perspectives on Reality

\$1.3 Science as Distributed Knowledge

\$1.4 The Postphenomenological Perspective of Technological Mediation

\$1.5 Immutable Mobiles and Scientific Networks: The Role of Scientific Instruments from an Actor-Network Perspective

$\$ 1.6$ Technological Mediation and Collective Knowing

\$1.7 Conclusion: Mediating Technologies and Scientific Collectives

Chapter 2: "Technology" and "Human-Technology Relations"

Introduction: "Classical" and "Empirical" Philosophy of Technology

\$2.1 Ready-to-hand and Present-at-hand: Heidegger's Phenomenology of Tool Use

\$2.2 From Tools to Technologies: A Postphenomenology of Human-Technology-World Relations

§2.3 Heidegger's Pessimism: Disclosing the World in The Question Concerning Technology

\$2.4 Conclusion: Enframing and Mediation Within Human-Technology Relations

\section{Chapter 3: Science and the Theoretical Disclosure of Nature}

Introduction: Science as Practice?

$\S_{3.1}$ Heidegger and the Primacy of Practice in Science

$\S_{3.2}$ Science as Re-search

\$3.3 Heidegger's Ambiguous Pessimism Concerning Science

$\$ 3.4$ Postphenomenology and Scientific Practice

\$3.5 Relating to the Present-at-hand: Science as a Specific Kind of Practice

\$3.6 Conclusion: Technological Mediations and the Theoretical Disclosure of Nature
Chapter 4: To the Scientific Objects Themselves: Gaston Bachelard and the Notion of Phenomenotechnique

Introduction: The Sciences and Their Objects

$\S 4.1$ The Epistemological Rupture: Science and Everyday Life

$\$ 4.2$ Phenomenotechnique

\$4.3 Scientific Practice Beyond Physics

$\$ 4.4$ The Rationality of the Scientific Project

\$4.5 Phenomenotechnique as Phenomenotechnology

\$4.6 Conclusion: Explaining Instead of Assuming the Epistemological Rupture

Chapter 5: Bruno Latour and the Difference Between Technical and

\section{Technological Mediation}

Introduction: Science as Explanans

$\S_{5.1}$ Understanding Science as Practice and Understanding Practice as Science

\$5.2 Latour's “Critique" of Critique: How to Avoid a Metalanguage?

$\S_{5.3}$ The Construction of Scientific Entities: Pasteur's Microbes

\$5.4 Scientific Instruments as Inscription Devices and the Constitution of New Entities

$\S_{5.5}$ Science-in-the-making and Science-as-it-has-been-made

\$5.6 Integrating (post-)Phenomenology: A Hermeneutics of Scientific Instruments

§5.7 Conclusion: An Empirical Philosophy of Technoscience: Towards a Methodological Basis

Part II: A Postphenomenological Ethnomethodology of Neuroscientific Practice

Chapter 6: Postphenomenology as Ethnomethodology: Studying How Reality is Accomplished Through the Appropriation of Technological

Mediations

Introduction: How to Study the Constitution of Scientific Objects

§6.1 Schütz's Stranger and Phenomenology: Intersubjectivity and Reality Through a Shared Stock of Knowledge

\$6.2 Ethnomethodology and Reality as Practical Accomplishment

\$6.3 Ethnomethodology and the Re-specification of Science: The Constitution of Galilean Objects

\$6.4 Investigating Scientific Practices Through Conversation Analysis and the Appropriation of Technological Mediations

§6.5 Ethnomethodology and Studying the Appropriation of Technological Mediations 
$\S_{7.1}$ Technological Mediations and Their Appropriations

Samenvatting

Acknowledgements

\$7.2 Data and Methods

About the Author

$\$ 7.3 \quad$ NIBS, EEG, and Visual Attention

$\$ 7.4$ Constituting Visual Attention through NIBS

Publications

$\S_{7.5}$ Combining NIBS and EEG: Complicating Causality

§7.6 Conclusion: Technological Mediations and the Normative Expectation of Causality

\section{Chapter 8: "Braining" Neuropsychiatric Experiments}

Introduction: The "Neuro" in Psychiatry

\$8.1 The Complexity of the Brain as Technologically Mediated

\$8.2 Neuropsychiatry and the Clinical Function of Psychiatry: Complexity and Simplicity

\$8.3 The Role of Diagnostic Labels in the Interpretation of Experimental Data

\$8.4 "Braining" Psychiatric Experiments

\$8.5 Conclusion: The Objectivity of fMRI in the Context of the Trade-off Between Complexity and Simplicity

Conclusion: A Philosophy of Technological Mediation as a Philosophy of

\section{Scientific Practice}

A Philosophy of Scientific Instruments as a Philosophy of Scientific Practice: Technological

Mediation as Reality Building

Towards a Broader Understanding of Technological Mediations:

Developing a Phenomenology of Technicity

The Mediated Reality of Neuroscientific Collectives and the Critical Potential of a

Philosophy of Technological Mediation 


\section{INTRODUCTION:}

Technological Mediations and (Neuro-)Scientific Practice 


\section{INTRODUCTION: TECHNOLOGICAL MEDIATIONS AND (NEURO-)} SCIENTIFIC PRACTICE

In 1665, Robert Hooke's Micrographia was published. In the preface, he writes, "By the means of Telescopes, there is nothing so far distant but may be represented to our view; and by the help of Microscopes, there is nothing so small as to escape our inquiry; hence there is a new visible World discovered to the understanding” (1665). Indeed, it was through a microscope that Hooke could observe the microstructure of organisms and be able to claim that all living organisms are essentially composed of cells (cf. Gest 2004).

In 1990, Seiji Ogawa and colleagues published an article in which they propose a new technique to image the functioning of the brain. They write that "the results suggest that BOLD contrast can be used to provide in vivo real-time maps of blood oxygenation in the brain under normal physiological conditions [...] and complements other techniques that are attempting [to measure] regional neural activity" (1990, 9868). This experimental result marked a key landmark in the development of the cognitive neurosciences because it provided a scientific instrument that allowed the visualization of brain activity in vivo.

These two developments share that new observational techniques allowed a range of new phenomena to become candidates for scientific investigation, thereby opening up new ways to understand the functioning of organisms. Through such developments, new scientific objects come into being (e.g., cells) or existing scientific objects transform, when considered in a new light (e.g., cognitive functions such as perception, attention, etc.). This demonstrates how the sciences co-evolve with technological developments. But how does a new world-revealed through scientific instruments-enter the domain of human understanding, and what kind of world is this?

To answer this question, one must focus on both the role of scientific instruments in scientific practice and how these instruments shape how scientists observe and interpret the world. In this dissertation, I develop an understanding of scientific instruments not as neutrally extending the sensory capabilities of scientists but instead as mediating the reality that scientists study (cf. Ihde 1990; Verbeek 2005). As will become clear, this implies that investigating how scientific instruments shape the reality of science entails simultaneously investigating how this reality is continuously transformed by them.

This dissertation focuses on how scientific instruments mediate the reality studied in scientific practice. This focus leans on two assumptions: (i) that a philosophy of science should focus on scientific practice, not just on scientific theorizing and (ii) that scientific instruments actively shape these practices. In this introduction, I legitimize these assumptions, and throughout this dissertation, I flesh out the consequences of these assumptions for our understanding of science.

\section{The Context of Discovery and the Context of Justification in Philosophy of Science}

Most twentieth century (analytic) philosophy of science assumed scientific theories as a central unit of analysis. This focus reflects Karl Popper's interpretation of Hans Reichenbach's distinction between the context of discovery and the context of justification. Popper argues that whereas the former is concerned with the circumstances in which scientific theories develop, the latter deals with their logical examination. According to Popper, only the context of justification should be of interest to philosophers of science. The context of discovery, on the contrary, fits into the domain of empirical psychology because scientific discoveries do not follow logical trajectories and are therefore inaccessible to philosophical inquiry. In reference to Einstein, he states that "there is no logical path [...] leading to universal laws. They can only be reached by intuition, based upon something like an intellectual love for the objects of experience" (Popper 1959, 31). Based on this distinction, a tradition in the philosophy of science arose that adopted universal laws and the theories in which they function as the proper units of philosophical analysis because these can be analyzed in terms of their rational justifiability.

Joseph Rouse (1996) has called attempts for the rational justification of scientific theories the "legitimation project" within the "traditional" philosophy of science that searches to eliminate subjective elements from scientific research. However, as Rouse argues, this perspective neglects that science and the rationality associated with it only exist to the extent that they are connected to human subjects and that scientific theories and the terms functioning within them cannot be dissociated from human activity. Because of this, a philosophical perspective on science should be able to account for the fact that the objects that the sciences postulate come into being in scientific practices and that the terms used in scientific theories refer back to the practical circumstances in which scientific objects are created. Such a perspective challenges the strict distinction between the context of justification and the context of discovery and suggests that a philosophy of science should be interested in the scientific practices in which the objects of science come into being. In line with this idea, the philosophy of science developed in this dissertation should essentially be considered a philosophy of scientific practice (cf. Ankeny et al. 2011)

\section{Instruments in the Philosophy of Science: Three Perspectives}

In recent decades, philosophers of science-explicitly or implicitly influenced by studies of science in practice-have begun to note the role of instruments in science. The works 
of Bas Van Fraassen, Ian Hacking, and Ronald Giere comprise three of the most wellknown philosophical accounts of scientific instruments.

Van Fraassen opens his analysis of scientific instruments with the question of whether we should understand them as engines of creation or as windows into the invisible world. In the latter case, scientific instruments are passive extensions of the human senses, while in the former case, the use of technologies involves the active creation of new phenomena. Accordingly, the question that Van Fraassen considers at the heart of an analysis of scientific instruments is whether the phenomena detected through instrumental observations must be considered new phenomena or are better understood as phenomena that already existed yet were invisible to us.

How we should conceive of the role of instruments in scientific practice depends on what we consider a scientific observation to be. According to Van Fraassen, "observation is perception, and perception is something [only] possible for us, if at all, without instruments" $(2008,93)$. In his view, "naked" perception is something that is contingent on the physiological make-up of human observers, and even then, it is questionable whether "naked" is an adjective ever to be used in the context of perception, as it implies that it is possible for perceptions to be neither theoretically nor historically laden. From this (empiricist) definition of scientific observation, it can be derived that in Van Fraassen's view, scientific instruments cannot be understood as neutral extensions of our perceptual abilities but instead constitute phenomena that can be observed. Even in his early works, Van Fraassen argues that the human organism is the measure of what can be observed: the "able" in observable refers to our limitations as human beings (e.g., 1980, 17). By definition, then, technologies that augment human perceptive capabilities are not windows into the invisible world but instead engines of creation that are constitutive of new phenomena.

However, this is not the only possible understanding of the concept of "observation." In his analysis of microscopic observations, Ian Hacking also extensively discusses the relation between instrumental observations and those made with human senses. He holds that microscopes do not passively extend the human senses, as "observation is a skill" $(1983,180)$. Hence, it is insufficient to explain the role of the microscope in scientific observation in terms of the neutral extension of our sensory field. As such, he proposes speaking of seeing with a microscope rather than seeing through it. Instead of allowing every observer to passively observe a microscopic body, Hacking argues that the microscope provides images that can only be recognized by skilled microscopists. Hence, according to Hacking, observations involve more than brute perception, as they are structured in relation to the habitual skills that scientists acquire.
Because the phenomena observed by trained microscopists stubbornly refuse to disappear, Hacking holds that we are justified in accepting that microscopic entities exist independently of the microscope. By extending our sensory field, microscopes provide us with already existing yet previously invisible phenomena that can be seen by a skilled observer. In terms of Van Fraassen's distinction, we can say that Hacking develops an understanding of scientific instruments as windows into the invisible world. This contrasts sharply with Van Fraassen's own view, which suggests that by moving beyond our biological limits, "microscopes [...] create phenomena, to be accounted for by theories" (2008, 101, my emphasis). However, both accounts conceptualize scientific instruments as active participants in the observation process, regardless of whether they are considered engines of creation or windows into the invisible world.

Yet, neither of the mentioned accounts explains how the use of scientific instruments allows us to observe previously unknown phenomena. This theme is addressed by Giere, who explains the coming into being of new scientific phenomena in terms of the physical laws that apply to scientific instruments-laws that differ from those that constitute human vision. He holds that, by working according to distinct physical mechanisms, scientific instruments disclose aspects of the world that cannot be detected with the naked human eye. Accordingly, scientific instruments "typically incorporate a built-in perspective on the world" that differs from ours (Giere 2006, 116). His analyses focus on advanced imaging technologies such as magnetic resonance imaging (MRI) and scanning tunneling microscopy. We can observe different phenomena with these technologies, because they provide us with new perspectives other than our human sensory perspective.

In Van Fraassen's terms, Giere understands scientific instruments function as windows into the invisible world, because "they are perspectival in that they interact with only restricted aspects of the world" (Ibid. 59). They allow the detection of phenomena in the world that would remain invisible if our perceptual abilities were restricted to the perspective of human vision. In other words, the world is apparently physically structured so that scientific instruments that possess a certain internal physical design allow us to detect certain physical processes in it. However, the perspective a scientific instrument offers does not itself determine what can be seen but only how phenomena become visible to us. How detected phenomena are subsequently modeled and interpreted is not guaranteed in the internal design of the technology. When we model these detections and theorize about them, "we simply cannot transcend our human perspective, however much some may aspire to a God's-eye view of the universe" (Ibid. 15). How we interpret observations made by scientific instruments is thus fundamentally dependent on the observing scientist(s). 
These three philosophical perspectives share a focus on how scientific instruments can help in establishing a relationship with a world external to the human observer. These are important contributions to a philosophy of science limited to the context of justification, because they ask whether it is rationally warranted to believe in the existence of phenomena unobservable by human perception alone. However, when accepting that the division between the context of discovery and the context of justification is not clear-cut, a philosophy of scientific instruments should also focus on how the objects that scientists reason with-and that end up with in scientific theories-are created in scientific practices, in which scientists relate to reality through technologies.

\section{The Technological Mediation Approach Applied to Scientific Practice}

In the philosophy of technology-contrary to the philosophy of science-the question of how human beings relate to the world through technologies has been widely discussed, particularly from the perspective of postphenomenology (e.g., Ihde 1979, 1990; Verbeek 2005). The point of departure of this line of thinking is phenomenological. Building on the work of Martin Heidegger, technologies are understood as actively shaping how human beings experience reality and the goals they wish to pursue instead of as neutral means that enables the pursuit of pre-existing human goals. The American philosopher of technology Don Ihde neatly captures this phenomenon in the term technological mediation and argues that technologies mediate how human beings relate to the world, thereby shaping their experiences and understanding of the world. In this dissertation, I build upon this idea and develop an understanding of the technological mediation of reality that is specific to the practice of science (cf. Forss 2012; Ihde 1991, 1998; Rosenberger 2008)

Studying how technologies mediate the reality studied in scientific practices requires considering the human beings that interact with technologies. Also, science and technology studies (STS) stress that relations between humans and technologies should be examined not in isolation but rather against the background of the fundamental collectivity of scientific practice (e.g., Coopmans et al. 2014; Vertesi 2012). When seriously considering this idea, we must ask how the reality that scientists study becomes present in relation to technologies and study empirically how this process occurs within scientific collectives. While STS importantly highlights that the constitution of scientific knowledge must be considered relative to the specificities of scientific collectives, it typically ignores the mediating role of scientific instruments in the constitution of the collectivity of science. In postphenomenology, the collective nature of scientific activity is often neglected, yet cannot be surpassed when investigating how technological mediations are appropriated by groups of scientists (cf. Verbeek 2016). For this reason, an investigation into the mediating role of instruments in scientific practice requires a combination of postphenomenology and STS. In Part 1, I outline a philosophy of scientific instruments based on this combination by exploring the following question:

How to understand the mediating role of technologies in scientific practice?

\section{Scientific Instruments in Neuroscientific Practice}

A study of the appropriation of technological mediations is not completed when only approached philosophically, but it also requires us to investigate empirically the role of instruments in scientific practice. ${ }^{1}$ The empirical study of scientific (laboratory) practices has been a central interest of STS from its early days onwards (e.g., Knorr-Cetina 1999; Knorr-Cetina and Mulkay 1983; Gilbert and Mulkay 1984; Latour and Woolgar 1986). A primary achievement was the stream of evidence it produced contradicting the idea that science has a "view from nowhere" from which a relation between a disembodied epistemic subject and an equally isolated object can be established. Studies in STS instead showed that scientific facts and objects are the products of local, collective efforts and are contingent on active human manipulation.

As the two historical examples at the beginning of this introduction demonstrate, Hooke attributed great importance to the microscope and telescope for the progress of science, and similarly functional magnetic resonance imaging (fMRI) is attributed great importance in the development of the cognitive neurosciences. However, such historical anecdotes about the importance of scientific instruments do not reveal much about what they do in scientific practice and how they shape the reality that scientists investigate. Building on the empirical approach developed in STS, I study how scientific objects and facts come into being in relation with scientific instruments. The mere fact that scientific instruments are crucial within science does not explain how this role must be understood. This requires an empirical investigation of how scientific instruments are adopted within collectives of scientists. Accordingly, in this dissertation, I investigate how technologies such as fMRI open up new ways to understand and study the world by examining how these function within scientific practices.

Investigating the role of technologies in scientific practice requires a focus on a specific type of practice. In my case, the focus is on an area of science that has been rapidly growing in recent decades: the (cognitive) neurosciences. I have two primary reasons for focusing on this specific area. Firstly, the development of the neurosciences into "Big Science" ran parallel with the development of advanced imaging technologies allowing the visualization of brain activity. This makes the neurosciences an excellent

Throughout this dissertation, I use the words "scientific instruments" and "(scientific) technology"-unless specified otherwise-interchangeably. The potential relevance for specifically conceptualizing scientific instruments as scientific technologies is specified in $\$ 3.4$ 
area to study how the objects that neuroscientists investigate are shaped in relation with technologies. Secondly, the neurosciences currently draw much public attention and media coverage, often conveying the message that mental phenomena are increasingly demystified by the neurosciences and can be explained purely in materialist terms. The enormous public interest in scientific explanations of the mind makes some suggest that we are currently witnessing a "neurohype" (e.g., Ali, Lifshitz, and Raz 2014). As such, it is pivotal to understand how the objects that neuroscientists investigate and make claims about are shaped by the technologies they use.

In Part 2, I investigate empirically how technologies that allow for the observation of brain activity shape neuroscientific research by addressing the following question:

How do technologies mediate the reality that collectives of neuroscientists investigate in neuroscientific practice, and how to study this empirically?

\section{Structure of the Book}

The dissertation is divided in two parts: Part 1 (Towards a Theory of Technological Mediations in Scientific Practice) is a philosophical exploration of how the reality that scientists investigate can be understood as technologically mediated. In it, I show how a postphenomenological perspective on scientific instruments must be augmented to understand how scientific instruments mediate the reality that scientists study. In Part 2 (A Postphenomenological Ethnomethodology of Neuroscientific Practice), I develop an ethnomethodological approach based on the philosophical explorations in Part 1. This approach is applied to two empirical case studies in which I investigate how knowledge of human cognition in the cognitive neurosciences is mediated by brain imaging and brain stimulation technologies. Part 2 can be regarded as an empirical translation of the theory of technological mediation in scientific practice developed in Part 1

In Chapter 1, I show that scientific instruments can best be understood as mediating technologies. I argue that the two of the most promising philosophical attempts to understand the role of instruments in science-Davis Baird's Thing Knowledge and Ronald Giere's Scientific Perspectivism-mistakenly assume (i) that technologies in science have a determined function and (ii) that the human members of scientific collectives potentially have immediate access to this function. This is illustrated with an example of the use of fMRI in the neurosciences. Using this example, I argue that fMRI instead constitutes a field of opportunities within which neuroscientific interpretations of cognitive functions can occur. These interpretations are themselves not presupposed the field of opportunities offered by fMRI. Because of this, neither can the human members of scientific collectives have immediate access-through fMRI-to their object of interest, nor do scientific technologies warrant interpretative stability within or across scientific collectives. I suggest that an understanding of scientific instruments as mediating technologies is not committed to Baird's and Giere's assumptions and therefore comprises a promising starting point for understanding the role of instruments and science. Thus far, no systematic account of technological mediations in scientific practices has been developed; doing so is the goal of the next chapters, which constitute the first part of this dissertation.

In Chapter 2, I take a detour through the philosophy of technology to explicate how a philosophy of technological mediation leads to a specific perspective on the study of scientific practice.Todoso,Idiscuss how theempiricalturninthephilosophyof technology, in general, and the focus on human-technology relations in postphenomenology, more specifically, can be considered attempts to overcome the uniformity of "classical" philosophers of technology. I show that the concept of "technological mediation" is central to the development of a postphenomenological philosophy of technology By tracing this idea back to Martin Heidegger's famous distinction between the readyto-hand and the present-at-hand, and by showing how Heidegger's phenomenology of tool use is transformed into a postphenomenology of human-technology relations, I flesh out the specific meaning of "technological mediation" in this dissertation. This is done by showing the relevance of the postphenomenological criticism on the late Heidegger's philosophy of technology that is often dismissed as "too pessimistic" and "too monolithic."

In Chapter 3, I show the sense in which the postphenomenological approach demands a modification when moving from the study of everyday practices to scientific practices. I argue that Heidegger's hermeneutics of science cannot be dismissed on the same grounds as his analyses of technology. In scientific practices, the explicit aim is to establish a relation with the present-at-hand that presupposes a deliberate rupture with (the objects of) ordinary experience. This suggests that a central concern for the study of scientific instruments in scientific practice is precisely how a theoretical mode of world disclosure arises from the relation with the ready-to-hand. I argue for a revitalization of Heidegger's hermeneutics of science and show that while Don Ihde's philosophy of scientific instruments rightly foregrounds the importance of technologies in scientific practice, it fails to take into account that engaging in scientific practice requires establishing a theoretical relation with the world. Building on Heidegger's hermeneutics of science, I argue that the theoretical character of scientific practices should-despite the importance of technologies-not be side-stepped.

Heidegger suggests that a turnover of our initial relation with the world can occur in relation with technologies but does not offer a clear picture of how this rupture must be 
understood. In Chapter 4, I turn to the French epistemologist Gaston Bachelard to better understand how this rupture is realized. I use Bachelard's term "phenomenotechnique" to clarify how an initial relation with the world is turned over in scientific practice. This allows me to develop an understanding of scientific objects as artificial objects that only exist insofar they are realized in the relation between existing concepts, mathematical techniques, available technologies, and experimental set-ups. When examining scientific practices through this lens, it becomes evident that scientists do not explain or make predictions about an external nature but about artificial objects realized in a phenomenotechnique. I suggest that only when considering this does it become possible to articulate what is specifically "scientific" about scientific practices. This is an important augmentation of postphenomenology: the intentional relation between scientists is mediated less by "material technologies" but rather by a phenomenotechnology (i.e., by the structure within which scientific objects are realized).

Bachelard uncritically assumes that there is a difference between scientific and ordinary practices. In Chapter 5, I introduce the work of the French philosopher-anthropologist Bruno Latour to critically scrutinize this strict distinction and highlight that, to explain the coming into being of the reality of science, the mundane practical aspects of science are crucial in the constitution of scientific facts. According to Latour, any $a$ priori acceptance of a fundamental difference between scientific and other practices is fictitious because the rationality of science is not the prerequisite for, but the outcome of, specific practices. To investigate how the "true" and the "real" come into being, Latour proposes beginning to study science-in-the-making, a term he develops to denote the practice of science before scientific facts have been accepted. These studies serve to reveal the hybrid nature of scientific facts and objects by laying bare the practices of mediation within which they arise. It is through these mediations that networks are created, within which scientific facts are accepted and acquire the status of "rational" and "true," while they are actually the products of actions of the relevant actants.

Latour crucially highlights the importance of practical aspects in the construction of scientific facts and rightly stresses that the situated practical character of scientific practice demands the empirical study of specific scientific practices. However, Latour's approach can be criticized from the perspective developed in the first part of this work. By contrasting Latour's notion of mediation with the notion of technological mediation as developed in dissertation, I argue that if we wish to understand how technologies allow scientists to relate to new objects, we must understand how the intentionality of scientists is specifically shaped in relation with technologies. I suggest-contrary to Latour-that this requires understanding the networks of actants as embedded in the project of disclosing reality theoretically such that it becomes accessible for scientific inquiry. Accordingly, an empirical approach to studying scientific practices should be developed that considers the theoretical character of the practical, situated activities of scientists.

Part 2 is concerned with the development and application of an approach to scientific practices that considers the insights obtained in the first part of this dissertation. I develop an approach to the mediating role of instruments in scientific practice that considers both the distinctly theoretical (e.g., scientific) character and the non-distinct practical character of scientific practice. I propose studying the appropriation of technological mediations in science in terms of the genesis of a collective epistemic stance. Since the specific of this genesis can only be studied empirically, I use this approach in two empirical case studies focusing on the neurosciences.

In Chapter 6, I show that postphenomenological studies of scientific practices to date have placed a strong focus on how technologies mediate how the phenomena that scientists study become perceptually present. The hermeneutic aspects of technological mediations have accordingly been analyzed in terms of the interpretative flexibility instantiated by the gestalt quality of the visual presentation of scientific phenomena I argue that it is necessary to augment this focus on perception with an analysis of how scientific objects appear in a conceptually meaningful space, such that a shared epistemic stance can be maintained. Phenomenologically inspired approaches in sociology (e.g. ethnomethodology (EM), conversation analysis (CA)) have questioned how a shared epistemic stance comes into being in terms of how an intersubjective reality is practically accomplished. Integrating such perspectives into postphenomenology allows the study of how a shared reality comes into being in the practical interactions between scientists and technologies and in the interactions between scientists. This combination of postphenomenology and EM allows the revelation of how the practical appropriation of technological mediations also shapes the concepts used in scientific theorizing and can help to unravel the conceptual and perceptual strategies that scientists employ to attribute meaning to the phenomena they investigate.

In Chapter 7, I use the approach developed in Chapter 6 to empirically study how the scientific object "visual attention" in the cognitive neurosciences is shaped through appropriations of technological mediations. With the development of brain imaging technologies in the 1980 s and 1990 s and the use of non-invasive brain stimulation (NIBS) since the early 2000s, cognitive neuroscientists have developed ways to study the presumed causality of brain-behavior relationships in vivo. Based on a qualitative study of a group of cognitive neuroscientists who combine brain imaging and brain stimulation techniques to establish causal brain-behavior relationships, I show that the constitution 
of visual attention is managed in terms of a trade-off between the epistemic norms of "causality" and "reality" and that how researchers orient themselves to these norms is mediated by the different technologies used. I argue that NIBS technologies introduce a strong causal imperative that introduces a cause-effect model of the relationship between brain and behavior and that this normative orientation is taken for granted in the scientists' research routine. This leads to a paradoxical situation in which a causal imperative is both a dominant assumption and the desired outcome of research in the cognitive neurosciences. Furthermore, I discuss what implications these results have for how the brain and mind are investigated in big science projects.

In Chapter 8, I turn towards another area that uses the methods of neuroscience to study the human mind: neuropsychiatry. Brain imaging technologies in psychiatry are claimed (i) to ultimately offer an objective foundation for diagnostic processes and (ii) to be able to prescribe forms of clinical (pharmacological) treatment that specifically target the symptoms of a specific mental disorder. I show how brain imaging technologies give rise to a conception of the brain as a complex network, which conflicts with the aim to develop straightforward causal explanations of mental disorders. I argue that the constitution of mental disorders in neuropsychiatric practice occurs through a trade-off of the epistemic norms of complexity and simplicity. Subsequently, I show that this trade-off mediates how the adequacy of earlier psychiatric diagnoses is evaluated and how experiments in neuropsychiatry are designed. My analysis suggests that neuropsychiatrists primarily appropriate brain imaging technologies to allow the mapping of cognitive functions to specific brain areas, instead of using them to orient to the brain as a complex network. To conclude, I discuss the implications of this specific appropriation of brain imaging technologies for how mental disorders are conceptualized.

In the conclusion, I discuss how a philosophy of technological mediation is challenged by the empirical study of scientific practices and how scientific practices can be critically approached from the perspective of a philosophy of technological mediation. On the one hand, I show how empirical case studies challenge the presuppositions of a philosophy of technological mediation; on the other hand, I argue that a philosophy of technological mediation-which explicitly aims to closely engage with scientific and technological practices-does allow for developing a critical position with regard to the practices it investigates and I clarify how this can be done with regard to the cognitive neurosciences. I suggest that a philosophy of technological mediation is best understood as a phenomenology of technicity that allows for revealing the technical modes of thinking at work in scientific practice.

Technoscientific developments are said to develop at such a pace that reflections on them are in danger of running behind. The philosophy of scientific instruments developed in this dissertation attempts to keep pace with technoscience so as to critically engage with it. 


\section{PART I}

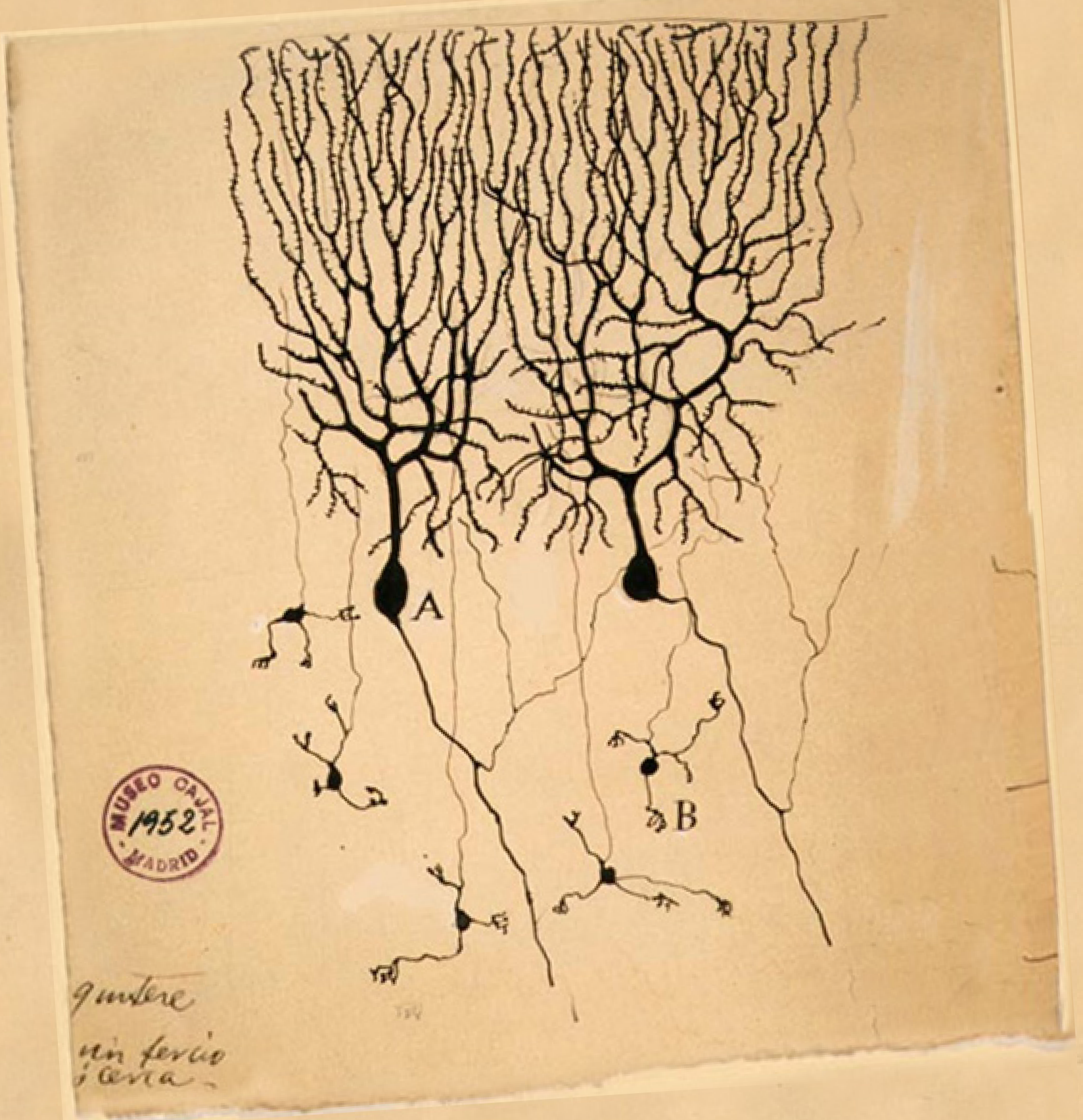

Towards a Theory Of Technological Mediations In Scientific Practice 


\section{CHAPTER 1:}

The Perspective of the Instruments: Mediating Collectivity ${ }^{2}$ 


\section{INTRODUCTION: SCIENCE AND SCIENTIFIC COLLECTIVES}

It is common knowledge in STS and the philosophy of technology that the collective and technological nature of scientific practice has consequences for how scientific knowledge is produced (e.g., Knorr-Cetina 1999; Latour 1987; Lynch 1994). However, the importance of these findings has only slowly been acknowledged in epistemology and the philosophy of science. Two attempts that attempt to integrate these findings into the philosophy of science are Ronald Giere's Scientific Perspectivism (2006) and Davis Baird's Thing Knowledge (2004). ${ }^{3}$ While they diverge in their specific approaches regarding the role of technologies in scientific practice, Giere and Baird share the intuition that the production of scientific knowledge is not something that is exclusively limited to the human realm and that technologies actively shape how scientists understand the world. Both Giere and Baird adoptas a starting point that the importance of scientific instruments becomes immediately clear when examining scientific practice. According to Giere, scientific knowledge is the product of a network of scientists using instruments that offer a specific perspective on the phenomenon being studied. These instruments are critical in structuring these networks; they offer a solid perspective dependent on their internal design. The central point of Baird's philosophy is that "instruments, just as theories, bear knowledge" (Baird 2004, xvii). Baird's central claim is that scientific instruments have an important epistemological function in guiding scientific developments. Contrary to Giere's idea, this occurs not because they are used in a specific way, or offer a certain perspective on the world, but because scientific instruments are instances of solidified knowledge. Instruments can be detached from the context in which they develop and can be used by other scientists who can learn new things from them (Ibid. 119). Their solidity allows different scientists to encounter a stable phenomenon, which makes scientific instruments essential in the development of scientific knowledge.

In this chapter, I argue that both Baird and Giere problematically assume(i) that scientific instruments have a universally determined function and (ii) that all human members of a scientific collective ${ }^{4}$ have immediate access to this function. However, empirical

3 Another branch within philosophers of science, known as New Experimentalism, also attempts to do justice to the importance of scientific instruments. However, rather than focusing on the general importance of scientific instruments, this work is specifically concerned with the use of scientific instruments in relation to experiments. A discussion of this line of research is beyond the scope of this chapter. For an excellent overview, see Boon (2015).

4 In this chapter, we use the notion of "collective" to denote a group of scientists that work in the same laboratory to investigate topic $\mathrm{X}$ through the use of specific set of technologies. While we think that a similar objective may apply to Baird's and Giere's theories if we would expand the notion of "collective" to a larger group of scientists (say, everyone investigating topic $\mathrm{X}$ through the use of a specific set of technologies), we restrict ourselves to this narrow notion of collective to make as clear as possible that scientific observation are grounded in human-technology relations. research on the impact and use of concrete technologies in STS and the philosophy of technology suggests that the function of technologies varies across cases, and that the specific nature of this function depends on how it is integrated in the lifeworld of the user. Postphenomenology is the movement aiming to develop a philosophy of scientific practice that is most closely tied to this line of empirical research (e.g., Friis 2012; Ihde 1991, 1998, 2011, 2012; Olesen 2012; Rosenberger 2008, 2011; Rosenberger and Verbeek 2015; Verbeek 2005). A central idea of this movement is that technologies mediate our relations with the world. In this view, scientific instruments are not neutral intermediaries but actively determining how the world is revealed to scientists. However, this active shaping cannot be cut loose from the scientists who use this instrument, which is captured in the postphenomenological notion of technological mediation.

As we clarify, the idea of technological mediation entails that nothing exists prior to the relation between scientist (human) and instrument (technology). In this chapter, we contrast this idea with Baird's and Giere's analyses of scientific practice, in which the internal design of a technology is decisive in how a scientist relates to the world. In doing so, we aim to specifically clarify how a philosophy of scientific practice grounded in human-technology relations differs from one in which the importance of either humans or technologies is prioritized. From a postphenomenological perspective, neither scientist nor technology is the decisive factor determining how the world is revealed.

But how can a scientific instrument offer a collective, shared perspective or a clear function when those are not pre-determined by the design of the instrument? The postphenomenological focus on human-technology relations has not yet formulated an explicit answer to this problem. ${ }^{5}$ In this chapter, we argue that to understand the collectivity of scientific practice from a postphenomenological perspective, it does not suffice to understand the specific individual relations between observers and scientific instruments. The relations between scientists should be considered as well. Scientific instruments are crucial in structuring these relations, as all involved scientists necessarily must relate to them. In this relation, it becomes clear what counts as intersubjective knowledge and what is subsequently acted upon (cf. Latour 1987; Hutchins 1995). ${ }^{6}$

The idea that scientific practice must be interpreted in terms of human-technology relations is compared with Latour's actor-network theory (ANT) account of collective

5 This question is related to what Rosenberger (2016) has recently called postphenomenology's problem of invariance. That is, if technologies in scientific practice should be understood in non-essentialist, nonfoundationalist terms, how can a (multi-)stable use of them be maintained across individuals?

6 In this chapter, the term "intersubjectivity" is not cognitively interpreted in terms of the mental states of a (se of) individual(s). Rather, it is understood as a shared stance that enables individuals to perform certain actions. 
scientific knowledge. We argue that in ANT, it is taken for granted that a group of scientists can have a clearly determined perspective with regard to an instrument. From the perspective of technological mediation, how it is possible that scientists engage in a similar relation with a scientific instrument is precisely the matter at stake. Furthermore, we argue that the collective relations between scientists and instruments are not presupposed or immediately given but that they are the product of negotiations between scientists. ${ }^{7}$ In other words, only in developing a relation with an instrument that is collectively workable does it becomes possible to produce scientific knowledge.

The chapter is structured as follows: we firstly discuss Giere's and Baird's understanding of the relation between scientists and technologies in scientific practice. Secondly, we discuss Giere's account of how networks of humans and nonhumans are capable of generating knowledge. Thirdly, the concept of technological mediation is used to criticize this understanding and to stress that scientific instruments can offer multiple coherent perspectives in relation with scientists. Fourthly, we argue that ANT's approach of revealing networks of humans and nonhumans that produce scientific knowledge neglects the importance of technologies in this process. Lastly, we sketch the contours of an account of how individual human-technology relations are integrated into a larger scientific collective, thereby clarifying how scientific instruments can give rise to an epistemic stance within such a collective.

\section{\$1.1 SCIENTIFIC INSTRUMENTS AS SOLIDIFIED KNOWLEDGE}

Baird's aims are to do justice to the importance of instruments in science and to connect this importance to the epistemic role of these instruments. His primary argument is that, just as with scientific theories, the instruments used in science bear knowledge that is independent of the presence of an individual observer. Accordingly, he argues that there is something in the instrument that is of epistemological significance (Baird 2004, 4). Baird's notion of "instrument" includes a wide array of devices, ranging from telescopes to Boyle's air pump and Watson's and Crick's material realization of the Double Helix. However, he does not aim to develop a generic framework capable of explaining the epistemic role of each instrument through a similar mechanism: "Different things, and even different aspects of the same thing, operate epistemologically in different ways" (Baird 2003, 40).

7 Note how this idea differs from the idea that the relation between scientists and instruments are structured through already existing social mechanisms. In our view, this view mistakenly assumes a social structure that exists outside of human-technology relations. A detailed discussion of this difference is beyond the scope of this chapter. For an analysis of how social relations between scientists change and take a specific shape in different human-technology relations, see Vertesi (2012).
Even though different things have different specific epistemic roles, they have in common that they are all instances of solidified thing knowledge. According to Baird, this type of knowledge is restricted to the domain of things and should be distinguished from our subjective (propositional) knowledge of the world. Contrary to the knowledge of the scientist (the subject), thing knowledge is objective knowledge, as "the epistemological world of science and technology is too big for a single person to comprehend" (Ibid. 44). It is only in the things that the knowledge of the scientific community remains solid. Hence, according to Baird, the knowledge of the scientific community is kept together not by the scientists but by the instruments. ${ }^{8}$

Although Baird recognizes that different instruments have different epistemic roles, he does not situate these roles in relation to the users of the instruments (cf. Pitt 2007, 53). In Baird's view, scientific instruments are in fact black boxes, and it is in this aspect that he identifies their epistemic roles. For example, it is because a radiologist need not possess a precise understanding of the working of MRI that he is capable of using it. The facts that misdiagnoses still appear and that medical images can give rise to different conclusions is unimportant for Baird in this context, since "there can be no question that our diagnostic capabilities are vastly improved with these new black boxes [new imaging technologies]" (Baird 2003, 59).

In Baird's view, an MRI scanner would be classified as a specific kind of thing knowledgeencapsulated thing knowledge (Baird 2004, 68)-indicating that the MRI offers a representation of the brain as well as it embodies the physics of magnet resolution. The scanner contains knowledge of magnet resolution physics, and this knowledge can be studied by investigating the specific nature of the working of the scanner. But, in addition, brain scans are used to obtain knowledge of the brain; knowledge that is external to the working of the scanner. From Baird's perspective, both are instances of objective knowledge: the MRI bears knowledge of both the human brain and the physics of magnet resolution independent of the presence of an observer.

However, a brain scan can neither be made nor interpreted without the involvement of at least two human individuals: a scientist and a subject lying in the scanner. As a consequence, the epistemic role of an instrument only becomes visible when users relate to it. Consider the following example to illustrate this: assuming that all cars work in a similar way, we would not need (and to some extent we actually do not need) precise knowledge of the exact working of a car. However, the practical situation is profoundly

8 In line with Popper's notion of the "third world," Baird argues that scientific instruments bear objective knowledge that may remain undiscovered. For a critical discussion of this aspect of Baird's philosophy, see Kletzl $(2014,199)$ 
different; traffic rules are not part of the internal structure of the car. In the relation between the driver and the car, the decision of how to interpret the traffic rules is made. Similarly, it is in the relation between a neurologist and MRI scan that an interpretation of a brain scan is made and in which the epistemic role of an instrument is revealed.

Baird is not entirely unsympathetic to the idea that something relevant occurs when an instrument is used by a scientist. He suggests that things can be "read" and that they "enlarge our ability to bring our cognitive apparatus to bear on the world" (Baird 2004, 40). However, how things are put to use remains unaddressed in his analysis. In the end, a gap remains between the objective knowledge present in the things and how scientists obtain knowledge through the use of scientific instruments. This gap is simply not there in scientific practice; in practice, scientists and instruments do interact to obtain scientific knowledge. As we demonstrate, the outcome of this interaction cannot be exhaustively determined with reference to what is "in" the scientific instrument; it is the product of the relation between the scientist and instrument. This change of focus enables us to ask how it is that scientists and instruments can interact such that scientific knowledge can originate within a particular practice.

\section{\$1.2 SCIENTIFIC INSTRUMENTS AS OFFERING PERSPECTIVES ON}

\section{REALITY}

This interaction between scientist(s) and instrument(s) is a focal point of interest for Giere. Giere's focus on the role of instruments in scientific practice functions to be able to subscribe to the contingency thesis, which states that "reality seems capable of sustaining more than one account of it" (Giere 2006, 8) without embracing social constructivism. His starting point is the idea that different scientific instruments-when put to use-offer different perspectives on reality. When using scientific instruments to detect phenomena that cannot be observed with the naked eye, we can only examine these things from the perspective of the instrument we use. And, precisely because we cannot cut ourselves loose from this perspective, it makes no sense to think of science as an attempt to grasp the objective structure of an external reality. The strongest claim a scientist can make is that "according to this highly confirmed theory (or reliable instrument), the world seems to be roughly such and such" (Ibid. 6).

In Giere's account, technologies are decisive in adopting this or that perspective: "these artifacts [scientific technologies] typically incorporate a built-in perspective on the world" (Ibid. 116). Which specific perspective a technology offers is in Giere's view determined by its internal design. However, this does not explain why scientific instruments offer perspectives instead of establishing a one-on-one relationship with the world out there. According to Giere, the perspectivism comes in because scientific instruments-just as human vision-obey physical laws. Telescopes and microscopes respond only to electromagnetic radiation, just as the human visual system does. As a consequence, all of these systems are blind to cosmic rays and neutrinos and are incapable of seeing the particles that constitute, for example, a tree (Ibid. 42). Apparently, the world is physically structured in such a way that specific technologies, which have a specific internal design, allow us to detect certain physical processes and blind us to others.

How the world becomes visible through the interaction between scientist and instrument, in Giere's view, is hence dependent on the interaction between the physical constitution of the world, the physical constitution of the instrument, and the physical constitution of the human visual system. For example, MRI images of the brain are the result of atomic interactions on a quantum mechanical level, and despite the fact that the structure of the image crucially depends on the choices made on which parameters to measure and how the data is analyzed, our access to the brain is the function of how the MRI scanner generates a certain output (a brain scan) on the basis of the input it gets (Ibid. 56).

Brain scans are therefore not photographs of the brain but offer a view onto the brain from the perspective of an MRI scan (cf. Roskies 2007). For example, electroencephalography (EEG) graphs offer a different perspective on the brain. It is in this sense that Giere understands the contingency thesis: the account of reality that science provides depends on the perspective offered by the scientific instrument. Still, scientists know that they can draw certain conclusions from MRI images that they cannot from EEG graphs, and vice versa. In choosing between these technologies, scientists decide which perspective to adopt in relation to the goals they have and to the aspects of the brain they wish to highlight. Despite it being impossible to exceed the perspective of one specific type of technology, it is possible to compare the results of these technologies and decide which is most likely to suit one's goals. Because of their relation to specific goals, perspectives are not rigid, and they change over time, either with the introduction of new technologies or by the combination of existing perspectives. However, as Giere stresses, the combining of different perspectives can never eliminate perspectivism; multi-perspectivism does not transcend perspectivism.

In this view, scientists have an active role in determining which perspective to adopt at which moment. Giere summarizes this in the formula "S uses X to represent W for purposes $\mathrm{P}$. Here $\mathrm{S}$ can be an individual scientist, a scientific group, or a larger scientific community. W is an aspect of the real world" (Giere 2006, 60). But where do the specific 
purposes of the scientist come from? Giere attempts to explain these purposes by expanding the notion of perspective from scientific technologies to the level of scientific theories. He argues that theories are sets of models of the world and that the matching of the models with the world can be tested through the provision of scientific instruments (Ibid. 61). Hence, a continuity exists between the perspective offered by an instrument and the reliability of the consequences of having a specific theoretical perspective, which can only be addressed through the use of a scientific instrument.

Scientific knowledge of the world is therefore always the function of the relation between the theoretical perspective of a scientist or a scientific community and the perspective of a scientific instrument, in which the latter allows for "an intersubjective objectivity in that there is roughly a way something looks from a particular location for most normal viewers" (Ibid. 13). Thus, according to Giere, shared theoretical perspectives can also never escape the relation between the internal design of an instrument and the physical structure of the world to which the instrument obeys.

\section{§1.3 SCIENCE AS DISTRIBUTED KNOWLEDGE}

According to Giere, obtaining scientific knowledge is an activity of a system containing at minimum a human and a non-human. Considering that no one is capable of conducting current scientific research on his own and that science always involves relations between humans and scientific instruments, Giere proposes interpreting scientific practice in terms of a distributed cognitive system (cf. Hutchins 1995). Rather than individual scientists, these systems as a whole are responsible for the output of scientific practices. From this perspective, it is no longer necessary to ascribe some form of hyperrationality or other special intellectual capacities to individual scientists. In Bruno Latour's words,

"No 'new man' suddenly emerged sometime in the sixteenth century. [...] The idea that a more rational mind ... emerged from darkness and chaos is too complicated a hypothesis" (Latour 1986,1).

Through a critical discussion of the work of Latour, Giere and Moffatt $(2003,308)$ argue that distributed cognition is the only plausible explanation for ordinary humans with normal cognitive capacities being capable of doing science. Accordingly, the collectivity of modern scientific systems consisting of both scientists and technologies is of primary explanatory value. In this collectivity, the roles of both concrete technologies and individual human cognition dissolve into the cognitive activity of a system that cannot be explained in terms of its parts. Thus, while Baird explains this success in terms of the objectivity of thing knowledge that exists outside the human subjective domain, Giere attempts to do justice to what counts as scientific knowledge is, in most cases, the outcome of relations between scientists and between scientists and instruments.

CERN's Large Hadron Collider can be used to exemplify this view. Located 175 meters under the ground, this 27-kilometer-long collider was developed to test the predictions of fundamental physical theories and is used primarily for the search of the Higgs boson. This project involves hundreds of scientists and engineers working from different continents, indicating that the experiments performed at CERN can hardly be considered the projects of individual scientists. Rather, it is the complex relationship between different scientists and the instrumentation of the CERN that produces new experimental results. Put in Giere's terms, we should treat the Large Hadron Collider as a distributed cognitive system and attribute cognitive capacity to this system as a whole (i.e., to the total organization of individuals and machinery) (Giere 2002, 5)

But how is knowledge generated by and distributed through these kinds of systems? And how do the human parts of the system relate to the system's non-human parts? At minimum, a distributed cognitive system must consist of a human and an external representation of some sort, for example, a symbolic manipulation of an arithmetic operation (say, 4,876 times 8,765), which for most of us is too difficult to perform "in our heads." While such a system is relatively simple, much more complex systems are responsible for obtaining scientific knowledge. Not only are there way more elements involved in the system, but the importance of scientific instrumentation adds to the complexity as well. As demonstrated above, Giere argues that these instruments force us to investigate things from a specific perspective that is determined by the instrument.

Key in Giere's analysis is the idea that scientific knowledge should be interpreted as the cognitive output of a system. In other words, he maintains that scientific knowledge in the end is a product of a mind. But when the cognitive output of the system cannot be located in the head of a single individual, not even in the heads of a group of individuals, but in a system consisting of both humans and nonhumans, where to find the mind(s) responsible for generating this knowledge? In the end, these systems "make possible the acquisition of knowledge that no single person, or a group of people without instruments, could possibly acquire" (Giere and Moffatt 2003, 305). Yet, how this acquisition can occur remains an open question in his analysis. 


\section{\$1.4 THE POSTPHENOMENOLOGICAL PERSPECTIVE OF \\ TECHNOLOGICAL MEDIATION}

Similar to Baird's analysis, Giere explains the role of scientific instruments as constituting this or that perspective in terms of the internal design of the instrument. As demonstrated above, in Giere's view, the physical structure of the world is organized in such a way that technologies having a specific internal physical design allows us to detect certain physical processes that scientists can then see. Such an analysis of the collectivity of scientific practice in fact crucially depends on two assumptions: (i) scientific instruments offer only one perspective on a phenomenon and (ii) all human members of a scientific collective immediately share this perspective. ${ }^{9}$

This section demonstrates, however, that both assumptions are problematic. Giere explains the relation between scientist and technology as a relation between a scientist and the pre-determined perspective of a certain technology. But how do scientists come to know what this perspective is, if it is shaped as the function of the relation between the scientist and the technology and cannot exist otherwise? Applied to scientific research collectives, answering this question would imply that we should gain an understanding of how what counts as knowledge is constituted in the relation between scientists and their instrumentation. For example, in the relationship between a scientist and a brain scan, some epistemic decisions are, to some extent, made on the basis of the scan itself (cf. Hutchins 1995). In other words, when using fMRI to access the brain, a researcher cannot but interpret human cognition in terms of brain activity that is represented in terms of the blood flow in a specific brain area. The underlying assumption of this kind of brain research is that blood flow and neuronal activity are coupled in one way or another. In postphenomenology, this relation between human being and technology is conceptualized in terms of technological mediation (e.g., Ihde 1991, 1998; Verbeek 2005). The MRI scan mediates our knowledge of the brain. In other words, what is considered knowledge about the workings of the brain is not solely determined by the scientific observer. And neither is this knowledge the consequence of the internal structure of the instrumentation. It is only in the relation between scientists and their instrumentation that knowledge is constituted, such that part of what counts as knowledge is to some extent determined by the scan itself. fMRI scans limit the range of explanations of human behavior (for example, they do not allow for understanding human behavior in terms of balancing the four human humors), but they require interpretation to be understood.

9 Giere uses the term "system" to denote a collective of humans and non-humans, which we believe to be closely related to his idea that scientific practices should be understood in terms of distributed cognition. We prefer to use the more general term "collective," because the view of scientific practice developed in this chapter is not necessarily to be understood in terms of distributed cognition.
How the brain is seen through an MRI scanner is not merely an interaction between two physical systems, such that the internal design of the scanner offers a specific perspective on the physical structure of the world, which is accordingly brought within the limits of the human visual system. Seeing the brain on an MRI generated image requires the prior active involvement of the researcher, who is actively manipulating the content of the image with an intention to filter and simplify the things that an MRI scanner detects, an activity that is not part of the causal interaction between two physical systems.

The MRI scanner confronts the scientist with an image that allows drawing inferences about the working of the brain (cf. Suárez 2004). However, not only the process of construction but also the constructed image itself allows for a variety of interpretations. In Ihde's words, these images are multistable; they can be coherently interpreted in several ways. To determine the meaning of an fMRI image is to determine the relevant features of the image: to consider certain aspects as relevant and others as not. A scientist must employ a specific hermeneutic strategy to be able to do so (Ihde 2009, 53; Rosenberger 2008,72 ). The relation between the fMRI image and the observer is what opens the possibility for deciding what counts as relevant brain activity. The knowledge of the brain is not just determined by the perspective of an MRI scanner that obeys the laws of physics. How a scientist observes and the kind of knowledge of the brain he can obtain are the products of this process of technological mediation.

When a scientist accesses the brain through fMRI, his interpretation of the brain scan cannot be reduced to an fMRI scan portraying brain activity in a certain way. When interpreting such a scan, the blue and red dots are related to a certain cognitive task. How we interpret the distribution of these dots is in itself not determined by the physical design of the imaging technology. The association of brain activity with certain cognitive tasks is not internal to the information present in the brain scan. While this imaging technology makes it possible to interpret human cognition in terms of blood flow in a certain brain area, the meaning of this increase cannot be reduced to how it is measured For example, when linking activity in certain brain areas to how human beings process visual information, neuroscientists must link the concept of visual processing to the red and blue dots present in the brain scan. Furthermore, the basic assumption underlying the use of fMRI in research in the cognitive neurosciences (i.e., the coupling of cerebral blood flow to neuronal activity) is itself not entailed in the working of the MRI scanner, and neither can this hypothesis be specifically put to test by the scanner. In relating toand investigating with-the MRI scanner, scientists must actively construct a perspective on the brain that necessarily requires the modeling of the relation between blood flow and neuronal activity, which greatly influences how the brain becomes present. 
Interpreted in this way, a brain scan does not offer a perspective on the pre-determined structure of the brain but makes the brain present in a very specific manner. This translational process is the product of the individual relation between the scientist and the brain scan. Varying on Giere, this can be formalized as "in the relation between $\mathrm{S}$ and $\mathrm{X}$, an aspect of $\mathrm{W}$ comes into being for purposes $\mathrm{P}$ at time T." S refers to an individual scientist having a relation with the mediating technology $\mathrm{X}$, such that an aspect of $\mathrm{W}$ (the brain) becomes present to him to investigate this or that phenomenon at a certain point $\mathrm{T}$ in time, in which a specific set of scientific technologies is available.

In this view, the brain scan does not stand in between the scientist (subject) and the brain he is studying (object) such that it offers a way to see aspects of the brain that the scientist was previously incapable of. Rather, it is in the relation between human and technology that a scientist can experience the brain in how it is portrayed on a brain scan (cf. Verbeek 2005, 130). In contrast with what Baird and Giere argue, the MRI scanner is not some technology in which a specific perspective or specific kind of knowledge is hidden that can be discovered by a scientist. From a postphenomenological perspective, the working of an MRI scanner cannot be reduced to the physical law that it obeys. When confronted with a brain scan consisting of several blue and red dots, the scientist is not presented with a photograph of the brain, but (s)he must interpret what these dots mean (cf. Carusi and Sissel Hoel 2014). And it is precisely the specific interpretation of this brain scan that is not part of the internal design of the scientific instrument.

\section{\$1.5 IMMUTABLE MOBILES AND SCIENTIFIC NETWORKS: THE ROLE OF SCIENTIFIC INSTRUMENTS FROM AN ACTOR-NETWORK PERSPECTIVE}

Studying how scientists and scientific instruments interact to construct "facts" about "nature" is a primary ambition of ANT, which aims to investigate science-in-the-making. Phenomena and their interpretations are not taken as "given" or "discovered" but as constructions that can be studied while being assembled. In his article Visualization and Cognition: Thinking with Eyes and Hands (1986), for instance, Latour developed an account of how knowledge is stabilized in networks of scientists, instruments, and other artifacts. His analysis focuses on how drawings and images are capable of mustering the largest number of well-aligned and faithful allies. One of his most important arguments is that it is precisely these visualizations that make it possible to muster allies, as they allow for showing the whole of the conducted research in one glance (Latour 1986, 5). stake but rather how the content of the image becomes factual because of its ability to muster as many powerful allies as possible. By introducing the concept of immutable mobile, he attempts to account for different people drawing similar conclusions when confronted with a specific kind of representation of an object. He states,

"If you wish to go out of your way and come back heavily equipped so as to force others to go out of their ways, the main problem to solve is that of mobilization. You have to go and come back with the "things" if your moves are not to be wasted. But the "things" have to be able to withstand the return trip without withering away. Further requirements: the "things" you gathered and displaced have to be presentable all at once to those you want to convince and who did not go there" (Ibid. 7).

In Latour's view, therefore, scientific images are in fact to be seen as embodiments of power-comparable to how Giere approaches them as embodiments of knowledge. Images have the power to bring facts into existence. Yet, the question remains whether this analysis exhausts the role of instruments in scientific practice, since it neglects how images are interpreted in the first place and how they inform the interpretational frameworks of scientists. Latour is primarily interested in the extent to which a scientist or a group of scientists is capable of mustering other allies and passes over the question of how this group of scientists itself comes to treat one potential immutable mobile as more effective than the other. ${ }^{10}$

The absence of this concern is clearly visible in Latour's and Woolgar's Laboratory Life. They stress that scientific "phenomena are thoroughly constituted by the material setting of the laboratory" (Latour \& Woolgar 1986, 64) and that "each item of apparatus [is] combined with certain skills to form specific devices" (Ibid. 69), while not paying any attention to how these phenomena are constituted or what skills are used to work with the available scientific instruments. Instead, they focus on how the material environment of the laboratory dissolves when transformed into a scientific paper. However, scientific instruments, and other technologies such as brain scans, must become immutable mobiles within a scientific community as well when they are to be used and interpreted in similar ways.

It is exactly at this point that the "postphenomenological" approach of technological mediation differs from ANT. Because of its phenomenological orientation, the mediation approach studies the role of technologies in scientific practices "from within." Rather

10 Note that this does not imply that a group of scientists is only interested in mustering allies outside science per se, but this also can be considered an attempt to convince other (groups of) scientists. 
than looking "outside-in" to the formation of networks of relations between scientists and technologies, it looks "inside-out" to the formation of perceptions and interpretational frameworks in relation to the technologies that play a role in scientific practices.

The central ambition is not to "deconstruct" the networks behind scientific facts and theories but to develop accounts of the mediating role of technologies in "science-in-themaking." From a postphenomenological point of view, such accounts can only be studied from a first-person perspective (i.e., by analyzing how scientists develop concepts and interpretations in interaction with the scientific instruments and technologies they use). In other words, the concepts that scientists apply when "reading" a brain scan cannot be reduced to the visual content of the brain scan itself. Establishing a relation between the visual content of a brain scan and a cognitive concept, such as aggression, requires interpreting the visual content in terms of something else (i.e., aggression). Only when a neuroscientist can make this translation do brain scans become relevant for cognitive research. A phenomenological perspective has the potential to take into account such "interpretational-frameworks-in-the-making." The central question then is not if and how scientific instruments "embody" specific interpretational frameworks or scientific theories but rather how they help such frameworks and theories to come into being.

Scientific instruments help to shape relations between scientists and the reality they study; in doing so, they help to organize how reality is "given" to scientists and how scientists are constituted in relation to the phenomena they study. Scientific instruments, therefore, must be seen as hermeneutic devices (Ihde 1998)-they are "epistemology engines" (Ihde \& Selinger 2004), establishing relations of investigation, in which both the investigator and the investigated are constituted in a specific, technologically mediated way. The event of constitution is what is further explored in this dissertation, in terms of the technologically mediated reality made present through scientific instruments, as in how these mediations are appropriated and give rise to collective forms of knowing.

\section{\$1.6 TECHNOLOGICAL MEDIATION AND COLLECTIVE KNOWING}

When it is only in relation to scientific instruments that the objects of research can be observed, instruments function as common denominators to which all scientists within a collective must relate to, both individually and collectively. As we demonstrated above, this has two important consequences: firstly, because scientific instruments are not neutral extensions of human sight but constitute a specific type of the observer and the observed, we should analyze scientific observations in terms of technological mediations." For example, how cognitive phenomena such as aggression must be explained changes when accessed through fMRI, as they become necessarily related to neuronal activity. The linking of neuronal activity to aggressive behavior requires a prior understanding of aggression that is materialized in an extensive experimental set-up that presupposes this specific understanding of aggression. This specific prior understanding is in turn reflected in how aggression is visualized through the use of fMRI. Hence, we hold, contrary to Giere's analysis, that the perspective an instrument offers is not merely a matter of the interaction between the physical constitution of a technology and the physical structure of the world.

Secondly, the human parts of a scientific collective must develop a shared epistemic stance with regard to the mediating technology that allows for multiple coheren interpretations. For example, there are several coherent ways to interpret the content of a brain scan. Since no specific perspective is built into an MRI scanner, a workable stance towards the epistemic function of the scanner is something that must be established. This forces the postphenomenologist to develop an alternative answer to the question of how a shared epistemic stance can come into being.

Let us attempt to answer this question through an analysis of an everyday example and by identifying the differences with Baird's and Giere's approaches. ${ }^{12}$ Imagine that you must walk from one place to another using a map of the area you are in. The map limits several possibilities; a possible route straight through a dark forest is not indicated on the map, since it only covers registered walking paths, but the map will also not stop you from taking an unregistered route. Moreover, it will not exactly tell you where you are; you must decide that in relation with the map. In other words, both you and the map have an active part in determining the path you will walk. In making certain aspects of the landscape relevant, while neglecting others, the map shapes the landscape and your position in it in a specific way. In other words, in your relationship with the map, the map mediates how the landscape that you are in is revealed to you.

Now, consider the situation that a group must perform a similar exercise. One or more of the more adventurous group members offer the suggestion to cross the dark forest even though its structure is not displayed on the map, because they are convinced that

11 Vertesi (2012) has recently discussed how human-technology relations shaped the social order in laboratories. The present discussion focuses on how scientific instruments structure epistemic judgments, rather than how they contribute to the social organization of laboratory work.

12 ANT is deliberately omitted from this comparative analysis, as we hope to have shown in the previous section that ANT primarily aims to understand the working of a scientific instrument when a shared epistemic stance is already established. 
it will be a faster route. Only after discussion is this possibility ruled out or accepted by the group as a whole; in this discussion, the members of the group start to display a similar epistemic stance with regard to the map (at least for the moment). Furthermore, in this situation, the map will also not "tell" the group where it is. The location of the group on the map will probably be the result of a discussion as well. In both situations, an intersubjective epistemic stance is not presupposed but is the consequence of how the group acts in relation to the mediating technology. The point here is that the road to intersubjectivity can be studied by analyzing the mediations of which it is the product (cf. Heritage 1984, 259).

Baird would understand the epistemic function of the map as offering a model of the relevant surface. In Baird's sense, this would mean that in the map, there is knowledge of the specific landscape. However, in his model, it remains unclear how, and if, the group can access what is inside the map; hence, it remains unclear how the group can obtain knowledge of the terrain through the map. What is at stake is the relation between the instrument and its knowledge of the landscape, without a user entering this epistemological picture. When considering larger collectives such as the one described in the example, Giere suggests that the perspective that an instrument offers is immediately grasped by every member of the collective. Thus, given that the visual capacities of the group members are roughly similar and share similar purposes, they will all immediately grasp how the map relates to the environment where they are. ${ }^{13}$ This immediacy is guaranteed by the "intersubjective objectivity" that is presupposed in the perspective offered by the map (cf. Giere 2006, 13). However, he acknowledges that the situation is slightly more complex than noted above when discussing the role of MRI in the neurosciences:

"MRI, in particular, makes it abundantly clear that not only is scientific observation perspectival, but also that there are multiple perspectives from which one must choose and no "objectively" correct choice [can be made]. A lot depends on the goals of the investigation at hand (Ibid. 56)".

Considering that scientists determine the goals of their investigations in relation with both each other and the scientific instrumentation, this would already imply a shared epistemic stance with regard to the instrument.

13 In his discussion of mapmaking, Giere for example states that maps are interest relative. He argues that road maps are useful to car drivers because they highlight relative distances, but that they are less useful for cyclists because they do not give a clear indication of elevation, which would be of great importance when riding a bike (Giere 2006, 73).
In terms of the map example, Giere understands "the goals of the investigation at hand" as already present before the map is put to use. However, as we have attempted to clarify, it is precisely these things that are still unclear when a map is used. Similarly, how and what can be seen while using an MRI scanner and which investigative goals are developed in relation with MRI are not part of the internal design of the scanner. Of course, our eyes cannot look beyond their visual capabilities, and the working of an MRI scanner must work in accordance with the technicalities of its design. However, collective knowing can never be reduced to these technicalities. As Van Baalen et al. (2016) have shown in the context of multidisciplinary clinical decision-making, collective knowing is always mediated by both the social relations between scientists and the technologies that shape the knowledge that is distributed within a group of scientists. We believe that this applies not only to multidisciplinary clinical contexts but to non-clinical and nonmultidisciplinary scientific practices as well.

While scientists use instruments that are capable of detecting and visualizing phenomena invisible to the naked human eye, the instruments do not provide us with an immediate understanding of those phenomena. Giere correctly emphasizes the importance of the former aspect, but he neglects that visualizations do not have a univocal meaning and can be interpreted in multiple ways. And if the goals of the investigation at hand coevolve with the interpretation of the visualization, there is no reason to presuppose agreement with regard to for which goals the visualization should be put to use. Hence, the perspective of the instrument cannot function as offering an objective ground that can establish intersubjectivity. Similarly, there is nothing in the map that allows the members of the group of travelers to establish an intersubjective understanding of its precise meaning. As indicated in the example, the displayed intersubjectivity is the consequence of how the members of this group relate to the mediating technology (in this case the map) and how this relation structures how the members of the group relate to each other.

\section{\$1.7 CONCLUSION: MEDIATING TECHNOLOGIES AND SCIENTIFIC COLLECTIVES}

The philosopher and historian of science Hasok Chang proposes something along these lines by suggesting that we should understand science in terms of epistemic activities that have a particular aim. According to Chang, it is possible to understand scientific practice in terms of the aims of scientists and the expectations that they possess. However, neither is a standard model of the actors at work within the collective, nor are the aims of a collective set from the start, as a scientific collective "only exists because someone 
upholds it by means of some mechanisms for propagation and maintenance" (Chang 2014, 73). Here, Chang opens the door for understanding the shared epistemic stance of a group of scientists as something that is actively put together by the involved agents rather than presupposing that they share some form of "intersubjective objectivity." This perspective makes it possible to understand how specific aims of a collective are related to the available instrumentation. After all, the agents within a collective are not rigid entities but come into being in relation to the technologies at hand.

Still, the question of how scientists can have a workable shared epistemic stance with regard to an instrument can potentially generate multiple perspectives remains unclear. It is clear that researchers working at CERN are capable of speaking the same language with regard to a similar set of objects and that neuroscientists can draw meaningful conclusions from brain scans collectively. That the technological mediation of knowledge originates in the individual relation between scientist and instrumentation does not prevent scientific theories from being developed or clinical decisions from being made.

But, when it is not the objective features of the scientific instrument that make it possible to adopt a similar perspective, how then is a shared epistemic stance with regard to the instrument established? Does it presuppose some form of intersubjectivity that makes it possible to use it collectively? These questions can be answered both in the positive and in the negative: in the positive, because an intersubjective epistemic stance seems to exist in scientific practice; after all, how would it otherwise be possible to talk about experimental results? It should be answered in the negative as well; the intersubjectivity is not presupposed. This is not to say that establishing intersubjectivity would be the final goal of such a collective; displaying a shared epistemic stance is the dynamic and preliminary product of the individual relations between scientists and mediating technologies. ${ }^{14}$

In the end, the ongoing development of a workable epistemic stance of a group of scientists with regard to an instrument mediates how the world becomes present to this group of scientists; however, we should interpret these collectives neither as instruments having access to "nature" or to "the world" nor as unchanging systems determining how the world comes into being. An epistemic stance is a fluid state changing over time and relative to the interactions of the members of the collective, rather than a universal decision to use a scientific instrument in this or that way such that the world can be accessed in this particular manner (cf. Te Molder 2015). The shared epistemic stance is not an extension of Giere's idea from the level of scientific instruments that "typically incorporate a built-in perspective on the world" to collectives having a similar built-in design. The crucial difference is that nothing can be built in into such a collective, since the relation between scientists and mediating technologies is not fixed.

This leaves us with the issue of how collective scientific practices are structured around individual human-technology relations. As we have attempted to clarify, this collectivity is not something that is an inherent property of the system as such. In stressing that agents are responsible for those mechanisms of propagation and maintenance, the implication is that the development of a mechanism requires action. These actions cannot be performed outside the technological realm when the mediation role of scientific technologies is considered. The specific nature of those actions is not pregiven but is structured by the relation with a mediating technology. Accordingly, what this mechanism looks like is dependent on the specific relations between scientists and mediating technologies, and the actions that are performed such that a shared epistemic stance is displayed within a scientific collective. In other words, technological mediations cannot be disconnected from how they are appropriated within scientific collectives. A philosophical account of the role of scientific instruments in scientific practice should therefore not be limited to investigating individual human-technology relations but should also be able to explain how a shared epistemic stance comes into being within scientific collectives.

In this chapter, I argued that if we wish to understand the role of instruments in scientific practice, they are best understood as mediating technologies. While several studies have analyzed scientific practices from this perspective (e.g., Forss 2012; Hasse 2008; Rosenberger 2008, 2013), no systematic account of the role of mediating technologies in science has been developed thus far. In this dissertation, I attempt to develop exactly such an account. This requires taking a detour to the philosophy of technology underlying the concept of technological mediation and clarifying how this account both requires and presupposes a phenomenological perspective on scientific practices. 
CHAPTER 2:

“Technology" and

"Human-Technology Relations" 


\section{INTRODUCTION: “CLASSICAL” AND “EMPIRICAL” PHILOSOPHY OF TECHNOLOGY}

Before starting our specific investigation into the role of technologies in scientific practice, I discuss how the role of technologies in daily practice is conceptualized within the current philosophy of technology. This functions to (i) provide an introduction to how technologies are understood as mediating reality in the philosophy of technology and (ii) show the phenomenological stance that this understanding of scientific instruments presupposes.

Let me first give an intuitive example of our dependency on technologies. My journey to work is dependent on a large technological infrastructure, which goes largely unnoticed unless specifically reflected upon: my alarm wakes me, and thereafter I use the shower, step on my bike, and cycle to the train station from which I travel to my work by train. Arriving at my work, I use the coffee machine and turn on my computer. Emails are waiting for response; the information that I need to continue my research I retrieve from papers that are accessible in an online environment. And, occasionally, I write down my thoughts and findings in the word processing program on my computer. In summary, without the presence of a highly technological system, my daily life could not be structured as it is presently.

Philosophers of technology up until the second part of the twentieth century approached both technology and science as all-encompassing forces that are external to society yet dominantly structure how society is organized (e.g., Ellul 1964; Heidegger 1977a; Jaspers 1951).Often in the form of a critique of Modernity, they were concerned with the possibility that technology would alienate human beings from reality and from each other.

Martin Heidegger's analysis of technology in The Question Concerning Technology is often singled out as the most important example of this "classical" approach in the philosophy of technology and remains an inspirational source for many thinkers. In this work, he attempts to find the essence of technology and identifies this essence as the disclosing of nature as standing-reserve. Technology is interpreted as a mode of being through which it is only possible to approach reality as a set of resources. According to Heidegger, this prevents human beings from having an authentic relation with reality, and as a consequence with their own being. In this view, the technological infrastructure described above is considered an alienating system that determines how society is organized and how individuals understand themselves.
These "classical" philosophies of technology presuppose that different technologies operate according to a uniform scheme and are often referred to as treating technology as a "monolithic phenomenon" (e.g., Feenberg 1999). Technology is considered an alienating force that prevents human beings from having access to their authentic form of being. In these cases, technology is conceived with a capital $\mathrm{T}$ and is not sharply distinguished from Science, which was thought of having a similar alienating power. For example, analyses criticized the presence of mass production, in which human beings were interpreted in terms of their production rather than in terms of their human qualities. These kinds of analyses often embody a fear that nature and human beings can only be approached as things that should be dominated or controlled.

At the end of the twentieth century, the philosophy of technology moved away from analyzing Technology as a uniform structural phenomenon that humanity should be guarded against. Instead, philosophers started to investigate how technologies provide human beings with new opportunities to relate to the world rather than how they necessarily alienate human beings from themselves and from nature (Achterhuis 2001; Ihde 1993; Verbeek 2005). This is often referred to as the "empirical turn in philosophy of technology," indicating that the subject matter of a philosophy of technology should no longer be "Technology" but rather "the actual workings of technologies in concrete practices" (Franssen et al. 2016; Kroes and Meijers 2000).

Postphenomenology is a primary approach within this empirical turn. This line of thinking focuses on how reality comes into being in the relations between human beings and technologies. A central idea within postphenomenology is that technologies mediate the relationships between human beings and the world, thereby giving rise to specific experiences and understandings of reality. The idea of technological mediation oscillates between technological determinism and technological instrumentalism: how human beings relate to the world is not determined by the technologies they are surrounded with, but neither are human beings free in choosing how the world is revealed to them through technologies.

This chapter specifically focuses on the relation between postphenomenology and the phenomenological hermeneutics of Martin Heidegger to sketch the general philosophical background of the notion of technological mediation used throughout this dissertation, to understand how scientists relate through technologies to the objects that they study. On the one hand, postphenomenology dismisses Heidegger's analysis of technology as developed in The Question Concerning Technology as treating technology in a monolithic manner. However, on the other hand, postphenomenology is heavily inspired by Heidegger's phenomenology of tool use as developed in Being and Time, where he 
argues that our everyday contact with the world occurs to a large extent in relation to the tools that we employ. Through a discussion of how postphenomenological approaches use Heidegger's early phenomenology of tool use as a corrective to his later analysis of Technology, I attempt to clarify what the central notion of technological mediation in postphenomenology amounts to.

This chapter is structured as follows: firstly, I discuss Heidegger's analysis of how we relate to the world through the use of tools via his distinction between ready-to-hand (Zuhanden) and present-at-hand (Vorhanden) (\$2.1). Secondly, I attempt to clarify how this idea is picked up within postphenomenology and how Heidegger's phenomenology of tool use is extended to a phenomenology of technologies and gives rise to a framework to analyze human-technology relations (\$2.2). Subsequently, I show how Heidegger’s phenomenology of tool use disappears from view in his later analyses of technology, giving rise to the idea that the essence of Technology is "the supreme danger" (Heidegger 1977a, 27) (\$2.3). Fourthly, I show how this discussion of Technology can be challenged by focusing on human-technology relations and how this focus gives rise to the idea that technologies mediate relations between human beings and the world ( $\$ 2.4)$.

\section{\$2.1 READY-TO-HAND AND PRESENT-AT-HAND: HEIDEGGER'S} PHENOMENOLOGY OF TOOL USE

In his phenomenology of tool ${ }^{15}$ (Zeug) use in Being and Time, Heidegger distinguishes between tools that are ready-to-hand (Zuhanden) and entities that are present-at-hand (Vorhanden). Heidegger argues that our primary encounter with the world is one in which the things around us are immediately put to use, that they disappear from view (i.e., are ready-to-hand). This he contrasts with a view of the world in which objects appear to us as entities with certain qualities that are to be described but yet are ultimately foreign to us (i.e., are present-at-hand). This distinction appears at the background of Heidegger's criticism of any ontology that takes as a starting point that the world in which we live and act is one where we attain knowledge of the entities around us through giving accurate descriptions of their appearance: "Houses, trees, people, mountains, stars. We can depict the way such entities 'look,' and we can give an account of occurrences in them and with them. This, however, is obviously a pre-phenomenological "business" (Heidegger 1985, 91). This is not to say that these descriptions of entities are necessarily incorrect but instead that even if they are, "in conformity with the basic assertions about

15 Although the German word Zeug is translated as "equipment" in Macquarrie's and Robinson's 1985 translation of Being and Time, I translate use the term "tool" to be consistent with the way it is usually translated within the philosophy of technology. this entity, which the mathematical natural sciences provide, [they] will never reach the phenomenon that is the "world"' (Ibid., 92, my emphasis). So, if we aim to develop an ontological understanding of the world around us, the qualities of the natural sciences do not suffice, because they remain to consider our relationship with the entities around us in terms of the present-at-hand.

This distinction is influential in the current philosophy of technology (e.g., Ihde 1979, 2010; Verbeek 2005) and is used as a phenomenological argument showing that our encounter with the world is always mediated by the technologies we use. In other words, the ready-to-hand is attributed ontological priority in how reality becomes present to the experiencing subject. In this chapter, I show how the perspective of technological mediation develops a philosophy of technology based on the ontological priority of the ready-to-hand. However, as becomes clear in the next chapter, placing too much focus on the ready-to-hand neglects that instruments in science also mediate how a relation with the world is revealed in terms of the present-at-hand being established in scientific practice. Before making this specific point, it is necessary to clarify howthrough phenomenological analysis-the ready-to-hand is ascribed ontological priority in Heidegger's thinking.

\section{The Being of Equipment}

In his famous analysis of hammering, Heidegger argues that we are no longer aware that we are using a hammer when we engage in the practice of hammering. The hammer becomes ready-to-hand when we put it to use, making it disappear in the whole of the context in which we are engaged. When using it, our concern is not with the hammer, but with something else, such as the nail we are hammering in the wall or with the table that we are making. Accordingly, the hammer becomes transparent; it goes unnoticed in our daily practice. The consequence of this phenomenological analysis is that our first acquaintance with the world is one of immediate relations with tools that are ready-tohand within a certain context. This notion of context, or "totality," is phenomenologically important, because we never discover tools in isolation but are always already immersed in a context that is constitutive of how we relate to tools:

"To the Being of any equipment there always belongs a totality of equipment, in which it can be this equipment that it is. Equipment is essentially 'something in-order-to ...' ["etwas um-zu ..."]. A totality of equipment is constituted by various ways of the 'inorder-to,' such as serviceability, conduciveness, usability, manipulability" (Ibid. 97).

Given that the particular way in which we relate to tools always presupposes a context in which they appear as something-in-order-to, the particular way in which a tool can 
become of service or is put to use cannot be reduced to the particular qualities of the tool that it is related to. Both our relationship with a hammer and how it is put to use already presupposes a larger totality of tools in which the hammering occurs. We always find ourselves already in a given context in which the ready-to-handness of tools already is shaped within and by this given context. It is through this context and the tools that are encountered within it that the world manifests for us:

"What we encounter as closest to us (though not as something takes as a theme) is the room; and we encounter it not as something 'between four walls' in a geometrical spatial sense, but as equipment for residing. Out of this 'arrangement' emerges, and it is in this that any 'individual' item of equipment shows itself. Before it does so, a totality of equipment has already been discovered" (Ibid. 98).

The argument Heidegger makes is thus that our relationship with the world is not one of a subject that encounters a manifold of objects in geometrical space that appear as in immediate need of specific description. On the contrary, the "arrangement" of the world and how tools reveal themselves is constituted by the situation in which we find ourselves hammering a nail in a piece of wood; because we wish to make a house, we must find shelter against storm. Or, less primitively, I find myself typing on a computer, which is meaningfully disclosed as something to use as a way to write my dissertation. My primary involvement with this computer is not one of looking explicitly at the specifications of this computer but is made relevant in this larger context. ${ }^{16}$ How the world is disclosed to us in this analysis is thus characterized by the ready-to-hand manner in which the tools around us appear as relevant as "something-in-order-to" within the totality in which we are immersed.

\section{Breakdown and the Present-at-hand}

The phenomenological observation that our primary encounter with the world is characterized by the ready-to-hand way in which we relate to the things around us does not necessarily rule out the possibility that these things can appear as present-at-hand. According to Heidegger, approaching the things around us in terms of the specific qualities that they have (i.e., in terms of their present-at-handness) does occur in cases of breakdown. For example, when the hammer no longer appears as "handy" during the practice of hammering, we start to conceive of it as an object that has certain qualities (a certain weight, a specific hardness, etc.) (i.e., the hammer becomes present-at-hand as a

16 Of course, if I wish to repair this computer, the specific workings of it may become relevant. However, from Heidegger's perspective, this would imply that my computer appears in a different totality. Rather than the computer itself, the tools I use to repair the hardware or software of the computer are the things that I primarily relate to against the larger background of repairing the computer. thing to be studied). Analogously, the specific make-up of the computer that I use only becomes apparent when it can no longer function within this context and it is no longer possible for me to continue writing this text. As such, the becoming of my computer as an object that is present-at-hand is caused by the breakdown of its initial function within the context I was using it; it was no longer of service within this specific context because its relation with the totality of tools had suddenly disappeared.

In instances of breakdown, "the presence-at-hand of the ready-to-hand makes itself known in a new way as the Being of that which still lies before us and calls for our attending to it" (Ibid. 104). As a consequence, I may ask myself why the computer is no longer working, which may make me interested in the specific weight of the object that can indicate that it has dropped because the motherboard of the computer has dropped out, which may make me conclude that this can be one reason why the things is no longer functioning as it should be, and so on. The computer is only revealed as present-at-hand when it no longer can be used to write this text and as turning over our initial experience of it within a totality of equipment. The things around us only become objects that are present-at-hand as the consequence of a breakdown of its functioning in a totality that we take for granted in our everyday contact with the world. Hence, Heidegger is not arguing that the things around us cannot appear in terms of their present-at-hand character but rather that this character is not phenomenologically (i.e., ontologically) constitutive of our relationship with the world. It is against the background of developing a way to understand how the world becomes present to me that Heidegger's phenomenology of tool use should be understood:

"A glance at previous ontology shows that if one fails to see Being-in-the-world as a state of Dasein, the phenomenon of worldhood likewise get passed over. One tries instead to interpret the world in terms of the Being of those entities which are present-at-hand within-the-world but are by no means proximally discoverednamely, in terms of nature (Ibid. 93)".

Thus what is at stake is not primarily giving an "adequate" description of how human beings relate to tools but rather what it means for human beings to be in the world. And to understand what this fundamental characteristic of human beings means, it is necessary to understand the phenomenon of worldhood as a state of human beings. When building an ontology grounded in giving accurate descriptions of the objects around us in terms of their present-at-handness, worldhood is surpassed, because

"Worldhood itself may have as its modes whatever structural wholes any special "worlds" may have at the time; but it embraces in itself the a priori character 
of worldhood in general [...] The derivative form "wordly" will then apply terminologically to a kind of Being which belongs to Dasein, never to a kind which belongs to entities present-at-hand "in" the world (Ibid. 93)".

This is the crux of Heidegger's argumentation; the world is not something that consists of a set of entities that are present-at-hand outside of human beings but should be understood as disclosed by them. This is why worldhood is defined as an existential of human beings, which is prior to our encounter with any "world." This world is not something that can be thought of as independent of human beings but is disclosed through the existential structure of human beings, which always implies the a priori character of its worldliness. So, crucially, Heidegger's phenomenology of tool use does not target mathematical and scientific descriptions as being incorrect or not worthy of consideration but functions to note that there is a form of engagement with the world that is prior to its mathematical-scientific disclosure.

\section{\$2.2 FROM TOOLS TO TECHNOLOGIES: A POSTPHENOMENOLOGY OF HUMAN-TECHNOLOGY-WORLD} RELATIONS

Complex technologies, such as smartphones, and, in the context of scientific practice, fMRI or the Hubble telescope, do not-strictly speaking-resemble the tools that Heidegger discusses in Being and Time. However, Heidegger's phenomenology of tool use can function as the foundation for analyzing how we relate through the world through more advanced technologies. In postphenomenology, this extension is made by replacing the notion of tool with the notion of technology. In this interpretation, a phenomenology of tool use is not limited to primitive tools such as hammers, but allows that more sophisticated technologies can also be analyzed in a phenomenological manner. One can think of fridges, computers, or bicycles, but also of larger technological infrastructure, such as railway systems and the printing press, as ways that shape how human beings relate to the world.

In Technics and Praxis (1979), Don Ihde clearly indicates how closely his ideas about the phenomenology of technology are aligned with Heidegger's phenomenology of tool use in Being and Time. At the same time, he argues that Heidegger's vocabulary needs some modification when applied to our relations with technologies and that the variety of ways in which the world can be experienced and interpreted through technologies requires a broader framework (Ihde 1979, 4). Heidegger's analysis on this point suggests that we engage in a similar relation with every tool and that the specific structure of this relation depends on how the tool relates to the background in which it is used. One of Ihde's central points is that the specific way in which a technology allows for a relation to the world is not only contingent on the totality in which it appears but also depends on the very structure of the technology itself. Accordingly, Ihde holds that

"experiences with machines themselves are diverse and are not simply reducible to any single primitive set" (Ibid. 4).

In his analysis of tool use in Being and Time, Heidegger shows that tools withdraw in our relation to them and only become visible as concrete entities that have certain properties in instances of breakdown. Ihde follows Heidegger on this point but sets it as his task to uncover the variety of relations that we may have with technologies, in which the world is constituted in a variety of ways. ${ }^{17}$ Accordingly, technologies are not primarily interpreted as things with certain properties that we encounter as objects that our foreign, but they shape our relation to the world by putting them to use. In doing this, not the technology itself, but how it makes us relate to the world, becomes the center of our attention. In this respect, Ihde argues that Heidegger's phenomenological analysis of tool use can be extended to technologies. He stresses that this analysis reveals that our everyday involvement with the world is through the ready-to-hand, which withdraws and shows the inadequacy of an ontological understanding of world in terms of the presentat-hand. It is precisely this focus on the ready-to-hand that Ihde takes to be a fruitful way to develop a philosophy of human-technology relations against existing tendencies in the philosophy of technology to approach Technology as a structural whole.

\section{The Ready-to-hand and Human-Technology Relations}

Ihde attempts to capture the variety of ways in which technologies mediate our understanding and experiences of the world in a set of schemas indicating how technologies make us relate to the world. These can best be understood as specifications of the more general framework of the ready-to-hand that we find in Heidegger's work. However, at the same time, Ihde significantly expands on Heidegger by anticipating that structural critiques of Technology "become possible precisely by either an implicit or explicit choice of one type of relation as primary or paradigmatic" (Ibid. 4). In this sense, if Heidegger's phenomenology of tool use is interpreted as capturing all human-technology relations, it would be deprived of its analytic potential. This is why it is pivotal to understand technologies as mediating how human beings relate to the world and that the different ways in which technologies do so correspond to different

17 Note that "world" in this context is used in a Heideggerian sense as discussed in the previous section. Thus, rather than referring a set of objects external to us, it is interpreted as worldhood. 
phenomenological structures.

The most elaborate discussion of these relations can be found in Ihde's Technology and the Lifeworld (1990) but have functioned as a starting point of his philosophy from Technics and Praxis (1979) onwards. He discerns four basic sets of relations with technologies: embodiment relations, hermeneutic relations, alterity relations, and background relations (Ihde 1990, 72-122). In each of these relations, technologies mediate between human beings and the world in a different way (i.e., make human beings experience and interpret the world differently). ${ }^{18}$ Different technologies mediate how human beings are intentionally directed at the world, thereby opening and closing possibilities of experience and interpretation. This is what Ihde calls the amplification-reduction structure of technological mediations. By mediating the intentional relation between human being and world, there is an "amplification [that] tends to stand out, to be dramatic, while the reduction tends to be overlooked, or may be forgotten" (Ihde 1979, 21). In this sense, technological mediations are never neutral: they transform how human beings can relate to the world. Let me illustrate this claim in more detail by examining the first two relations Ihde discerned: the embodiment relation and the hermeneutic relation:

In embodiment relations, technologies mediate how our bodily experience of the world without becoming thematically present as an object in the world. In other words, in our experience, we do not differentiate between what is our own body and what is a technological extension of it; the body has incorporated the technological extension as being a part of it (cf. Ihde 2010, 42). This can be illustrated by our experience of slicing bread. When we tear bread into smaller pieces with our bare hands, we may feel its warmth, softness, and so on, but when we use a knife to cut it, we experience the surface of the bread through the knife, that is, the carvings of the knife allow is to cut the bread more easily and precisely (amplification), but we no longer experience the warmth of the bread (reduction). Furthermore, we do not experience the presence of the knife specifically; it makes us relate to the bread, not to the knife. In this example, the knife is incorporated in our bodily experience, making it impossible to distinguish between ourselves and the knife in this experience. In our relationship with the bread, the knife becomes transparent: it is no longer experienced as a knife but makes us experience the bread in a different way.

We can engage in a similar kind of relation when using more advanced technologies. For example, when using a vacuum cleaner, my primary experience is not with the specifics of this artifact but with the surface that I am cleaning. In analogy with the discussion of
Heidegger's distinction between the ready-to-hand and the present-at-hand, the vacuum cleaner is not experienced as an object with specific properties but is something-inorder-to do something else, cleaning the surface, in this instance. The vacuum cleaner withdraws from our attention and becomes part of what we experience as our body. Both of these examples of embodiment relations show the continuity between Heidegger's phenomenology of tool use and Ihde's postphenomenological framework because in these cases, the technology withdraws in how it constitutes a relation with the world.

A second type of relation with the world mediated by a technology Ihde calls the hermeneutic relation. In this type of relation, we relate to the world through an artifact, but it does not become transparent. Contrary to an embodiment relation, we do not incorporate a technology in our body schema, but the technology presents an interpretation of the world that is related to as an object of interpretation. Crucially, the technology already partly interprets the world for us; our intentionality is directed a the technologically mediated phenomenon that enters our sensory space. The standard example that Ihde uses is the thermometer (e.g., Ihde 2010, 43). When relating to a thermometer, temperature becomes readable for us in a particular way. In this case, rather than being a tactile sensation that may induce feelings of warmth or cold, temperature becomes something that can be numerically appreciated in our relationship with a thermometer with a certain degree of precision. In this case, a thermometer constitutes a relation with the world that makes us understand temperature in a specific way. When relating to temperature through a thermometer, the bodily sensation of warmth is lost (reduction). However, it also allows for specific aspects to stand out, namely, the ability to specifically compare temperature over time in a precise way (amplification).

Also, in this relation, the thermometer does not appear to us as something that is presentat-hand; rather, it makes us relate to something else. It is something that we relate to in order to be able to know the specific degree of Celsius precisely. Just as in the case of embodiment relations, the thermometer withdraws in how it mediates our relationship with the world. In other words, it does not appear as foreign object but is integrated in how we interpret the world. While in terms of withdrawal, this relation is continuous with Heidegger's phenomenology of tool use, it augments it in terms of the different ways in which different technologies mediate our relationship with the world. Not only do we relate to technologies to discover the objects around us, but these also mediate how existing objects (such as temperature) can be interpreted, thereby changing what is understood as "the world." Understood in this way, technologies not only transform our capacity of bodily experiencing the world but also create new possibilities to appreciate 
the world hermeneutically. ${ }^{19}$

\section{Disclosing the World Through Technologies}

How technologies mediate our interpretation of the world is a theme further developed in Verbeek's What Things Do (2005). Central in his discussion of Ihde's human-technology relations is the idea that technologies do not merely allow us to relate to an already existing world in a variety of ways, but they shape what we take to be the world in the first place. In other words, technologies are not merely constitutive of how we interpret the world (as if they would allow establishing a relationship with an already existing set of entities) but are constitutive of the world proper:

"Of necessity, any description of reality cannot avoid being a rationale, explanation, or constitution. That is not to say that the world is only a construction, just that we can never know the world as it is in itself, but only as we disclose it. An uninterpreted world, a world in itself, cannot be experienced an untouched world cannot be lived in. Human beings never encounter a world in itself, only and always a world for them" (Verbeek 2005, 107, my emphasis).

In emphasizing that the world is disclosed within human-technology relations and that it does not make sense to speak about a world in another manner, Verbeek further radicalizes the notion of technological mediation: because our intentionality is always the function of how we relate to a technology, the world is disclosed through our relation with technology as well. In the mediated relation between human beings and technologies, "a specific 'objectivity' of world and a specific 'subjectivity' of human beings" is constituted (Ibid. 112). Accordingly, technological mediations should not be understood as re-presenting possible experiences and interpretations that already potentially resided in the world-or in the subject, for that matter, but instead as presenting those, precisely because it only make senses to speak about "the world" insofar it is constituted within human-technology relations.

Verbeek's use of mediation comes close to how Heidegger uses the notion "worldhood”: technologies are constitutive of the existential structure of human beings because they help constituting both subject and world. Whereas Ihde takes Heidegger's analysis of tool use as a starting point for understanding our relations with the world, Verbeek seems to be closer to Heidegger, because it is within these relations that the notion "world" attains its meaning. The world is a function of worldhood taking shape in our

19 Herewith, I do not mean to imply that there is a strict difference between having an embodied and a cognitive (or interpretative) relation with the world. However, the structure of a hermeneutic relation is one in which primarily are interpretative capacities are mediated by a technology. everyday interaction with technologies. From this perspective, we do not just relate to the world through technologies, but how the world is disclosed is also the function of our relationship with a specific technology.

For example, my smartphone does not just allow me to relate the world in which the number of contacts that I can reach immediately has increased suddenly, but the very appearance of this contacts as contacts that can be immediately reached changes how the world becomes present to me. Both the individual (subject) and the world he encounters (object) are specifically shaped in our relationship with a technology, in this case, a smartphone. At the same time, I become a subject with the capability of contacting people in an easy way, and the world is disclosed such that it becomes a world in which others are present as easy to be contacted. Thus, a specific artifact allows for the specific constitution of the world (i.e., our world in our relationship with it). This makes immediately clear that a technology is not something between me and a world external to me but constitutes how the world is revealed and my relation to it. In this more radical interpretation of Heidegger's phenomenology of tool use, the focus is less on the withdrawal of tools in our relationship with them (as was the case in Ihde's appropriation of Heidegger) but increasingly on the variety of ways of disclosing the world that are mediated within human-technology relations.

\section{\$2.3 HEIDEGGER'S PESSIMISM: DISCLOSING THE WORLD IN THE QUESTION CONCERNING TECHNOLOGY}

To get a better grasp of the notion of technological mediation, it is important to be precise about the non-neutrality of technologies that it implies. As Verbeek argues, precisely because technologies mediate relationships between technologies and the world, they should not be considered mute things at our disposal that allow us to pursue our pre-set goals more effectively:

"Contrary to what many people intuitively think, [...] technologies are not simply neutral instruments that facilitate our existence. While fulfilling their function, technologies do much more: they give shape to what we do and how we experience the world. And in doing so they contribute actively to the ways we live our lives" (Verbeek 2011, 1).

A similar intuition on the non-neutrality of technology can be found in Heidegger's famous essay The Question Concerning Technology, where he writes that "we are delivered over to [technology] in the worst possible way when we regard it as something neutral" 
(Heidegger 1977a, 4). Through an analysis of Heidegger's seminal essay, I sketch the contours of the sort of non-neutrality of technologies Verbeek and Ihde have in mind when using the term technological mediation. In this analysis, I explain what Heidegger takes to be a neutral-or instrumental-relation with technology. Secondly, I discuss what he means by the essence of technology. Lastly, I show how, according to Heidegger, having a neutral relation with technology prevents us from seeing its essence. ${ }^{20}$ As the next section demonstrates, how the non-neutrality of technology is appropriated within postphenomenology does not necessary amount to the conclusions about technology that Heidegger draws.

\section{Technology's Non-Neutrality}

From the start of the essay, Heidegger's goal is clear: "We shall be questioning concerning technology, and in so doing we should like to prepare a free relationship to it. The relationship will be free if it opens our human existence to the essence of technology" (Ibid.3). But what is this essence to which human existence must open up? To answer this question, Heidegger first identifies two common, interrelated conceptions of technology that do not reveal its essence: technology as a means to an end and technology as a human activity. He derives the following common definition of technology from these two conceptions:

"The manufacture and utilization of equipment, tools, and machines, the manufactured and used things themselves, and the needs and ends that they serve, all belong to what technology is. The whole complex of these contrivances is technology. Technology itself is a contrivance, or, in Latin, an instrumentum" (Ibid. 4-5).

The whole network of man-made tools and machines that are used to fulfill certain ends constitute a complex network that can be called "technology." From this perspective, technology is a complex instrument developed by human beings who have manufactured and connected tools and machines. In this common definition, the damaging potential of technology lies in the fact that-with the advent of modern technology-it will fall outside of human control. From this perspective, establishing a free relation with technology depends on "'getting' technology 'spiritually at hand”' (Ibid. 5). ${ }^{21}$ Doing this requires using the instruments that constitute "technology" in a justifiable way as

20 I do not aim to give a comprehensive discussion of the Question Concerning Technology and its place in Heidegger's oeuvre, but I focus on the differences and similarities in how the non-neutrality of technology is discussed by Heidegger and within postphenomenology. For a detailed general discussion of The Question Concerning Technology, see, for example, Loscerbo (1981), 129-153; Visser (2014).

21 This refers most likely to Ernst Jünger's instrumental conception of technology developed in The Worker (1932), which Heidegger deemed to be inadequate. For a detailed discussion, see Blok (2011) means to fulfill the goals that human beings have set. In other words, it requires that the complex network of tools and machines does not run out of control and that its development remains in the hands of human beings.

However, Heidegger holds that conceiving of technology in this manner is unable to reveal its essence, since "the essence of technology is by no means anything technological" (Ibid. 4). The essence of technology cannot be found when it is considered in terms of the tools and machines that can be described as "technological." While the above instrumental definition of technology is correct, it is not true, because it fails to reveal the essence of technology:

"The correct always fixes upon something pertinent whatever is under consideration. However, in order to be correct, this fixing by no means needs to uncover the thing in question in its essence. Only at the point where such an uncovering happens does the true come to pass" (Ibid. 6).

However, this correct definition can function as a starting point for opening up to the essence of technology: "[I]n order that we may arrive at this, or at least come close to it, we must seek the true by way of the correct" (Ibid. 6). Thus, when grasping why technology is commonly understood in terms of instrumentality and neutrality, we can come to an understanding of its essence. This assumes that the common understanding of technology is not a "necessary" one but is instead a specific way in which technology is already disclosed. It is by analyzing how technology is disclosed in terms of instrumentality that its essence can be revealed. To do so, "[w]e must ask: What is the instrumental itself? Within what do such things as means and end belong?" (Ibid. 6).

An instrumental definition of the use of technology could be something like this: A uses B as a means to cause C, such that without any B, A would be unable to cause C. Consequently, there is a close connection between the notion of instrumentality and the notion of causality. But what form of causality is implied here? According to Heidegger, the modern way of understanding causality reduces it to the causa efficiens, which is only a specific way of causality when interpreted against the background of the different forms of causality distinguished by Aristotle. In modern times, this form of causality sets the standard for all forms of causality, thereby reducing it to the structure "B is effected by A". However, Heidegger holds that the word "cause" can be traced to the Greek aition. This etymological exercise reveals a profound other meaning of causality: as "that to which something else is indebted" (Ibid. 7). Contrary to the above characterization of the causa efficiens, this conception of causality is of the structure "B is indebted to A," thereby not interpreting the effect "B" to be identified as caused by a singular actor "A." 
Rather, this understanding opens up the possibility that B is indebted to something else.

But how then must we understand the manifestation of "B" as indebted to something else? Must we move back to the Aristotelian scheme and say that "B is indebted to A, C, D, and E," where A is the causa efficiens, C the causa materialis, D the causa finalis, and E the causa formalis? According to Heidegger, this would not point in the direction of the meaning of the Greek word aition, because in Aristotle's analysis of causality, it also remains unclear "whence does it come that the causal character of the four causes is so unifiedly determined that they belong together" (Ibid. 7). What unites these four causes is that they are at play within what Heidegger calls bringing-forth. Being indebted in terms of aition is the bringing-forth of the concealed into unconcealment: Aristotle's four ways of causation are "unifiedly ruled over by a bringing that brings what presences into appearance" (Ibid. 10). In this sense, what unifies the four causes is a poiesis; it is an event in which something brings into self into appearance as this or that something. In this specific way, what characterizes what nowadays is called "causation" is the unconcealment of a thing in a specific way which is revealed (entbergen). Heidegger also proposes asking for the essence of technology in these terms: "What has the essence of technology to do with revealing? The answer: everything" (Ibid. 12). And since how technology is revealed is in terms of instrumentality, it is in this specific way of revealing that essence of technology can be opened up to.

\section{The Essence of Technology: The Enframing of Nature}

But in what sense does how technology reveals itself as instrumental simultaneously reveal its non-neutrality? To illustrate this, Heidegger illustrates why Technology must be understood as a way of revealing by discussing the bringing-forth of the Rhine through the presence of a hydroelectric plant:

"The hydroelectric plant is set into the current of the Rhine. It sets the Rhine to supplying it hydraulic pressure, which then sets the turbines turning. This turning sets those machines in motion whose thrust sets going the electric current for which the long-distance power station and its network of cables are set up to dispatch electricity. In the context of the interlocking processes pertaining to the orderly disposition of electrical energy, even the Rhine itself appears as something at our command" (Ibid. 16, my emphasis).

It is in this respect that Heidegger understands technology as non-neutral; through the presencing of the Rhine by the hydroelectric plant, the Rhine is revealed in terms of instrumentality (e.g., as a source of electricity). Technology manifests its non-neutrality by bringing the Rhine out of concealment as something at our command rather than revealing it as something that inspires awe and admiration.

While it is possible to interpret this as a desirable development-we must only be remembered of the Baconian ideal of mastering nature-Heidegger conceived this way of revealing as a challenging of nature: It "puts to nature the unreasonable demand that it supply energy that can be extracted and stored as such" (Ibid. 14). This mode of revealing makes it impossible to interpret the Rhine as a source of artistic inspiration but only reveals it as a source of calculable energy.2. As challenging nature to reveal itself in terms of calculability, technology as a way of revealing transcends the particularities of technologies. In fact, Heidegger argues it is through the lens of Technology as a way of revealing that the development of modern physics should be understood: "Modern physics, as experimental, is dependent upon technical apparatus and upon progress in the building of apparatus" (Ibid. 14). As a way of revealing, Technology is a worldview that challenges nature forth as being unconcealed in terms of calculability and manipulability. ${ }^{23}$ This is what Heidegger calls the ordering of nature as a standing-reserve (bestand) (Ibid. 17). According to Heidegger, it is through this particular way of bringingforth as challenging-forth that nature is revealed as something at our disposal, as is the Rhine as brought into concealment through the presence of the hydroelectric plant.

However, since it was mankind that was responsible for the installation of a hydroelectric plant, does this not presuppose that the challenging forth of nature is caused by mankind rather than by technology? Anticipating this criticism, Heidegger shows that such a perspective assumes that there is something that can be called "mankind" prior to Technology. Yet, mankind participates in how the unconcealed is revealed through Technology: "The unconcealment of the unconcealed has already come to pass whenever it calls man forth into the modes of revealing allotted to him" (Ibid. 19). Before man sets a technology such as an energy plant into the current of the Rhine, nature is already concealed as a standing-reserve (i.e., as something that is at our command). This is what Heidegger calls the Enframing (Gestell) of nature, which "concentrates man upon ordering the real as standing-reserve" (Ibid. 19). In this sense, the essence of Technology must be understood in terms of non-neutrality; if forces the ordering of nature as standing-reserve. The essence of technology as Enframing is not a passive property of Technology but is conceived as something active; it unconceals nature from concealment as standing-reserve. As such, mankind has become impotent to conceive of nature in

22 Anticipating the postphenomenological discussion of Heidegger's work, it should be noted that ordering the Rhine as a source of electricity and as instantiating feelings of awe and admiration are not necessarily mutually exclusive. This is discussed in more detail in the next section.

23 This is the central claim of Heidegger in his essay The Age of the World Picture, which discusses the conditions of possibility of modern science, and is further discussed in the next chapter that specifically deals with Heidegger's evaluation of modern science and its relation to modern technology. 
other ways; it is only the source of energy that nature delivers that man can relate to:

"Thus when man, investigating, observing, ensnares nature as an area of his own conceiving, he has already been claimed by a way of revealing that challenges him to approach nature as an object of research, until even the object disappears into the objectlessness of standing-reserve" (Ibid. 19).

The uniformity of the standing reserve makes it impossible, through how other appropriations of nature are ruled out when revealed through Technology, to relate to nature in other possible ways. It is only in terms of instrumentality that it can be appreciated.

\section{Technology's Neutrality as Threat}

Does the Enframing leave us with no choice than being delivered over to Technology, or does it allow for developing new relations with nature? Heidegger is ambivalent on this point: "[W]hen we once open ourselves expressly to the essence of technology, we find ourselves unexpectedly taken into a freeing claim" (Ibid. 26). However, this "freeing" has nothing to do with the bringing under control of a technological system that has got "out of our hands"; this would assume that in the end, technology is something neutral that can be brought under our control. When dismissing this perspective, it becomes clear what Heidegger really is criticizing:

"The treat to man does not come in the first instance from the potentially lethal machines and apparatus of technology. The actual threat has already affected man in his essence. The rule of Enframing threatens men with the possibility that it could be denied to him to enter into a more original revealing and hence to experience the call of a more primal truth" (Ibid. 28).

When interpreted as something neutral, man is not capable of seeing that it is Technology that challenges nature as standing reserve and is prior to every human involvement. This is why he stresses at the beginning of the text that the worst way to conceive of technology is to conceive of it as something neutral; this would rob us of the possibility to open us to technology's essence. What is at stake for Heidegger is that not being opened up to the essence of Technology prevents man from seeing their own way of being (i.e., how nature is brought out of concealment by the Enframing). What Heidegger eventually calls for is an opening up to the essence of technology of the Enframing, and he does not present it is a "problem" that demands a "solution"-the very idea of a "solution" to the Enframing is absurd from a Heideggerian perspective. Instead, it is the recognition that Technology is a way of revealing that cannot but unconceal nature as standing-reserve that might constitute a relation between humans and how they are. Cautiously, we can say-invoking the terms that Heidegger uses in Being and Time-that Technology reveals the "worldhood of the world," and thereby mediates how we are in this world.

\section{\$2.4 CONCLUSION: ENFRAMING AND MEDIATION WITHIN HUMAN-TECHNOLOGY RELATIONS}

Heidegger hardly discusses concrete technological practices in The Question Concerning Technology because his starting point is that the essence of technology is "by no means anything technological” (Heidegger 1977a, 4). As a consequence, any investigation into the nature or working of individual technologies would by definition not be of interest in relation to his particular philosophical concern. Within postphenomenology, this lack of interest is used to criticize Heidegger's later philosophy of technology because it presupposes a uniformity of all technologies, and it is argued that his phenomenology of tool use can be seen as a more fruitful way for understanding relations between humans and technologies (Verbeek 2005, 80, cf. Zwier, Blok, and Lemmens 2016). However, to transform the observation that Heidegger did not pay attention to the workings of individual technologies into a criticism against him, it is necessary to show either the relevance of individual artifacts in the search for the essence of technology or that the philosophical question regarding the essence of technology is misguided. In other words, it must be shown that the essence of technology is by any means technological, or that Technology has no uniform essence.

As noted by Peter-Paul Verbeek, the portrayal of Heidegger's philosophy of technology as too abstract and monolithic is gratuit when based on an external assessment of Heidegger's philosophy of technology, without engaging with Heidegger on his own terms (Verbeek 2005, 48). More fine-grained arguments against Heidegger's philosophy can be found within postphenomenology and are explicitly formulated in Verbeek's What Things Do and in Don Ihde's Technics and Praxis. In this section, I discuss the central important postphenomenological argument against Heidegger's view: the transcendentalist foundation of his philosophy of technology that prevents it from seeing how concrete technologies help constitute new intentional relations with the world. Subsequently, I show how this argument develops into a specific way in which technologies should be understood as mediators of human experience and human understanding.

\section{Postphenomenology's Criticism of Transcendentalism}

The central element of the postphenomenological criticism against Heidegger's philosophy of technology is that it confuses the workings of technologies with their 
conditions of possibility (i.e., Enframing) and therefore fails to notice the several different ways in which technologies disclose the world (e.g., Ihde 1979, 106; Verbeek 2005, 75). Heidegger and postphenomenologists share a critique of any instrumentalist understanding of technology that conceives of it as a neutral means. However, postphenomenological thinking breaks with Heidegger's analysis in its rejection of the uniform manner of revealing nature that Heidegger attributes to Technology. For Heidegger, it was unnecessary to differentiate between individual technologies, since each of these participate in a technological way of revealing. According to Verbeek and Ihde, this uniform understanding of Technology is the consequence of his (eventually unjustifiable) equating of the workings of concrete technologies with how these have come into being. As I demonstrate below, this gives rise to a more varied way in which the non-neutrality of technologies can be understood and analyzed.

The primary criticism of postphenomenology against Heidegger's position is the idea that it is possible to strictly differentiate between the workings of technologies and their conditions of possibility. As such, the difference between the two positions is grounded in a different definition of "technology." Whereas Heidegger from the start assumes that Technology has a uniform "essence" that can be opened up to, postphenomenologists maintain the view that the actual practices in which technologies mediate relationships between human beings and the world are so diverse that any analysis of technology should reflect this diversity. If one would like to speak about technologies in terms of essence(s), this should be done through an analysis of technological practices, and the different ways in which technologies manifest in practices reveals that its essence is in constant flux-which in a sense makes any attempt to search for an essence obsolete. Therefore, rather than understanding Technology in terms of uniformity (i.e., assuming that Technology is a structural phenomenon that can be approached in a uniform manner), a postphenomenological perspective maintains that a philosophy of technology should be grounded in the analysis of concrete technologies (e.g., Ihde 2010, 18).

To use analyses of concrete technologies as a criticism of Heidegger, it is necessary to show that the essence of technology is something technological. Only as such can the variety of ways in which the world is disclosed through technologies function as an argument against the philosophical ambition to ground technology in a singular essence. According to Verbeek, Heidegger's different treatment of concrete technologies and his preference for premodern technologies already hints at the idea that the essence of technology is not something that is "above" the things:

"Without the selectivity in Heidegger's approach either the hydroelectric plant would have to reveal the fourfold as well or the bridge could not be understood as a thing that essentially (ahistorically) reveals the event of coming into being. In other words, Heidegger's understanding of modern technology in terms of alienation, in which something originary gest lost, would not have been possible without applying a double standard (Verbeek 2005, 74)".

As Verbeek argues, there is nothing wrong with nostalgia per se: after all, why should we accept a priori that we should not prefer premodern technologies over modern ones (Ibid. 68)? However, revealing Heidegger's nostalgia as a consequence of his investigation of the conditions of possibility of technologies allows its transformation into a criticism. From this perspective, Heidegger arbitrarily attributes the Enframing to the hydroelectric plant and, on this ground, distinguishes it from the (non-Technological) disclosing of the Rhine by a bridge. While it is perfectly possible that the bridge and the hydroelectric plant disclose the Rhine in a different manner, there is no fundamental reason why one should be preferred over the other. It is precisely this difference that Verbeek considers irreducible to the conditions of the possibility of Technology; on the contrary, it is this difference that demands philosophical analysis. This does not necessarily imply that investigations into the conditions of possibility of technologies are unable to offer insights in the workings of technology, but it shows that Heidegger's transcendental interpretation of technology cannot account for the operativity of technologies in society and hence is unable to acknowledge that technologies can constitute new practices in society and new interpretations of reality (Ibid. 9).

\section{Technological Mediation: A Non-Transcendentalist Conception of Non-Neutrality}

Although Heidegger surely acknowledges the non-neutrality of technologiesactually, this is central in his idea that they challenge nature as standing-reserve-his transcendentalist understanding of non-neutrality fails to bring to light the different new ways of beings that technologies help constitute. For example, he sees the revealing of the Rhine as standing reserve by the hydroelectric plant as the only way that this specific technology discloses the world, thereby neglecting that it also allows families to light their houses or lets hospitals function more efficiently. As Ihde shows, Heidegger's negative evaluation of the typewriter also has a similar connotation: Heidegger writes that "the typewriter snatches script from the essential realm of the hand-and this means the hand is removes from the essential realm of the word" (Heidegger 1982, 118119). As Ihde points out, a difference surely exists between handwriting and writing on a typewriter, and this difference is worthy of investigation. However, on what ground can we a priori determine that handwriting allows for entering the essential realm of the word, while this possibility is removed by the typewriter (cf. Ihde 2010, 77)? When extending this example to the contemporary use of the computer, the lack of explanatory value of Heidegger's transcendentalist perspective becomes even clearer: even if we 
accept that the essential realm of the world is concealed through the computer, must we not also attempt to understand how computers and similar devices enable us to communicate more quickly and how the use of computers and more developed internet and communication technologies (ICT) allows for a fundamentally different way of understanding-and dealing with-cases of natural disasters, to give an example?

This serves to illustrate the lack of explanatory value in Heidegger's conception of technology. This is not necessarily the consequence of his understanding of technology in terms of its conditions of possibility but is rather caused by his distinguishing between the actual workings technologies, on the one hand, and their conditions of possibility, on the other. In postphenomenology, these two appear as intertwined, which makes it possible to make both different workings of technologies and how they disclose the world subject to philosophical analysis. This does not necessarily prevent one from understanding the hydroelectric plant as challenging forth the Rhine as a standingreserve (i.e., as a mere source of energy). However, it shows that how the world is revealed through the hydroelectric plants cannot be reduced to this specific event. Furthermore, how electricity functions in society cannot be traced back to the place where it was produced, as its concrete manifestations differ in different times and periods. For instance, the hydroelectric plant gives rise to new technological developments that were not incorporated in its original challenging of nature. This is not to say that there are essential features of the hydroelectric plant that should be preferred over the features of a bridge over the Rhine. After all, electricity has also been key in the production of advanced weaponry that might cause great damage. It is in this sense that both technological objects should be interpreted as revealing the world within their specific historical embeddings; it is only in this aspect that how reality is revealed in relation to them can be appreciated.

The Heideggerian understanding of the essence of technology as a way of revealing leads to an ahistorical understanding of technology. Neither humans nor technologies are capable of relating to this typical way of revealing consciously or unconsciously. This is most clearly formulated in the idea that technology eventually prevents man from understanding his own essence: "In truth, however, precisely nowhere does man today any longer encounter himself, i.e., his essence” (Heidegger 1977a, 27). This assumes that the essence of technology is preventing access to an authentic human essence that is independent of time and place. In both cases, an essence is not something that is found in concrete reality but rather is an ahistorical concept that exists outside space and time. On this point do postphenomenology and Heidegger diverge most clearly; while Heidegger interprets essence as something that is universal, postphenomenologists stress that it is in constant flux because it changes within specific practices. To illustrate this shift, postphenomenologists speak of technologies as mediating relations between human beings and the world, rather than conceptualizing them as a way of revealing (entbergen). The concept of mediation reveals that because technology is a dispersed phenomenon scattered across different individual technologies, it opens up multiple ways to relate to the world. Accordingly, the "essence" of technology is in constant flux, as is our understanding of reality.

In concrete practical environments, technologies disclose the world in a specific way. However, this disclosure does not occur in isolation, independent of the presence of other technologies and human beings. When we must think of technologies as embedded in concrete practices, it becomes clear that they disclose a variety of realities in a variety of ways. Conceptions of technology as alienating human beings from their own authenticity or as determining the "structure" of modern society do not appear as adequate within this postphenomenological perspective-they are neither "correct" nor "true," to use a Heideggerian terminology. Surely, "alienation" can be one manner that a particular technology reveals reality in a concrete practice. However, several other ways of disclosure are possible as well: just as technologies can instantiate feelings of alienation, they can create new experiences that could not be imagined without them, such as advances in medical care, which induces a fundamentally different understanding of health and hygiene. To capture this diversity, postphenomenology uses the term "technological mediation": this term is continuous with Heidegger's later work, which sees technologies as disclosing the world, but simultaneously breaks with it because it takes his phenomenology of tool use as a starting point and sees the disclosing of the world as an event that occurs within the relation between human beings and technologies. In this dissertation, I build on this understanding of the notion of technological mediation to understand how the reality that scientists study is revealed to them in a particular way when relating to particular technologies. 


\section{CHAPTER 3:}

Science and the Theoretical Disclosure of Nature 


\section{INTRODUCTION: SCIENCE AS PRACTICE?}

When a scientist arrives at a laboratory, (s)he encounters a technological infrastructure that is only comprehensible for people who are trained to use it. Contrary to the use of my coffee machine, it requires a particular theoretical background and extensive training to be able to engage with this specific set of technologies. For example, when a cognitive neuroscientist arrives at work and is finished answering her emails, (s)he may engage in data analysis through the use of highly specialist calculation programs, or she may test a participant in an MRI scanner, of which the outcome will become part of a data set that must be analyzed. It is clear that this scientist is equally unable to function without the presence of a large technological infrastructure. Considering that both our scientific and daily practices crucially depend on technologies, can we still distinguish between the two, or must we acknowledge that both depend on technology in a similar way? In this chapter, this question is explored by asking to what extent postphenomenological analyses of human-technology relations as introduced in the previous chapter can be fruitfully integrated into a philosophy of scientific practice.

Within the field of postphenomenology and the related field of STS, the dependency of both scientific and ordinary practices on technologies resulted in the idea that in one way or another, a continuum exists between the two (e.g., Alač 2008; Ihde 1991, 1998; Rosenberger 2008; Verbeek 2005, 2011; Vertesi 2012). In all of these cases, it is tacitly assumed that the framework used to analyze technologies in everyday life can be extrapolated to the domain of science. However, can we indeed analyze the role of technologies in scientific practices on the same ground, or is there something distinct about science that instantiates a specific use of technologies? For example, is the dependency of scientific research on existing scientific theories, an aspect that is often absent in our daily practice, reflected in how technologies are used in scientific practice? Or, more generally, is the reality to which scientists relate essentially the same as the reality encountered in everyday life?

In this chapter, these questions are addressed by exploring whether the postphenomenological criticism on Heidegger's analysis of Technology that culminates in a philosophy of technological mediation can be unproblematically extended to Heidegger's analysis of science. The previous chapter showed that when focusing on individual technologies, nature need not appear as standing-reserve. In the postphenomenological literature, Heidegger's analysis of science is dismissed along similar lines, with reference to the idea that if Technology is ontologically prior to science, Heidegger is committed to the idea that the essence of science can be traced back to the ordering of nature as standing-reserve (e.g., Ihde 2010). This seems to suggest a that Heidegger's thinking about science should be understood as analogous with his thinking about Technology. However, as I show in this chapter, in Heidegger's thinking a starting point for developing a hermeneutics of scientific practice can be found that attempts to capture both the practical and the scientific characters of scientific practice.

The chapter is structured as follows: firstly, I show how Heidegger's phenomenology of tool use can be extended from the context of everyday life to the context of science (\$3.1). Secondly, I show how this phenomenological perspective disappears from view in Heidegger's later thinking about science (\$3.2). Thirdly, I argue that-despite the similarities-this trajectory should not be equated with how Heidegger moves from a phenomenology of tool use to understanding Technology as Enframing (\$3.3). Fourthly, I show how Heidegger's phenomenology of tool use functions as an important inspiration for a postphenomenological analyses of the role of technologies in scientific practice (\$3.4). Fifthly, I argue that such analyses neglect an important insight of Heidegger's hermeneutics of science: namely, how in scientific practices, a relation with objects appearing as present-at-hand is established (\$2.5). To conclude, I argue that Heidegger's hermeneutics of science can be used to articulate the distinct scientific character of scientific practice and therefore is an important augmentation of existing postphenomenological approaches (\$2.6).

\section{§3.1 HEIDEGGER AND THE PRIMACY OF PRACTICE IN SCIENCE}

Heidegger's thinking about science is often discussed on par with his philosophy of technology, and critics dismiss it as being unable to account for positive developments in science and medicine (e.g., Feenberg 1999, Svenaeus 2013). While this may be partly true for his questioning for the essence of science in his later works, Heidegger's earlier thinking was not dismissive of science per se, only insofar as it claimed to be ontologically foundational (cf. Caputo 2012). In Being and Time, Heidegger was concerned with developing a hermeneutics of science that understood science as a specific kind of practice explicitly concerned with disclosing the world as a set of present-at-hand objects (cf. Glazebrook 20oob; McManus 2012). In this context, Heidegger asks how the possibility to discover the world in terms of present-at-hand objects can arise, given that our initial contact with the world always occurs in relation with the ready-to-hand.

Rather than understanding science in terms of a set of theoretical propositions in need for justification, Heidegger's hermeneutic of science attempts to understand science as a "way of existence and thus as a mode of being-in-the-world" (Heidegger 1985, 408; cf. Nordmann 2012), in which the world and the entities in it are disclosed in a specific 
way. Accordingly, he asks “which of those conditions implied in Dasein's state of Being are existentially necessary for the possibility of Dasein's existing in the way of scientific research" (Ibid. 408). As a way of existence, science is understood as being constituted through the existential structure of human beings, instead of belonging to a separate sphere of rationality that is disconnected from any practical concern. Scientific activity, and also scientific theorizing, is, in Heidegger's view, a fundamentally worldly activity that cannot be separated from the human being that engages in it. This resembles his argument that initially, human beings never relate to a world that is perceived as an object that is foreign to us but that the disclosure of the world is grounded in the existentiality of worldhood. Because of this, "nature [can be revealed as] an entity which is encountered within the world and which can be discovered in various ways and at various stages" (Ibid. 64). According to Heidegger, precisely because our initial contact with the world is not one in which it appears as a set of objects with certain properties, a specific way of disclosing the world is presupposed when engaging in scientific research. It is important to note that Heidegger does not dismiss that the sciences may be very informative and yield genuine results; what is at stake is that science can never function as the basis of an ontology, as it is derivative on a specific disclosure of the world rather than capturing the most accurate way to disclose it. Heidegger calls this the projection of the world in which it becomes present as a set of objects that are present-at-hand and can be made subject to scientific investigation (cf. Glazebrook 20oob, 5). When understood in this way, we cannot circumvent an understanding of science in terms of the worldhood of human beings (i.e., as in one way or another being constituted in relation with the readyto-hand). In other words, disclosing the world as nature is a special case of disclosure that is dependent on a specific kind of practice.

Heidegger points to the fact that the scientific disclosure of the world is dependent on material technologies that must be practically dealt with: "[T]heoretical research is not without a praxis of its own. Reading off the measurements which result from an experiment often requires a complicated 'technical' set-up for the experimental design. Observation with a microscope is dependent upon the production of "preparations"' (Ibid. 409). In Denis McManus's book Heidegger and the Measure of Truth, this is summarized as Heidegger's Primacy of Scientific Practice claim, which indicates that "scientific knowledge presupposesis bound up with, is unintelligible without reference to-certain practices” (2012, 63). Thus, in one way or another-and this is what commentators on Heidegger generally agree upon"the ready-to-hand is prior to, or more fundamental than, the present-at-hand" (Ibid. 69).

How then must we understand the priority or more fundamental nature of the ready-tohand in this context? It seems that from Heidegger's analysis of worldhood, it minimally follows that the priority of the ready-to-hand can be found in how it is constitutive of the worldhood of Dasein, and thereby prior to a structural whole of "world." As such, it is clearly not a claim about the priority of ready-to-hand to present-at-hand in the sense that the latter can be reduced to the former. On the contrary, these categories do not exist independently of human beings but take shape in the relation between human beings and the world. Heidegger's claim is about how we relate to a "world" through our relationship with the things around us. Accordingly, both the ready-to-hand and the present-at-hand must be understood as modes through which a relationship with reality is established. Later in this chapter, I draw on postphenomenology to show how the ready-to-hand is considered prior to the present-at-hand in the constitution of these modes.

An Existential Conception of Science: Deliberately Relating to Reality as Present-at-Hand Heidegger discusses the transformation of a relation with the ready-to-hand into a relation with the present-at-hand in §69b of Being and Time, in which he develops an "existential conception of science" $(1985,408)$. Whereas he initially discussed the present-at-hand as emerging in occasions of breakdown (cf. Ibid. $\S \S 16-18$ ), in this section, he considers how this disclosure is constituted deliberately. In this process, the entities of concern are brought closer to the investigating subject, such that it can become an object of study to which a certain set of properties can be described. This is realized through stepping over our initial contact with the world (i.e., the ready-to-hand character in which entities become normally present to us must be turned over). This indicates that it is not only because of a breakdown that it is possible to relate to the world as present-at-hand; the deliberate disclosure of the world in this way is not suddenly caused by accident.

According to Heidegger, the primary concern of science is to make the totality of readyto-hand present as if the individual entities in this totality do not relate to each other but instead that certain aspects can be explicitly made to stand out. This does not imply that the totality of a world structured in relation with the ready-to-hand is overcome but rather that a new totality comes into being with particular features. "The scheme peculiar to this [totality] is the 'if-then'; if this or that, for instance is to be produced, put to use, or averted, then some ways and means, circumstances, or opportunities will be needed" (Ibid, 410). The very possibility to relate to an entity as present-at-hand, the "then" in the above fragment, presupposes an "if," making it necessarily dependent on a ready-to-hand encounter of the world.

It is thus through particular practical concerns that a situation in which objects appear as isolated from the whole of which they are a part can manifest. To illustrate this, Heidegger returns to the example of the hammer introduced in $\S 15$ of Being and Time and states that we have two different ways of relating it. On the one hand, we can assess the hammer in terms of whether it is too heavy to perform the job; in doing this, it becomes 
present-at-hand because it no longer withdraws. On the other hand, we can relate to the hammer, encountered in a totality, as an object that has the property of heaviness that can be exactly measured. In this way, it is cut loose of its initial environment and the things it related to in this environment: the hammer is dissociated from the practice of hammering. Therefore, we can no longer assess it in terms of hammering, which makes it no longer sensible to speak of heaviness in terms of "too heavy." Heidegger proposes interpreting this as a modifications of the space in which a hammer is encountered: "Its place becomes a matter of indifference. This does not mean that what is present-at-hand loses its 'location' altogether. But its place becomes a spatio-temporal position, a 'worldpoint,' which is in no way distinguished from any other" (Ibid. 413).

In emphasizing the modification of the space in which the present-at-hand is encountered, it becomes clear that to relate to a "physical nature" implies disclosing space in terms of a well-defined spatio-temporality, thereby leaving behind the totality in which physical objects are normally encountered. This is what Heidegger calls the a priori mathematical disclosure of the world; relating to objects as present-at-hand is to project nature as mathematical. Only if nature is encountered in this way, "anything like a 'fact' [can] be found and set up for an experiment, regulated and delimited in terms of this projection" (Ibid. 414). Heidegger's hermeneutics of science (i.e., his hermeneutics of the mode in which a relation with the present-at-hand is established) has two important consequences: (i) for science to function, a mathematical disclosure of nature is required, and (ii) this mathematical disclosure is grounded in the ready-to-hand, that is, in scientific practice.

This clarifies that we can distinguish between two different possibilities for relating to an object that is present-at-hand. On the one hand, we have the Breakdown Mode of relating the present-at-hand, as discussed in \$2.2, in which our relation to it is the consequence of the sudden breakdown of a tool against a certain background. On the other hand, Heidegger introduces an alternative model of establishing a relation with the present-athand, discussed in this section, which I term the Deliberative Mode. In the next part of this chapter, I show how this understanding of science disappears from view in Heidegger's analysis of the essence of science and in what sense this would make Heidegger vulnerable to the critique that he fails to consider positive scientific developments.

\section{\$3.2 SCIENCE AS RE-SEARCH}

In Heidegger's later works, science is no longer a special way of disclosing the world as present-at-hand (i.e., as nature) but is equated with the general technological disclosure of world as standing-reserve. Contrary to his earlier analysis in Being and Time, he no longer differentiates between the disclosure of the world in general and the disclosure of world specific to scientific practice. As such, science becomes part of the modern epoch, in which nature is disclosed as standing-reserve. However, through a close analysis of The Age of the World Picture and in Science and Reflection, I attempt to show the ambiguity in Heidegger's later understanding of science. On the one hand, he criticizes the disclosure of the world through science as ruling out all other possible relations with it, because the essence of technology is presupposed in the science's way of revealing (cf. Heidegger 1977a, 23). On the other hand, he seems to be uncritical of a scientific disclosure of the world per se. ${ }^{24}$ The point of this detour is to show that it remains possible to adhere to the view that science presupposes a specific mode of relating to the world without monopolizing science as the only way of revealing the world. In other words, we can continue to ascribe a distinct "scientific" character to scientific practice, indicating that science need not be reduced to our relationship with the ready-to-hand.

This difference between Heidegger's early hermeneutics of science and his later analysis of the essence of science is best illustrated when we compare a fragment from Being and Time with one from The Question Concerning Technology. In the former, the scientific disclosure of the world is explicitly thematized in terms of the possibilities through which the world can appear as scientific: "Even the 'unity' of the manifold present-at-hand, of Nature, can be discovered only if a possibility of it has been disclosed" (Heidegger 1985, 184). In the latter, this "as-structure" is no longer understood as one possibility among others, but the scientific disclosure of the world is an omnipresent way of revealing: "[W] hen man, investigating, observing, ensnares nature as an area of his own conceiving, he has already been claimed by a way of revealing that challenges him to approach nature as an object of research" (Heidegger 1977a, 19). In this case, the world can no longer be disclosed as scientific, but scientific practice is also already conditioned by a particular way of revealing. This indicates that the ambiguity found in Heidegger's later work is grounded in that he no longer considers science as a special case of worldhood, but is part of a prior technological way of revealing. As such, Heidegger no longer conceives of having a mathematical relation to the world as particular to scientific practice, but it has become the only possible mode through which the world can be approached (cf. Glazebrook 2000a, 95).

24 In this regard, I align with Glazebrook (200ob), who argues that although the possibility of the scientific disclosure of the world has been central to Heidegger's thinking from the start, but that how this relation is interpreted differs. She points out that, contrary to his analysis in Being and Time, Heidegger does no longer understand science is one possible relation with nature as it becomes part of the necessary technological disclosure of the world per se. For a detailed discussion, see Glazebrook (200oa, 5-9) and Wolf $(2003 ; 2005,139-171$ and $231-240)$. 


\section{The Essence of Modern Science}

What exactly is this mathematical relation with nature? Heidegger explicitly connects it to a form of exactness particular to modern science. The exactness demands that "all events [...] must be defined beforehand as spatiotemporal magnitudes of motion" (Heidegger 1977b, 119). This presupposes that science has a particular "object sphere [that] has the character of exactitude" (Ibid. 120). According to Heidegger, this exactitude that is presupposed in modern science makes that the essence of modern science should be characterized as research. For Heidegger, this implies that the sciences project a pregiven space in which natural events happen and clarifies what types of objects can be retrieved from this domain.25

By having research as its essence, modern science must be set apart from practices of knowledge gathering in ancient Greece or in the Middle Ages. For example, Heidegger holds that it does not make sense to compare modern science with ancient Greek inquiries into nature, because "the Greek understanding of the essence of body and place and of the relation between the two rests upon a different interpretation of beings and hence conditions a correspondingly different kind of seeing and questioning of natural events" (Ibid. 117). The sphere of beings corresponding to the Greek way of questioning nature thus differs from how the world is projected through modern science. Consequently, it does not make much sense to compare the two, because the essence of both endeavors is principally different.

Because modern science is essentially research and presupposes a mathematical way of disclosing the world, the sphere of objects it aims to describe is thought of as principally containing no riddles (i.e., in principle, everything in the world would be controllable or predictable when research with sufficiently rigorous exactitude is conducted). Heidegger attempts to clarify this with reference to the Greek understanding of mathematics:

"Ta mathêmata means for the Greeks that which man knows in advance in his observation of whatever is and in his intercourse with things: the corporeality of bodies, the vegetable character of plants, the animality of animals, the humanness of man. Alongside these, belonging also to that which is already-known, i.e., to the mathematical, are numbers. If we come upon three apples on the table, we recognize that there are three of them. But the number three, threeness, we already know. This means that number is something mathematical" (Ibid. 118-119).

25 In the English word "research," the Heidegger idea becomes immediately clear. The "re-" implies that something must be found in a pre-given space and is stipulated as already there, something that was not the case in medieval and ancient practices.
The specific shape mathematics takes within physics is derivative of how nature is already revealed. As such, the worldness of the world, the question what and how the world is, has already been answered before any specific investigation of any natural phenomenon has started. This makes it so that it cannot be questioned that the world is a "self-contained system of motion of units of mass related spatiotemporally" (Ibid. 119).

This is what characterizes the essence of science as research; it must obtain a rigorous exactitude, as all events in nature are conceptualized as spatio-temporal motions relative to a given domain. Given that Heidegger defines the essence of modern science as research and establishes a close connection between science and technology, how does research relate to his idea that technology reveals nature as standing-reserve? Does the mathematical disclosure of the world through modern science by necessity have the same consequence? This issue becomes especially pressing if we consider the reliance of science on technology. Without the presence of technologies, the modern sciences would simply cease to exist, as it is technologies that enable scientists to detect their objects of investigation.

\section{Science and the Danger of Technological Projection}

The embedding of technologies in the sciences is, according to Heidegger, necessary because their essence is research. The procedures and machineries are necessarily a reflection of the exactness of the object sphere essential to modern science: "Within the complex of machinery that is necessary to physics in order to carry out the smashing of the atom lies hidden the whole of physics up to now" (Ibid. 124). It is only in this way that the sciences remain capable of grasping nature in terms of their own projecting. According to Heidegger, the technologies through which the objects of the sciences are approached thus cannot transcend the boundaries of the object sphere that is defined through the research character of modern science. This does not rule out that through technological developments, a potentially infinite set of experiments can be developed through which new aspects of this sphere can be made visible. However, in Heidegger's view, this will not result in any fundamentally new findings or insights, since every experimental result is the function of the pre-defined domain that is approached. This is what he calls science as ongoing activity (betrieb).

Again, we may ask if this is necessarily problematic, as the development of physics has allowed us to uncover the subatomic structure of the world and medical treatments have greatly increased due to a better understanding of cell structures. Does this not imply that the effectiveness of science is the consequence of the "research" character of modern science? Heidegger's ambivalent stance towards modern science is most clearly visible in The Age of the World Picture. Let me first quote at length his primary problem 


\section{with science as research:}

"The scholar disappears. He is succeeded by the research man who is engaged in research projects. These, rather than the cultivating of erudition, lend to his work its atmosphere of incisiveness. The research man no longer needs a library at home. Moreover, he is constantly on the move. He negotiates at meetings and collects information at congresses. He contracts for commissions with publishers. The latter now determine along with him which books must be written. The research worker necessarily presses forward himself into the sphere characteristic of the technologist in the essential sense" (Ibid. 125).

In this fragment, it seems that the emergence of a pre-defined object sphere has the consequence of leading to a specific kind of individual that must be developed to work in such an environment. There is no longer room to think because the set of problems that must be handled is already defined. This makes it so that the scientist runs the risk of turning into a businessman who must fulfill the needs of external parties rather than spend time thinking about science itself. If this were true, the distinction between scientific research and technological businesses would cease to exist. Accordingly, science should be understood on par with other parties with technological interests and would belong to a similar schematic, in which the ordering of nature as standing-reserve through science would be reinforced. However, in a footnote accompanying the above quote, Heidegger nuances his initial negativity:

"The phrase "ongoing activity" [Betrieb] is not intended here in a pejorative sense. But because research is, in essence, ongoing activity, the industrious activity of mere "busyness" [des blossen Betriebs], which is always possible, gives the impression of a higher reality behind which the burrowing activity proper to research is accomplished. Ongoing activity becomes mere busyness whenever [...] [it] never again confirms and verifies its own self-accumulating results and the calculation of them, but simply chases after such results and calculations" (Ibid. 138, note 2).

While the danger of becoming another branch of business always remains, science need not necessarily act as such. Science as research always faces the danger of being reduced to business, but when relying on its own critical potential, it still remains possible to reflect on its calculations and results. This suggests that modern science can become aware of the specific mode of disclosing the world in which it engages and hence come to terms with the domain of objects that it investigates being defined beforehand. This suggests that there always remains a possibility to recognize the limits of the mathematical disclosure of the world and the contingencies involved in the particular set of objects under investigation.
But how can science enact this critical potential? And to what extent does the ubiquitous presence of technologies in scientific practice threaten science to become mere busyness? If the essence of science is ontologically conditioned by the essence of technology, then it seems that science must concede that its critical potential cannot be enacted. Thus far, Heidegger still leaves open the question of whether the sciences are victim to the same scheme as technology and must necessarily approach nature as standing-reserve. However, this is precisely the question at stake.

In The Age of the World Picture, Heidegger in the end seems to interpret the culmination of the essence of science as research as part of a larger scheme present in modern times (i.e., as being ontologically conditioned by a technological way of revealing). It is only in this epoch that the world is encountered as something to which man is opposed and is represented by man as opposed to him:

"Therewith man sets himself up as the setting in which whatever is must henceforth set itself forth, must present itself, i.e., be picture. Man becomes the representative of that which is, in the sense of that which has the character of an object" (Ibid. 132).

In other words, it is a property of Modernity that the world is represented as objectified by man and is disclosed to man as objectified consequently. Through the active engagement with nature that allows scientists to relate to the world as a set of objects, the ordering of nature as standing-reserve seems to be re-established. From this perspective, the conditions in which science as research occurs simultaneously seem to constitute its limitations.

\section{\$3.3 HEIDEGGER'S AMBIGUOUS PESSIMISM CONCERNING SCIENCE}

The question now arising is that if this lack of critical potential is present in scientific research, does it also force its particular way of disclosing the world onto other domains? In his essay Science and Reflection, Heidegger answers this question affirmatively, because "[t]he reality within which man of today moves and attempts to maintain himself is, with regard to its fundamental characteristics, determined on an increasing scale by and in conjunction with that which we call Western European science" (Heidegger 1977c, 156). However, to what extent would this be a problem, given the positive developments accomplished through scientific research leading, which have led to better medical treatment and the ability to manipulate interactions on a subatomic level? This question is addressed in Heidegger's essay Science and Reflection, in which he discusses the 
relationship between the form of world disclosure presupposed in modern science and the possibility to reflect on it. According to Heidegger, if a critical relation to the sciences is to be established, it must develop a form of reflection independent of the sciences, because the sciences are-as research-bound to the limits of a mathematical disclosure of reality. ${ }^{26}$ This rules out the possibility of reflection, because

"if we want to assert something about mathematics as theory, then we must leave behind the object-area of mathematics, together with mathematics' own way of representing. We can never discover through mathematical reckoning what mathematics itself is" (Ibid. 177).

Heidegger argues that modern science lacks the possibility to reflect on its own activity, because it is essentially to be understood as "the theory of the real" (Ibid. 157). To understand why this definition culminates in the idea that science is unable to reflect, we must specify the meaning that Heidegger attributes to the two central terms in his definition: "theory" and "real."

\section{Science as a Theory of the Real}

In German, "real" translates as das Wirkliche. It is by specifying the etymological background of this German noun that Heidegger develops his understanding of "real." Wirkliche contains the German verb Wirken (to work), which has the connotation of action: to be real implies to do something. According to Heidegger, working must be understood as a making present that can be understood both in terms of "something bring[ing] itself forth hither into presencing of itself [and as] the bringing hither and forth of something as accomplished by man" (Ibid. 16o). Thus, presencing can rest on either internal principles through which something reveals itself as itself or on external principles that depend on human beings doing the presencing in a specific way. It in the possibility of the latter sense of presencing that the development of modern science must be understood. Because, so Heidegger argues, the presencing of something as accomplished by an external principle has historically developed into the concept of causality, what is real started to be defined as something that was the consequence of a previous cause. Modern science relies on this principle of causality and sets as its task to precisely determine the relation between the consequence and that which was its cause. This requires having a conception of the real that allows for the human being to intervene in exactly, and exactly determine, the consequences of interventions. Accordingly, "the real now shows itself as object, that which stands over against" (Ibid. 162). The specific way of presencing particular to the age

26 Unless indicated otherwise, "mathematics" should be understood in terms of Heidegger's understanding of the Greek Ta mathêmata. of modern science is therefore the re-presenting of something as object.

Now Heidegger asks how the re-presenting of the real as an object sphere relates to science as theory. Just as he did with the term "real," Heidegger's first step in defining "theory" is etymological. He traces the noun theory back to the Greek theorrein and holds that this etymology points to an interpretation of theory as the "attentive way of looking by the involved human being: 'It follows that theorrein is thean horan, to look attentively on the outward appearance wherein what presences becomes visible and, through such sight-seeing-to linger with it"' (Ibid. 163). This meaning of theory disappears in modern science, so Heidegger argues, because it represents reality by turning it into a mathematical domain of investigation (i.e., as presenced in terms of objectivity). In modern science, theory no longer means looking attentively on what presences itsel but is transformed into an understanding of theory as the observation of the real (Betrachtung). It is through this transformation that science today is associated with the disinterested studying of nature. However, "disinterested" observation can only occur if nature is represented as a set of objects and only if theory "challenges forth the real specifically through aiming its objectness" (Ibid. 167).

In Heidegger's view, observing nature presupposes a specific setting up of the real, in which nature appears as something that can be passively observed from the outside. In other words, nature must be entrapped as an object, such that a subject-object relation between an observer and nature can come into being. Rather than interpreting observation as happening within nature as an act that has an openness to the other things in it, a subject with the specific quality of not being part of nature ensures the possibility and ongoing existence of modern science. The observing subject must secure that nature is disclosed in this way, because this allows for a delimitation of questions of which it is already known that they can be answered in principle:

"Theory makes secure at any given time a region of the real as its object-area. The areacharacter of objectness is shown in the fact that it specifically maps out in advance the possibilities for the posing of questions. Every new phenomenon emerging within an area of science is refines to such a points that it fits into the normative objective coherence of the theory" (Ibid. 169).

This does of course not imply that scientists know in advance what the exact answer to their question will be, but they know that it is to be found within the disclosure of nature as mathematical. Every scientific object that appears will appear within this specific conception of nature and will therefore not challenge how science observes nature as real. 


\section{Reflection as the Limit of Science}

But would we not say that theoretical change in science is accompanied with a reconceptualization of nature? Do we not see a radically different representation of nature in the shift from classical mechanics to quantum mechanics, or from vitalism to Darwinism? According to Heidegger, we should abstain from interpreting these changes within science as re-interpretations of nature, as he argues that these can only occur in the ongoing disclosure of nature as mathematical. For example, he interprets changes from classical mechanics and quantum mechanics not as a re-interpretation of how nature should be theoretically represented but as a narrowing of the validity of physics within the already existing disclosure of nature. The distinction between the two epochs in physics he finds "in the experience and determination of the objectness wherein nature sets itself forth. Nevertheless, what does not change [...] is this: the fact that nature has in advance to set itself in place for the entrapping securing that science, as theory, accomplishes" (Ibid. 172-173). Even though what is taken to be the most fundamental characteristics of what is considered "nature" change, in both physical theories nature is conceived of as something whose behavior can be calculated in advance. To deny the calculability of nature would mean to deny the essence of modern science. As such, changes in the set of objects that exist within the mathematical space in which nature is disclosed should not be equated with reflecting on the re-presenting of nature presupposed in modern science.

Similar to his line of reasoning in The Question Concerning Technology, Heidegger argues that this is the consequence of the fact that in the end, the entrapping of nature as a spatiotemporal coherence of motion is not caused by the activities of individual scientists. The disclosure of nature in its objectness is not happening in science, but somewhere else: "The essence of science is rendered necessary by the presencing of what presences at the moment when presencing sets itself forth into the objectness of the real. This moment remains mysterious, as does every moment of this kind" (Ibid. 168-69). It is precisely this mysterious moment that must be reflected upon and points to the need for developing a position that does not a priori equate nature with objectivity.

This points to the questions of how the presencing of modern science relates to Heidegger's idea that Technology challenges nature to be revealed as standing-reserve, because "[s]cientific representation, for its part, can never decide whether nature, through its objectness, does not rather withdraw itself than bring to appearance the hidden fullness of its coming to presence. Science cannot even ask this question, for, as theory, it has already undertaken to deal with the are circumscribed by objectness" (Ibid. 174). When reflection on science does not occur, nature is unproblematically equated with the objectness in which it is presenced in modern science. However, "[n]ature, in its objectness for modern physical science, is only one way in which what presences [...] reveals itself and sets itself in position for the refining characteristic of science. [...] Scientific representation is never able to encompass the coming to presence of nature; for the objectness of nature is, antecedently, only one in which nature exhibits itself" (Ibid. 174). There is always a surplus in how nature can become present, besides how it is represented through a theory of the real, and because of this, it precisely is problematic to unproblematically equate nature with how it is presenced in modern science.

\section{Is Science With or Without Practice?}

The dual nature of modern science points to an ambiguity in Heidegger's conception of modern science: On the one hand, he seems to put modern science and the "theory of the real" that grounds it on equal footing with his analysis of Technology as an Enframing of nature to reveal itself as standing-reserve. On the other hand, however, it is only when modern science is a "theory of the real," in which nature "shows itself as object," that can be related to be an observing subject that we can understand the accomplishments of science. This leaves us with an unresolved tension in Heidegger's later work. Contrary to his analysis of the theoretical disclosure of the world in Being and Time, science can no longer be interpreted as a practice.

In §3.1, I have argued that Heidegger's analysis of having a scientific relation with the world rests on two assumptions: (i) for science to function, a mathematical disclosure of nature is required, and (ii) this mathematical disclosure is grounded in Zuhandenheit, that is, in scientific practice. In his later work, the latter of these prerequisites is no longer present; it is only the mathematical disclosure of nature that is presupposed in a scientific worldview. Because this disclosure is no longer grounded in practice, it is no longer possible to interpret it as a rupture with our initial understanding of the world. This is why Heidegger can conclude that only in the modern epoch can we speak of having a worldview in which the only possibility to relate to the world is through its mathematical disclosure. Contrary to his earlier analysis, this is not a special case of world closure occurring in a practical context. The challenge left to solve this tension is to understand how the mathematical-theoretical-disclosure of the world can be reflected upon in terms of the relations between scientists and the ready-to-hand.

\section{§3.4 POSTPHENOMENOLOGY AND SCIENTIFIC PRACTICE}

In postphenomenology, the answer to the disappearance of practice in Heidegger's later analysis of science is formulated in terms of the need to return to Heidegger's early phenomenology of tool use. The criticism that Don Ihde has of Heidegger's monolithic 
approach towards Technology in The Question Concerning Technology is treated as mutatis mutandis, also applying to Heidegger's analysis of science. Ihde sees Heidegger's relevance-and hence the relevance of the philosophy of technology-in the philosophy of science in the inversion of the idea that technology is applied science. Following Heidegger, a key insight of the philosophy of technology, according to Ihde, is the idea that technology is somehow prior to science, that is, to theory. Thus, Ihde subscribes in one way or another to what I have earlier referred to as the Primacy of Scientific Practice claim (i.e., he holds that-in one way or another-the ready-to-hand is more fundamental than the present-at-hand). In this section, I show in what sense Ihde understands this being more fundamental of the ready-to-hand in terms of the importance he ascribes to scientific instruments in scientific practice.

Ihde's starting point is the observation that "scientific knowledge is instrumentally dependent upon technologies. It is 'constructed' through the use of instruments which are technologies" (Ihde 1997,73, my emphasis). The importance of conceptualizing scientific instruments as technologies is not to be surpassed; it allows Ihde to conceptualize scientific instruments as mediating the reality that scientists study. "They are the concrete and material operators within scientific praxis" (Ihde 1991, 45), which "non-neutrally transform $[\ldots]$ the project or object towards which the technology is directed, and reflexively, the human user of that technology" (Ihde 1997, 73-74). Thus, when scientific instruments are understood as mediating technologies, the principle distinction between scientific practices and other practices disappears from view, since both can be equally analyzed in terms of the role that mediating technologies play in them.

Ihde's analysis of the role of technologies in scientific practice has a clear Heideggerian legacy: he holds that technology is ontologically prior to science, thereby turning theorizing into a minor part of scientific practice: "Theorizing becomes a special, highly speculative exercise of scientific imagination-important, but both reduced in size and open to greater skepticism-in regions outside the current reaches of instrumental possibility" (Ibid. 100). He argues that "increasingly many scientific phenomena are technologically carpented phenomena” (Ibid. 137). This implies that an increasingly large set of scientific phenomena could not be observed when the relevant technologies were not available. Secondly, he holds that science is likely to follow the inclinations of a technological trajectory, which are related to "the capacities opened up by instruments, capacities of a technological possibility leading to the productive capacities of experimental science" (Ibid. 137). Accordingly, he proposes dropping the notion of science and replacing it with the more appropriate label "technoscience." Thus, Ihde's analysis of science can be understood in terms of the Primacy of Scientific Practice claim, because he holds that scientific knowledge is bound up with certain practices and that these practices are thoroughly technological and thus that we cannot intelligibly discuss science without reference to these practices.

\section{Mediated Perception: Scientific Instruments as Disclosing Reality}

Ihde gives a substantial twist to the late Heidegger's understanding of the ontological priority of technology, by understanding the priority of technology in science in terms of how reality is made present by concrete technologies (i.e., scientific instruments). Ihde dismisses Heidegger's later analysis of science as being on par with his analysis of technology and considers it an unfounded romanticism that science cannot but reveal the world as a standing-reserve (1991, 58; 2010, 74-85). While he takes up the late Heidegger's idea that technology must be understood as a way of revealing, he does not do so by taking "Technology" to be a metaphysical principle, but rather he is interested in how particular technologies reveal the world in specific ways in scientific practice. By moving back to Heidegger's phenomenology of tool use, he is interested in how the world is constituted in relation with the ready-to-hand. From this perspective, technologies open a domain in which a set of scientific objects may appear to which it is possible to intentionally relate. In Ihde's case, it is technologies that allow us to disclose the world in new ways. Analyses of scientific practices should accordingly focus on, for example, how the telescope shaped the development of astronomy, or how our understanding of the human being is shaped through the use of brain imaging technologies (cf. Ihde 2009, 51-61).

Given that postphenomenology focuses on human-technology relations, an analysis of technological practices does not end with an analysis of the technologies involved, but it also must consider the human subjects relating to them. After all, it is concrete individuals such as Galilei who point a telescope to the moon and collectives of cognitive neuroscientists who use brain imaging technologies to investigate human cognition. To articulate how scientific instruments shape the world that scientists observe, Ihde appeals to Merleau-Ponty's phenomenology and departs from the non-controversial assumption that a fundamental condition of scientific observations is to bring the phenomena to be observed within the domain of human perception, and with Merleau-Ponty, he stresses that perception always implies embodied perception. However, secondly, he also draws on Merleau-Ponty to argue that interpretations of the world are transformed by how the world is perceived. Consequently, how the world that becomes both present and a candidate for interpretation is dependent on the specific technologies through which human beings relate to the world. Merleau-Ponty illustrates this with an example of how the world appears to a blind man using a cane to orient himself to his environment. When doing so, the point of the stick

"has become an area of sensitivity, extending the scope and active radius of touch, 
and providing a parallel to sight. [...] The position of things is immediately given through the extent of the reach which carries [the blind man] to it, which comprises besides the arm's own reach the stick's range of action. [...] [This] is knowledge in the hands, which is forthcoming only when bodily effort is made, and cannot be formulate in detachment from that effort" (Merleau-Ponty 2005, 165-166).

The case in point is here that when using his cane, there is only a world present to the extent that it becomes present through the stick, thereby making any experience and interpretation of this world contingent on the stick.

According to Ihde, we can extrapolate this idea to how the world becomes present to scientists when they relate to it through specific technologies, because he maintains that "the cane fall[s] into the same existential use as many scientific instruments" (Ihde 1991, 30). This is why Ihde holds that science is not "abstract" and "theoretical" but should rather be considered in terms of how the reality investigated in scientific practices comes into being through the scientific instruments that are used. This requires focusing on how scientific instruments bring the phenomena of science within the domain of embodied perception

Ihde characterizes science as a fundamentally visual practice and therefore develops his material hermeneutics in terms of a visual hermeneutics (Ihde 1998). Accordingly, the primary way in which scientific phenomena are made visible to scientists is by turning them into readable images. In Ihde's view, the images that scientists are confronted with allow for multiple coherent readings; they embody a multistability. In other words, the images that scientists are confronted with are not immediate depictions of reality but can be interpreted in multiple coherent ways. As a consequence, a scientist must also engage in a hermeneutic act: images "must be 'read,' 'decoded,' to detect [...] what is being presented" (Ibid. 67). Analogous to an interpretation of a Necker Cube, there is a variety of interpretations of a scientific image possible that exclude each other but are in principle equally valid (cf. Ihde 2009, 56). Accordingly, a continuity between ordinary practices and scientific practices can be found in an invariant way, in which images are brought within the reach visual perception, thereby instantiating multistability. Accordingly, Ihde makes instrumentally mediated vision the central category in his analyses of scientific practices, thereby turning how technologies shape our perception during scientific observation into the central question about scientific practice.

This brief analysis of Ihde's understanding of the role of technologies in scientific practice allows the articulation of in what sense he subscribes to the Primacy of Scientific Practice Claim: precisely because he defines scientific practices as technological practices, science must be understood in terms of the relations between scientists and technologies that appear as ready-to-hand, thereby mediating the reality that scientist study. Furthermore, he characterizes the relations between scientists and technologies as ones in which technologies mediate human vision, thereby interpreting the priority of the ready-tohand in terms of how they transform the phenomena to be observed into phenomena that are susceptible to an embodied subject. Accordingly, the priority of the ready-tohand must be understood in terms of the priority of embodied perception in scientific practice.

\section{§3.5 RELATING TO THE PRESENT-AT-HAND: SCIENCE AS A SPECIFIC KIND OF PRACTICE}

Ihde understands the message of Heidegger in The Question Concerning Technology in continuous terms with his phenomenology of tool use. However, the former he considers a "romantic amplification of the deeper inside from the [ready-to-hand] period" (Ihde $1998,55)$, in which the ready-to-hand is attributed a metaphysical meaning in which it-as generalized-threatens to reveal nature as standing-reserve. Despite this later-in Ihde's view-unmotivated romanticism, he urges to not dismiss Heidegger's work completely, because hit later work "does not mitigate the early insights involving technology as a way of seeing" (Ihde 1991, 52, my emphasis). Accordingly, Ihde translates what Heidegger calls a technological "way of revealing" into a technological "way of seeing," through which the priority of technology over science is affirmed. But to what extent does this translation allow an understanding of how scientists establish a relation with the present-at-hand (i.e., to also consider the distinct scientific character of scientific practice)?

In this section, I argue that Ihde's take does not adequately conceptualize the distinct "scientific" character of "scientific practice" and point to an alternative reading of technologies in scientific practice that does capture this aspect. To do so, I discuss how my reading of Heidegger departs from Ihde's on two points: firstly, I reject the idea that the ubiquitous presence of technologies in scientific practice diminishes the importance of science as a theoretical endeavor. Secondly, I argue-relatedly-that the Heideggerian idea of Technology as a way of revealing must be understood much more broadly than Ihde does (i.e., the mediating role of technologies should not be restricted to the level of perception). As I attempt to show, this allows me to both understand scientific practice as dependent on technologies and distinguish it from other practices in terms of the deliberate rupture mode.

The primary advantage of the postphenomenological criticism on the classica 
philosophy of technology, of which Heidegger is often identified as a key representative, is that it opened the possibility to understand the impact of technologies on our lives through our interaction with them on a concrete level. In interpreting technologies as part of the ready-to-hand, it becomes possible to examine them as tools through which a world is revealed to us in our relationship with them. Following this idea allows us to interpret technologies in scientific practice in a similar way: as mediating the relation between scientists and the objects they observe. From this perspective, we can ask for how technologies make it possible to relate to nature by considering them an important part of scientific practice. In centralizing this idea, Ihde stresses that most, if not all, objects that scientists relate to in modern science are related to through technologies.

In this model, it is the transparency of the ready-to-hand that allows for establishing both an intentional relation with a phenomenon and a specific hermeneutic strategy to interpret it. Analogous to how we may relate to a nail through a hammer, we may relate to a brain scan through a brain scan. This paves the way for the postphenomenological idea that we should consider the importance of technologies in science and move beyond the Heideggerian analysis of either Science or Technology as Enframing. In other words, just as in ordinary practices, technologies in science allow us to relate various new scientific objects rather than their necessarily taking part in the Enframing. It is exactly this openness of concrete technologies that can be seen as instantiating the continuum between ordinary and scientific practices. Ihde takes this to be the central meaning of Heidegger's interpretation of Technology as a way of revealing; technologies in scientific practice allow us to relate to scientific objects in myriad ways, because they literally allow us to see the world differently.

Typically, these technologies withdraw from our attention within the whole of the readyto-hand such that they are no longer experienced as technologies. Rather, they become transparent precisely because they allow us to relate to something, for example, a brain scan (e.g., Ihde 2009, 43). This is an extension of how Heidegger discussed a primary characteristic of tools being that they withdraw when put to use. Similarly, in mediating our relationship with the world, the relevant technology dissolves in how it allows us to relate to a certain scientific object. Only when a technology stops functioning within this context does it appear as an object to us. In other words, Ihde limits Heidegger's analysis of the phenomenology of tool use to the breakdown mode of establishing a relation with the present-at-hand.

\section{Technologies as Mediating the Deliberative Mode of Relating to the Present-at-Hand}

In the context of scientific practice, we relate not to technologies but to something else as present-at-hand, namely, the scientific object mediated by the technology that is transparent. Indeed, as Ihde argues, precisely because of the transparency of scientific instruments, scientists can focus on interpreting images rather than being explicitly engaged with the process of their creation. Hence, he identifies the reading of these scans as subject to a similar mechanism as how we can read a Necker Cube (i.e., that these images can be interpreted in multiple coherent ways). Accordingly, so Ihde argues, fMRI mediates how a scientist can relate to the brain. However, if we examine concrete scientific practices involving brain scans, these are scientific objects such as disease or psychological traits that are related to through a brain scan. For example, a medical doctor might use MRI to detect a brain tumor, or a cognitive neuroscientist might use fMRI to study a scientific object, such as visual attention. In these cases, strictly speaking, it is not "the brain" that is related to through a scientific instrument but some scientific object that is transformed when related to through a brain scan. These transformations are not immediately perceptually given but require an existing conceptual apparatus that can be found in theories within the relevant scientific domain.

Because of the multistability involved when reading images, it has been stressed that scientists must apply hermeneutic strategies to make sense of what is being presented and that (i) these images allow for multiple hermeneutic strategies and (ii) these strategies may yield conflicting interpretations (cf. Ihde 2009; Rosenberger 2011). This idea serves as a way to understand conflicts between scientists as grounded in having developed different hermeneutic strategies to interpret a technologically mediated phenomenon. Accordingly, by continuing to focus on how technologies mediate human perception, we cannot answer the questions of why a specific hermeneutic strategy is thought to be appropriate or why this specific strategy leads to specific conclusions. A focus on the technological mediation of perception neglects that a variety of scientific objects can be made present through a brain scan and that theoretical knowledge is required to be able to perceptually differentiate between these different objects. This points to our need to not only understand the role of scientific instruments in terms of the mediation of perception but also focus on how the world is disclosed in scientific practice, as mediated by technologies.

As already emphasized in this chapter, this practice is precisely regulated such that the world can be disclosed as a domain of objects that can be measured. I have termed this practice the deliberate rupture mode of relating to the present-at-hand through the mathematical disclosure of the world. Following this model, we can interpret the technical set-up of an experiment and the preparations of microscopic observations as the practical concerns both necessary for a specific form of world disclosure and as mediating new forms of world disclosure. We should consider that the mode of relating to the world through a deliberate rupture differs from Ihde's interpretation of Heidegger's 
phenomenology of tool use. Firstly, it emphasizes that technologies in scientific practice function to mediate a specific mathematical disclosure of the world. Secondly, scientific instruments serve not only to let all entities dissolve in the whole of the ready-to-hand but also to make objects specifically appear as present-at-hand.

In this sense, the mediating role of scientific instruments must be understood not only as instantiating a specific way of seeing but rather as mediating how the world in scientific practice is revealed by co-constituting the observing subject to which the world is revealed (cf. Verbeek 2005, 143). This is somewhat stronger than Ihde's idea that scientific instruments give rise to new ways of perceiving reality the world. Rather, it seems that technologies not only reshape how the world is seen but also change the domain of objects that this world consists of. Consequently, "world" in this context refers to the mathematical disclosure of the world in scientific practice, which implies that the domain of objects within this world does only relate to each other within how the world is disclosed in scientific practice. ${ }^{27}$ Precisely because technologies in scientific practice function within the deliberate rupture mode, they are constituted in terms of how the world is disclosed when it is explicitly attempted to establish relations with the presentat-hand. In analogy with Heidegger, we may say that technologies primarily reveal new domains of objects rather than instantiating new ways of seeing in the first place.

\section{§3.6 CONCLUSION: TECHNOLOGICAL MEDIATIONS AND THE \\ THEORETICAL DISCLOSURE OF NATURE}

If scientific practice is to be interpreted as presupposing a mathematical disclosure of the world and as a practice in which technologies reveal new domains of objects, we can identify one similarity and one difference with the Heideggerian notion of Technology as a way of revealing. On the one hand, this idea departs from the universalist conception of Technology as Enframing nature, as technologies are interpreted as embedded in scientific practice and attain their meaning within the practice that I have interpreted as aiming to constitute a deliberate rupture with our initial contact with the world. On the other hand, however, the mathematical disclosure of nature in scientific practice seems to come close to the idea that for science to function, the Enframing of nature must be presupposed. This seems to imply that in this model it is Science, rather than Technology, that holds the danger of challenging nature to reveal itself as standingreserve.

27 Note that this does not necessarily imply that they do not correspond to objects in our daily practice, but neither suffices as an explanation why they may or may not do so.
When returning to Heidegger's analyses of Science in The Age of the World Picture and Science and Reflection, we encounter a similar dilemma. Is there a way to interpret Science as a manner of disclosing the world mathematically without reducing nature to this specific manner of disclosing? This is where the postphenomenological criticism of Heidegger's conception proves useful. In stressing that neither Technology nor Science are forces exerting influence on society from the outside, postphenomenologists argue that a focus on concrete technologies and how scientific objects are revealed through them only attains meaning within practice. ${ }^{28}$ Interpreted in this way, the notion of Science must be replaced by "scientific activity" or "scientific practice," notions referring to both the practical character of science and the specific nature of this practice, namely, the theoretical disclosure of the world.

If we connect this with Heidegger's idea that Science or Technology must be interpreted as the Enframing of nature, or of the setting-upon of a scientific worldview onto nature it seems that the mathematical disclosure of nature is indeed "a normative theory of nature” (Heidegger 1977b, 169). However, instead of taking this as a negative consequence of modern science per se, we can also interpret this normativity in terms of the deliberate rupture mode as developed in Being and Time. From this perspective, scientific practice does indeed depend on a normative theory of nature, and it is precisely this theory that creates the rupture with ordinary practices. Contrary to ordinary practices, where entities only become present-at-hand because of their malfunctioning, scientific practices are structured to disclose nature as this set of entities.

If, therefore, we wish to ask for the role of technologies in scientific practice, we must acknowledge both that it is a general feature of scientific practice that it attempts to constitute a rupture with ordinary practice insofar that it discloses nature as a set of present-at-hand entities and that this by no means removes the practical character of this act. What I take to be the primary contribution of Ihde's reading of Heidegger is his idea that technologies embody a specific way of revealing, such that scientists establish relations with objects only through the use of a specific technology. I have extended this idea by arguing that these technologies do not only instantiate new ways of seeing but open up new domains of objects that can be related to, both theoretical-conceptual and practical-perceptual. As such, the set of entities that nature in its mathematica disclosure consists of is by no means fixed but is in constant flux because of changes in the technologies we use to disclose it.

28 Note that this implies two things; firstly, it allows us to ask for the role of technologies in scientific practices. secondly, it allows for the role scientific discoveries play in the structuring of daily practices. In this dissertation, I am primarily concerned with the former implication. 
"To the things themselves!" is Husserl's often quoted imperative. But what are the things in scientific practice? Answering this question requires investigating what the objects are that are intentionally related to in scientific practices and how these objects come into being. Accordingly, "the things" towards which I turn in the coming chapters have two distinct meanings. On the one hand, "things" are interpreted in terms of Heidegger's deliberate rupture mode (the scientific objects that scientists relate to). On the other hand, the concrete technologies in scientific practice are interpreted as "things" that open up new scientific phenomena. In doing this, I hope, by building on both Heidegger's idea that technologies can be understood as a way of revealing within a mode of deliberate rupture and on Ihde's postphenomenology of instrumentally mediated perception, to clarify what relation between "science" and "practice" constitutes a "scientific practice." 


\section{CHAPTER 4:}

To the Scientific Objects Themselves:

Gaston Bachelard and the Notion of Phenomenotechnique ${ }^{29}$ 


\section{INTRODUCTION: THE SCIENCES AND THEIR OBJECTS}

In the previous chapters, I have attempted to argue that to answer how technologies function in scientific practice, we must consider both the scientific and the practical characters of scientific practice. I have argued that whereas Heidegger emphasized the scientific (theoretical-mathematical) character of scientific practice in Being and Time, this property of a specific practice is swamped under his analysis of technology in his later works, which forces him to think of science as part of the enframing. This would imply that science, just as technology, must disclose nature as standing-reserve. As I have attempted to show, this creates a tension in Heidegger's work that does not entirely dismiss the value of scientific progress or the activity of science per se. Furthermore, my analysis of the role of scientific instruments in scientific practice in postphenomenology shows that while this branch of thinking does consider scientific instruments as functioning within practices, it does not consider the scientific character of scientific practice. In other words, in acknowledging the importance of technologies in every aspect of science, a postphenomenological approach neglects the importance of how this practice is structured around a theoretical disclosure of the world. In this chapter, I aim to begin to answer the question concerning the role of scientific instruments by considering both of these aspects of scientific practice.

Doing so forces us to ask what kinds of objects scientists relate to and how they differ from the objects encountered in other practices. Intuitively, we think of an object that is something concrete (a chair, a table). In the context of science, people tend to share a similar intuition: brain scans allow us to understand the brain in a new way, and telescopes allowed Galilei to see the moon in a new light. However, the objects of scientific investigation are often not such concrete objects that relate to our understanding of them in daily life. In the case of the neurosciences, it is often not the brain that is investigated, but rather the mathematical relation between a certain behavioral task and the electrical activity in a certain brain area (in the case of EEG). As such, the intentional object of the scientist within this investigation is not the brain as such but rather the relation between a behavioral task and electrical activity, which can be visualized in a brain scan.

When taking into account that in modern science, it is only through scientific instruments that scientific objects can be encountered, we must ask how they shape our relation and understanding of these objects. Scientific observations are also guided by theoretical expectations, past experiences, and the types of questions that are posed. Furthermore, it is not the instruments themselves but how scientists relate to them that constitutes the scientific practice as a scientific practice aiming for a specific theoretical disclosure of the world. Thus, to develop a philosophy of scientific instruments, we must investigate the relation between the theoretical and the practical aspects of this practice. In other words, we must focus on how instruments allow for the construction of new scientific objects and how these scientific objects become meaningful within the context of science as a theoretical enterprise.

As I have attempted to clarify in the previous chapter, Don Ihde largely dismisses the importance of theory in contemporary scientific practice and emphasizes the importance of observational technologies in the construction of scientific objects. In other words, he strongly focuses on how scientific instruments enhance and change our perceptual capabilities rather than on how they influence how we interpret the world conceptually. This is reflected in the importance in his philosophy of Merleau-Ponty, who emphasizes the importance of perception in the experience of the human subject. Following Michel Foucault, David Hyder and Hans-Jörg Rheinberger (Foucault 1989, Hyder 2003, Rheinberger 2005), I consider Merleau-Ponty one line of phenomenologically inspired thinking about science in France that stressed the subjectivist side of scientific perception. The other line in this tradition is more concerned with how scientific objects are grasped conceptually and can be associated with philosophers as Gaston Bachelard, Jean Cavaillès, Georges Canguilhem, and Michel Foucault.

The present chapter is concerned with the earliest representative of this latter tradition, Gaston Bachelard, who was one of the first to note both how technologies shape the reality studied in scientific practice and how they help providing conceptual access to this reality. In this chapter, his epistemology functions as a guideline in attempting to understand the role of technologies in scientific practice. According to Bachelard, philosophy needed to move beyond existing philosophical systems to become open to the developments of science: "When, in particular, you try to shed light upon the problems of science by metaphysical reflection [...] then you are confronted by the necessity of applying philosophy, which is perforce and closed, to scientific thinking, which is opened" (Bachelard 1962, 4). Bachelard considered it his central task to develop a philosophy that could incorporate the nature of scientific thinking and that was closely tied to the actual working of scientific practice. Hence, his philosophy offers a fruitful starting point when asking what the ubiquity of technologies in scientific practices implies for how scientific knowledge is made. Making this transition to a philosophy that is grounded in the actuality of scientific practice is no easy task, as indicated by the quote at the start of this chapter.

The second feature of Bachelard's epistemology that is of interest for the purposes of this dissertation is his idea scientific objects are not "real" in the strict sense that we use 
the word in everyday life. Rather, he argued that scientific objects are the product of phenomenotechnique: they come into being as the consequence of their relationship with the available scientific instruments, existing scientific theories, and the experimental set-up in which they appear. Consequently, the things to which scientists relate are not objects as we encounter them concretely but instead form a special class of objects that manifest within the phenomenotechnique. In this chapter, I attempt to show how this concept is grounded in a break between scientific and ordinary experience and how Bachelard attempts to connect scientific practice with scientific theory through it.

The chapter is structured as follows: firstly, I analyze why Bachelard's philosophy of science is grounded in an epistemological break between everyday experience and scientific experience, and how this break is realized in scientific practice (\$4.1). I explain how this break is realized through a phenomenotechnique, the idea that scientific phenomena come into existence as the consequence of their relationship with the available instruments, existing scientific theories, and the experimental set-up (§4.2). Thirdly, I discuss to what extent Bachelard's epistemology is limited to his primary interest in the natural sciences, or that the other sciences, most importantly the life sciences, can also be interpreted in terms of his idea of phenomenotechnique ( $\$ 4.3)$. Fourthly, I argue that Bachelard's concept of phenomenotechnique does not primarily refer to the creation of scientific phenomena in practice but rather concerns the realization of an objectively rational environment in which science can function in the first place (\$4.4). To conclude, I show why Bachelard's epistemology is primarily of help when we wish to understand what is specifically scientific about scientific practice but seems less useful when referring to the practical aspects of scientific practice. To end, I reconceptualize Bachelard's notion of phenomenotechnique as phenomenotechnology and argue that this allows a constitution of the rationality of science in practice to become a topic of (post-) phenomenological investigation ( $\$ 4.5)$.

\section{$\S 4.1$ THE EPISTEMOLOGICAL RUPTURE: SCIENCE AND EVERYDAY}

\section{LIFE}

A central concept of Bachelard's philosophy of science is the "epistemological rupture", which poses a fundamental divide between science and everyday life, and hence between scientific experience and ordinary experience. He holds that science should overcome the "obstacles that everyday life has set up" (Bachelard 2002, 28). He juxtaposes the imaginative character of everyday life with the rationality of science and argues that science should break with our natural experience to function properly. In this section, I show why Bachelard holds that science requires breaking with everyday life. To so, I discuss how Bachelard conceptualizes our primary experience of reality and why this can be considered an epistemological obstacle for scientific thinking. Furthermore, I show how science progressively overcomes epistemological obstacles with reference to Bachelard's theory of scientific progress.

Bachelard's philosophical work is structured around two primary themes: science and poetics. On the one hand, he aims to show how and why science must get rid of everyday experience to be able to engage in rational activity. On the other hand, he attempts to develop an account of how everyday life experience can give rise to meaningful experience and how these experiences are translated into poetic images. In the context of science, however, everyday experiences appear as obstacles that must be overcome. But why does the distinction between science and poetry lead to a distinction between everyday experience and scientific experience, and does everyday experience have no place in science?

The idea thatscience must break with ordinary experience is grounded in two assumptions: on the one hand, he holds that the objects of science do not coincide with the objects encountered in everyday life (cf. Chimisso 2015, 65). On the other hand, Bachelard argues that our primary experiences are always primitive in the sense that they refer back to subjective forms of reverie and have no place in rational activity. Of course, we cannot do away with our subjectivity entirely: "even the scientist, when not practicing his specialty, returns to the primitive scale of values" (Bachelard 2002, 4). However, when scientist do practice their specialty, the danger of falling back into primitive experience also remains present, because the scientific mind "takes up the same primitive themes time and again and always operates as it would in primitive minds, and this in spite of the successes of systematic thought and even in face of the findings of scientific experiments" (Ibid. 4). But through what kind of primitive drives do we experience reality ordinarily, and why are they hindering the development of science?

\section{Bachelard's Poetics}

Before specifically addressing the question posed above, it is necessary to take a short detour through Bachelard's poetics to clarify why he holds that every day experience is an obstacle for scientific thinking. ${ }^{30}$ Contrary to the rationalist purpose of science, our initial contact with the worlds is always one of reverie and dream. The primitive encounter with an object induces a reverie that transforms initial experience into an image that transcends the object that it is concretely related to. This transcending

30 This short detour does not at all aim to give a full overview of Bachelard's philosophy of imagination. For such an overview, see, for example (Kaplan 1972). 
occurs through our primitive values and precedes any kind of reflection: "We are being faithful to a primitive human feeling, to an elemental organic reality, a fundamental oneiric temperament" (Bachelard 1999, 5). Only when overcoming this oneiric state can something as a rationalist stance towards the world come into being: "In point of fact I see no solid basis for a natural, direct, elemental rationality. [... ] Rationalist? That is what we are trying to become" (Ibid. 7).

This already indicates that our primary experience with the world cannot be taken as the foundation for rationality, as it can also not be the product of some transformation of our primary experiences. In describing these transformations, poetic images can be formed. However, these images do not say something about reality itself; rather, a poetic image is poetic to the extent that it is supra-natural. Hence, imagination "is not the faculty for forming images of reality; it is the faculty for forming images which go beyond reality, which sing reality" (Ibid. 16). Thus, for Bachelard, poetry is the forming of a linguistic manifestation of the images induced by the reveries that we engage in when relating to objects in our primary experience.

This project on the relation between poetry and our initial relation with the world is sharply distinguished from Bachelard's project of overcoming our primitive relation with the world in his epistemological works. For example, in The Flame of a Candle (2012), he writes that this essay on our primary relation with humanized fire should not be confused with his epistemological project aiming for the establishing of objectivity in science: "The history of combustion remains, until Lavoisier, a history of pre-scientific views. The examination of such doctrines belongs to a psychoanalysis of objective knowledge. This psychoanalysis would must get rid of images to determine how ideas are organized" (Bachelard 2012, 8).31 The primary difference between these projects is precisely that Bachelard's poetics is interested in how images established through reverie can attain meaning in poetry, while this notion of image is precisely something to be avoided when scientific knowledge is considered. In summary, we may say that Bachelard's poetics ask for how poetic imagination derives from ordinary experience, while his epistemology aims to show how the rationality of science must be obtained through a break with this ordinary experience..$^{32}$

31 Such a psychoanalysis of objective knowledge is the purpose of Bachelard's The Psychoanalysis of Fire.

32 When comparing this view with the Heideggerian idea of science and technology having their essence in the Gestell, it becomes immediately clear that in Bachelard's philosophy, nature can never be reduced to how it is approached by science and its technological manifestations. The rationalization of nature in terms of its resources we know from Heidegger's work would from a Bachelardian perspective never occur, as our image of nature can never become one of rationality. Rationality and control belong to the domains of science and epistemology, and nature is precisely what should be overcome to engage in these activities and is resistant to technoscientific reduction.

\section{Everyday Experience as an Epistemological Obstacle}

Our daily experiences are obstacles to scientific theorizing, precisely because they are grounded in nature. Nature forms an epistemological obstacle because it remains a source of primitive experience and oneiric reverie that may give rise to poetic imagination. For Bachelard, our relationship with nature is always one that can instantiate a variety of meaningful experiences. Why are these immediate experiences something to be overcome in Bachelard's epistemology? Could we not say that imagination and reverie can be seen as forms of creativity that may be helpful when developing theories about reality? To understand why Bachelard maintains a clear distinction between the oneiric character of everyday experience and the rational character of scientific practice, his concept of epistemological obstacle is introduced. To do so, why our individual psychology forms an obstacle for the development of a rational relation with the world is discussed.

The epistemological obstacle of ordinary experience is grounded in how human beings experience reality psychologically. This clarifies that Bachelard's epistemology is in effect a normative theory of rationality (cf. Bachelard 2002, 27). The normativity in Bachelard's epistemology takes science that is presently accepted as the standard of rationality, and it is from this perspective that specific obstacles are identified. Bachelard's discussion of these obstacles has a twofold aim: on the one hand, he aims to show the rationality of the scientific mind differs from the pre-scientific mind because it has overcome existing obstacles in its own development. On the other hand, he holds that each individual scientist must overcome the epistemological obstacles present in her own psychology (Ibid. 20). His general principle for establishing rationality in science is that it "must be formed against nature, against all that come from nature's impetus and instruction, within us and outside us, against natural allurements and colourful, diverse facts" (Ibid. 33). When remaining too much attached to nature, specific obstacles are encountered that should be avoided: verbal obstacles, substantialist obstacles, and animist obstacles. The pre-scientific mind is too attached to using ordinary language in science (verbal) to reduce the different qualities of a phenomenon to a single substance (substantialist) and to interpreting the workings of scientific phenomena in terms of biological processes in the human body (animist) (cf. Bachelard 2002).

Let me explain how Bachelard conceives of these obstacles by showing how he invokes the substantialist obstacle to argue against the validity of Descartes's wax thought experiment as a way to doubt the trustworthiness of the senses. Descartes argues that the wax cannot be clear and distinctly be perceived by the senses when its form has changed when it is heated, "for whatever came under the senses of taste, smell, sight, touch or hearing has now changed; and yet the wax remains" (Descartes 1993, 21). This is why he 
concludes that the continuous nature of the wax, namely its extension, is not grasped by the senses but by the mind alone. Bachelard, however, argues on the contrary that the diverse manifestations of the wax under different circumstances is the basis of every scientific research, because it shows the complexity of the wax. In other words, it is only in this complication that science can be formed against our natural inclination to think of wax as an object in our ordinary experience. Thus, while Descartes concluded that the only certainty concerning the wax should be found in simplicity (extension), Bachelard holds that scientific certainty should be found in the complexity of the shape of the wax under different circumstances.

More concretely, Bachelard's criticism amounts to Descartes's mediations being grounded in the individual subjectivity of the philosopher and not coinciding with the scientific aim of objectification. In Bachelard's view, the phenomena of science can never exist in the mind alone but has a twofold relation with the empirical. Firstly, the world of science is made complex in scientific experiments that force us to acknowledge the complexity of scientific phenomena. Secondly, it is only in relation with this increasing complexity that science can overcome the subjective and imaginary aspects of ordinary experience. When comparing Descartes's way of approaching the wax with contemporary laboratory science, he argues that "subjective [Cartesian] meditation is bent on attaining clear and definitive knowledge; objective meditation differs from this by the very fact that it makes progress, by its intrinsic need always to go further, to extend the limits of the known" (Bachelard 1984, 171). This objective meditation of the laboratory scientist marks an epistemological rupture with how we encounter nature ordinarily.

It is at this point that it becomes clear why Bachelard holds that Descartes's meditations fall prey to the substantialist obstacle. While Descartes concludes that the changing qualities of the wax force us to dismiss the trustworthiness of sensory experience, for Bachelard, it is, on the contrary, precisely this experimental diversification that grounds the objectivity of the sciences. Because Descartes continues to interpret wax as a substance, he fails, so Bachelard argues, to note that certainty about wax can only come into being because of its diversification. The scientific mind must be open to the new experience of a new reality and rationalize the complexity of scientific phenomena by relating them to each other. The objective meditation strives to continuously expand the limits of the known through the rational incorporation of experimental diversity.

\section{Normativity in Bachelard's Epistemology}

As hinted at in Bachelard's discussion of Descartes's wax experiment, it is only in comparison with contemporary scientific practices that earlier types of inquiry can appear as irrational (i.e., as not having been able to break with ordinary experience).
Similarly, the specific epistemological obstacles necessary to overcome when practicing science are themselves defined by how science is presently practiced. Hence, Bachelard does not refer to any standards of rationality that are external to scientific practice and transcend the limits of time and space. Only by examining up-to-date scientific practices themselves can philosophers sense the rationality that scientists must strive for.

Then, how does contemporary scientific practice relate to these earlier inquiries into nature, and how does it differ from them in terms of rationality? Firstly, Bachelard holds that science always develops in relation to previous scientific discoveries and therefore partly involves the incorrect scientific judgments of the past. ${ }^{33}$ Secondly, he holds that scientists can never fully overcome epistemological obstacles (i.e., they can never fully break with the fundamental structure of the human mind) (Ibid. 20). While I have explained this latter part in the previous section in terms of the psychological structure of human individuals, Bachelard's second explanation of the latter claim is due to the specific character of how science develops. Precisely because science always develops against previous scientific discoveries, it always stands in a dialectical character with its own past. For Bachelard, this means that the epistemological obstacles of previous scientific activity are always included in the present.

According to Bachelard, science can never progress towards a pre-defined notion of truth. Progress is not defined in goal-oriented terms but as a flow of obstacles that are encountered and must be relationally overcome. It is only in relation with earlier scientific theories and scientific objects that new objects can emerge that can be theorized about (cf. Rheinberger 2005, 315). This is one crucial reason why Bachelard argues against the idea that science can never be a process of linear progress towards truth: if new scientific objects are subject to change, the world that scientists and scientific theories relate to is similarly subject to change. Hence, science is characterized as a dynamic process that changes in relation to the objects it speaks about.

The only constant characteristic of science is its rationality. In establishing its break with everyday experience, science also breaks with the world that is ordinarily experienced Bachelard spoke of the world science speaks about in terms of the rational realization of the real (e.g., Bachelard 1968, 1984). In other words, the world of science is not given but is constituted by the norms of rationality at work in scientific practice. This is why

33 This implies that scientific theories or paradigms can never be fully discontinuous, as each new scientific theory necessarily develops in interaction with the flawed scientific judgments that it aims to overcome. Despite their seeming similarities, it is on this point that Bachelard's epistemology significantly differs from the Kuhnian notion of paradigm (1962). For further discussion on the relation between Bachelard and Kuhn, see, for example, Gaukroger (1976), Lecourt (1975). 
Bachelard speaks about scientific knowledge as being constructed; rather than being about a pre-defined concept of nature or a given set of objects, science continuously realizes its own set of objects. How science does so is twofold: it (i) is explicitly formed against the irrationality of nature and (ii) is always the dialectical negation of previous judgments about scientific objects. Whereas (i) can be understood in terms of Bachelard's distinction between science and ordinary experience addressed above, to understand (ii), a special treatment of his notion of scientific progress is needed.

\section{Objectivity and Scientific Progress}

When we cannot understand scientific developments in terms of cumulative progress towards truth, how can we still speak of progress? Furthermore, how must we relate this idea of progress to the fact that scientific rationality cannot be cut loose from how science is actually practiced at a certain point in time? Bachelard simply states that the progress of science is directed at objectivity and that the meaning of objectivity is determined by how it is rationally conceived of in the most up-to-date scientific practices (cf. Tiles 1984, 44). Hence, scientific progress should be understood in terms of objectivity, and that objectivity is defined in terms of how the real is rationalized in scientific practice.

This coincides with the normative function of the standards of rationality in the most up-to-date scientific practices, which can only be characterized as rational insofar as they are measured against earlier scientific practices. Only in the relation with the irrational character of these earlier practices can science be considered as progressive. Without the presence of earlier errors, no possibility for knowledge would exist at all (cf. Chimisso 2008a, 390). Only in asking how these errors can be solved can new scientific knowledge come into being: "It is indeed having this sense of the problem that marks out the true scientific mind. For a scientific mind, all knowledge is an answer to a question. If there has been no question, there can be no scientific knowledge" (Bachelard 2002, 25). Hence, it is only in this dynamism that science can remain to progress.

One of Bachelard's clearest examples to illustrate this idea is Einstein's interpretation of the Michelson-Morley experiment. This series of experiments was designed to measure the effect of the velocity of the earth on light waves. Through the invention of a technology that greatly increased the accuracy of measuring the speed of light, Michelson believed that this experiment would close discussions concerning the existence of the ether. ${ }^{34}$ Put roughly, the idea of the experiment was that if the ether was stationarily moving at the same velocity in which the earth moves through space, we would expect that if a light

34 There is no room for a detailed treatment of the set-up of the experiment and interpretation of the results in this chapter. For a more detailed discussion, see, for example, Canales (2015, 98-114), Hacking (1983, 256-261). beam angles the direction of the earth's motion, the velocity of this light wave would be somewhat less than the velocity of a wave of light that moves in the same direction as the earth's motion. However, much to Michelson's surprise, he was unable to find a difference in the velocity of the different light waves. Even after continuously updating the experimental set-up to rule out possible errors, Michelson's experiments indicated that the speed of light was constant, rather than dependent on the velocity of the earth. Einstein interpreted this experiment as giving proof that the speed of light must be understood as constant rather than considering it a failure to measure the influence of the velocity of the earth on light waves. ${ }^{35}$ According to Einstein, a dramatic consequence of this interpretation was that it forced physicists to dismiss the existence of the ether In Bachelard's view, Einstein could see that the seemingly negative results "proceeded from an intelligent question, a question which had to be asked" and were "the occasion for an immense positive construction” (Bachelard 1949b, 566). In other words, Michelson's experiments were the consequence of how he needed to ask questions within the paradigm of classical mechanics, which eventually revealed the erroneous assumptions of this theory. In Bachelard's interpretation, physics (personified in the figure of Einstein), revisited these errors of the past and incorporated them in a new theoretical framework that abandoned the fundamental assumptions of classical mechanics.

This is why an epistemology inspired by Bachelard should particularly examine how scientific assumptions materialize and how specific technological developments allow for theoretical developments and the emergence of new scientific objects. It is within and through these developments that it becomes possible to understand what specifically must be included in the epistemological rupture.

\section{§4.2 PHENOMENOTECHNIQUE}

The beginning of the twentieth century saw many great developments in physics. It saw the birth of relativity theory and quantum mechanics and broke with earlier theories in physics that were grounded in classical mechanics. Science was no longer an activity of describing and understanding the objects as they appear to us. Rather, "its purpose is to amplify what is revealed beyond appearance” (Bachelard 2002, 13). This revealing

35 There is still discussion among historians concerning the value that Einstein attributed to the results of the Michelson-Morley experiment. For an account arguing for the independency of Einstein's thought, see, for example, Holton (1968). For an account arguing for the opposite position, see, for example, Van Dongen (2009). However, for the purposes of this chapter, the historical accuracy of the dependency of Einstein's thought on the experiment is of less importance, as Bachelard clearly established a relation between the two (e.g., Bachelard 1949b, 1968). 
can only occur in specific experimental conditions that cannot be cut loose from the scientific instruments used to create them, but amplification cannot be reduced to them. Scientific objects are never mere phenomena but are always the product of observed phenomena to which we can only relate to through the instruments, concepts, and scientific theories-it is through these that science can amplify what is revealed beyond what is empirically observable. In Bachelard's words, scientific objects are constituted within a phenomenotechnique.

In this section, I elaborate on what it means for scientific objects to manifest within a phenomenotechnique. I do so by explicating the most important differences Bachelard sees between twentieth century physics (Einsteinian physics and quantum physics) and earlier manifestations of science and how this difference can be framed in terms of both a difference in technological apparatus and a difference in the application of mathematics.

\section{Philosophy from Science}

As already noted, in Bachelard's view, we cannot think of any philosophy of science without considering both the most up-to-date scientific discoveries and practices. The development of relativity theory and quantum physics opened a new era in science, which should be understood as a clear break with all earlier manifestations of scientific activity. According to Bachelard, this break did not just have scientific consequences; it also forced philosophy to "modify its language if it is to reflect the subtlety and movement of contemporary thought" (Bachelard 2002, 3). In his view, epistemology cannot be cut loose from the most recent scientific developments, because "science in effect creates philosophy" (Ibid. 3). Consequently, if the findings of the most recent scientific developments contradict traditional epistemological models, these models should be revised. According to Bachelard, the developments within physics indeed contradicted existing philosophical models, as they (i) made the strict distinction between realism and idealism obsolete and (ii) made it impossible to strictly distinguish between a subject that observes an object and an object that is observed by a subject.

The most prominent site of analysis for observing the differences between twentieth century physics and previous theories in physics is microphysics in the case of Bachelard. According to Bachelard, philosophers searching for the foundations of certain knowledge (i.e., science) were either realistic (knowledge is the product of the relation between the subject and the world) or idealistic (knowledge is the product of the human mind) terms. Bachelard aimed to construct a middle-ground position between these positions on the basis of his analysis of the scientific practice of microphysics, which "makes rational entities real" (Ibid. 13). It is in this context that he develops his notions of phenomenotechnique to show that scientific objects are dependent on the rationality of the scientific mind but only become accessible in their empirical manifestation.

Scientific phenomena, such as the Zeeman effect, butalso entities such as electrons, cannot be understood in terms of our ordinary experience of nature, as their manifestation depends on a structure that is fundamentally different from our daily encounter with reality. This structure, then, includes both idealistic and realistic aspects but can never be reduced to either of the two. On the one hand, the structure presupposes an idealism, because it transcends how our sensory encounter with the world, while on the other hand, in this transcending, a new world is created, of which the reality is rationally warranted. It is in the search for scientific knowledge that the world of science is created, a view summarized by Bachelard, with reference to the French proverb: "Tell me how you are sought and I will tell you what you are" (Bachelard 1984, 143).

According to Bachelard, such developments within physics and chemistry at the start of the twentieth century mark a break with earlier physical theories. He argues that we should interpret contemporary physics and chemistry as ways of thinking that instantiate an epistemological break with our ordinary way of knowing (Bachelard 1949a, 102). In pre-twentieth century physics, the scientist was still "one of us" (Bachelard 2005b, 73), in the sense that scientists spoke about the objects present in our ordinary reality and that an epistemology should reflect this continuity of objects. However, as physics was no longer in accordance with our ordinary experiences, Bachelard held that both of these position were no longer tenable and should be replaced with an epistemology grounded in the actual practice of science and reflecting the non-ordinary domain theories in physics are about (cf. Bachelard 1970, 14-16).

\section{The Phenomenotechnical Realization of Scientific Objects}

A key insight in Bachelard's epistemology is that the objects spoken about in scientific practice cannot be cut loose from the instruments used to observe them. Furthermore, he holds, the objects of science do not exist in nature as we ordinary know it. Accordingly, one thing his epistemology must account for is that scientific objects are created by the technologies used to observe them: "We must demonstrate that what humans create through scientific technologies does not exist in nature, and is not the natural cause of a natural phenomenon" (Bachelard 1949a, 102). Consequently, the observation of scientific phenomena necessarily coincides with their creation; only when understanding the object's process of becoming can a scientist understand what he has created and subsequently observed. The objects of science are in constant development, as they are dependent on how they are technologically constituted, and also the objects of the different sciences are different, as each of them employs a particular set of technologies, 
with their own set of accompanying objects. Hence, he advocates a pluralistic mindset within epistemology that is inspired to consider 'each hypothesis, each problem, each experiment, [and] each equation (Bachelard 1968, 12). Reflecting on these concrete instances occurring in scientific practice is the foundation of Bachelard's new epistemology that breaks with the traditional dichotomies of empiricism/idealism and positivism/rationalism.

Acentral concept in this new epistemological framework is the idea of phenomenotechnique, the idea that we cannot understand our experience of scientific objects without an understanding of how they are technically realized (cf. Bachelard 1949a). It is important to note that for Bachelard, this concept is not limited to material technologies. Most importantly, he considers mathematics a technique capable of realizing new scientific objects. This is the second crucial difference instantiated by twentieth century physics:

we can no longer understand scientific objects in a continuity with our ordinary experience, as they are mathematical relations rather than concrete substances. In other words, scientific objects can only be considered real insofar they are rationallymathematically-related to, and the only way to achieve rational objectivity "is to set forth, in a discursive and detailed manner, a method of objectification” (Ibid. 12).

According to Bachelard, what is unique about the objects of twentieth century physics is not only that they must be realized but that their coming into being cannot be understood without reference to the realization technique that accompanies them. On the one hand, this refers to the scientific instruments that are needed to produce phenomena, while on the other hand, it concerns how these phenomena are dependent on theoretical developments. This is why he speaks about the objects of science in terms of a phenomenotechnique:

"It is then that we understand that science realizes its objects without ever just finding them ready-made. Phenomenotechnique extends phenomenology. A concept becomes scientific in so far as it becomes a technique, in so far as it is accompanied by a technique that realizes. We are therefore very conscious that the problem of modern scientific thought is once again a problem that is philosophically intermediate. As in Abelard's time, we would like to take op an intermediate position between realists and nominalists, positivists and formalists, between advocates of facts and of signs" (Bachelard 2002, 70).

This notion emphasizes how scientists always relate to the object under study through a technique by which it is constructed. Science cannot be cut loose from the phenomenotechnique in two ways, as it (i) embodies a technological mode of action in the sense that it produces phenomena, and (ii) these phenomena only become manifest through the materiality of scientific instruments. We can understand neither of these without reference to theoretical developments, because it is through these that a particular mode of action is taken and through which the working of material technologies can be manipulated. Hence, the objects of science are both technologically and theoretically invested, and to understand how they are realized is to understand the interplay between technology and theory.

The making present of scientific objects through a phenomenotechnique forces us to develop a new philosophical position in between rationalism and empiricism: "In relativity, the terms of the dialectic are rendered solid and cohesive to the point of presenting a philosophical synthesis of mathematical rationalism and 'technological' empiricism" (Bachelard 1949b, 565-566). At other places, he refers to this middle position as an "applied rationalism" or a "technical materialism." These terms illustrate that a philosophy of science should always oscillate between the rationality of science itself that creates a domain of inquiry that breaks with ordinary experience and the objects that are present in this domain that are the product of technological manipulations. ${ }^{36}$

\section{Technologies Within the Phenomenotechnique}

For Bachelard, the importance of the presence of technologies becomes most apparent when considering that, in twentieth century physics, it is impossible to strictly distinguish between scientific phenomena and the experimental set-ups in which they appear. He connects this issue to the increasing need for precision in scientific practice, which can only be obtained through the use of technologies through which precision can be guaranteed (cf. Bachelard 2005). In addition, he holds that this increasing need for precision realized through material technologies is of crucial influence on how scientific thinking develops as "hypotheses must be coordinated from the perspective of the instrument" (Bachelard 1933, 40). Whereas Bachelard argues that theories and the testing of them cannot be meaningfully separated, he does not consider scientific technologies as the primary creator of the reality that scientists study. Technologies function within the phenomenotechnique and accordingly are closely connected to theoretical developments.

He illustrates this point with reference to both scientific experiments and measuring instruments. Measuring instruments such as thermometers can change the line of questioning regarding the phenomenon of heat, as they stabilize this phenomenon

36 An excellent discussion of these concepts can be found in Rheinberger (2010, 25-37). 
and allow for its increasingly precise standardization. They are both the product of the existing theoretical knowledge concerning heat, as a manifestation of the technological opening-up of a new line of physical research; as an object, the thermometer provides an increasingly objective manifestation of the phenomenon of heat. ${ }^{37}$ Similarly, the phenomena observed in experiments, such as electrons, cannot be detached from how they are humanly observed, indicating the dependence of scientific theories on our technological means to test them. This is why the concept of phenomenotechnique must be introduced; it is only in the specific techno-epistemic locus of a specific science that scientific objects attain their meaning.

While it is tempting to interpret the standardization of heat and our capability to experimentally detect electrodes in terms of science as cumulative progress towards scientific truth, Bachelard's view of scientific progress does not validate such a conclusion. Although he believes that state-of-the-art science should be understood as the standard for rationality, this rationality is not guaranteed with reference to its capability of discovering the truth about something that is external to it. The standardization of heat through the thermometer forces extends the range of phenomena that science must theorize about, as "temperature is seen on a thermometer, one does not feel it. Without theory, one would never know whether what is seen and what one feels correspond to the same phenomenon" (Bachelard 1968, 9). Hence, a change in the technical structure of the phenomenotechnique forces scientists to develop scientific theories to account for the existence of two different ways of phenomenologically accessing the same object and must show that both of these ways establish a relation with the same object-and this requires a rational, theoretical foundation.

Thus, even though Bachelard argues that "when we have followed contemporary physics, we have departed nature to enter in a factory of phenomena" (Bachelard 1951, 10), we should not conceive of this analogy as diminishing the distinction between scientific practices and the practices of mass production in industrial factories. Scientific practices are dependent on the uniform working of scientific technologies, which are interpreted as "reified theorems" (e.g., Bachelard 1949, 103) that "provide a certitude which is lacking in more passive knowledge" (Bachelard 2005a, 180). Technologies provide the basis for the construction of phenomena that remain stable in different experimental contexts in a similar way that mass production creates a stability among a set of products. However,

37 This closely relates to Baird's (2004) conceptualization of thermometers as instances of representational thing knowledge. However, the crucial difference with Bachelard's line of thinking that I follow is Bachelard's emphasis on how the thermometer opens up new domains of theoretical inquiry rather than that it is a mere stabilization of existing theories of heat. That is, from my perspective, the thermometer is part of a phenomenotechnique that creates a new domain of scientific objects. while the maintaining of this stability is a sufficient condition for pursuing the ends of technological thinking, in scientific practice, this stability must be transcended to gather new knowledge.

The transcending of the stability of the given phenomenon is what Bachelard refers to as an "unanticipated paradox which shows knowledge to be fleeting and mobile, and the action which it brings to light to be solid and assured" (Ibid. 176). According to Bachelard, the crucial difference between science and industry must be located in the end of a technological process for industrial means being part of how it is realized, while this goal directedness is absent in science. Industry deals with closed systems that can be explained in terms of their functional working. For example, the working of a water wheel that produces electricity can be exhaustively explained in terms of the functional mechanism through which the electricity is realized. However, developments in science cannot be limited to the schemes in which technological systems work in everyday situations. As the end of science cannot be reduced to how it is practiced, scientific practices cannot be reduced to how their objects are technically produced. Hence, the phenomenotechnique of scientific practice must not be equated with a particular technical mode of action that realizes its goals by employing technologies.

\section{Science is Irreducible to Technolog}

But what is this extra element that marks the difference between the working of technologies in everyday practice and how they function within scientific practices? Bachelard's answer to this question is formulated along two lines or argument: on the one hand, he makes a distinction between action and knowledge. On the other hand, he stresses the importance of mathematical thinking in scientific practices and argues that this marks a discontinuity with our ordinary practices. The conjunction of these two arguments is what, according to Bachelard, differentiates the phenomenotechnical nature of scientific practices from the technical mode of action found in industrial practice.

The first line of argumentation is concerned with the distinction between action, which is concerned with closed systems, and knowledge, which is concerned with that which is not part of closed systems. In industrial systems, technological processes are used to create the same product over and over again, and any unexpected results would be considered a failure. In mass industry, the goal is to create a large number of products that cannot be distinguished from another, and the coming into being of each individual product can be defined in terms of the mechanism that has created it. In scientific experiments, the opposite is the case. While scientific experiments are of course designed to test hypotheses and scientists have expectations concerning the result, this result itself is 
not part of the experimental design. The outcome of a scientific experiment should add to the existing scientific knowledge in a given domain (i.e., scientific experiments are supposed to generate something new).

Furthermore, the degree of certitude needed in scientific experiments differs from that needed for technological constructions. While technological constructions contain certitude on a very general level, they lack certitude on the micro-level that science is concerned with and in which things become increasingly complex (cf. Bachelard 2005a, 177). The end of a closed system is clear; the degree of certainty of the technologies involved is relative to the goal of the system. However, because science does not strive for any particular goal, it cannot neglect how this operation works on a detailed level (i.e., it precisely aims to understand the micro-phenomena that technological systems neglect). In scientific experiments, the working of technologies is based on hypotheses, because the specific outcome of the experiment is uncertain. Thus, while technological systems are principally closed, scientific experiments always entail the possibility that something unexpected happens, thereby creating a continuous openness.

The second primary difference between technological and scientific practices is that twentieth century science concerns a domain "that is of a mathematical sense before having a phenomenal signification" (Bachelard 2005b, 75). Following the Kantian distinction between phenomenon and noumenon, Bachelard holds that strictly speaking, scientific phenomena do not have their foundation in sensory experience but are products of mathematical thinking. However, Bachelard gives a twist to the Kantian distinction, which conflicts with Kant's conception of the noumenon (cf. Chimisso 2008a, 387). While the noumenon is principally inaccessible for human beings in Kant's view, Bachelard holds that the fact that some scientific phenomena, such as electrons, can never be sensory experienced as stable objects does not prevent scientists from having epistemological access to them.

Precisely because the phenomena of twentieth century physics are mathematically formed and cannot be found in ordinary experience can the rationality of science be warranted. Contrary to the Kantian noumenon, Bachelard's noumenon, which is scientifically constructed, is knowable to the human being and functions as the ground for the coming into being of scientific phenomena. The mathematical construction of a rational plane in which scientific objects appear can be understood as "a noumenology that elucidates a phenomenotechnique through which new phenomena are not simply found but invented, constructed and built from all parts" (Bachelard 2005b, 76). In this specific sense, mathematics also appears as a technique for creating a noumenon in which scientific phenomena appear in a rational manner.
This specific mathematical grounding is the second way in which scientific practices differ from ordinary practices in which technologies are involved. This does of course not imply that technological systems do not involve the use of mathematical reasoning. For example, the product output of an industrial factory may well be mathematically predicted in terms of the number of products the machinery is likely to manufacture in a certain amount of time. However, in contrast with scientific practices, the existence of the product (say, a shoe) is not dependent on this mathematical prediction. In other words, contrary to scientific phenomena, the presence of mathematics is not constitutive of the existence of technical products.

However, the sciences should not be reduced to their mathematical character. While on the one hand, Bachelard argues that the sciences should rationalize reality to construct scientific phenomena against nature, he holds, on the other hand, that these rationalizations should become real in the sense that they can be empirically observed. It is precisely this empirical realization of rational thought that constitutes the experimental character of twentieth century science. If we place the notion of phenomenotechnique in this context, we clearly see that it cannot be reduced to the stable function of the involved technologies but always transcends these material aspects. The structure of the phenomenotechnique always works on the basis that a mathematical surface is rationally already there and can only realize scientific phenomena within this surface. Within the phenomenotechnique, the rationality of mathematics constitutes a noumenal plane that is potentially subject to change, and material technologies help remaining this plane relatively constant, such that they help reveal the phenomena through which scientific objects are constituted.

\section{$\$ 4.3$ SCIENTIFIC PRACTICE BEYOND PHYSICS}

It can be questioned whether Bachelard's analysis of (micro-)physics can be taken as a model for the sciences in general. Does his epistemology allow for attributing a specific rationality to different scientific practices in different disciplines? In other words, does Bachelard's epistemology allow for a scientific pluralism, or does he consider (micro-) physics the most mature science up to his day that functions as a model of rationality for science as a whole?

In this section, I attempt to answer these questions. I first discuss how Bachelard's focus on microphysics is criticized by his pupil Georges Canguilhem, who holds that a physics-based epistemology differs from an epistemology developed in relation to the life sciences-for example, in relation to the current neurosciences (e.g., Canguilhem 
1991). Secondly, I argue that while Bachelard's epistemology is in the first place oriented towards physics and chemistry, he sees no reason to treat other sciences on the same terms. I show how this idea culminates in his notion of regional rationalism, thereby opening up the possibility that, on a micro-level, scientific rationality can be realized in various ways. I end with a critical note by asking to what extent Bachelard's pluralism conflicts with his idea of developing an epistemology that incorporates a form of rationality that is a normative standard for all scientific domains.

Cornelius Borck has argued that the brain, as an object of neuroscientific research, is subject to continuous change, because it is made increasingly complex through the technologies used to investigate it. He claims that "the brain' must be understood as an artifact in the precise sense of the term Bachelard had in mind when he described modern physics" (2016, 8). How the neurosciences conceive of the brain is dependent on how it appears within the phenomenotechnique. Because of the increasing complexity of the brain that scientists discover in relation to the phenomenotechnique in which it is made present, the neurosciences become a diverse field consisting of several subdisciplines that each work on their own set of problems. This suggests a continuity between the natural and the neurosciences in terms of how their object of research is created and how it is made increasingly complex. But to what extent does a continuity in terms of how scientific objects come into being also lead to a continuity in terms of the nature of these objects?

\section{Georges Canguilhem and the Uniqueness of the Objects of the Life Sciences}

Canguilhem, a direct pupil of Bachelard, argued that a philosophical reflection on the life sciences gave rise to a different kind of epistemology, because these different domains are concerned with different scientific objects. His most important criticism on the work of Bachelard develops along two different, yet interrelated, lines of argument: on the one hand, Canguilhem stresses that the natural and life sciences are necessarily different, because the object of the life sciences (life) cannot be conceived without reference to the specificities of individual living organisms. On the other hand, he utilizes a different concept of normativity than Bachelard; whereas Bachelard held that contemporary physics prescribes the norm of rationality, Canguilhem does not identify the rational norm in terms of scientific practices but places it in life itself, a principle that cannot be reduced to the practices in the life sciences.

What, then, makes life something distinct from the life sciences? And, more specifically, what is it that distinguishes the scientific objects in the life sciences from what Bachelard considered the objects in the natural sciences, which should be formed against nature? According to Canguilhem, the object of research in the life sciences must be defined as the living being and the sicknesses that this being experiences (cf. Chimisso 2008b, 162-164). This implies that we cannot clearly distinguish between the life sciences and medical practices and that the objects of the life sciences should be understood as coming into being in the relation between these domains. Because of this, it is necessary to involve the concept of "experience," which marks a fundamental difference between Canguilhem's and Bachelard's when it comes to which objects can be considered scientific objects. Experience implies the presence of something that experiences a certain disease. By definition, then, the object of the life sciences can never be fully objectified-which would be a necessary condition in Bachelard's epistemological reflections on physicsbut always includes the relation between the organism and its sickness.

The meaning of "technique" in Bachelard's notion of phenomenotechnique refers to how scientific phenomena are created in a context that is material, mathematical, theoretical, and conceptual. While Canguilhem also emphasizes the fundamentally technical character of the life sciences, he holds that the life sciences are always already invested in something non-scientific: medicine is concerned with the restoration of the well-being of an organism, rather than with the disinterested creation of a new scientific object. The sickness of an organism can never be purely defined in physiological terms, because it concerns the organism as a whole, which relates to its environment (cf. Canguilhem 1991, 223). Because of this relationality, the objects of the life sciences are not artificial objects in a Bachelardian sense, because they always have a relationship to something external to them.

Can this medical understanding of the life sciences, which understands its object as a relation between an organism and its experience of sickness, be a model for the life sciences in general? Or can we speak of the life sciences in terms of the rationalization of the real through the increasing complexity of the phenomena appearing within different phenomenotechnical structures in non-clinical contexts, as seemingly suggested by Cornelius Borck? According to Canguilhem, life contains a vitalism that can never be fully rationalized, because a part of life always resists any principle explanation: living organisms cannot be understood without considering that life is about adaptation to the environment and changing the environment such that it can be adapted to.

This vitalism brings me to the second line of argument that separates Canguilhem from Bachelard. A central aspect of Canguilhem's vitalism is the idea that life, as lived by living beings, continuously creates new norms in relation to the environment. In other words, in the process of adapting to the environment, there is never a solid state that can serve as the rational basis of life. Each organism "has its own vital norms" (Canguilhem 2008, 113). These norms should be considered in the life sciences. The life sciences "must first 
hold the living to be a significative being, and must treat individuality not as object but as an attribute within the order of values. To live is to radiate; it is to organize the milieu from and around a center of reference, which cannot itself be referred to without losing its original meaning" (Ibid. 113-114). Although how an organism organizes its milieu can never be cut loose from the actual physiological state of it, the life of this organism can only be understood in terms of its interplay between the biological constitution of organism, the social context in which it lives, and its relation with the environment. Thus, while Canguilhem develops the idea of the relationality of organism and environment in the context of the medical sciences that deal with illnesses, it is grounded in his conception of the general biology of living organisms.

Because Canguilhem embraces that the life sciences should consider the irreducible vitalism of life, he holds that a different standard of rationality should be at work than the rationality that Bachelard develops in relation to the natural sciences. ${ }^{8}$ The ultimate standard for rationality in Bachelard's work must correspond to the most up-to-date scientific developments. In Canguilhem's work on the life sciences, the norm of rationality is located outside of the practice of science. Does this mean that the individuality of the living organism is principally at odds with the goals of the life sciences to study it? No, but to be capable of giving an objective picture of an organism, the life sciences must necessarily consider this aspect as "research which causes its object to vanish is not objective" (Canguilhem 1991, 87). For Canguilhem, this placing of the normative standard outside of science does not imply that the life sciences in general, and medicine in particular, are unable to attain objectivity. Contrary to Bachelard's idea that the goals of the sciences can be understood as the rationalization of the real, Canguilhem holds that, as put by Christina Chimisso, the object of the life sciences can never be fully rectified or purified (cf. Chimisso 2013, 431).

But how then must we think about the relation between practice in the life sciences that deal with physiology that isolates life from the living being, and the fact that life always is more than how it is physiologically organized? A neurobiologist I spoke to stated the problem like this: "it remains strange that an organ [the brain] can study itself." An answer to this question can be found in the idea that the life sciences and the knowledge generated through it can also be understood as a specific way of dealing with the environment, that is, when situating the life sciences within life itself. Or, in the words of Monica Greco: "the science of life is, itself, a manifestation of the living, a manifestation

38 There is no room to give a full account of Canguilhem's vitalism in this chapter, and I discuss it just to highlight the possible differences between the object of the life sciences and the object of the natural sciences. For a more complete picture of his vitalism, see, for example, Gayon (1998), Greco (2005), Hertogh (1986), Rabinow (1994). of its own subject matter" $(2005,18)$. In other words, the life sciences are themselves part of the normative interactions with the environment that constitute are constitutive of living organisms. For example, through the developments in the medical sciences and the accompanying means to intervene in the human organism, the biological notion of life remains subject to constant change.

In Canguilhem's philosophy of the life sciences, life itself can never fully appear as an artificial object that is not naturally there but only exists because of its construction. Although physiologically speaking, we can say that the cellular or neuronal structure of organism can only appear within a phenomenotechnological structure and does not exist independent of the technologies used to access them, this phenomenotechnical object does not coincide with life itself. There is always something that escapes-and must escape-the artificiality of a phenomenotechnical construction, and this is the very principle that livings organisms are always defined in terms in their interactions with the environment. Thus, while, according to Bachelard, the objects of the natural sciences can be defined in terms of their artificiality, the object of the life sciences can never be fully artificialized, as it always concerns the concrete manifestation of the organism in an environment that transcends scientific practice per se.

\section{Different Ways of Rationalizing the Real}

While they differ in their specific practical make-ups, physics and the life sciences are equally concerned with the rationalization of the real. It is the eventual conclusion of Canguilhem that there simply is a fundamental difference between the life sciences and the natural sciences in terms of the different objects they are concerned with (e.g., Canguilhem 2008). And hence Canguilhem maintains that a Bachelardian epistemology cannot be unproblematically applied to the life sciences. Does this difference also imply that the life sciences and natural sciences do not share a similar rational structure (i.e., that they pose a limit on Bachelard's epistemology)?

Bachelard is well aware that the different sciences deal with different objects but does not consider this to be in conflict with his epistemology, because the different sciences each have their own regional rationalism (cf. Bachelard 1949a). Because the sciences should for making their objects increasingly complex, specialization is a natural consequence. Bachelard attempts to develop a positive account of the implication of this specialization and places it in the context of the actual development of the sciences. Specialization is the positive consequence of the non-substantialist character of the sciences, which leads to the increasing complexity of the objects present in scientific research. Precisely because of this increasing complexity, it is necessary that a plurality of specializations must come into being to do in-depth research into each of these phenomena (cf. Bachelard 1951, 
13). Each of these specializations develops its own rational structure specific to how its object is made complex.

This view can be illustrated with reference to the development of the cognitive neurosciences. When the brain is treated as an explanatory substance for cognitive functioning, it is maintained that human behavior is the consequences of the interactions on a neuronal level, which in turn may be caused by interactions on a cellular level, it is clear that the mechanisms underlying cognitive functioning become increasingly complex. To begin to understand this system, one would need knowledge of cell biology, physics, and chemistry. As a consequence, specialized groups are formed that deal with the different aspects of human cognition through the lens of their specific fields. Hence, through its increasing complexity, cognition becomes a scientific object that is scattered across different scientific disciplines that each deal with it in a specific manner.

This complexity causes a plurality of separate scientific disciplines that each offers its own specific perspective on human cognition. To function as specialized, each discipline must construct "its" human cognition in a specific way, and they cannot do so without using technologies. When observing the cellular structure of brain tissue through a microscope, a different object comes into being than when studying networks of neurons through the use of fMRI. Each of these different ways of observation comes with different problems, questions, and theories concerning its specific domain. Following Bachelard, we can say that each of these domains constructs its objects within its own phenomenotechnique.

In Bachelard's view, this falling into pieces of cognition into different specific scientific objects does not rise to the fear that these pieces can never be reconnected into the original object of research. On the contrary, he sees this as a natural consequence of how objectivity is manifested in the sciences; the scattering of the initial object is precisely what transforms it into a truly scientific object of research. He argues that "through scientific thinking, the object acquires a deepened perspective" (Bachelard 1951, 12). The initial object can be described in terms of different conceptual frameworks that each explain its workings on a specific level (cellular, neuronal, etc.). As a consequence, each of these different scientific practices that constructs its own objects within distinct phenomenotechnical structures develops its own regional rationalism in relation to the specific technologies it uses and the concepts it employs.

This notion of specialization shows how a scientific object can be differently realized within different domains but does not address what is specific about the object of the life sciences in comparison with the natural sciences. Bachelard's discussion of specialization explains the varieties of rationalism in the sciences in terms of an engagement with an object that has already appeared as scientific and turns into a variety of objects when it is made increasingly complex. However, Canguilhem's argument for the specificity of the life sciences revolves around the idea that there is something specific to life that resists its transformation into a purely scientific object in the first place and that this resistance is precisely what should be considered within the life sciences. If we understand the sciences of life (which include the sciences of cognition) in terms of Bachelard's notion of specialization, we can only study it in terms of its physiological functions. In this view, these functions may appear in a variety of ways in different areas of specialization. For example, there is a difference in which physiology appears on a cellular level and on a neuronal level. However, the distinction between the life and natural sciences in terms of the specific lived aspect of life (as Canguilhem aims to do) and the acknowledgement of the scientific character of the life sciences cannot be incorporated in Bachelard's notion of specialization. Either the lived aspect of life is swamped by physiology or the life sciences cannot be described in terms of the rationality of physics, because their object can never be objectified.

\section{\$4.4 THE RATIONALITY OF THE SCIENTIFIC PROJECT}

Is there any other way in which Bachelard can account for the scientific character of both the natural and life sciences, such that they can both be interpreted as participating in the rational structure of the sciences? According to Bachelard, the different regional rationalisms in science are unified because they all equally engage in a rational apodicticity, which ensures "the application of the rational technique of scientific thinking determines a genuine recurrence of rationality" (1949, 121). This seems to suggest that what the different sciences (for example, the natural and the life sciences) keep together is the rational techniques they apply to make scientific objects appear within a rational domain.

Bachelard conceptualizes scientific practices in relation to the project of science as the possibility to engage in theoretical activity. The rationality at work within the scientific project should aim for the ongoing correction of previous errors. This suggests that insofar as other sciences participate in this same rationality, there is no a priori reason to make a strict division between the physical and the other sciences. No matter what technologies, research objects, or concepts are present, the different sciences can all be considered scientific insofar as they participate in the rationalist project of science at large. In other words, the structure of the particular phenomenotechnique at work within a particular scientific context functions because it participates in a scientific 
rationality. Accordingly, the micro-activity of scientific practice can only be considered scientific to the extent that it is part of the macro-aspect of science as a rational project.

Now, what is the relation between the micro-aspects of scientific practice that occur through the phenomenotechnique and the general rationality of the scientific project? The relation between these two aspects is discussed in terms of (i) Bachelard's discussion of the general project of science in terms of obtaining rationality and (ii) how this normativity is embedded in scientific practices that deal with artificial objects that do not exist outside of a phenomenotechnical structure.

\section{The Scientific City}

In Bachelard's view, science, as a project, is purely rational and independent of any material circumstances. Science occurs in a "scientific city," and the inhabitants of this city seem to be perfectly rational actors that come to a collective understanding of a scientific phenomenon, because they all participate in the rationality of science. In Bachelard's view, objectivity and rationality can only emerge out of social exchanges between different scientists. Only within collectives is it possible that individual scientists do not obey their instinctual desires and drifts, which would culminate in an imaginative experience of nature, and are classified by Bachelard as epistemological obstacles that should be overcome (cf. Chimisso 2013, 401).

Also, this idea of the scientific city is grounded in how Bachelard conceives of the actual structure of scientific practice. For example, when discussing that most of the papers appearing in scientific journals are written by several authors, he stresses that this cooperative aspect is typical for how rationality manifests in the newest manifestations of science (i.e., in twentieth century physics) (Bachelard 1951, 9). ${ }^{39}$ This collective rationality functions as a model for how science should be organized and how scientists can attain a position of rational apodicticity. The idea that rationality can only be obtained when participating in actual scientific practice and by relating to other scientists is most dramatically expressed in Bachelard's posthumously published fragments on poetics, where he writes,

"I am of the conviction that an active rationalism must be associated with scientific labor, transforming all knowledge into scientific knowledge. Thus, if I were to write a new book as a rationalist, I would have to go to the school of one of the contemporary

39 The claim that cooperation between scientists is typical for $20^{\text {th }}$ century science can be doubted on historical grounds. For an account of the cooperation in the $17^{\text {th }}$ century between scientists (natural philosophers) and the need for experiments to be public events to be observed by other scientists, see, for example, Daston and Galison (2007), Shapin and Schaffer (2011). sciences. One can no longer be rationalist by oneself, on the fringe of contemporary scientific activity. It is necessary to learn together with the workers of rationality" (Bachelard 1997, 9).

The lonely individual is unable to produce rational knowledge, because rationality is constituted in the scientific city through the discursive practices between scientists. Only in this environment can the human mind be rectified such that it overcomes epistemological obstacles. The individual, on the contrary, is capable only of producing desires and dreams that are private by definition and can only be expressed in poetry. Hence, the social structure is a necessary precondition for engaging in the scientific project (cf. Chimisso 2001, 93).

\section{Scientific Experience is Rational Experience}

This collective rationality is not limited to personal interactions between scientists, but it also structures how scientists relate to the phenomena they study. In the scientific city, the collective discursive layer of the written word provides an extra foundation of the sciences, which is as important as the construction of the scientific noumenon through mathematical techniques. Polemically, Bachelard refers to this discursive structure as providing a bibliomenon that provides an ongoing stability for the existence of scientific objects within the scientific community. Furthermore, through the constant interaction with the scientific phenomena that exist within the bibliomenon, scientists remain constantly aware that the objects that science concerns are not natural objects but phenomena that are artificially created. Hence, this discursive structure functions as a mechanism that helps scientists to continue to overcome the epistemological obstacles they are faced with (cf. Bachelard 1951, 8). This continuous wake-up call is especially important for Bachelard, because the danger of falling back into the non-rational mode of everyday life remains ever-present.

According to Bachelard, this collective and discursive structure of the scientific city guides how science is practiced on a micro-level. The micro-experience of scientific practice participates in the scientific project that guides all scientific thinking. No matter which technologies, research objects, and concepts are present, the different sciences can all be considered scientific insofar as they participate in the rationalist project of science at large. In other words, the structure of a particular phenomenotechnique at work within a particular scientific practice only functions insofar as it participates in a scientific rationality; the micro-activity of scientific practice can only be performed to the extent that it is part of the macro-aspect of science as a rational project. Only within this rational structure, which is materially represented in the scientific city, can scientists relate to scientific objects (Bachelard 1949a, 121). This structure is realized in the 
construction of a rational environment in which scientists are capable of continuously overcoming epistemological obstacles in their interactions with each other and the books in which scientific objects are stabilized. This structure is purely dependent on the internal development of scientific rationality and should avoid having any inference with external factors, because these function as obstacles to the very possibility of scientific rationality.

\section{$\S 4.5$ PHENOMENOTECHNIQUE AS PHENOMENOTECHNOLOGY}

Bachelard primarily understands technologies as techniques that are involved in the construction of a rational environment in which science occurs. In the end, the most important use of technologies is how they stabilize scientific phenomena in experimental environments. The micro-functioning of technologies in scientific experiments is only relevant insofar as it contributes to science in a general sense as a rational project. The macro-aspect of the scientific project seems to always be prioritized over the microexperience of scientific practice, which is why Bachelard eventually disconnects all materialities of scientific practice from science itself. In this section, I reconceptualize Bachelard's notion of phenomenotechnique as phenomenotechnology. In doing so, the concept augments postphenomenology, because it emphasizes that the intentional relation between scientists and the world is mediated by a phenomenotechnological structure rather than by isolated technologies. At the same time, precisely because I understand a phenomenotechnology in phenomenological terms, this does not require assuming a form of rationality beforehand. Rather, what is taken to be "rational" is itself shaped within the mediated relation between scientists and the reality they investigate.

\section{The Limits of Bachelard's Phenomenotechnique}

As demonstrated above, in Bachelard's view, the lonely individual is unable to produce rational knowledge, because rationality is constituted in the scientific city through the discursive practices between scientists. Only in this environment can the human mind be rectified such that it overcomes epistemological obstacles (i.e., relating to objects that are reified within science). The individual, on the contrary, is capable only of producing desires and dreams that are private by definition and can only be expressed in poetry. Hence, the social structure in which it becomes possible to engage in a state of rational apodicticity is a necessary precondition for engaging in the scientific project.

How then must we think of Bachelard's notion of phenomenotechnique when we wish to understand the role of technologies in scientific practice? This idea of science as crucially dependent on techniques in Bachelard's work seems to have at least three different implications. Firstly, "technique" refers to the technologies through which scientific objects come into being. Secondly, technique refers to the mathematical creation of a noumenon in which these phenomena must appear. Thirdly, technique refers to the creation of the scientific city, in which scientific phenomena are rationally discussed among scientists. Thus, despite Bachelard's (and many others) use of the words "technique" and "technology" interchangeably, the "technique" in phenomenotechnique should be understood as allowing for phenomena to be made and for the making of a rational environment in which the sciences can conduct objective research.

In this view, technologies are primarily conceptualized in terms of allowing for the creating of a stability within which scientific objects appear. After the creation of a phenomenon within a phenomenotechnical structure, the phenomenotechnique disappears the moment that the phenomenon is stabilized. Instead of remaining part of the materiality of scientific practice, the scientific phenomenon becomes part of the rationality of the scientific project that transcends all practices. While Bachelard attempts to integrate the role of technologies in epistemology, he is primarily interested in how they function as techniques to let scientific phenomena come into being in a rational manner. This macro-aspect of ensuring the rationality of the scientific project is prioritized over the micro-experience of scientific practice, which is why Bachelard eventually disconnects all materialities of scientific practice from the scientific project. In other words, when the rational is realized, the scientific phenomenon and the technologies that accompany it dissolve into the rationality of the scientific project.

Phenomenotechnology: A Postphenomenological Reading of "Phenomenotechnique" Then, how must we connect Bachelard's epistemology to the suggestion that his work could be an important addition to debates in-and between-the philosophy of science and science studies? Does this manufactured rational environment provide a link between the practical and theoretical aspects of scientific practices? When considering that Bachelard conceptualizes the working of technologies in terms of creating stability across scientific experiments, these ensure that scientific practices are rationally organized through this stability. In other words, because of this stability, different scientists are capable of theorizing about the similar scientific phenomena. However, this theorizing that occurs within the rational structure of science is itself independent of how scientific phenomena are created. It presupposes a social structure (the scientific city) and a mathematical structure that must already be there to ensure the rationality of both the phenomena appearing in the phenomenotechnique and the theories that are subsequently developed about these phenomena.

When we compare this view of Bachelard's with how technologies in scientific practice 
are dealt with in postphenomenology, the focus on how technologies, as part of the phenomenotechnique, make phenomena more complex allows for gaining a deeper understanding of the "scientific" aspects of scientific practice. While Don Ihde primarily focuses on how technologies make phenomena visible to us by detecting signals that cannot be perceived with human biological capacities, Bachelard's epistemology adds to this idea that scientists must also make sense of these phenomena in a conceptual manner. Framed in terms of Ihde's notion of material hermeneutics, a postphenomenological epistemology primarily focuses on how the phenomena that technologies detect are transformed into readable images that are read at a glance by the observing scientists, who encounter an image that is transformed into an immediate Gestalt. Ihde locates the hermeneutic moment in this process in the transformation of what the technology has detected into an image that is brought within the domain of human perception.

As I hope to have shown in this chapter, with Bachelard, we can augment this approach by also focusing on how scientific phenomena arise as the consequence of (i) concepts that already frame how a phenomenon comes into being and (ii) how these concepts play an integral part in understanding the meaning of a scientific phenomenon. Considering this, the hermeneutic moment is not limited to how technologies transform what they have detected into readable images or bring scientific phenomena within the human sensory domain in another way but also occurs in the conceptual (trans)formation of scientific objects. Hence, there is a doubled hermeneutic at work in scientific practice: on the one hand, this hermeneutics concerns the material technologies that makes a phenomenon perceptively visible, while on the other hand, the hermeneutics also concerns how this visible phenomenon is conceptually transformed into a relevant scientific phenomenon that can be meaningfully reasoned about in scientific practice.

Let me illustrate this double hermeneutics with an example of research in the cognitive neurosciences. When a researcher is interested in studying visual attention in this scientific domain, she typically encounters a brain scan that is meant to explain the neuronal mechanism that coincides with this type of behavior. ${ }^{40}$ This includes the transformation of what is detected through fMRI into a brain scan that enters the human perceptive field as well as the transformation of the pattern depicted on this scan into the scientific object of visual attention. This second transformation occurs because an image of the brain entering a human perceptive field does not entail on its own that the content of this image can be related to visual attention. To put it bluntly, a picture of the brain is not necessarily a picture of cognitive functioning. There must be a second

40 For a detailed discussion of the neuroscientific study of visual attention and the way it includes both perceptual and conceptual transformation, see Chapter 7 . hermeneutic moment that allows for the transformation of an image of the brain into an image of visual attention.

A second advantage of integrating the work of Bachelard into a postphenomenological epistemology is that it allows an understanding of how technologies influence how scientific phenomena are actively created. In postphenomenology, technologies are centralized in this process. Don Ihde terms them "epistemology engines," which open up new domains of scientific inquiry by creating new paradigms within which scientific research occurs (cf. Ihde and Selinger 2004). For example, he holds that, today, we cannot but understand the brain in terms of fMRI scans. According to Ihde, because we can only access the brain in our relationship with mediating technologies and can never step out of this mediation, we can only perceptively encounter the brain through fMRI. When invoking the Bachelardian notion of phenomenotechnique, we see that the cognitive neurosciences do not deal with the object "brain" but with the increasing complexity of human cognition that can be understood in terms of neuronal activity.

Because Bachelard's notion of phenomenotechnique does not isolate individual technologies from the broader structure and aims of scientific practices, this shows that the relation between scientist and the reality that they investigate is mediated by a phenomenotechnology, rather than by "concrete technologies." Replacing the term "phenomenotechnique" with "phenomenotechnology" is not mere wordplay: while "technique" refers to the structure within which scientific objects are constructed, "technology"-in a postphenomenological vocabulary-must be understood in phenomenological terms. Accordingly, a phenomenotechnical structure is "phenomenotechnological" because it structures the intentional relation between scientists and the reality they investigate. Within this structure, then, the scientific character of this reality comes into being as a consequence of the specific way in which scientific objects are realized.

\section{§4.6 CONCLUSION: EXPLAINING INSTEAD OF ASSUMING THE EPISTEMOLOGICAL RUPTURE}

The postphenomenological reformulation of 'phenomenotechnique' as 'phenomenotechnology' makes the epistemological rupture that Bachelard simply posits a subject of inquiry: As indicated, Bachelard sees it as the primary task of technologies in their role within the phenomenotechnique that helps creating an epistemological rupture with our ordinary experience. Only in this domain can rationalist activity take place that ensures the of objective knowledge. This seems to suggest that Bachelard's account can 
be of aid when we wish to understand what is scientific about scientific practices. In the end, it is the rationality of science per se that is capable of discovering new scientific phenomena that can instantiate theoretical change and not the interactions between humans and technologies that constitute new phenomena scientists can theorize about. However, his epistemology does not offer an answer to the question of how scientific objects come into being within the practical interactions between scientists and technologies and the relationships between scientists.

For Bachelard, scientific practice continues to be discussed in terms of the preconditions necessary for engaging in the scientific project, thereby reducing practical interactions to be of interest insofar as they are a manifestation of a form of rationality external to scientific practices. As I suggest above, when understood as a phenomenotechnology, there is no need to posit an a priori form of rationality that structures scientific research. When understanding the phenomenotechnique as mediating the reality that scientists study (i.e., as phenomenotechnology), it becomes possible to both consider the benefits of Bachelard's approach and allow for the possibility to make the constitution of rationality a subject of phenomenological investigation. In other words, it becomes possible to turn Bachelard's epistemological rupture into a subject of investigation by considering how the reality of science-as rationalized-takes shape as mediated by a particular phenomenotechnology.

In the next chapter, Bruno Latour's empirical philosophy is presented as an important attempt to study the coming into being of the epistemological rupture. He presents a radical alternative to Bachelard's view: while Bachelard assumes a rationality that is internal to science, Latour holds that rationality is not prior to, but is the outcome of, scientific practices. As such, the rationality of science and the specific shape it takes in relation to scientific instruments and in the relation between scientists can become a subject of empirical investigation. As demonstrated below, following this route allows for more adequately fulfilling Bachelard's insight that every philosophy of science should depart from an analysis of scientific practice. 


\section{CHAPTER 5:}

Bruno Latour and the Difference Between Technical and Technological Mediation ${ }^{41}$ 


\section{INTRODUCTION: SCIENCE AS EXPLANANS}

"Taking away the trash can, for example, would be unlikely to harm the main research process; similarly, withdrawal of the automatic pipette would not prevent pipetting by hand, even though this takes longer. By contrast, if the gamma counter breaks down, it is difficult to measure amounts of radioactivity merely by sight! The observation of radioactivity is entirely dependent on the counter" (Latour \& Woolgar 1986, 64).

How do technologies function within scientific collectives? Can we indeed assume, as Bachelard did, that to understand scientific practices, we should ask scientists to "tell us what you think, not when you quit the laboratory, but during the hours when you leave your ordinary life behind you and enter scientific life" (Bachelard 1968, 11)? As the previous chapter demonstrates, accepting this radical divide between scientific and ordinary practice problematically assumes that the rationality of science is guaranteed by the internal logic of the scientific project. From this perspective, how scientists relate to technologies-as part of the phenomenotechnique-is also explained in terms of a rationality that is external to scientific practices. Would it not be possible to develop a different understanding of scientific practices, performed by scientific collectives that relate to technologies, without presupposing that these practices are rational in themselves?

In the previous chapters, I explore the "scientific" in scientific practices and investigated to what extent human-technology relations are specifically shaped through scientific standards, such as the theoretical or rational character of the sciences. In this chapter, I focus on the "practical" part of scientific practice. The point of departure of my analysis of the practical character of the scientific, and the roles of technologies in it, is the work of the French philosopher-anthropologist Bruno Latour, whose work-developed in close collaboration with Michel Callon and John Law-gained widespread influence under the denominator of ANT. I show how his work can be understood as a radical alternative for Bachelard's internalist conception of scientific rationality. Rationality, according to Latour, is not the prerequisite for, but the outcome of, scientific practices. As demonstrated below, focusing on these networks importantly allows for revealing the collective character of scientific practice and the fact that a philosophy of scientific instruments should not be limited to individual human-technology relations.

In Latour's view, "scientific" cannot be used as an explanatory term that guarantees the truth of statements or the reality of objects. On the contrary, "scientific" is the explanans: the phenomenon that must be explained (cf. De Vries 2016, 56). "Truth" and "reality" do not appear as absolute givens in Latour's work but rather are interpreted as the outcome of a practice that creates statements that are "true" and objects that are "real." In other words, it requires much work to create facts, and this work can become a topic of investigation. Thus, rather than taking for granted that there rationality is at work in the sciences, Latour asks why a specific, distinct practice can employ categories as "true" and "real" in the first place.

When the rationality of the sciences, the objectivity of scientific research, and the existence of scientific phenomena are not considered as given, it becomes possible to also consider scientific instruments as parts of these processes. Latour attributes an important role to scientific instruments because they function as what he calls inscription devices. Conceptualized in this way, they are defined as "any set-up, no matter what its size, nature and cost, that provides a visual display of any sort in a scientific text" (Latour 1987, 68). As I show in this chapter, this understanding does not attach sufficient importance of scientific instruments. Furthermore, I show that this underlying conception of technologies is derivative of Latour's approach to science-in-the-making.

In fact, as I show, although Latour argues that his approach allows for an investigation of science-in-the-making, he eventually analyzes science-as-it-has-been-made, which can only engage in the post-hoc deconstruction of these practices. After all, it requires for a fact to be already made to investigate how it is shaped in this specific way. Based on this, I argue that adding a hermeneutical understanding of science to Latour's semiotic approach allows us to not only deconstruct scientific practices but also understand why specific interpretational frameworks come into being within scientific collectives. As I demonstrate, this addition is necessary to investigate why specific facts, and not others, are made in scientific practice and how this specificity relates to the elements that are present in how scientists relate to the world through a phenomenotechnology.

The chapter is structured as follows: firstly, I introduce Latour's philosophy as a radical alternative to Bachelard's internalist conception of scientific practice and the rationality that guides it and explain how this radical difference is grounded in Latour's denial of the existence of an epistemological rupture between scientific and ordinary experience ( $\$ 5.1)$ and how this denial can be understood in terms of how he breaks with the tradition of Enlightenment criticism ( $\$ 5.2$ ). Secondly, I show how this continuity of scientific and everyday experience allows for understanding how facts are made by establishing relations between different scientists and scientists and technologies ( $\$ 5.3)$. Thirdly, I critically discuss Latour's philosophy by pointing out the limits of his deconstructionist approach. To do so, I focus on why his philosophy must be augmented with a closer analysis of how specific interpretational frameworks and scientific concepts to allow for specific facts to come into being $(\$ 5.4)$. I argue that this postphenomenological augmentation 
of Latour's philosophy moves beyond an understanding technologies as techniques that allow for the making of facts. In addition, technologies should be understood in terms of how they shape the phenomena that potentially can become facts in the first place (\$5.5). As I show, this shift of focus has consequences for the methodological starting point when empirically studying science-in-the-making ( $\$ 5.6)$.

Studying science-in-the-making should not only have the purpose of answering the question of how scientific facts are constructed. While this issue can (at least partly) be answered in terms of the deconstruction of networks, as it presupposes that a specific fact has already come into being, the question of why a certain statement becomes a candidate for facticity is not bound to this condition. To investigate this latter question, it is necessary to develop an approach that allows the study of how scientific objects are constituted such that they can be integrated into factual statements. As I argue, this requires moving beyond an understanding of scientific instruments as inscription devices and instead investigating their role in the process of reality building occurring in scientific practice.

\section{\$5.1 UNDERSTANDING SCIENCE AS PRACTICE AND UNDERSTANDING PRACTICE AS SCIENCE}

As the previous chapter outlined, Gaston Bachelard traces the working of scientific instruments in scientific practice back to a scientific rationality that remains detached from any practical context. He postulates a rationality that is internal to science and assumes that scientific practices participate in this rationality. Bruno Latour's philosophy can be considered a radical alternative to this view: he holds that rationality is not prior to, but the outcome of, scientific practices. In other words, Latour denies that there is an essential discontinuity between the reality of science and the reality of everyday life that can be attributed to the rationality of science. From this perspective, it becomes possible to explore the working of technologies in scientific practice without letting them dissolve in a scientific rationality and to highlight the dependency of scientific practice on the presence of technologies.

In this section, I discuss how Latour attempts to circumvent descriptions of scientific practice in terms of an a priori concept of rationality that guides it by contrasting his approach to scientific practice with Bachelard's. Whereas Bachelard is primarily interested in how scientific instruments help maintain the presence of a scientific rationality, Latour, by denying the a priori presence of scientific rationality, attributes a much wider variety of functions and meanings to them. He attempts to understand scientific instruments in their own right without explaining them away with reference to the rationality of the sciences. The importance attributed to scientific instruments becomes clear from the following statement by Latour and Woolgar: "[T]he observation of radioactivity is entirely dependent on the [gamma] counter" (1986, 64). In principle, this claim can still be understood in a sense when we take it to mean that the reality of radioactivity is constructed by how the gamma counter rationalizes its phenomenal appearance. However, as becomes clear in this chapter, Latour takes this statement to mean something different. Instead of attributing the construction of the reality of radioactivity to scientific rationality, Latour understands this process in terms of the specific efforts and skills of the scientists who use to the gamma counter, skills and efforts which, as demonstrated below, cannot be understood in terms of a detached scientific rationality.

\section{Ready-made Science and Science-in-the-making}

At the heart of Latour's picture of science is his refusal to attribute a special kind of rationality to the sciences that would distinguish them from other human affairs. Contrary to Bachelard, he does not presuppose any epistemological break between ordinary and scientific practices that can explain the rationality of the latter type. Bachelard argues for the importance of close analyses of scientific practices to challenge existing philosophical systems, but he primarily examined the scientific objects that were the end product of scientific practices. This is precisely the view of science that Latour criticizes when distinguishing between ready-made-science and science-in-themaking (cf. 1987, 4). He argues that we should understand science in terms of a Janus face. The left side of Janus says that when scientific facts are ready made, they appear as unquestionable, as undisputable properties of nature discovered by the proper rational method. However, the right side of Janus speaks when the facts are under construction and when it is undetermined what nature is and what is the proper rational method to access it. According to Latour, this latter process cannot be interpreted as guided by rationality of nature, because the meanings of terms such as "rational" are precisely what is at stake in science-in-the-making.

Latour argues that the reason that we should interpret scientific practices in terms of a Janus face is that established scientific facts are black boxes: things that "no matter how controversial their history, how complex their inner workings, how large the commercial or academic networks that hold them in place, only their input and output count" (Ibid. 3). However, black boxes can only function as such when remaining closed, and this is what happens when examining ready-made science. When opening these (i.e., when examining the science-in-the-making), we see that the facts of science are the product of controversies and that this process cannot be interpreted as guided by rationality 
of nature, because the meaning of terms is precisely what is at stake in science-in-themaking. In science-in-the-making, it is impossible to distinguish between context and content, such that the outcome of a controversy cannot always be understood without reference to the context in which it occurred. Thus, the closing of a controversy is caused by the messy relations between scientists, instruments, institutional concerns, and personal interests, and it is only when the controversy is gone that all of this disappears from view when becoming black-boxed.

\section{Black-boxing the Process of Science-in-the-making}

The central question of Latour in this regard is how the process of science-in-the-making can become black-boxed such that all the previous efforts cease to exist and that the products of science appear as if they have always been out there waiting to be found. In Latour's terminology, answering this question forces the opening of black boxes to uncover the networks that are responsible for the stability of scientific facts. Latour's starting point in treating this question is semiotic; he argues that statements are never factually true in themselves but become so in the hands of the later users of these statements, which he formulates as the central message of his Science in Action when stating that the essential point he wishes to make is that "the status of a statement depends on later statements" (Ibid. 27).

For example, Latour refers to how scientific articles use and qualify the work of others to clarify that it is only in later articles that the value of previous statement can be interpreted. The enrollment of other articles in turn makes it more difficult for outsiders to disagree with the conclusions of a paper. After all, how many individuals have time to work through all of the previous papers? According to Latour, this marks an important difference between scientific and ordinary statements; scientific literature "is made to isolate the reader by bringing in many more resources" (Ibid. 44). Scientists can simply put their hands on a larger amount of resources, which makes it increasingly difficult for the isolated reader to come up with a reasonable disagreement. In this view, the establishment of facts is not due to some form of rationality present in the science and absent in other practices but the consequence of the extreme sociality of the sciences. There can be no factuality without collectivity: "[Scientific] literature is so hard to read and analyze not because it escapes from all normal social links, but because it is more social than so-called normal social ties" (Ibid. 62).

The process of isolation is not primarily set in motion because scientific articles contain references to other scientific articles but more importantly because they contain visualizations of findings that make disagreement even more difficult. After all, so Latour holds, how can one disagree with something of which one can see that it is the case? This is where Latour locates the crucial role of instruments in scientific practice: "I will call an instrument (or inscription device) any set-up, no matter what its size, nature and cost, that provides a visual display of any sort in a scientific text” (Ibid. 68). For example, when being confronted with a brain scan showing brain activity in the frontal lobe, to disagree with the content of this scan requires disagreeing with the working of the scanner and with the experimental set-up of the researchers. And to be able to come well-equipped for this disagreement requires (i) being able to use instruments yourself and interpret the visualizations they produce and (ii) having the resources to build a counter-laboratory to convince others that they should put trust in your rather than in their instruments. Thus, in this view, technologies function to contribute to help establishing the factuality of scientific statements, and they do so by providing visualizations of observations that are increasingly difficult to disagree with.

In connection with Latour's argument that the truth of scientific statements is not yet there when examining science-in-the-making, he rules out "nature" as an explanatory factor when considering how controversies are solved. Just as science itself, nature is Janus faced: "Nature is the final cause of the settlement of all controversies, once controversies are settled, [but] as long as they last Nature will appear simply as the final consequence of the controversies" (Ibid. 98). From the perspective of science-in-the-making, Nature is only there after disagreement was made impossible, because no possible competitors can gather a sufficient amount of resources to allow them to continue their battle. In other words, nature, as the outcome of scientific practice, was never already there but is what is constructed in science-in-the-making.

\section{Phenomenotechnique and Science-in-the-making}

The idea that nature is never already there but is always what is constructed in scientific practice is a view that Latour seems to share with Bachelard, who argues that the objects that the sciences speak about are constructed in a phenomenotechnique. In Laboratory Life, Latour and Woolgar quote Bachelard approvingly when discussing how material arrangements (i.e., inscription devices) are constitutive of the phenomena of science. Consider the following lengthy quote:

"The central importance of [...] material arrangement[s] is that none of the phenomena "about which" participants talk could exist without [them]. Without a bioassay, for example, a substance could not be said to exist. The bioassay is not merely a means of obtaining some independently given entity; the bioassay constitutes the construction of the substance. [...] The artificial reality, which participants describe in terms of an objective entity, has in fact been constructed by the use of inscription devices. Such a reality, which Bachelard (1953) terms the "phenomenotechnique," 
takes on the appearance of a phenomenon by virtue of its construction through material techniques" (Latour and Woolgar 1986, 64, my emphasis).

Although Bachelard is quoted approvingly in the above fragment, it simultaneously reveals a major difference between Bachelard and Latour. For Bachelard, it would not make sense to speak about an objective entity that in fact is created through a phenomenotechnique. In Bachelard's view, it is evident that objective entities are created within a phenomenotechnique, because it is for this very reason that these entities can be called objective..$^{42}$ Only by creating an artificial reality against nature can notions such as "objectivity" be introduced; the presence of phenomenotechnique is a prerequisite for the construction of scientific phenomena in the first place.

When arguing that scientific entities are in fact artificially constructed within a phenomenotechnique, Latour and Woolgar juxtapose objectivity with construction. The separation of construction and objectivity implies a perspective suggesting that while the researchers in the laboratory act as if they are speaking about an entity that is objectively out there, they are in fact speaking about something that is constructed and does not exist outside of the structure of the laboratory and hence is not objectively out there. According to Latour and Woolgar, we should better understand "objective entities" as created through a material arrangement that provides "inscriptions which can be used to write papers or to make points in the literature on the basis of a transformation of established arguments into items of apparatus" (Ibid. 66). Thus, the phenomenotechnique is part of what Latour sees when opening the black box of a scientific fact; it disappears from view when examining ready-made science, while it has been of crucial importance when examining science-in-the-making.

This difference in the use of "phenomenotechnique" can be traced back to the different ways in which Bachelard and Latour think about the difference between scientific and ordinary practices. Bachelard considers scientific practices in terms of the rationalization of the real and of the phenomenotechnique as a prerequisite for both the rationality of science and the possibility for empirical observation in science. The phenomenotechnique realizes an epistemological break with ordinary practice, thereby giving rise to the rationality and objectivity of the sciences. According to Latour, however, the rupture between science and everyday life and the supposed rationality and irrationality accompanying these different situations cannot be assumed but must be explained. From this perspective, Latour's phenomenotechnique should be understood as an instrument offering inscriptions in a visual form. In doing so, the phenomenotechnique

42 See, for example, Bachelard (1949a, 1968, 2002). contributes to the coming into being of the black box by constructing inscriptions that narrow down the possibility of disagreement. In other words, Latour understands the phenomenotechnique as mediating how scientific facts become black-boxed, thereby pointing to importance of scientific instruments in science-in-the-making.

\section{\$5.2 LATOUR'S “CRITIQUE” OF CRITIQUE: HOW TO AVOID A} METALANGUAGE?

Should we understand Latour's refusal to attribute a special kind of rationality to scientific practices as a critique on the scientific enterprise at large? Yes and no. What he does criticize is the idea, found, for example, in Bachelard's epistemology, that there are a priori reasons to distinguish between scientific and non-scientific practices. Latour's criticism of Bachelard can be connected to Latour's idea that no metalanguage or rationality should be used to account for the differences between scientific and everyday practices. As demonstrated above, Latour instead holds that the sciences are not more rational than other practices but that they are more social. Scientists must enroll an enormous amount of resources to make their work credible. It is this social dimension that marks the most important difference between scientific and everyday practices. However, Latour refuses to see this sociality as a meta-principle through which the functioning of scientific practices can be explained. The "social" is not already there to subsequently afford a structure but is the outcome of what Latour observes when closely studying how facts come into being. That is, he refuses to replace the metalanguage of rationality with that of the social. Latour anticipates that his specific understanding of the "social" might confuse scholars interested in developing sociological explanations of science. An imaginary reader might therefore respond by asking,

"What do you mean 'social'?" [...] Where is capitalism, the proletarian classes, the battle of the sexes, the struggle for the emancipation of the races, Western culture, the strategies of wicked multinational corporations, the military establishments, the devious interests of professional lobbies, the race for prestige and rewards among scientists? All these elements are social and this is what you did not show with all your texts, rhetorical tricks and technicalities!" (Latour 1987, 62).

When closely examining the researchers engaged in science-in-the-making, abstract concepts such as "capitalism" belonging to specific metalanguages are not observably present in the relations between scientists. Similarly, when approached from a Latourian perspective, the possibility of also referring to "technology" as a structure determining how science-in-the-making occurs is ruled out. Would the absence of any metalanguage 
not suggest that there is no language at all through which we can understand scientific practices?

To understand why Latour refuses to speak about science through any metalanguage and still believes that there is a language to speak about science, it is necessary to understand how he situates the value of his own work through a discussion around the notion of "Critique." Discussing this notion allows for two things: (i) showing how Latour, based on the work of Michel Serres, positions his own work against the tradition of Enlightenment critique and (ii) exploring the value of postphenomenological descriptions of humantechnology relations in scientific practice and understanding the importance of describing those.

\section{Enlightenment Critique as Denying Hybridity}

As Graham Harman has remarked, Latour's most important “criticism” of critique is that it makes things less real, while its goal is to make things more real (cf. Harman 2004, 120). This loss of reality is, according to Latour, grounded in what he calls the Modern Constitution: the idea that things and objects are either natural or social, that they either belong to the purity of science or to the messiness of the social world (cf. Latour 1993b, 35-38). However, as Latour painstakingly attempts to show, entities can never be placed in either of the domains. They are hybrids, continuously oscillating between the two domains, and can never be explained in terms of either of them. The logic of the "either/or" opens up a limited domain in which the actual objects of science cannot have a place, yet the Critique philosopher forcefully puts them in the natural domain. Latour understands this philosophical endeavor in terms of a process of elimination instead of a process of clarification.

Latour exemplifies his position with reference to the tradition of literary criticism. Because the repertoire of the text is much larger than the vocabulary of the critic allows for, parts of the text necessarily disappear when analyzed: "With one word in the critic's repertoire, for instance 'Oedipus' complex,' you can explain four dozen novels and five hundred plays" (Latour 1988a, 88). Crucial for Latour is that this "explanation" is in fact an "elimination" that puts itself in a position of domination towards the text through which large aspects of the text disappear in favor of a single explanatory principle (e.g., the Oedipus complex). Similarly, calling Lucretius's De Natura Rerum a poem is to place it in the domain of irrationality and position it against the rationality of contemporary physics. Through this criticism, the potential scientific character of the text is thus eliminated. According to Latour, Michel Serres is one of the few philosophers who successfully escape this eliminative form of criticism:
"He does not use one metalanguage, but many, and he does not substitute his commentary for what he is commenting on. Instead of mobilizing the referent inside the text as scholarly works do-by footnotes, descriptions, pictures, diagrams, instrumentations, allusions-Serres inserts his texts as a legend for us to read our world" (Ibid. 97).

When involving a metalanguage, the process of destroying the text is set in motion by restricting it to only one of the many aspects through which it exists. Texts are hybrids, at one point appearing as scientific, at another point as literary, and at yet another as political. None of these adjectives are ultimately explanatory of the text's content, but they rather should be understood as potentialities through which texts can add meaning to the world. Because these potentialities are always altogether simultaneously present in a text, Serres understands text as hybrid. The task of the philosopher (or the commenter on the text) is to highlight the hybridity of the text and show the possible ways in which texts add meaning to reality. In doing so, a new text is produced, which in its turn can also be understood as a new hybrid that is added to reality.

In Latour's view, the hybrid character of texts can be extended to all entities. Therefore, developing a legend is not restricted to texts but can also be extended to the study of practices and of what technologies do in them. And it is precisely because of this hybridity that no metalanguage can be used to explicate the "true" character of how these hybrids come into being. In analogy with Latour's remarks concerning texts, we can say about the relation between critic and practice that the critic's vocabulary is too limited to highlight all aspects of the richness of the practices. This is why Latour dismisses explanations of scientific practices that state that science is "rational" or "social"; either of these adjectives destroys part of the practice that is supposed to be revealed. The practice of constructing facts is simply too rich to be described as either a rational or a social process.

\section{How Science Adds to Reality}

Following Serres and Latour, we can say that scientific practices therefore add something to reality. In Latour's view, the primary thing that scientific practices add to reality is factual statements. Latour clarifies this process of addition with reference to Whitehead's discussion of the bifurcation of nature with reference to how scientific explanations increase the possibilities in which sunlight can be described: "For us the red glow of the sunset should be as much part of nature as are the molecules and electric waves by which men of science would explain the phenomenon" (Whitehead 1920, 28-29 op. cit. Latour 2004, 244). From this perspective, reality has increased through scientific developments, rather than its having eliminated other possible relations with the sun. 
This possibility of what Whitehead has called the bifurcation of nature is used by Latour to dismiss the value of phenomenology: "The solution to this bifurcation is not, as phenomenologists would have it, adding to the boring electric waves the rich lived world of the glowing sun" (Ibid. 244). In other words, the phenomenologist also follows the either/or logic of Enlightenment critique, by arguing that we, depending on the situation, relate to the sun either through science or through our richer lived experience, thereby contrasting facts and experiences. If nature is indeed bifurcated, a clear separation between these two domains can never exist because nature is always both simultaneously.

While this criticism seems to apply to phenomenological thinkers who indeed strictly distinguish between the world of science and the lifeworld, the postphenomenological emphasis on the fundamental intertwinement between science, technology, and the lifeworld seems to escape Latour's criticism. Indeed, if we must understand our relation to the world in terms of human-technology relations, there is no isolated lifeworld existing independently of the products of science or the presence of technologies (cf. Ihde 1990). As a consequence, it is impossible to prioritize either "science" or "the lifeworld" when understanding how human beings understand reality. In postphenomenology, the bifurcation of nature is not part of its presuppositions, as human beings necessarily experience the world through the products of scientific practices.

As I highlight only briefly for the moment but flesh out more fully below, adding a postphenomenological perspective to Latour's descriptions of scientific practices allows us to do two things. Firstly, it allows us to understand what the products of science add to reality in terms of the meaning that they add to it, which opens up the possibility to understand these additions in terms of hermeneutics. Secondly, in doing so, technologies in scientific practice can also be understood as adding meaning to reality and as extending the things that scientists can relate to. This opens up the possibility to specifically investigate human-technology relations in scientific practice, without interpreting the workings of technologies in relation only to the construction of facts.

We have seen that if we interpret nature as bifurcated, there is no need to assume that reality can be divided into a domain that is "social" and "experiential" and one that is "scientific" and "rational." This position does not necessarily force one to become a relativist with regard to the validity of scientific knowledge but rather circumvents debates between scientific realists and relativists/social constructivists. Latour clarifies this by referring to the complexity of the entities dealt with in the sciences that is not recognized in philosophical debates concerning scientific realism:
"Philosophy never deals with the sort of beings we in science studies have dealt with. And that's why the debates between realism and relativism never go anywhere. As Ian Hacking [in The Social Construction of What? (1999)] has recently shown, the engagement of a rock in philosophical talk is utterly different if you take a banal rock to make your point (usually to lapidate a passing relativist!) or if you take, for instance, dolomite, as he has done so beautifully" (Latour 2004, 234).43

If we took scientific objects such as dolomites and human cognition as a point of departure, we would encounter complex entities about which we could unproblematically say that they are constructed, contrary to about, for example, ordinary objects such as rocks and pieces of wood. This is not to say that these objects do not "really" exist but rather to emphasize that for these things to exist, much work must be done. For example, to observe the cognitive function of human beings, scientific instruments must be used, participants must be gathered and rightly prepared, an experimental set-up must be carefully managed, statistical analyses must be performed, images must be discussed with colleagues, and after all this has been done, a neuroscientist can maybe finally claim to have "seen" a relevant scientific object. The end product, the scientific object, is at the end of a chain of previous relations that have allowed it to come into being. This implies that in scientific practice, knowledge and reality are simultaneously co-produced (cf. De Vries 2016, 48).

This relational conception of scientific phenomena resembles Bachelard's notion of phenomenotechnique, which expresses that the existence of scientific phenomena depends on their relationship with scientists, experimental set-ups, technologies, and earlier scientific theories. However, as demonstrated above, while Bachelard assumes a scientific rationality providingstructure to the phenomenotechnique, nosuch structuring principle is present in Latour's work. The relations within the phenomenotechnique must be mapped and interpreted in terms of their own relationality without reference to an external explanatory principle. Each relation adds something to reality: a new inscription, a new ally, a new relation, a new possible meaning.

\section{\$5.3 THE CONSTRUCTION OF SCIENTIFIC ENTITIES: PASTEUR'S MICROBES}

In The Pasteurization of France, Latour states that he aims to "follow the mechanisms that

43 For an analysis for the rhetorical strategies behind the many references to rocks and tables in debates concerning scientific realism, see Edwards, Ashmore and Potter (1995). 
may allow me to understand at once the content of a science and its context" (Latour 1988b, 12). In this section, I examine how Latour develops a view of science in which the distinction between content and context disappears. To do so, I show how Latour redefines the notion of "laboratory" to understand how the microbes of Louis Pasteur came into being.

Pasteur's "discovery" of microbes is a key case study in Latour's oeuvre. The question he searches to answer through this study is how a new entity was added to reality through which it became clear that "there are more of us than we thought" (Latour 1988b, 35). As demonstrated in the previous section, Latour does not wish to attribute the coming into being of this new entity to either the brilliance of Pasteur, who had finally discovered what had always been there, or as the outcome of political and social forces that had a specific interest in Pasteur's work and would benefit from microbes to enter society. Indeed, if content and context really merge, we can no longer set up a dichotomy between the "scientific" and the "social," nor between "internal" and "external" explanations of scientific discoveries.

\section{Debunking the Modern Constitution: Pasteur's Extended Laboratory}

According to Latour, the false dichotomies of the Modern Constitution are grounded in a mistaken understanding of what a laboratory comprises. An internal explanation of the coming into existence of microbes would be something like this: Pasteur makes a discovery in his laboratory, which is subsequently transmitted to society, thereby adding an extra element to it. In an external explanation, social and political forces actively create interest in Pasteur's work, and it is these forces that are responsible of welcoming the microbe into society. This would imply that microbes were either created in Pasteur's laboratory or that they were created outside of it. For Latour, both of these explanations are mistaken. The former reduces scientific practice to ready-made science, while the latter is unable to see that the interest in microbes is "the consequence and not a cause of Pasteur's efforts to translate what they want or what he makes them want" (Latour 1983, 144). Latour attempts to escape these either/or explanations by showing that Pasteur's laboratory itself is a place in which the social context and the scientific content of his work merge.

Instead of stable places of "splendid isolation," laboratories must be understood as unstable processes that must constantly be able to convince their own relevance. In doing so, they destabilize the interests of the others they wish to convince. Latour presents the story of Pasteur and the discovery of microbes by discussing the interrelation between the interests of the hygienists, the solving of practical problems in society, and the experiments of Pasteur and his cooperators. While his discussion ultimately focuses on the success of Pasteur, I focus primarily on the questions of how microbes came into being and how they were recognized as a new element of reality. In doing so, I approach Latour's work as an account of how a new object through which human beings can relate is added to reality.

In the second half of the $19^{\text {th }}$ century, France was suffering from a contagious disease stemming from an unknown source that was referred to as "morbid spontaneity." This disease was characterized by an enormous uncertainty, and it occurred in almost every element of society. Most of the people traveling to foreign countries came back healthy; most of the midwives did not kill their client's babies; most of the wounds of people did not get infected; most cattle remained healthy and could be used for farming. However, in some cases, the opposite occurred, causing sickness, death, and rotten portions of food needing to be thrown away. In the absence of a plausible explanation for these sudden tragedies, this disease was treated as appearing spontaneously (cf. Latour 1988b, 32-34).

Several scientists were studying the cause of this disease in their laboratories, Pasteur among them. Without the presence of any regularities in its appearance, it seemed almost impossible to understand this disease in terms of a cause instantiating an effect in all these cases. Yet, this was exactly what occurred when Pasteur and his cooperators started to understand all of the irregularities in terms of microbes. However, microbes could only be observed in a controlled environment, which greatly diverged from the variety of circumstances in which people got sick. When microbes were indeed an extra layer of reality, Pasteur had to show not only that he could observe microbes in his controlled environment but also that they existed and played the important role Pasteur ascribed to them outside of this controlled domain. Only in this way could an extra invisible element be added to reality that allowed the explanation of both the cause of "morbid spontaneity" and the variety of occasions in which it occurred.

Latour argues that we can only understand how microbes became part of our reality when giving up the strict distinction between the inner domain of the laboratory and the outside domain of the society. Initially, microbes did only exist in the laboratory, because studying the properties of microbes required transporting them from the conditions in which they caused diseases to another. Pasteur needed another environment that "was an ideal one for the microbe, since for the first time since the existence of microbes in the world they were allowed to develop alone. It was also an 'ideal' condition for the observer, since in developing so blithely, the microbe, freed from the competition of other living beings, made itself visible by increasing and multiplying" (Ibid. 63). However, it is only when microbes are considered to exist everywhere, rather than only under specific laboratory conditions, that an extra element is added to reality. In Latour's words, "[A] laboratory microbe is not yet a 'contagious ferment”' (Ibid. 63). 
But how to understand the relation between the microbes in Pasteur's laboratory and the contagious ferments that were causing sickness? In one way or another, Pasteur had to clarify that we were speaking about the same thing in these two situations. Latour describes this in terms of the creation of an equivalence between a controlled laboratory environment and the mess of actual sickness. The equivalence of the two is not a priori given, but Pasteur actively must show that microbes act similarly under different circumstances. This creation of equivalence can be readily observed in how Pasteur linked his microbes to the existence of the so-called anthrax disease. This disease caused the death of a large part of French cattle, causing great concern among French farmers and veterinarians (cf. Latour 1983, 144). As a form of "morbid spontaneity," the anthrax disease had a variety in which no clear pattern could be detected, and it was thought that the disease defied explanation in terms of a single cause.

Yet, proposing this single cause explanation based on his laboratory studies was exactly what Pasteur would do. But how did he succeed in convincing others that microbes not only existed in his laboratory but also caused the death of cattle on farm sites? According to Latour, because Pasteur constantly showed the relevance of his laboratory in a variety of places, farmers and veterinarians were forced to move through Pasteur's work when attempting to cure the anthrax disease. In other words, Pasteur actively showed that his laboratory and the farm sites were indeed equivalent places when microbes were concerned and that his laboratory could change the circumstances of the farm site by managing the behavior of microbes. Thus, he showed (i) that his laboratory was of interest to the farmers and (ii) that only in the laboratory could a position of domination over microbes be maintained.

When Pasteur solved the problems of the farms, he needed to show not only that he could dominate the anthrax disease in his laboratory but also that his experiments could help prevent the outbreak of disease at farm sites. "Here, the problem is to find a compromise that extends Pasteur's laboratory far enough-so that the vaccination can be repeated and work-but which is still acceptable to the farming representatives so that it is seen as an extension of the lab science outside" (Ibid. 151). Again, an equivalence between the farm sites and Pasteur's laboratory had to be created, ensuring that the same microbes did the same things in two previously different situations. When this equivalence is created, the farm site has become a laboratory, and only because of this is it possible to show that microbes are the cause of the anthrax disease. Only by extending the laboratory to the farm sites can a situation in which "wherever the veterinarian comes the small parasite [microbe] has to go" (Ibid. 154) come into being. At this point, it is no longer possible to distinguish between what is laboratory and what is not or between what is scientific and what is social.
Latour's purpose when explaining Pasteur's success in this way is to debunk the myth of the isolated scientist, in that through his participation in a transcendent rationality, he can discover what has always been there, on the one hand, and the idea that scientific discoveries are entirely dependent on social forces, on the other. Rather, Pasteur's microbes became real not because they were suddenly there but because they interacted with other aspects of the world in which they played a crucial explanatory role. It is only because of their content that microbes act in a certain context, and it is only in this context that microbes can display their content. Only in actively constructing the existence of the microbe did it become possible to ascribe certain actions to them, and only by constructing equivalence was Pasteur capable of showing that the same element acted in two different situations.

\section{\$5.4 SCIENTIFIC INSTRUMENTS AS INSCRIPTION DEVICES AND THE CONSTITUTION OF NEW ENTITIES}

In this section, I show which role Latour ascribes to scientific instruments in laboratories when conceptualizing them as inscription devices that produce immutable mobiles. I end with a critical note suggesting that Latour's approach to science-in-the-making requires that certain facts are already there of which their coming into existence can be retrospectively analyzed. I argue that it is because of this retrospectivity that scientific instruments are identified as inscription devices and suggest that their role can be better analyzed when approached from a hermeneutic perspective.

\section{Scientific Instruments as Inscription Devices that Create Immutable Mobiles}

In Latour's story about Pasteur's microbes, scientific instruments and the material context in which scientists work play only a minor role. Although the notion of "laboratory" suggests the existence of a place in which scientists talk with each other, make observations using a variety of instruments, and carefully develop an environment in which phenomena can be controlled, Latour seems to use it primarily in a metaphorical sense. In other words, his narrative needs a laboratory in which microbes did exist for the Pasteurians because they can be isolated and visualized, in contrast with the farm sites, where the microbes remained invisible. Latour suggests in several places that there is something specific to laboratories that allows for establishing a specific relation with phenomena, yet-for reasons described above-he refuses to call this relation "scientific." However, he does single out something that is specific to laboratories when explaining what Pasteur did in his laboratory: "Why did Pasteur gain strength in the laboratory? He did so because there, as in every laboratory, phenomena are finally made smaller than the group of men who can then dominate them" (Latour 1988a, 74). Whereas at the farm site, 
the entire environment is dominated by the invisible microbe, the laboratory creates a new environment in which the tables are turned, a where the microbe has become visible to a scientist who relates to it through a microscope.

Latour highlights as the central force of the laboratory and its equipment that through it, microbes are objectified and individualized because their behavior in specific circumstances and reactions to changes in these can be carefully monitored. The power of the laboratory strongly depends on scientific instruments that Latour conceptualizes as inscription devices. Their function is defined as follows: "No matter the size, cost, length, and width of the instruments they build, the final end product of all these inscription devices is always a written trace that makes the perceptive judgment of the others simpler" (Latour 1983, 161). Through these devices, Pasteur can manage the behavior of the phenomena under study: "[T]hey are experts inside their own walls at setting up trials and instruments so that the invisible actors-which they call microbesshow their moves and development in pictures that even a child would see them. The invisible becomes visible and the 'thing' becomes a written trace they can read at will as if it were a text" (Ibid. 163).

This notion of manageability is further specified in the idea that inscription devices not only organize perceptions but also create an immutable mobility. Because of this, inscriptions can travel from one place to another without being subject to change. Latour exemplifies this with an example taken from the history of cartography. In the $18^{\text {th }}$ century, the French naval officer Jean-François de la Pérouse traveled through the Pacific to bring back a better map of the location of Pacific islands for Louis XVI. As Louis XVI himself did not travel by sea, his knowledge of Pacific topography depended upon what De la Pérouse brought back to him, something that should remain stable between the Pacific and the Versailles. The only way to do so was by creating a map-that is, an immutable mobile-through which something new was inscribed that was stabilized and could move without being destabilized (cf. Latour 1986, 7). The spatio-temporal distance between the place where the inscription was developed and the place where it acted was overcome by this immutable mobility. While Latour primarily discusses this in terms of cartography, we can see a similar process at work when scientists graphically visualize their experimental findings, which readers encounter in scientific papers.

\section{Scientific Instruments Beyond Inscription Devices: How Do Instruments Add to Reality?}

Does this analysis of laboratories as sites where instruments are built that function as inscription devices exhaustively analyze how scientific instruments contribute to the coming into being of new scientific objects? Of course, the behavior of phenomena must be carefully managed to become interpretable, but understanding this management process does not explain why and how a specific kind of phenomenon is studied. For example, Latour makes perfectly clear how the microbes where transferred from Pasteur's laboratory to the environment of the farm sites and shows how this environment changes with the introduction of microbes. However, he does not pay attention to how microbes came into being in the first place or why the Pasteurians would make them a candidate cause for "morbid spontaneity." Because of this, how scientific instruments allowed the Pasteurians (and eventually also farmers and French society in general) to relate to the world in a new way with the introduction of the concept "microbe" remains unanalyzed. Accordingly, Latour's analysis does not capture why microbes, rather than something else, were added to reality.

Latour's lack of attention to how the possibility arose to interpret the epidemics in French society in terms of microbes is one criticism made by Simon Schaffer in his review of The Pasteurization of France: "Latour systematically understates the work of experiment. Experimental labor is neglected in Les Microbes [The original French version of The Pasteurization of France] because the book's narrative is marked by the heresy of hylozoism, an attribution of purpose, will and life to inanimate matter, and of human interests to the nonhuman" $(1992,182)$. Schaffer uses Latour's interest in the nonhuman as a critique of his supposed lack of interest in the human, and especially as a lack of interest in the relation between Pasteur's and other scientists attempting to work on a cure for the French epidemics. However, Latour's "hylozoism" can also be read as an attempt to extend the domain that is of interest for a philosophy of science that takes the role of technologies seriously.

What Schaffer interprets as hylozoism-as the anthromorphization of inanimate matter-has a less problematic connotation if we understand how Latour speaks about the "acts" of microbes in terms of his semiotic approach and his idea that nonhumans and humans always are part of networks in which they have a relation to one another. For example, when microbes were seen as responsible for the sick cattle, veterinarians and farmers had to engage in different practices than they had previously. The network between cattle, veterinarians, and farmers changed with the introduction of microbes; it is in this sense that they should be understood as actors-or as actants, in Latour's terminology. From this perspective, we need not say that the microbes have the will to change practices, do so intentionally, or possess certain interests in different practices but simply that their existence instantiated change. The situation after the introduction of microbes is different from the previous one, and this is how Latour conceptualizes the "actions" of microbes.

When action is understood in this minimal sense, we need not attribute specific human 
characteristics to nonhumans such as microbes and other material devices. However, the revolutionary move that Latour makes is that he also refuses to attribute a specific form of agency, will, or freedom to human actors. He proposes a symmetric understanding of humans and nonhumans in terms of the minimal semiotic definition of action (e.g., Latour 1987,144$)$. This symmetry is reflected in how he interprets both humans and nonhumans as "actants." The consequences of this equal treatment of nonhumans and humans is not explicitly worked out in Latour's analyses of scientific fact-making but forms an integral part of how he analyzes the role of artifacts in our society. Not only microbes but also mundane artifacts such as chairs, tables, and hammers can be understood as actants. The presence of a speed bump creates a different traffic situation than a perfectly asphalted flat highway would. In this brief example, we can already see how these different artifacts (perfectly flat asphalt vs. a speedbump) act, in the sense that they instantiate the presence of specific practices. While the speedbump asks cars to slow down, the flat asphalt asks cars to speed up, thereby creating two entirely different traffic situations in which different rules apply.

Can we also understand how artifacts and instruments function within a scientific context as instantiating new scientific practices, which open up new ways of acting in the world? In Latour's understanding of scientific instruments as inscription devices, which may include technologies, a prior existing framework that must be inscribed is already assumed. Even if we accept how he analyzes laboratory practices as creating inscriptions that have an immutable mobility, we must acknowledge that a Latourian analyses does not address how the content of the inscription itself is formed. However, the inscribed is also not already there but must be actively worked upon. For example, a brain scan depicting the relevant brain networks for a specific human cognitive task assumes that scientists (i) already understand what "cognition" is, which is (ii) accessed in relation with a specific technology. The interaction between these two elements in the creation of an interpretational framework to understand human behavior is absent in Latour's work, yet it must be understood if we wish to understand how scientists, and subsequently also other human actors, acquaint themselves with a specific understanding of reality.

In the remainder of this chapter, I hope to show that nonhumans can also be understood as actants in a relevant sense in the creation of a specific understanding of reality (i.e., in terms of what is inscribed in the inscription device). As is demonstrated, this requires a reconceptualization of the Latourian understanding of science-in-the-making, which allows for an understanding of how nonhuman actants in general, and technologies in particular, allow for the instantiation of new practices, in which scientists can develop a new understanding of reality. In doing so, technologies will be conceptualized as helping to instantiate new scientific practices, because they allow scientists to encounter new experiential phenomena. This understanding of technologies allows for a merger between Latour's semiotic approach and a postphenomenological approach to scientific practices.

\section{\$5.5 SCIENCE-IN-THE-MAKING AND SCIENCE-AS-IT-HAS-BEEN-} MADE

At the start of this chapter, I introduce Latour's idea of science as being Janus-faced: the left side of the Janus face speaks in the name of ready-made science, while the other side speaks in the name of science-in-the-making. On the one hand, scientific facts are unquestionable when ready made and then become heralded for being exemplary of a specific form of scientific rationality. On the other hand, however, when examining science-in-the-making, in which facts are not yet there, the rational method to be used when doing scientific research is at stake. This discrepancy explains Latour's interest in analyzing how facts and scientific objects are constructed in science-in-the-making. But when and how is science being made?

According to Latour, to answer this question, we should return to the moment before a clear distinction between content and context can be made (Latour 1987, 5). Ready-made science speaks about facts that embody a uniform content that is sharply distinguished from the context in which they have developed. In Latour's terminology, when confronted with ready-made science, we are confronted with black boxes. However, in science-in-themaking, these boxes are not closed yet. This forces to ask the question: "[H]ow are we going to account for the closing of the boxes, because they do, after all, close up?" (Ibid. 7). Science is being made before the black boxes are closed, and in this stage, there is no clear distinction between what is factual and what is not.

Latour's approach presupposes the existence of a specific black box, of which the process of making can be retrospectively analyzed. For example, it requires that the existence of Pasteur's microbes is no longer questioned to start to understand the conditions by which they became unquestionable. As Latour has shown, the coming into being of microbes required a strong network that made it impossible to question that infection and diseases were caused by invisible microbes. Understanding how microbes came into being thus requires deconstructing the network in which microbes are stabilized and unraveling the relation between the actants that hold the network in place. This method of analysis has become a primary approach in STS, under the header of ANT.

In this section, I critically discuss the notion of "network" in Latour's philosophy and identify the limits of this deconstructionist approach. In doing so, I show how Latour's 
analysis of what he calls science-in-the-making boils down to an analysis of science-asit-has-been-made, because it is limited to the post-hoc deconstruction of networks that construct scientific facts. Subsequently, I argue that a philosophy of scientific practice that is not limited to Latour's specific question concerning the construction of facts opens up the opportunity to actually analyze science-in-the-making. This requires considering how scientists are capable of experiencing new phenomena that are potential candidates of becoming ready-made science.

\section{The Notion of Network}

As demonstrated in the previous sections, Latour interprets scientific discoveries in terms of the construction of factual statements that come into existence when being stabilized within networks of actants. We have also seen that the term "actant" encompasses both humans and nonhumans and interprets how actants "act" in terms of their relation(s) with other actants. These relations form a network in which new facts and entities come into being. But how do relations between actants allow for stabilizing the existence of something else: of microbes, of new facts? Latour attempts to understand this relationality as an "actor-network," giving rise to a central theoretical approach in STS, under the header of ANT. A crucial inspiration for this theory is Deleuze's and Guattari's term rhizome (cf. Latour 1999a, 1999b). I discuss this concept in more detail to establish the Latourian idea of network as expressing a dynamic, rather than a static, relation between actants.

Repeatedly, Latour argues that he regrets that he decided to refer to a set of relations between actants as a network (e.g., Latour 1996, 1999b, 2005). He urges his readers to refrain from understanding networks in terms of their common technical meaning in the sense of train or telephone networks that are strategically stabilized to fulfill a specific goal, for example, travel or communication. Furthermore, he stresses that we should not understand networks in terms of social relations between human individuals, because networks do consist of actants, not of humans, and because, as demonstrated in this chapter, the social relations between individuals can never be used as an explanatory models in Latour's work. If not in these ways, how must we understand his notion of network?

In his paper On Recalling ANT, Latour links his notion of network to Deleuze's and Guattari's term rhizome, which, contrary to the ordinary technical meaning of network, "meant a series of transformations-translations, transductions-which could not be captured by any of the traditional terms of social theory" (Latour 1999b, 15). There is no possible social explanation outside of the rhizome, nor can it be understood in terms of the goal-oriented nature of technical networks. Rather, as this quote suggests, we should attempt to investigate how the different actants continuously transform each other in their relations with one another. Deleuze and Guattari use the term rhizome to emphasize that we should not attribute any substance to individual entities but only examine how entities relate to other entities that also only attain their meaning in relation with other entities. In other words, entities only exist insofar as they are multiplicities, insofar as they relate to other multiplicities. According to Deleuze and Guattari, philosophy should reveal multiplicities, against the tendency to interpret entities as individual substances: as subject or object, as one or as many. They argue,

'The multiple must be made, not by always adding a higher dimension, but rather in the simplest of ways, by dint of sobriety, with the number of dimensions one already has available-always $n-1$ (the only way the one belongs to the multiple: always subtracted). Subtract the unique from the multiplicity to be constituted; write at $n-1$ dimensions. A system of this kind could be called a rhizome' (Deleuze and Guattari $1987,6)$.

Let me attempt to make this fragment comprehensible by relating it to Latour's refusa to explain events in terms of any metalanguage (such as the social, or the scientific). To reveal the multiplicity of entities, we must not explain their coming into existence in terms of a higher principle that reduces the entity to something else. For example, we must not attribute the "discovery" of microbes to Pasteur's genius but should aim to reveal the multiplicity of factors through which microbes could come into existence. In other words, we should subtract the unique factors (e.g., Pasteur's laboratory set-up, the interests of the farmers, the political interests of the Hygienists) from the seemingly uniform microbes to make them visible. It is in this process of dismantling that we can see how different heterogeneous entities transform each other, which allows for the coming into being of the microbe: a new multiplicity that embodies the transformations of the heterogeneous. It is in this sense that the absence of a metalanguage reveals what Deleuze and Guattari call the multiplicity of entities and the relations between them.

When attempting to explicate more clearly how rhizomes should be understood, Deleuze and Guattari turn to a biological metaphor: "We form a rhizome with our viruses, or rather our viruses cause us to form a rhizome with other animals" (Ibid 10). Again, let me attempt to make this clearer with reference to Latour's work: before Pasteur's microbes, people and cattle got sick because of what was known as "morbid spontaneity," thereby forming the relation between human beings and between human beings and their environment in a specific way, largely characterized by the uncertainty of the spontaneity of a fatal disease. When microbes were presented as the cause of this disease, a situation in which the disease was no longer understood as spontaneously arising, the relations between human beings and between human beings and the 
diseases were altered (i.e., a different rhizome with different viruses and animals came into being). In other words, the relation between those elements was transformed when microbes became an explicit part of how human beings related to their viruses and to other animals; with the introduction of the microbe, the network through which human beings related to their environment changed, which can be revealed by showing how the multiplicity is transformed.

This understanding of networks as rhizomes differs from both the common technical understanding of network and from an understanding networks in terms of social relations, because there is neither an a priori goal-orientedness nor an a priori sociality assumed. How actants orient towards one another should be understood in how they transform each other within the network through which a shared world comes into being. According to Latour, the notion of rhizome reveals that all actants have a world-making capacity insofar as they transform other actants (Latour 1993a, 131). Accordingly, insofar as networks should be understood as continuous transformations of actants, humans and nonhumans are of equal importance within these rhizomes. When methodically revealing the multiplicity of actants that hold a network together, a method that does not a priori distinguish between humans and nonhumans must thus be found. Latour argues that this methodological principle requires a semiotic approach (cf. Latour 1988b, 1993a, 1999, 2005).

\section{Latour's Semiotic Approach and its Limits}

Latour's specific take on semiotics becomes most clearly visible in relation to his analysis of Pasteur's microbes. He primarily situates his take on semiotics as a consequence of his methodological principle that does not allow deciding beforehand which actants are important and which are not:

"The fact that we do not know in advance what the world is made up of is not a reason for refusing to make a start, because other storytellers seem to know and are constantly defining the actors that surround them-what they want, what causes them, and the ways in which they can be weakened and linked together" (Latour 1988b, 10).

Semiotics offers Latour the desired entry point that allows him to reveal the acts of actants without presupposing anything but their own goals and intentions and how these transform and are transformed by other actants. Two concepts borrowed from semiotics are crucial in Latour's methodological approach to understand these transformations: (i) the interdefinition of actors and (ii) the chains of translations (Ibid. 11). "Interdefinition" is a concept that Latour takes from the Lithuanian linguist Algirdas Grimas, which expresses how particular actions situate themselves within a context and which this particular situating allows one to understand the relation between actor and context (cf. Høstaker 2005). More concretely, we can say that interdefinitions show how actors are shaped by the networks they are part of. This still suggests a primacy of the context of the network over actions, but by adding the idea of translation, Latour clarifies that there is no rigid network that shapes the actant's actions but that the network is also shaped by the translations made by the relations between actants.

Examining interdefinitions and translations allows Latour to understand how an actornetwork is stabilized, dependent on the already acquired stability of the network in which a heterogeneity of different actants can be shown to have transformed each other in their mutual relations. This semiotic approach is fruitful insofar as one is interested in what generates the stability of networks when this stability is not to be attributed to factors that are external to the network. This is what Latour calls the distinctive feature of his interest in networks, which came to be known as ANT:

"Whereas, for the sociologists of the social, the great virtue of appeals to society is that they offer this long lasting stability on a plate and for free, our school views stability as exactly what has to be explained by appealing to costly and demanding means" (Latour 2005, 35).

In other words, the central question of ANT is how networks attain stability if we can no longer pretend that stable external factors such as "social" or "rational" exist that fulfill this task (cf. Latour 2005, Law 2007). Semiotics is specifically invoked to answer this question, as it allows the analyst to enter the world of the actors and the networks that they are part of without arriving with his own presuppositions. In the language of Science in Action, we must semiotically approach science-in-the-making to understand how readymade science is constructed. In other words, there should first be the existing stable framework of ready-made science that needs explanation. Actor-networks are explanatory devices that allow for retrospectively understanding how specific utterances have been constructed as facts and how specific entities have been constructed as signifiers.

The interpretation of science-in-the-making in terms of ready-made science is why scientific practices are primarily understood as fact-making practices. Latour takes the current existing order as a starting point and aims to reveal the fluid networks through which this order appears. But why should we assume that the actions performed in scientific practices are (only) structured around fact construction? Furthermore, if science adds new entities to the world to which human beings can relate, why not attempt to understand how scientists are allowed to relate to something new? These novelties will indeed transform networks and come into being within a specific network, 
but their birth need not necessarily to coincide with the birth of a potential new fact. While Latour interprets scientific practices as participating in processes in which black boxes are closed, another way to examine them is by understanding them as processes in which new interpretations of reality are opened. In other words, scientific practices can be interpreted as practices of emergence as well.

\section{Understanding Science-in-the-making Hermeneutically}

The limits of Latour's approach can be conceptualized in terms of the distinction between "science-in-the-making" and "science-as-it-has-been-made." Latour takes the external reference frame of ready-made science that needs explanation as the starting point of his analysis into scientific practice and is interested in how ready-made science has been made. However, when examining scientific practices as practices in which new unstable objects emerge, we can no longer point to a stabilized referent that needs explanation. From this perspective, scientific practice seems not to be completely reducible to how its end-products come into being and become part of reality. This aspect of scientific practice, in which new phenomena emerge, is what I shall call science-in-the-making and contrast with science-as-it-has-been made.

The phenomena that scientists relate to do not come into being spontaneously but emerge within observational and experimental circumstances-which we can call a phenomenotechnology. In such circumstances, a relation between an observer (who observes) and a phenomenon (which is observed) is established. It is in this relation that the phenomena that are potential candidates for becoming facts are being made. Constructing new phenomena and establishing a new relation with them is a central aspect of scientific practice. In doing so, scientists are capable of disclosing the world in a new way and henceforth developing new ways to interpret reality. The active creation of new phenomena in scientific practices that allow for the emergence of a new relation with reality is what I take to be the process of science-in-the-making. Thus, while Latour is interested in revealing the networks that are "behind" what is already there, a study of science-in-the-making is also interested in how something new can emerge in scientific practice.

When interpreting science-in-the-making in terms of the emergence of new phenomena, we must ask which processes underlie emergence. In other words, we must ask how a relation between scientist and phenomenon comes into being in scientific practice. Only when a scientist relates to something that appears as real can we say that (s)he has observed this phenomenon; when considering the emergence of phenomena, the question to be asked is thus how does a relation between a scientist and something that is revealed as both new and real come into being?
As demonstrated above, Latour addresses the question of how facts come into being from the perspective of semiotics and shows that facts are not constructed by individual knowers but arise within networks in which both humans and nonhumans play important roles. The construction of facts would not be possible without the presence of instruments that function as inscription devices that produce immutable mobiles. In other words, in the relations between humans and nonhumans within networks, images are created that are stable enough to move between different locations without being subject to change. For example, graphs of chemical reactions or maps of specific areas can be shown at other places without changing the messages they convey. A similar mechanism was at work when Pasteur extended his laboratory to the French farm sites, showing that by managing the behavior of the microbes, he changed how farm sites were structured. These acts can be understood as reshuffling of the relation between actants, thereby creating a new network (i.e., thereby bringing a new "context" into being).

The emergence of new phenomena in scientific practice is also the product of collective work that involves both humans and nonhumans. After all, scientists need technologies to relate to the phenomena they study, and the existence of a laboratory in which these phenomena are collectively investigated must be presupposed. In other words, the emergence of new phenomena also occurs within a network-like structure in which humans and nonhumans transform each other, thereby allowing for constructing new types of observers and new phenomena that can be observed. When changing the network, new relations between observer and observed are made through which new interpretations of reality can be developed. Thus, the construction of new phenomena implies (i) a reshuffling of the relations between observer and observed and, accordingly, (ii) the potential for interpreting reality in a new way.

According to Latour, only semiotics is capable of analyzing the transformations of relations between actants, because, he holds, it is the only methodology that does not a priori distinguish between humans and nonhumans. Hence, only when practicing semiotics can we analyze how nonhumans transform relations within networks and influence human possibilities to act. Central to this methodology is the idea that human subjects can manipulate their relations with objects at will without being changed by objects themselves is false. Both humans and nonhumans perform actions and transform the relations between parts of the network, and both have the possibility to reshuffle possibilities of action. Thus, semiotics should be understood as a methodological continuation of Latour's symmetry principle that does not prioritize the actions of humans over those of nonhumans.

To what extent can semiotics help us to understand how new phenomena and 
interpretations emerge in scientific practice? Introducing something new in a network implies that something is added that was not already there (i.e., it implies that reality is disclosed in such a way that a novel element has come into being. As I have argued, the construction of new phenomena should be understood in terms of reshuffling the relationship between observer and observed and opening up potential new ways of interpretation. On the one hand, this seems to imply a symmetry between human and nonhuman, because both observer and observed are transformed through the specific change in relations in a network. On the other hand, there seems to be an asymmetry involved, when the construction of something new implies the interpreting for something new as new. Only human beings are capable of interpreting something as this or that; it does not make sense to think of a nonhuman interpreting a human being to be this or that specific way. Thus, a specific appropriation of the observed is involved in the construction of a phenomenon that is unique to the human component of the relation between observer and observed.

If the construction of new phenomena is dependent on the interpretation and appropriation of the observed, the Latourian notion of network must be reworked such that it can account for the active transformation of the act of appropriation. Acts of appropriation occur within laboratories and are dependent on technologies and collectives of scientists and against the background of existing theoretical frameworks (i.e., they are dependent on networks of humans and nonhumans). However, we should not mistake dependency for determinacy. Within networks, phenomena are constructed and become visible to the observer. However, attributing meaning to phenomena (i.e., observing phenomena) involves an activity on the side of the observer that is absent on the side of the observed. In other words, if we understand science-in-the-making as a practice of emergence, we cannot uphold Latour's symmetry principle but must instead attribute interpretative qualities to humans that are absent in nonhumans.

The asymmetry in the observer-observed relation consists of the fact that the observer (i) perceptually experiences and (ii) attributes meaning to the observed. Hence, when studying science-in-the-making, we should be capable of studying these endeavors of the scientist. Furthermore, we should be able to understand how interpretations both arise within and constitute new networks. In other words, a study of science-in-the-making should be a study of how actors are reshuffled within networks and how these reshufflings give rise to specific types of interpretations above others. Using the framework of postphenomenology, I argue in the next section that relations between humans and technologies are placed within networks in which new experiential phenomena emerge. The specific manner in which these phenomena manifest to observers gives rise to specific interpretations of the phenomenon. Only when considering this can we understand how science is made within the process of making rather than retrospectively investigating how scientific facts have been made.

\section{\$5.6 INTEGRATING (POST-)PHENOMENOLOGY: \\ A HERMENEUTICS OF SCIENTIFIC INSTRUMENTS}

We have seen that Latour and postphenomenology each approach scientific practices differently. The former is more concerned with the sociological issue of how science is capable of constructing facts without assuming any force that is specifically reserved to the sciences, while the latter is concerned with the question of how reality becomes present to the scientist in the first place. In this section, I suggest that the role of technologies in scientific practice must not be reduced to just stabilizing networks but must also be understood in terms of how scientists can reason about-and act upon the existence of-new scientific phenomena. This aspect cannot be explained when scientific instruments and the scientists who relate to them are reduced to their semiotic function as actants.

Firstly, I show why Latour argued against the plausibility of both epistemology and phenomenology, because they are grounded in a subject-object dichotomy that is an artifact of what he calls the Modern Constitution. I subsequently argue that Latour's radical symmetry between humans and nonhumans is incapable of incorporating a concept of human intentionality that is necessary to understand scientific practices as practices of emergence. To conclude, I distinguish between Latour's concept of technical mediation and the postphenomenological concept of technological mediation and argue that while the former establishes an understanding of how practices come into being, the latter describes relations between scientists and the world within practices. Therefore, considering both of these concepts of mediation allows us to understand scientific practices both in terms of the closing of black boxes and as practices of emergence.

Latour's Criticism of the Modern Constitution: Mediation and Purification

A central target of Latour's project is the dichotomy between subject and object that prevails in modern philosophy. According to him, the idea that the world is divided into human subjects, endowed with agency and intentionality, and nonhuman objects, which are mute, is mistaken. As demonstrated above, he argues that nonhumans shape practices as much as humans do. When analyzing how facts and entities come into being and how networks attain different shapes he proposes rigorously applying the symmetry principle, indicating that no a priori distinction between the acts of humans and nonhumans 
should be made. Similarly, we should neither distinguish between a knowing subject and a known object nor ask how the gap between the two should be bridged.

Latour understands the presence of the subject-object dichotomy as an artifact of what he calls the Modern Constitution. Latour defines Modernity in terms of the simultaneous birth of both humans and nonhumans. In this worldview, humans are understood in terms of consciousness and agency, while nonhumans are understood as mute entities governed by natural laws or human intentions. According to Latour, this worldview is deeply mistaken, because in fact, stable entities that are dividable into humans and nonhumans do not exist, only hybrid entities (cf. Latour 1993b, 13-15). He considers Modernity as an extremely effective way to act as if hybridity does not exist and the world can be divided into clearly different domains. He argues for this position along two lines: firstly, he shows how the "Moderns" were capable of setting up the dichotomy between subject and object, which he calls the work of purification, and secondly, he argues for the hybridity of reality by showing how practices are always hybrid (are always constituted by both humans and nonhumans, which he calls the work of mediation).

The work of purification consists of two complementing moves. On the one hand, nature must be made foreign to us and be stabilized as something that has always existed. On the other hand, spokespersons of nature must be created who are capable of discovering the secrets of nature and establishing those as facts. As Latour remarks in the context of the laboratory of the $17^{\text {th }}$ century natural philosopher Robert Boyle, "Despite their artificial construction inside the vacuum pump (such is the phase of mediation or translation), the facts completely escape all human fabrication (such is the phase of purification)" (Ibid. 31). He generalizes this idea as part of a larger schema that guarantees the subject-object dichotomy underlying the worldview of Modernity: (i) we have constructed Nature, yet Nature is as if it is not; (ii) we have not constructed Society, yet it is as we did; and (iii) these two domains must remain absolutely different; mediation and purification should not be mixed (cf. Ibid. 32). Thus, although natural phenomena and facts are constructed within laboratories, we do not recognize these as such, and although we simply find ourselves in society, we do not recognize this.

Latour warns us not to interpret the creation or the Modern Constitution as a deliberate act created by an evil genius or through a false consciousness or ideology ${ }^{44}$ but considers

44 This absence of a deliberate creation of the myth of the Modern Constitution is at the core of his criticism on the idea that the Enlightenment is primarily a political movement that makes citizens subject to a form of instrumental rationality. For example, he does not side with analyses such as Horkheimer's and Adorno's that argue that Enlightenment rationality is a historical movement that culminates into political and cultural oppression (cf. Horkheimer and Adorno 1969). it as the anthropological background of how modern individuals live:

"[T] he relation between the work of purification and that of mediation is not that of conscious and unconscious, formal and informal, language and practice, illusion and reality. I am not claiming that the moderns are unaware of what they do, I am simply saying that what they do-innovate on a large scale in the production of hybrids-is possible only because they steadfastly hold to the absolute dichotomy between the order of Nature and that of Society, a dichotomy which is itself possible only because they never consider the work of purification and the of mediation together" (Ibid. 40).

The paradox of constructed, yet non-constructed, Nature is, according to Latour, at the core of modern epistemology. Therefore, exposing the Modern Constitution as a myth means simultaneously exposing modern epistemology as mistakenly grounded. In other words, epistemology fails to consider the work of purification and mediation together and only focuses on how a purified subject can establish a decontextualized position from which knowledge about the objects of nature can be obtained. However, when purification is considered an activity instead of a given, it becomes impossible to circumvent the mediation with which it is accompanied.

What do we miss if we only consider purifications? According to Latour, it is the precise hybrid nature of the entities in the world that are the product of mediations and how mediations transform practices. Latour locates mediations as acts constituted by "actors endowed with the capacity to translate what they transport, to redefine it, redeploy, and also to betray it" (Ibid. 81). In other words, mediators are actants that change the structure of the network by redefining other actants. Potentially, every actant can have this mediating role. Because this process of changing is often neglected, it is as if science grasps nature through pure reason. For example, when leaving out the story of how Pasteur extended his laboratory to the farmer sites, it seems that it is Pasteur's pure reason, rather than his practice, that allowed him to cure the anthrax disease by linking it to the invisible microbes. However, when considering how mediators function within networks, the disease was solved not because a subject (Pasteur) was finally able to observe an object (the microbe) but because a stable network was present that transformed the farming site into a place where Pasteur could do his work. In other words, linking the anthrax disease to invisible microbes was the product of a series of mediations.

\section{Latour's Analysis of Technical Mediations Applied to Scientific Practice}

In We Have Never Been Modern, Latour does not yet link the notion of mediation to specific mediating instances. However, in his later studies on the working of artifacts, he explicitly links mediations to specific material entities. He distinguishes between four meanings of 
mediation:(i) translation, (ii) composition, (iii) reversible black-boxing, and (iv) delegation (cf. Latour 1994). Mediating artifacts (i) instantiate new courses of action, (ii) create new types of composite agents, (iii) often conceal the composite nature of the composite agent, and (iv) have programs of action inscribed in them. While Latour establishes these different forms of mediation in the context of the role of artifacts in everyday life, let me attempt to exemplify them with a brief example from scientific practice.

When applying Latour's analyses of mediating actants to the technologies that allowed for the visualization of brain activity and thus shaped how human cognition is to be studied, we can see the four types of mediation at work. Imaging technologies (i) instantiate new laboratory practices in which experiments must be developed in which they can be specifically incorporated. They (ii) create a type of researcher who can no longer observe cognition with his naked eyes (for example, in the form of behavior) but must relate to the imaging technology to be able to relate to the object of research. Imaging technologies (iii) are referred to as methodologies by researchers, thereby presenting them as one among several choices in the study of human cognition and concealing how the cognition is made visible in a different way to the researcher. Furthermore, when communicating experimental results to the public, the work of the scientists is presented in terms of a subject that establishes a relation with a previously unknown object. Finally, these technologies (iv) have inscribed in them that when someone wishes to engage in studying human cognition, he must interpret it in terms of neurophysiology, which can be interpreted as a consequence of the program of action inscribed in the imaging technology.

Latour's analyses of mediating artifacts to the context of scientific practice offer a much broader picture of the workings of technologies in scientific practice than his earlier analysis of scientific instruments as inscription devices creating immutable mobiles. When considering these mediations, we need not interpret technologies in light of how specific facts about human behavior are created, or of the construction of specific entities, but should instead see how human cognition becomes visible to a scientist through the mediation of technological artifacts. In other words, it becomes possible to understand how the investigative domain of science is set up and how nature in general (and in this case, human cognition in particular) becomes an accessible interpretative domain within scientific practice.

\section{How a Postphenomenological Understanding of Scientific Instruments Escapes Latour's} Critique of Phenomenology

When interpreting scientific instruments as mediating the domain in which the objects of research appear, do we not fall back into the scheme of epistemology so vigorously contested by Latour? Are we not back at a model in which a subject must bridge the gap with an object, and that just the domain in which this bridging problem appears is limited? When approached phenomenologically, this problem can be circumvented: there is nothing to bridge between subject and object, as scientific instruments can be understood as mediating the intentional relation between scientists and the world. Accordingly, not only is the domain in which scientific phenomena appear the consequence of a series of mediations, but how researchers intentionally relate to the phenomena under study is also mediated by the technologies that they are using.

When phenomenologists speak about intentionality, they refer to the fact that when human beings think or have beliefs, these thoughts and beliefs are always about something. Similarly, human beings do not merely experience; they always experience something. Thus, when scientists have beliefs about an object of research, or experience the presence of a phenomenon in observation, these beliefs and experiences are about something. In other words, a researcher experiences or has beliefs about something other than himself. Thus, human intentionality consists of the relation between the human being and the world in which the phenomena (s)he relates to emerge.

Latour is critical of phenomenology and its concept of intentionality and argues that phenomenology is (i) an artifact of the Modern Constitution and (ii) trapped in theories of a bifurcated nature. According to Latour, phenomenology reaffirms the yawning gap between subjects and objects:

"[L]ike so many anxious modernizers, they [the phenomenologists] no longer trace anything but a line between poles that are thus given the greatest importance. Pure objectivity and pure consciousness are missing, but they are nevertheless-indeed, all the more-in place. The "consciousness of something" becomes nothing more than a slender footbridge spanning a gradually widening abyss" (Latour 1993b, 58).

Although Latour does not specify which phenomenologists he is targeting, he seems to primarily refer to (a caricature of) the work of Edmund Husserl, who considered intentionality an idea to bridge the gap between the subject and the object pole and to show why human beings can interpret objects in a meaningful way. The notion of intentionality guarantees that human perception is necessarily related to something that is not part of it; it entails the object that is intentionally related to (cf. Husserl 1913). From the perspective of Latour, however, this position does not solve but rather reaffirms the Modern Constitution, because it presupposes the existence of an isolated subject capable of having a consciousness relation with something distant from it. According to Latour, the concept of intentionality establishes a relation between two poles, which 
phenomenologists mistakenly take to be separated in the first place.

Latour argues that the consequences of continuing to adhere to the Modern Constitution become most clear in the phenomenological reactions to scientific developments. Earlier in this chapter, it is described how Latour uses Whitehead to argue against phenomenologists who would add "to the boring electric waves the rich lived world of the glowing sun" (Latour 2004, 244). This assumes that there are specific qualities that can be attributed to the objects (the "boringness" of electric waves) and other qualities that can be attributed to the experience of the human subject (the rich, lived world of the glowing sun). The reason to emphasize these distinct human qualities are the fears that the experiences of the human subject will be objectified and that the domain of human experience will be reduced to the language of scientific explanation. Precisely this idea is contested by Latour when he argues that this fear is grounded in the mistaken assumption that something like decontextualized human experience that must be protected does exist. In this way, objects are reduced to the "dull hurrying of nature" that occurs in opposition to the rich inner lives of human individuals (cf. Latour 2008). Following this line of reasoning, phenomenologists fail to notice that the objects around us mediate how the world is experienced, observed, and acted in.

No isolated subject exists that is capable of thinking, experiencing, observing, or acting on its own: "I live in the midst of technical delegates: I am folded into nonhumans" (Latour 1999a, 189). Actions and objects have an influence on how the world is experienced, whether they are materially present or have occurred in the past. There is no escape from the influence of these other actors on how practices are shaped or reality is experienced. Applied to scientific practices, researchers cannot escape the influence of existing concepts and theories, the functioning of the technologies they use, the material infrastructure of the laboratory, or the presuppositions of their colleagues. Researchers are folded into these human and nonhuman elements, as are the objects they study. In other words, how scientists study reality is mediated by the specific way in which they are folded.

As demonstrated above, Latour proposes studying these foldings by "unfolding" the networks that constitute practices. When reconstructing the history of practices (i.e., by studying how practices come into being, Latour shows how our current practices and acts are dependent on the networks of which they are products. Earlier in this chapter, I distinguish between two different ways of interpreting scientific practices. On the one hand, I characterize them (following Latour) as concerned with the closing of black boxes. On the other hand, however, I characterize them as practices of emergence in which new interpretations of reality are opened. I link the former to the study of science- as-it-has-been-made and the latter to the process of science-in-the-making. So, even if we grant that Latour has found an effective way to study science-as-it-has-made (or practicesas-they-have-been-made for that matter), important aspects of scientific practice still remain invisible to his analysis.

To study scientific practices as practices of emergence, we must start to understand how scientists relate to the world within foldings. Doing so requires the concept of intentionality, yet in a way that it is understood in terms of the relations between a human observerand the things that allow him to establish a relation with the world. Postphenomenology is specifically concerned with how combinations of humans and nonhumans establish an intentional relation with reality. Similar to Latour, philosophers as Don Ihde and Peter-Paul Verbeek argue that no isolated subject exists that establishes a relation with an object but that human intentionality is always shaped in relation with a technological environment (cf. Ihde 1979; Verbeek 2005). However, contrary to Latour, Ihde and Verbeek hold that the fact that relations to the world are always the consequence of combinations of humans and nonhumans does not require us to treat them on entirely equal footing. Human beings are inevitably intertwined with technologies and the other artifacts they use but have capacities that technologies do not. The world made related to through technologies is the world that must be interpreted by the human being. Something distinct in the human being does relate to a technology that makes it possible to intentionally relate to a world. Or, to put it in Heideggerian fashion, human-technology relations have a world, technologies, and other artifacts that in themselves do not (cf. Heidegger 2004).

From this perspective, intentionality is shaped by both the technologies that human beings relate to and the structure of the practice in which these relations occur, and accordingly, the world that is related to is the product of the relation between human and technology within this practical structure. The relation between human being and world is mediated by the technology (s)he relates to, and in this relation, a specific human being and a specific world are constituted. However, as demonstrated above, these relations are not isolated events but occur within practices that are already there and are structured around existing concepts and theories, the relations between scientists, and the specific infrastructure of the laboratory. Integrating the notion of intentionality allows viewing how human beings relate to the world within a folded environment, which can be seen as complementary to the work of Latour, because it allows us to not only understand how specific practices come into being but also how interpretations of reality are opened within this practice. 


\section{On the Difference Between Technical Mediation and Technological Mediation}

For both Latour and postphenomenology, mediation is a central concept when describing the relationship between human beings and technologies. However, while Latour speaks of technical mediation, postphenomenologists speak about technological mediation. In this section, I aim to reveal the relevant differences between these two notions. Whereas technical mediation refers to how previous technical acts that are black-boxed have created a specific practice, technological mediation is a concept used to describe how relationships between human beings and reality are shaped within practices. Thus, technical mediations primarily refer to how the present is constituted in relation to past events, while technological mediations shape relations in the here and now.

Latour develops his concept of technical mediation largely independently of his work on the construction of scientific facts, yet he acknowledges that important parallels exist between facts and artifacts: "Technical artifacts are as far from the status of efficiency as scientific facts are from the noble pedestal of objectivity" (Latour 1999a, 193). Just as we should not understand the construction of scientific facts in terms of an assumed underlying rationality, we should not understand technical objects in terms of an assumed efficiency. Technical objects are "never the beginning but the end of a long process of proliferating mediators, a process in which all relevant subprograms nested one into another, meet in a 'simple' task" (Ibid. 192). Thus, both in the domain of science and in the domain of technical actions, Latour urges us to understand both of these in terms of not their presumed objectivity or efficiency but the mediating acts that allowed for the attribution of these terms to certain states of affairs in the first place.

In a discussion about Latour's concept of technical mediation, Jeff Kochan has argued that Latour treats mediation as a black box that-although remaining closed itselfserves as an explanatory term to understand other events. He argues that Latour explains the distance between laboratory scientists and the layman in terms of the establishment of black boxes that have an indisputable authority. The central concept in the distancing between laboratory and layman is the concept of mediation: "Mediation is the primitive phenomenon by which all other phenomena will be explained, but which is itself closed to explanation. Latour seems to believe that we have no choice but to accept the inexorable hegemony of mediation" (Kochan 2010, 593). Kochan treats this as a criticism against Latour that reveals the modernist foundations of Latour's explicit non-modernist position, because of his affirmation of technoscientific productions over the interests of human individuals.

In line with the argument developed in this chapter, I treat Latour's use of mediation as a consequence of his interest in the post-hoc deconstruction of the networks "behind" scientific factuality and technical efficiency. For example, Pasteur's microbes have been constructed and become a new inhabitant of our society. Therefore, it seems impossible to neglect the "successes" of the mediations of which the microbes are the product. In other words, technical mediations are used to explain science-as-it-has-been-made and are explanatory of how scientific facts and objects are constructed. Latour must assume the existence of scientific facts precisely because his philosophy is primarily concerned with how they came into being. This is reflected in his understanding of technologies as instruments, which are solely understood in relation to the construction of the entity whose existence is to be explained.

The idea of technological mediation is not limited to this retrospectivity. Because of its grounding in phenomenology, it treats technologies not in relation to the existence of something external (say, a microbe) but as allowing human beings to relate to the world in specific ways. Furthermore, the idea of technological mediation embraces that these relations are never between a decontextualized subject and world but are shaped within a specific practical context. The intentionality of the subject is thus constituted in relation with both the technology and the specificity of the practices in which the subject does relate to a technology. Thus, whereas Latour's concept of technical mediation ends with the closing of black boxes or the construction of specific practices, postphenomenologists-while acknowledging the value of understanding the construction of practices in terms of technical mediations-have a broader interest when speaking about how technologies shape our relation with the world in a specific way.

\section{\$5.7 CONCLUSION: AN EMPIRICAL PHILOSOPHY OF TECHNOSCIENCE: TOWARDS A METHODOLOGICAL BASIS}

The reconceptualization of science-in-the-making through the lens of technological mediation requires a methodological shift from a semiotic to a hermeneutic approach. The question of how to understand the role of scientific instruments in scientific practice should be answered through a methodological framework other than the question of how scientific facts are constructed. While the latter question can (at least partly) be answered in terms of the deconstruction of networks, as it presupposes that a specific fact has already come into being, the former question is not bound to this condition. Therefore, a methodology to study how scientists relate to technologies should allow one to draw conclusions about how scientists relate to technologies in real time, which does not limit their influence on how they help construct scientific facts.

Latour's style of philosophy has been repeatedly referred to as "empirical philosophy" 
(e.g., De Vries 2016; Latour 2008; Schmidgen 2014), but to what extent is this actually reflected in how he approaches science? Latour himself argues that his philosophy should be considered empirical, because it acknowledges that

"actors know what they do and we have to learn from them not only what they do, but how and why they do it. It is us, the social scientists, who lack knowledge of what they do, and not they who are missing the explanation of why they are unwittingly manipulated by forces exterior to themselves and known to the social scientist's powerful gaze and method" (Latour 1999b, 19).

However, when studying actors in scientific practices, he must understand their actions in relation to something that is not yet empirically witnessable: the constructed fact or entity as a black box. This is most clearly visible in his analysis of the coming into existence of Pasteur's microbes, which function as a starting point from which all previous acts are interpreted. This seems to seriously undermine the idea that we should learn from actors about what they do and why they do it. After all, we, as analysts, know that something like a microbe (or another scientific object or fact) has come into being; they, as actors, do not know that. Hence, there seems to be a clear interpretive surplus on the behalf of the analyst when describing the actions of the Pasteurians.

Must we also concede this surplus if we move from science-as-it-has-been-made to science-in-the-making? Not necessarily, because the advantage of studying science-inthe-making consists precisely of the fact that neither the scientists nor the philosopher interested in scientific practice know what eventually will be made. Furthermore, this allows us to understand the working of technologies not only in the relation to future events but also as constituting a specific relation with the world that allows researchers to start to observe new phenomena that might lead to new interpretations of reality.

Will this make the job of the analyst easier? Probably not, because where Latour could structure actions with reference to (at least) one certainty (the constructed fact or entity), a study of science-in-the-making lacks such a starting point. The question to be answered then is not whether the analyst has a certainty from which other events can be interpreted but whether it is possible to discover what the certainties of the researchers under study are: why they perform the acts that they perform, and how their reality is shaped in relation with technologies, but also with existing theories, concepts, and epistemological frameworks (i.e., the phenomenotechnology). These are the phenomena that an ethnomethodological approach towards science-in-the-making should reveal. In this way, scientific practices can be studied as scientific practices proper, without $a$ priori equating scientific practices with fact-making practices. In the second part of this dissertation, I develop an empirical approach that does allow for studying science-in-themaking and exemplify this approach through a discussion of two case studies from the neurosciences. 


\section{PART II}

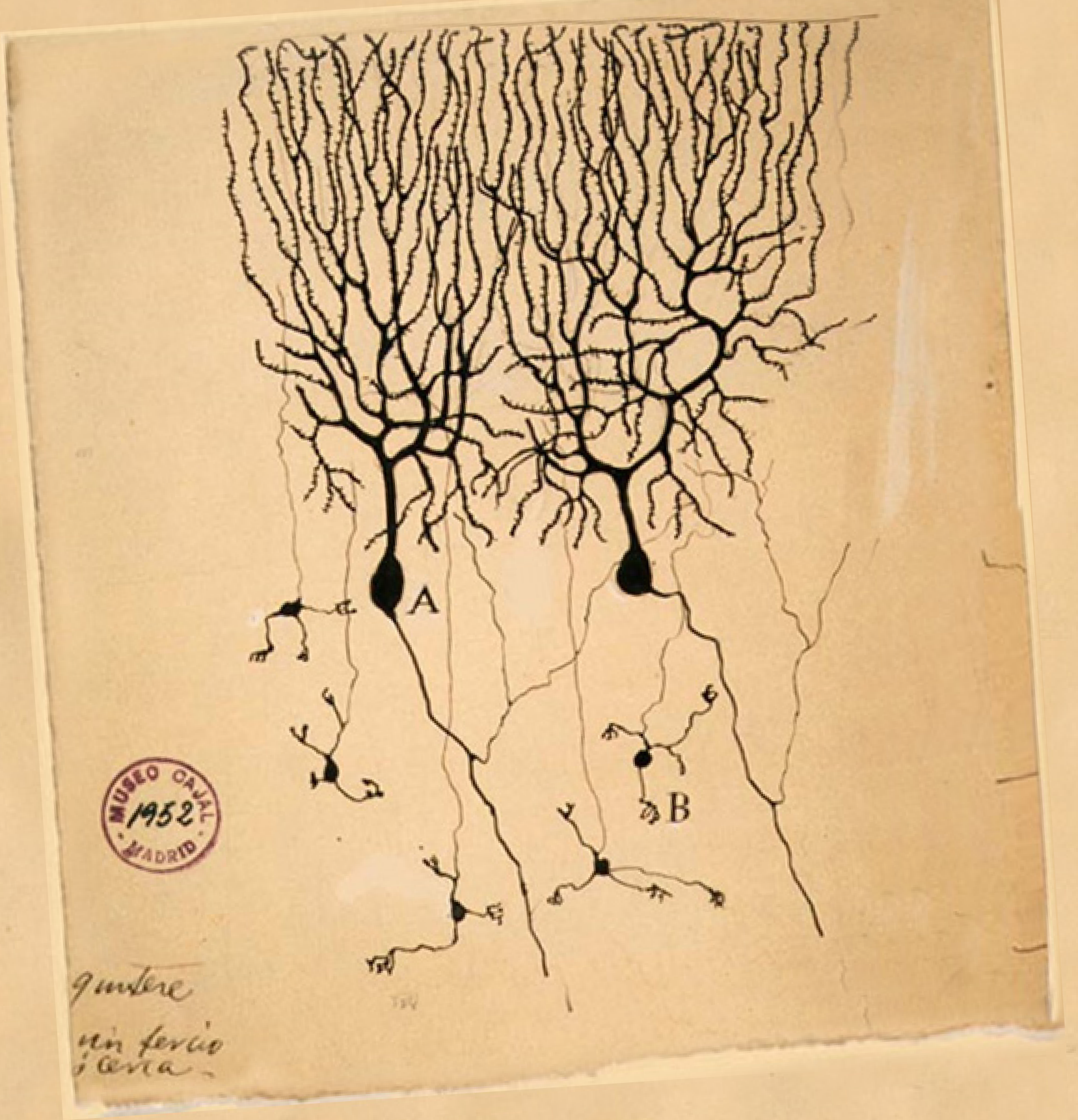


CHAPTER 6:

Postphenomenology as Ethnomethodology: Studying How Reality is Accomplished Through the Appropriation of Technological Mediations 


\section{INTRODUCTION: HOW TO STUDY THE CONSTITUTION OF SCIENTIFIC OBJECTS}

At the beginning of the first part of this dissertation, I proposed understanding the process in which scientific objects are made present in scientific practices in terms of the display of a shared epistemic stance within a collective of scientists. In the remainder of that part, I focused on how the mediating role of scientific instruments in processes of object constitution can be understood. In the second part of this dissertation, I focus on how collectives of scientists appropriate these technological mediations. If we cannot attribute rationality to scientific practices beforehand and cannot equate the reality of scientific objects with the technologically mediated perceptions that allow for seeing them, how then must we conceptualize the coming into being of a shared epistemic stance? To address this problematic, the second part of this dissertation is concerned with the following question: how does a shared epistemic stance with regard to the reality of scientific objects come into being within scientific collectives such that they can be meaningfully interpreted?

\section{Integrating Empirical Approaches into a Theory of Technological Mediation}

Postphenomenological studies of scientific practices have thus far focused primarily on how technologies change observational practices by altering the perceptual field of the observing scientist (Ihde 1998; Rosenberger 2011, 2013). Also, the postphenomenological understanding of hermeneutics is strongly visually oriented, as it understands the interpretative flexibility-or multistability-of visual objects in terms of the gestalt quality of their presentation (e.g., Ihde 2009, 56). However, a shared reality is constituted not only through the mediation of the perceptual field of the scientific observer but also by the interpretative shaping of the phenomenon that is to enter one's perceptual field. Accordingly, I suggest understanding the practical accomplishment of reality as the accomplishment of an interpretative space, in which perceptual phenomena become present as objects that are conceptually meaningful. In doing so, I aim to further flesh out Verbeek's (2016) suggestion that studies of technological mediations must be accompanied by a study of how human beings appropriate those and how a shared reality is constituted within this process.

The Austrian phenomenologist and sociologist Alfred Schütz attempted to develop a phenomenological understanding of how members of a group could assume that they shared a reality, despite that reality being differently constituted for each individual member. This resembles our question of how scientists can develop a shared epistemic stance in relation with the scientific objects they aim to investigate. Schütz attempts to solve this problem when arguing that members of a group share a stock of knowledge through which reality is-to a certain extent-similarly constituted because of a stock o shared previous experiences (Schütz 1945, 534). Because group members assume that this stock of knowledge is roughly similar within a group, a space of collective, meaningful reasoning comes into being. While this offers an interesting starting point for studying scientific practices, a primary problem Schütz faces is, as I argue, showing how this stock of knowledge-as grounded in the inner life of group members-can be empirically observed (cf. Heritage 1984, 66).

Ethnomethodology is much indebted to Schütz's ideas but is critical about their relevance for understanding how intersubjectivity comes into being. Instead of treating intersubjective as something cognitive, ethnomethodologists considered intersubjectivity as being constituted in action: action that could be observed empirically. Accordingly, its aim was to make explicit "how members' actual ordinary activities consist of methods to make practical actions, practical circumstances, common sense knowledge of social structures, and practical sociological reasoning analyzable," and aims to do so "from within' actual settings, as ongoing accomplishments of these settings" (Garfinkel 1967, vii-viii). If, as I attempted to demonstrate above, science cannot a priori be granted a special form of rationality, then an EM of scientific practice has the potential to reveal the collective forms of reasoning through which scientific objects come into being. In other words, an ethnomethodological perspective opens up the possibility to study how a shared reality comes into being for the practical purpose of doing science.

Harvey Sacks worried about the absence of a clear methodological grounding of the ethnomethodological program and proposed investigating the practical actions constituting a shared reality through the analysis of conversations. He aimed to develop a sociological program grounded in observable social activities, modeled after primitive observational sciences, such as $19^{\text {th }}$ century biology (Lynch and Bogen 1994, 66). Practices are, according to Sacks, already well ordered for the participants in them and therefore accessible to observers without preparation, but they can be analyzed by collecting conversations between participants. The task for the sociologist is to collect these observations systematically and make them methodically reportable and reproducible to others. At the same time, this method also applies to the reports of scientists themselves, since "they provide for the reproducibility of their actions on the part of themselves or others, by the use of methods" (Sacks 1992, 804). This view of science opens up the possibility to investigate the methods through which scientists make their actions reproducible and reportable, because this is how Sacks understands the practica possibility of doing science. This is illustrated by discussing two laboratory studies of neuroscientific practices drawing on CA: Michael Lynch's Art and Artifact in Laboratory 
Science (1985) and Morana Alač’s Handling Digital Brains (2011)

These different approaches all open up the possibility to study empirically how a shared reality to which scientists can relate to, but they-as I show in this chapter-problematically assume a distinction between the (supposedly mundane) practice of science and scientific theorizing. This affects how the technologies that are present in laboratories are treated by these approaches, because relations between scientists and technologies are located in the (non-theoretical) domain of practical action. For example, when discussing the distinction between the attitudes of daily life and scientific theorizing, Garfinkel writes in a footnote, "To avoid misunderstanding I want to stress that the concern here is with the attitude of scientific theorizing. The attitude that informs the activities of actual scientific inquiry is another matter entirely" (Garfinkel 1967, 272, fn. 8).

The purpose of this chapter is to break through the supposed dichotomy between these two attitudes by developing an approach to the study of scientific practices that embraces the intertwinement of theorizing and the practical concerns of scientific inquiries. As I will show, focusing on the appropriation of technological mediations may aid in this regard. This approach to the study of scientific practices aims to reveal two things: (i) how different technologies mediate forms of reasoning by giving rise to new scientific objects and constituting new norms for what is treated as valid knowledge and (ii) how such appropriations of mediations constitute a meaningful reality within scientific collectives. From this perspective, the practical interactions between scientists and technologies are constitutive of the forms of reasoning that constitute a discursive space, in which scientific objects can come into being and become interpretable.

I argue that a combination of postphenomenology and EM can fulfill both of these demands, because it addresses both how group members in relation with technologies orient to a shared discursive reality (EM) and how this reality becomes meaningful in scientists' appropriation of technological mediations (postphenomenology). In this way, it becomes possible to both investigate how scientific collectives maintain an orientation to a shared reality and how within this reality, meaningful interpretations of technological mediations can come into being.

The chapter is structured as follows: firstly, through a discussion of Alfred Schütz's concept stock of knowledge, I show how a phenomenologically inspired sociological analysis opens up the possibility to pose the question of how a shared epistemic stance can come into being (\$6.1). Secondly, l discuss the relation between phenomenology and EM and show how an ethnomethodological perspective on scientific practice offers the concepts to understand the reality of science as a practical accomplishment (§6.2).
Thirdly, I argue that if the aim of scientific practices is to construct certain knowledge, there must be epistemic norms that scientists hold each other accountable for and that can be made explicit (§6.3). Fourthly, I show how these norms can be studied using CA and how they are shaped through appropriations of technological mediations (§6.4). To conclude, I suggest that a combination of postphenomenology and an ethnomethodologically inspired approach to scientific practice can help reveal how technologies not only mediate how scientists act and perceive but also mediate the terms with which they reason, thereby mediating the norms that are oriented to in the process of object constitution ( $§ 6.5)$.

\section{§6.1 SCHÜTZ'S STRANGER AND PHENOMENOLOGY: INTERSUBJECTIVITY AND REALITY THROUGH A SHARED STOCK OF KNOWLEDGE}

In his essay The Stranger, Alfred Schütz aims to contribute to a general theory of interpretation of the "adult individual [...] who tries to be permanently accepted or at least tolerated by the group which he approaches" (Schütz 1944, 499), based on the phenomenological experience of individuals looking for group membership. Contrary to the members of an existing group, strangers need explicit knowledge of the basic assumptions and norms that constitute both the group and its members. However, having knowledge of these assumptions is not sufficient to warrant acceptance in the group, because these norms are "incoherent, only partially clear, and not at all free from contradictions" (Ibid. 500). A certain order exists within this group that cannot be clearly explicated. Yet, the behavior of the approached group functions as a cultural pattern that-for its members-does not require explication and allows for an orderly cooperation within the group. However, it is clearly in the stranger's interest to be able to explicate the structure of this pattern and act upon it. Schütz suggests unraveling this structure by transforming our own interpretation of the world by getting access to the stock of knowledge based on the shared experiences of the approached group.

In this section, I do two things: firstly, I elaborate on how the concept stock of knowledge functions as a way to account for intersubjectivity in Schütz's phenomenological sociology and how this leads to the-from the perspective of postphenomenologyproblematic idea that the use of tools and technologies within an established stock of knowledge can be explained in terms of the purpose they are designed for. Secondly, I show that this conception of technologies in terms of their usefulness informs Schütz's conception of their role in scientific practice, which is reflected in his distinction between science as practice and science as theory. I suggest that this sharp distinction 
must be overcome if we wish to understand how technologies mediate how the reality to which scientists relate is constituted.

\section{Sharing a Stock of Knowledge and Assuming Intersubjectivity}

According to Schütz, group members share a world by taking for granted "the unquestioned, though at any time questionable stock of knowledge at hand" $(1953,5)$. In The Stranger, he uses the concept stock of knowledge to describe the problematic situation of the outsider, but in other works, he uses this concept to investigate how it is possible that group members can relate to a shared reality within an established group. He begins to address this problem by asking how a shared stock of knowledge within a group can come into being in the first place. This issue arises because Schütz's phenomenological background makes him sensitive to the idea that the reality that human beings relate to is constituted through and for the individual subject. At the same time, however, he observes that different subjects seem to have a shared reality in common. Thus, the concept stock of knowledge serves to answer the question of how group members practically achieve intersubjectivity (i.e., maintain a shared reality when relating to one another).

To understand the background of why intersubjectivity can appear as a "problem," it is necessary to unravel how Schütz understands the constitution of reality for the individual subject. For Schütz, our natural attitude to reality must be understood in terms of the work required to realize the purposes we pursue. He terms this a wide-awakeness in relation with our surroundings, which "denote[s] a plane of consciousness of highest tension originating in an attitude of full attention to life and its requirements" (1945, 537-538). Thus, our perception, understanding of, and interaction with our surroundings is first and foremost characterized in terms of the requirements one has set. Because of this, the subject "lives within its acts and its attention is exclusively directed to carrying its project into effect, to executing its plan" (Ibid. 538). As how we attend to our surroundings is contingent on the plans we aim to execute, how our reality is constituted is also dependent on how our plans structure our perceptions.

How we perceive our surroundings-and execute our plans accordingly-is dependent on what Schütz calls a stock of previous experiences (Schütz 1953, 4). Borrowing a Husserlian terminology, he holds that our relationship with the world is already typified before our direct experience of it. Accordingly, typification is directly constitutive of how we experience our surroundings. This constitution occurs in a twofold manner. On the one hand, it is biographical: we already have experienced objects that have had a certain effect on us, which influences how we will experience future encounters with the world. On the other hand, it is socially derived: constituted by what we have inherited by our cultural background (e.g., through families, teachers, thereby shaping also our experience of objects that we have not encountered before).

However, even though our contact with reality is grounded in a stock of previous experiences, it remains necessary selective because of its embeddedness in a certain project that calls for a specific course of action. When perceiving or describing certain states of affairs, Schütz states that "[i]f I assert with respect to an element of the world as taken for granted: "S is p," I do so because under the prevailing circumstances I am interested in the p-being of S, disregarding as not relevant its being also q an r" (Ibid. 6). For example, when having the plan to go home at night after leaving a bar, I might assert that "the forest is dark," thereby highlighting the darkness of the forest as constituting an undesirable route. This perception is necessarily selective, because it does not highlight the number of trees constituting the forest, the aesthetic qualities of the forest, and so on

Schütz holds that these two features of the stock of knowledge that constitutes reality are particular to individual subjects. Moreover, actors know that the reality that other subjects encounter is inevitably inaccessible to them. It is only by making two idealizations that subjects can assume a "common world" that transcends their individual experiences: (i) the idealization of the interchangeability of standpoints and (ii) the idealization of the congruency of the system of relevance. (i) assumes that when I change places with another subject, his "here" becomes mine, and vice versa, while (ii) assumes that unique biographical situations are irrelevant to our interpretation of common objects and that we use their features in roughly similar ways for all practical purposes (Ibid. 8). Managing the sustainability of these idealizations is a prerequisite for the constitution of a stock of knowledge that is intersubjectively shared and hence for the constitution of a common reality (cf. Heritage 1984, 53-54).

\section{Schütz's Phenomenology in Light of a Philosophy of Technological Mediation}

A possible criticism against Schütz is that he explains intersubjectivity "within a cooperative framework in which the chessboard of meaning is never willfully overturned" (Heritage 1984, 73). Despite a stock of knowledge being an unquestioned, yet always questionable framework, Schütz is primarily interested in showing how the maintenance of intersubjectivity succeeds, by showing how the idealizations we make in transcending our private world are practically sustained. This makes him primarily focus on how stability is constituted through the experiences and dealings we have with the objects around us. One way in which this explicit search for stability becomes visible is in how Schütz's understands the functioning of tools and technologies: "A tool, for example, is not experienced as a thing in the outer world (which of course it is also) but in terms of the purpose for which it was designed by more or less anonymous fellowmen and 
its possible use by others" (Schütz 1962, 56). However, the continuous introduction of new technologies in both scientific and non-scientific practices requires-provided that we cannot explain their use in terms of their design-to continuously develop new typifications of how we relate to our surroundings through them, as they help constitute new projects that can be carried out and introduce new forms of action to do so. Accordingly, the variety of ways in which subjects relate to technologies requires continuously re-negotiating a shared reality, as new technologies question the stability of an existing stock of knowledge.

If we wish to understand the possibility of maintaining a shared reality, we must overcome the-from the perspective of a philosophy of technological mediationproblematic assumption that how technologies are used can be explained in terms of the purpose they are designed for or through an understanding of how others use them. This assumption puts two interrelated constraints on Schütz's framework: (i) it conceptualizes technologies first and foremost in terms of their usefulness, thereby neglecting the other possible ways they contribute to our experience of reality, and it therefore (ii) surpasses the variety of ways in which technologies mediate these experiences differently across subjects. Thus, while Schütz helps to pose the question of how a shared reality is constituted, it is necessary to move beyond his framework if we wish to understand how group members maintain a shared reality when their shared stock of knowledge is called into question.

\section{Schütz's Approach to Science: Science as Theorizing in a Distinguished Province of} Meaning

Also, in the context of science, Schütz argues that how scientists cooperate is grounded in a shared stock of knowledge. This shared stock of knowledge is necessary for scientific research to occur and is to a great extent dependent on technologies. However, when engaging in scientific theorizing, it only plays a secondary role. Scientific theorizing is

"[b]ased upon working acts (such as measuring, handling instruments, making experiments); [it] can be communicated only by working acts (such as writing a paper, delivering a lecture); and so on. All these activities performed within and pertaining to the world of working are either conditions or consequences of the theorizing but do not belong to the theoretical attitude itself, from which they can be easily separated" (Schütz 1945, 565).

The distinction between working acts and the theoretical attitude is made on the basis of the idea that subjects can relate to multiple realities-or provinces of meaning-that exist more or less independent of one another. However, the subject cannot do so simultaneously: it can only relate to one specific reality at a time. This allows him to strictly distinguish between the reality of daily life and the reality of scientific theory and contemplation (Ibid. 533).45 Whereas the reality of daily life is constituted-as sketched in the previous section-in relation with the practical purposes we engage in when realizing projects, Schütz understands scientific theorizing as not serving any practical purpose, because "its aim is not to master the world but to observe and possibly understand it" (Ibid. 564)

The absence of practical purposes is what distinguishes scientific theorizing from theoretical contemplations in the reality of daily life. When we make up our mind when developing projects or plans, ask pedagogical questions as fathers, or anticipate public opinion as politicians, these contemplations are directed at practical purposes, in this case, at the development of children or a political career. Schütz distinguishes these contemplations from scientific theorizing and proposes to understand those as "'enclave[s]' of theoretical contemplation within the world of working [rather] than a finite province of meaning" (Ibid. 564). Contrary to the attitude of scientific theorizing, the constitution of an enclave is an event occurring within an already experienced reality, rather than constituting a new province of meaning

Building on Schütz, Bischur (2014) distinguishes between the clear and distinctness of rational knowledge and the messy ways in which scientists relate to technological equipment. While he grants both an equally important role in the construction of scientific objects, he holds that they remain clearly distinguishable. Drawing from the work of Hans-jörg Rheinberger (1997a), Bischur distinguishes between the technical and the epistemic objects present in scientific practices. Epistemic objects are th objects that scientists wish to obtain knowledge of, such as human cognition, atomic interactions, and so on, while technical objects are those things that allow scientists to attain knowledge of epistemic objects, for example, an MRI scanner. In Bischur's analysis, only epistemic objects should be understood as participating in the process of scientific reasoning, while technical objects provide an infrastructure that is established through pragmatic reasoning $(2014,144)$. Clearly, the former is dependent on the latter, but only in the sense that pragmatic interactions with laboratory equipment create an environment in which scientific theorizing can occur

However, if the working of technologies cannot be explained in terms of their functionality but rather as mediating the reality that we encounter, it seems that

45 In the essay On Multiple Realities (1953), Schutz further distinguishes the realities of the world of phantasn (myths, fictions) and dreams that remain undiscussed in this chapter. For a detailed discussion of the differen ways in which these realities are constituted, see, for example, Cox (1978),23-30. 
technologies should be understood not just in pragmatic terms but also as constitutive of how scientific theorizing occurs. In other words, scientific technologies seem to do more than create a stable environment in which scientific research can be conducted. In fact, Bischur already alludes to such a view when breaking with Schütz and proposing understanding scientific theorizing as an enclave within the lifeworld of scientific practice "that ultimately is linked to the practical activities of the laboratory and therefore cannot constitute a closed province of meaning" (Ibid. 144). If understood as an enclave, the theoretical contemplations of scientists also occur in the same experiential world in which they interact objects around them.

Although Bischur's analysis potentially points to a direction in which the relation between scientific theorizing and the practice of science-and hence between epistemic and technical objects-becomes a potential topic of inquiry, an understanding of scientific theorizing in terms of a phenomenological epoché makes it principally inaccessible for analysis. However, if, as Schütz suggests, yet does not explicitly elaborated upon, "theoretical thinking has to be characterized as belonging to the 'natural attitude,' [...] in contradiction to 'phenomenological reduction"” (Ibid. 567, fn. 36), it seems that the epistemic objects that scientists relate to are also embedded in the practical environment of the laboratory and hence intersubjectively shaped in the relations between scientists and scientists and technologies. As we cannot displace these objects to a rational environment "outside" of the laboratory, an analysis of scientific practice should focus on how they are shaped by both the interactions between scientists and the presence of specific technologies. In this way, we can understand collectivity in science not in terms of the collective bracketing of subjectivity but rather as the constitution of a shared epistemic stance through which a shared reality is shaped.

\section{$\S 6.2$ ETHNOMETHODOLOGY AND REALITY AS PRACTICAL ACCOMPLISHMENT}

The development of EM is much indebted to Schütz's sociology, yet it questioned the researchability of his analyses. Building on Schütz, Harold Garfinkel aimed to develop a way to study the coming into being of a shared reality. Only when sharing a reality, actors can behave in such a way that a social order can come into being. Garfinkel proposed studying this shared reality as "an ongoing accomplishment of the concerted activities of daily life, with the ordinary, artful ways of that accomplishment being by members known, used, and taken for granted" (Garfinkel 1967, vii). Accordingly, order is considered to be accomplished by maintaining a shared reality that comes into being in local practices and cannot be explained in terms of rules that are external to such practices.
Accordingly, the "realization of reality" is something that can be ethnomethodologically described. Garfinkel's project can be understood as an attempt to describe the traceable interactions between individuals through which realities are practically accomplished. In addition, these interactions can be traced in scientific practices. In the context of his research at the Los Angeles Suicide Prevention Center, in which he investigated how psychological reports are legitimized, Garfinkel writes, "Office activities are methods for accomplishing reports that are scientific-for-all-practical-purposes" $(1967,16)$. When applied to scientific practices more broadly, this insight fits well with our aim to study how the objects constructed in scientific practice become meaningfully present within collectives of scientists. From this perspective, the reality of psychological reports is constituted by how they are of practical use within practical courses of action Accordingly, the process of constitution becomes accessible to the analyst because scientists are also concerned with the making accessible of how their reality comes into being.

\section{Making the Accomplishment of Reality Researchable}

Both Schütz and Garfinkel denied that either the meaning of the actions of individuals or the reality that individuals share were the product of external codes or rules. They hold that there is no order external to practices through which a meaning is given to the events occurring but rather that the reality of specific events and the meaning attributed to them is constituted through the rules to which participants in practices orient. If we cannot understand these rules in terms of a system that is external to actual practices, this prompts the question of in what other way can group members collectively relate to a shared reality. As described in the previous section, Schütz attempts to answer this question in terms of a shared stock of knowledge within specific groups. In the work of Garfinkel, however, the empirical researchability of Schütz's theoretical work is questioned. According to Garfinkel, if we wish to understand how a shared reality comes into being, it is pivotal to empirically investigate how members themselves remain oriented to this reality in practice.

Inspired by Schütz, Garfinkel wished to answer the question of how social actors come to understand in common the circumstances in which their actions occur (Garfinkel \& Sacks 1986, 159-6o). However, contrary to Schütz, Garfinkel treated the question of how actors make collective sense of the world they live in from the beginning of his career onwards not as a theoretical question but as one that is empirically answerable. In his $\mathrm{PhD}$ dissertation, he already noted that

"[t]he big question is not whether actors understand each other or not. The fact is that they do understand each other, that they will understand each other, but the catch is 
that they will understand each other regardless of how they would be understood" (Garfinkel 1952, 367, op. cit. Heritage 1984, 119).

In placing direct emphasis on empirically analyzing the empirical interactions between individuals, Garfinkel directly challenges Schütz's idea that intersubjectivity is grounded in a cooperative framework between actors. Instead of being the product of a seemingly deliberate cooperation between actors, intersubjectivity should be understood as always present in social interactions, regardless of the intentional motives of the actors that participate in them.

Garfinkel holds that we should take seriously the incongruence between how actors would like to be understood and how they are actually understood, so as to remain faithful to the ethnomethodological attempt of "the discovery of common culture [...] from within the society by social scientists of the existence of common sense knowledge of social structures" (Garfinkel 1967, 76-77). By starting "from within society," Garfinkel departs from the idea that a shared reality between different actors can be understood in terms of aligning the perceptions and goals of individual actors. Only within an already situated environment can actors develop and pursue their goals and relate to a recognizable field of objects. What people see and relate to thus only comes into being only in social practices and in the relation with other actors and requires a shared form of vision within which objects become collectively interpretable. However, "the work involved in the coherence of a phenomenal field" (Garfinkel 2002, 97) is typically surpassed in sociology. When focusing on the member's methods to accomplish a shared reality, Garfinkel aimed to bring this work into the center of sociological analysis.

While how Garfinkel analyzed the coming into being of a shared phenomenal field focuses specifically on how objects can be perceived, he believed that a similar process was constitutive of the non-perceptual aspects of a shared reality. Borrowing a term from the German sociologist Karl Mannheim, he holds that every actor always uses a documentary method of interpretation when making sense of reality, which "consists of treating an actual appearance as 'the document of,' as 'pointing to,' as 'standing on behalf of' a presupposed underlying pattern" (Garfinkel 1967, 78). This method functions in a similar manner as the idealizations whose remaining existence Schütz thought to be necessary for maintaining a shared reality. The documentary method of interpretation moves beyond Schütz, because it is not a cognitive-conceptual, but a practical-social, method of interpretation that can be empirically scrutinized.

The documentary method already applies to the most basic level in which individuals interpret reality. For example, if I walk around a table and occasionally close my eyes, only to see the table again when opening my eyes, I treat these two appearances no as two randomly generated events but as pointing to an underlying pattern, namely, the table I am walking around. The key move that Garfinkel makes-contra Schützis that the underlying pattern ("table") is not an idealization made by an individual consciousness but that assuming this pattern is the product of interactions between individuals. If I were to deviate from treating the table in front of me as a stable entity, for example, by asking, "Is there a pattern underlying the set of appearances of something brown and rectangular in front of me?," others would hold me accountable for this action. Accordingly, I must come up with an account of why I am not sitting down at the table and using it to lean on. For example, I might say that I am pursuing a philosophical question, which may (or may not) be treated by others as a convincing account of my deviation of the interpretative pattern "table."

This example indicates that my perception of the object "table" is structured by the maintenance of an underlying pattern and that this pattern is visible in the interactions with others, because I am held accountable for its ongoing maintenance (Ibid. 9) The case in point here is that approaching the maintenance of a shared reality in this way opens up the possibility of how it is constituted within the interactions between individuals. Garfinkel urges sociologists to actively pursue this line of research instead of constructing fictitious examples like the one given above, which remain abstract and artificial..$^{6}$ Only when this pattern is maintained can the practical purposes of human conduct remain in place. In developing this perspective, Garfinkel thus paved the way for empirically studying how a shared reality is accomplished by focusing on how actors hold each other accountable for the maintenance of an underlying pattern that allows for a continuous flow of practical action.

It is this aspect of Garfinkel's EM that seems fruitful for a philosophy of technological mediation; the appropriation of what is revealed through scientific instruments can be analyzed in terms of how this revealing is dependent on particular epistemic norms that are oriented to. As is demonstrated below, this allows for the consideration of technologies in what Garfinkel calls the constitution of Galilean objects (i.e., of the objects that science speaks about). However, making this shift requires first investigating whether an ethnomethodological perspective can indeed be unproblematically extended from the study of everyday life to the study of scientific practice.

46 Thoroughly reviewing the specificities of Garfinkel's empirical studies of the maintenance of a shared reality exceeds the purposes of this chapter. See, for example, Garfinkel (1967, 38-43, 79-88). For further discussion, see, for example, Heritage (1984, 89-97). 


\section{§6.3 ETHNOMETHODOLOGY AND THE RE-SPECIFICATION OF SCIENCE: THE CONSTITUTION OF GALILEAN OBJECTS}

In the context of the work of Schütz, we observe that a clear demarcation was made between the theoretical attitude that structures the sciences and the natural attitude assumed in everyday life. Also, Garfinkel seems to maintain to a similar distinction between the theory of science and the practice of everyday life. When discussing the differences between the attitudes of daily life and scientific theorizing, Garfinkel stresses in a footnote that "to avoid misunderstanding I want to stress that the concern here is with the attitude of scientific theorizing. The attitude that informs the activities of actual scientific inquiry is another matter entirely" (Garfinkel 1967, 272, fn. 8). However, Garfinkel argues in his later works that EM has the tools to "respecif[y] the natural sciences as discovering sciences of practical action" (Garfinkel 2002, 278). How do these different perspectives on the possibility to study science ethnomethodologically relate to one another? Or, stated differently, must we concede that the theorizing activities of scientists are surpassed when scientific practices are approached from the perspective of EM?

To answer these questions, I firstly describe the context in which Garfinkel makes the distinction between the rationality of daily life and a scientific rationality (i.e., outline the practical purposes that this distinction serves in Garfinkel's work). Secondly, I show how the re-specification program of EM serves to study scientific practices as science-forall-practical-purposes. I suggest that instead of diminishing the theoretical aspects of science in favor of an understanding of science in terms of practical actions, as Garfinkel seems to suggest, an ethnomethodological approach to scientific practice calls for a reconceptualization of scientific theorizing.

\section{The Rationality of Science and the Practical Purposes of Scientific Activity}

Garfinkel's early remarks on the rationality of the sciences are made in the context of the relation between the scientific discipline "sociology" and the world of everyday action. He is concerned with the fact that sociologists primarily "study the features and conditions of nonrationality in human conduct. The result is that in most of the available theories of social action and social structure rational actions are assigned residual status" (Garfinkel 1967, 263). Terming certain conduct as "irrational" assumes that (i) there is a rationality in place within sociology and (ii) this sociological form of rationality can be unproblematically transferred to the domain of everyday life. The type of sociology that aimed to identify instances of irrationality by applying rational sociological models later come to be known as a sociology of error (e.g., Bloor 1976). When distinguishing between the rationality of scientific theorizing and the rationality of everyday life, Garfinkel aims to show that while (i) might be true, (ii) must be rejected because of the status aparte of scientific theorizing. In doing so, he aims to challenge the conception of sociology as providing a form of rationality that can be normatively applied to the context of everyday action.

In The Rational Properties of Scientific and Common Sense Activities, Garfinkel shows the difference between everyday rationality and scientific rationality by discussing the difference between the presuppositions underlying both. He presents five (cf. Garfinkel 1967, 272-277):

(i) In everyday life, actors assume an undoubted correspondence between the appearances of objects and an underlying object appearing in this particular fashion, and assumes that other actors do the same. Scientific rationality, on the contrary, prescribes to suspend the belief that the objects of the world are as they appear.

(ii) In everyday life, the relevant features of objects that stand out are dependent on the plans that actors (Schütz's wide-awake individuals) aim to execute. In contrast, scientific theorizing suspends the judgment with regard to the relevant features of objects, but rather aims to conceive them regardless of their place in the real world.

(iii) In everyday life, actors assume the correctness of a standard time to schedule and coordinate their actions with those of others, of which they assume they adhere to a similar standard time: there is "one big clock identical for all"' (Ibid. 274). This aspect is absent in scientific theorizing. In this context, time serves not to coordinate events in relation to others, but to identify cause-effect relationships, regardless of their relation with standard time.

(iv) In everyday life, actors assume that they share a background with others such that when making sense of events, different actors will "code" an event in a roughly similar way. This common intersubjectivity is absent in scientific theorizing. Instead of conceiving of others as experiencing subjects, those are treated as ideal, disembodied beings that make sense of phenomena in an objective manner.

(v) The events of daily life are informed by the assumption that part of the background of others always remains private, i.e., inaccessible to other actors yet of significant influence on how they conceive of events. Everyday rationality embraces this assumption and tries to act accordingly. In scientific theorizing this is no longer the case: "All matters that are relevant to [the] depiction of a possible world are public and publicizable" (Ibid. 276)

The case in point for Garfinkel is that while the principles of scientific theorizing do indeed give rise to a scientific rationality, this form of rationality cannot serve as an explanatory scheme for everyday life events. When sociologists consider their task as 
to identify irrationalities against the models derived from a scientific rationality, they neglect that everyday life has its own form of rationality-one that does not coincide with the rationality of scientific theorizing. For this reason, the theoretical attitude of science must be sharply distinguished from the practical forms of rationality guiding everyday conduct.

\section{The Sciences as Accountable Sciences of Practical Action and Practical Reason}

In Garfinkel's early work, these specific characteristics of scientific theorizing serve to juxtapose the rationality of everyday life with the rationality of science. However, in his later work, the rationality of the sciences become a topic in its own right, because he begins to treat to practices of scientists in the same terms as everyday life practices, namely, in terms of how scientists hold each other accountable for the maintenance of an underlying pattern that allows for a continuous flow of practical action. Applied to this new domain, "ethnomethodology is directed to the reform of technical reason, and doing so with the premier aim of specifying the work of the social sciences and the natural sciences as naturally accountable sciences of practical action and practical reason" (Garfinkel 2002, 93). This should be a central focus of EM, because society is increasingly shaped by rationally formalized scientific theories and models. Understanding these processes of formalization and their foundation in practical action allows to reveal how the plenum of everyday reality is transformed into the reality that is relevant to the rationality of the sciences.

The ethnomethodological study of scientific practice goes back to Garfinkel's principle that every utterance and action is made for "all practical purposes" $(1967,7)$. Hence, if we wish to understand how the reality of scientists is constituted, we should investigate how they do so for all practical purposes (i.e., by focusing on how they shape a meaningful context of interpretation). In line with the general program of EM, this approach must be sharply contrasted with a study of scientific practice by means of interviewing scientists, because the practical purposes at stake in answering an interview question are profoundly different from the context in which the reality of science is shaped. In this context, Garfinkel, Lynch, and Livingston speak of a difference between studies about scientific practices and studies of them $(1981,132)$. While the former provide detailed descriptions of the social networks that scientists function, stress their financial stakes, and analyze their social roles, the latter is primarily concerned-as is EM-with what makes the occupation "scientist" significant in the first place, namely, the aim to make valid knowledge claims about the reality that is investigated (Heritage 1984, 298).

Studies of scientific practices in an ethnomethodological sense focus on how scientists maintain and manage an order in the unstable and constant stream of phenomena they encounter and asks what the member's methods are that underlie the maintenance of a specific order. Maintaining this order implies the typification of what enters the phenomenal field into a collectively witnessable object, such that members can hold each other accountable for the reality of these. These methods are not transcendentally grounded in a scientific rationality but must be understood as local and contingent ways to stabilize what enters the phenomenal field. They are "are probatively suited to the specific thing's accountable production as workplace-specific, discipline-specific work in ordered shop floor phenomenal field details in-and-as-of-the-thing's-generality-and these NOT analytically by explicating lexical generics but contingently analytic, and therein just in any actual case" (Garfinkel 2002, 102). From this perspective, the reality of the objects studied that is constituted in scientific practices is approached not as grounded in the underlying structural of an external nature but as constituted within the process of maintaining order in the phenomenal field. Uncovering the processes through which this reality is constituted is the core of EM's project to re-specify the work of the social and natural sciences.

\section{The Shop Floor Problem of Scientific Practice}

Making encounters with phenomena topically and collectively relevant to the involved parties such that a shared reality is constituted is what Garfinkel calls the shop floor problem (Garfinkel 2002, 108-112; Lynch 1985). Understanding the constitution of reality in scientific practice in terms of a shop floor problem by no means implies the relativization of the importance of the sciences or counters the idea that the scientists produce objective knowledge. Rather, the objectivity and rationality of scientific practices are interpreted as processes that can be traced in time rather than participating in transcendental forms of objectivity and rationality. In fact, the shop floor problem of scientific practices is the creation of what Garfinkel calls Galilean objects, which are "Details in structures' stand[ing] proxy for independent Galilean objects, not the lived in vivo achieved things of immortal ordinary society. Galilean objects are things independently of the work of achieving them" (Garfinkel 2002,108, fn.30). The challenge for an EM of scientific practices is accordingly to re-specify how scientists construe details in the structures they observe into Galilean objects that seemingly transcend the work that gave rise to them.

Identifying details in structures requires the use of indexical expressions as a method of identification, which is the in vivo work involved of scientific practices. However, to be able to stand as proxies for Galilean objects, it is precisely the indexicality-the hereand-now-ness-of expressions that must be overcome. To create a generalizability of such as objects as appearing outside of the locality of scientific practice, it is necessary to work upon a "programmatically relevant distinction between objective and indexical expressions, and a programmatically relevant substitutability of objective for indexical 
expressions" (Garfinkel \& Sacks 1986,166). In scientific practice, indexicality is constituted as objectivity. Within this act, objects come into being that seemingly transcend the situated character of scientific practice. This is what EM identifies as the shop floor problem of scientific practice, which can be studied in terms of the norms that scientists hold each other accountable for.

A primary contemporary figure proposing an ethnomethodological approach to study scientific practices is the American sociologist Michael Lynch. According to Lynch,

"[T]he ideals of objectivity and scientific method can be identified as mythopoetic constructs made in the service of actions that in their own domain are ordinary. Again, this does not imply that methods are necessarily faulty or that it makes no sense to speak of objective states of affairs. Although no transcendental grounding may warrant its efficacy and certainty for all time, nothing precludes scientific conduct from being orderly, stable, reproducible, reliable, and ordinary" (Lynch 1997, 151)

Lynch proposes that EM should aim to re-specify the central epistemological topics of scientific practices, such as "representation," "measurement," "proof," and so on. Here, "a "respecification" of these topics [does not] mean a [...] redefinition of the meaning of terms but a way of investigating the different activities in which "order," "logic," "meaning," and so forth are locally and practically relevant' (Lynch 1993, xi, fn. 1). In doing so, epistemological issues are transformed into epistemic concerns (i.e., instead of understanding scientific practices as concerned with issues that can be logically solved by means of theory, Lynch proposes to treat these as belonging to the domain of practical action).

In line with this proposal, Lynch approaches judgments such as "(adequate) representation" and "(adequate) measurement" as indexical judgments that scientists hold each other accountable for and that are practically relevant terms through which the reality of the object under study is constituted. Of course, the epistemic categories that scientists use when shaping the reality of their object must be empirically determined and may not coincide with notions such as "measurement" and "representation" that have been the central categories in the theory-oriented philosophy of science. Accordingly, one of the aims of his approach to scientific practice is to reveal which epistemic categories are practically relevant and how the use of the categories constitutes norms to which scientists orient themselves during the constitution of the reality of scientific objects.

\section{The Rational Realization of the Real as Practical Accomplishmen}

What does such a perspective on the constitution of reality within scientific practice imply for our question of the relation between the "ordinary" and the "theoretical" aspects of scientific practice? In Lynch's ethnomethodological account of scientific practice, scientific theorizing cannot be explained in terms of a (set of) contemplating cogito(s) external to the ordinary course of practical actions. This does not imply that scientific theorizing can be reduced to practical actions, nor does it eliminate rationality from the domain of science. What an ethnomethodological approach to scientific practices instead points to is that the creation of the "Galilean objects" of science requires the integration of observable details in structures that are indexically present to into more complex scientific objects. This requires a concept of practice in which the making present of theoretical objects in the rationality of practical action can be accounted for. Accordingly, making sense of the here-and-now-ness of observable effects in scientific practice requires attributing meaning to them in terms of what is not empirically observable in scientific practices. This process can be analyzed in terms of how scientists hold each other accountable for how observable details in structures are made to stand as "proxys" of scientific objects.

Understanding the rationality of scientific theorizing in terms of constituting the reality of scientific objects in scientific practice allows the connection to an ethnomethodological understanding of scientific practice with the Bachelardian understanding of scientific objects as realized within a phenomenotechnique. Also, in the phenomenotechnique, the practical interactions scientists have with technologies and each other are entangled with and structured by the integration of different complex observable phenomena into scientific concepts, and vice versa. However, while Bachelard's analysis of scientific practice in terms of a phenomenotechnique is based on an external assessment and can to a certain extent, be considered an idealization of the rationality of scientific practice, EM offers the tools to analyze "from within" the processes through which scientific objects are rationally realized.

\section{\$6.4 INVESTIGATING SCIENTIFIC PRACTICES THROUGH CONVERSATION ANALYSIS AND THE APPROPRIATION OF TECHNOLOGICAL MEDIATIONS}

Understanding the practical validation of epistemic judgments requires a focus on two interrelated aspects: on the one hand, we must understand the work through which a meaningful reality is practically accomplished, and on the other hand, we must 
understand how epistemic judgments are made correspondent with this reality. Both of these aspects can be considered by studying the conversations between scientists in which the results of their experiments are discussed, as well as analyzing how these discussions are shaped by the technologies mediating how scientific phenomena become present in scientific practices. Postphenomenology has emphasized the actively mediating role of technologies in this process but has tended to overlook how human beings subsequently understand and act upon these mediations. Therefore, Verbeek has recently argued that analyses of technological mediations deserve to be complemented with analyzing human appropriations $(2015,191)$.

To also address how technological mediations are appropriated, I suggest augmenting postphenomenology with insights from CA, as applied within ethnomethodological research. Related to EM, CA studies, from a participants' perspective, how people use language as a medium to construct a reality in which meaningful actions can be performed (cf. Lynch 1985, 1993; Potter 1996; Sacks 1992; Te Molder and Potter 2005). Because of its relationship with EM, I propose using CA to further augment the approach developed in this chapter. The goal of integrating CA into our ethnomethodological perspective on scientific practices is to reveal the epistemic norms that scientists hold each other accountable for when making knowledge claims. In holding each other accountable for certain epistemic norms the reality of the object under study is shaped. The presence of these norms can be observed in conversations between scientists and develop in the relation between scientists and the particular technologies they use.

In this section, I aim to show two things: (i) how the accomplishment of reality and the practical validation of epistemic judgments can be understood as discursive (i.e., conversational and gestural work) and (ii) how making specific this work can be understood as making visible how technological mediations are appropriated within scientific practices. To do so, I firstly discuss two seminal works studying neuroscientific practices that draw on CA: Art and Artifact in Laboratory Science (1985) by Michael Lynch and Handling Digital Brains (2011) by Morana Alač. These discussions serve to clarify how the objects that scientists study are constituted in the discursive and gestural interactions between researchers. Secondly, I show that such analyses can be deepened by understanding these interactions as appropriations of technological mediations. Lynch aims to reveal how order is established from within scientific practices, and Alač further elaborates on this question by showing how gestural interactions allow scientists to ascribe meaning to brain scans, thereby allowing for the establishment of a common workable stance towards the contents of brains scans. Focusing on the appropriation of technological mediations moves one step further and attempts to reveal how technologies mediate the coming into being of epistemic norms through which the objects of research are shaped. This serves as a way to understand how technologies mediate the coming into being conceptual typifications of perceptual phenomena.

Empirically Studying Laboratory Practices (I): Lynch's Ethnomethodology Study of Psychobiology

Among the first wave of laboratory studies conducted in the end of the 1970s and the early 1980s, Michael Lynch's Art and Artifact in Laboratory Science was explicitly inspired by EM. Similar to Bachelard, Lynch aimed to treat neuroscientific practices and the objects arising within them as phenomena that are worth studying in themselves and that should not be treated as helping to settle existing philosophical debates: "Treating the contingent productions of scientific work as evidence for principled epistemologica positions and arguments holds the work accountable to issues and questions which are not demonstrably part of the practical setting in an invariant fashion" (Lynch 1985, 275). In doing so, Lynch wishes to move beyond philosophical debates on whether we should adopt a "realist" or "anti-realist" stance against unobservable theoretical entities or whether scientific facts depict a stable external world or must be understood as constructed through social interests. Rather, the order established within the practice of doing natural science is the topic of investigation. To do so, the established facts and objects should not be subject of study, but Lynch instead aimed to analyze "from within" scientific practices what where the accountable concerns that scientists attribute to one another in the flow of scientific conduct.

Lynch's study is situated at a university-based psychobiology laboratory primarily studying neurotransmitters in both the human and the animal brain, and the regenerative capacity of the brain, also known as brain plasticity. Studying the practices of these neuroscientists from within and doing justice to their flow requires being able to study their activities and how they hold each other accountable for these activities. To do so, Lynch proposes using CA, which allows the study of "talk which accompanies the work as that work is underway; not talk about the work but talk in the work, talk which is part of the work" (Ibid. 10). Drawing on the ethnomethodological tradition and its interest in studying practices in terms of the specific shop floor problem that is dealt with, Lynch study focuses on how the measurable data is read by scientists and how specific readings of this data allows for the ongoing continuation of their work in an orderly manner.

Crucial in Lynch's approach is the idea that scientific objects and their treatment cannot be cut loose from the project that temporalize, and thereby order, the work conducted in scientific practices. Reminiscent of the Schütz's description of the "wideawake individual," it is by orienting themselves to a project that the actions of scientific 
collectives are structured and within which certain features of the obtained data stand out as relevant. However, "the relatedness of actions in a project's sequence of actions [...] was not available in the continuous monitoring of the spectacle of events which where witnessed in the lab" (Ibid. 55). Accordingly, "the continuity of a project is not a 'real-time' continuity [...] but the analysis [of practical activities] need to supply [...] a way of indexing successively displayed actions to their appropriate projects" (Ibid. 68). By analyzing conversations between scientists, Lynch aims to reveal which actions must be performed to realize the continuity of the practices that are oriented to as ordering themes within scientific practices. ${ }^{47}$

Lynch identifies the identification and removal of so-called "artifacts" in their experimental data as a central shop floor problem of the neuroscientists he studies. Artifacts are interferences in the experimental set-up that researchers understand as distortions of the observability of the natural features of the world. These can be caused by technological failures or other circumstances interfering with the naturalized experimental circumstances. An important aspect of neuroscientific practices is to detect these artifacts and find ways to eliminate them from the data under study. This indicates that the obtained data "are and are not the things studied per se; they are conditions within which "the things" are addressed in particular instances of shop work" (Ibid. 10). The obtained data must be actively read and interpreted to make claims about the brain and its functioning. By studying the conversations in which artifacts are eliminated from the data, Lynch aims to show how interpretations of experimental data come into being within scientific collectives, and how specific interpretations allow for perceptual phenomena to "stand proxy" for the scientific object under study (i.e., the brain[s] of the experimental subject[s])

Focusing on artifacts makes Lynch's study specifically relevant for our understanding of scientific instruments, because artifacts exists by virtue of the instruments used to observe the human brain. The observation of the brain and its functioning is mediated by the electron microscopes used by the scientists that Lynch studies, which instantiates a process in which brains must be aligned with the particular technical specificities of microscopes. Studying the detection of artifacts allows one to bring to the fore the conditions under which scientists speak of a "proper" microscopic observation of the functioning of the brain.

The process of observation starts even before the neuroscientists start to explicitly

47 This already presupposes an interpretation of CA that slightly deviates from the traditional aim of CA to study in real-time the way conversations are ordered by focusing on phenomena such as turn-taking and further general characters of the sequential organization of conversations. For a more detailed discussion about the relationship between Lynch's approach and CA, see, for example, Lynch (1985, 6-12), Ten Have (1990). look through microscopes to observe brain tissue. In the context of a project studying plasticity through observing how a rat's brain recovers from the effects of a lesion, Lynch notes that "the requirement of microscopical observation necessitated the rendering of the animal to comply with the conditions of instrumental observation" (Lynch 1985, 35). As electron micrography does not allow for observing continuous organic processes yet is the only way to observe the brain on an ultrastructural level of analysis, this required the "sacrifice" of a large number of animals to display how the brain reacts and recovers from a lesion in a temporally ordered series of displays of the rat's brain.

The relevant questions have now become to what extent the set of displays of the brain of several dead rats can actually stand proxy for the observation of recovery processes in the living brain of a single rat and to what extent the specific way of observing organic processes by means of electron micrography shapes how the functioning of the brain is understood. Lynch's analysis of the detection and treatment of artifacts focuses on the former question and attempts to show how the "making-stand-proxy" of series of displays of dead rats' brains for the recovering capacities of the living brain requires the elimination of artifacts during the process of making the animal comply with the conditions set by electron micrography.

Analyzing the conversations during the identification and treatment of artifact serves as a means to show that studying how scientific claims come into being requires a focus on the technical vocabulary of natural science, instead of being explained in terms of the vocabulary of the social sciences: "The technical access to these issues of the social production of natural order was distinct from those technologies of inquiry which are featured in sociology methods texts and departmental pedagogies" (Ibid. 276). How the interpretational frameworks of scientists are shaped by the technologies they use is not at stake in Lynch's study, but he instead focuses on showing how artifacts become accountable phenomena that problematize the visibility of natural phenomena. At stake is thus not primarily showing how the objects of interest in the neuroscientific laboratory come into being, but rather that this process of coming into existence cannot be reduced to the social scientific vocabulary that is entrenched in explanations in term of institutional networks, or social and personal interests. When studied from within, so Lynch holds, such explanations appears as abstractions from how order is actually produced in scientific practices. Scientists hold each other accountable not in terms of institutional networks or social interests but within the domain to which their technical vocabulary applies.

However, as can be inferred from the above example in which organic process ar made to comply with the conditions of electron micrography, studying the practices 
of neuroscientists allows to reveal how the way technologies are appropriated by scientists gives rise to specific conceptualizations of biological processes. Although this is not an explicit focus of Lynch, I suggest that explicitly focusing on how technological mediations are appropriated helps not only understand how order is generated from within but also how appropriations give rise to new typifications of observed phenomena and embody interpretational frameworks accordingly. In Lynch's words, artifacts "provided circumstances in which the positive manner of addressing a field of instrumentally revealed phenomena was interrupted" (Ibid. 84). So, clearly, Lynch's work suggests that his approach can not only be used to study how order is obtained within scientific practices but can also serve as a starting point for understanding the extent to which technologies shape how scientists interpret reality. When researchers encounter artifacts, they are confronted with troubling interferences with the phenomena they aim to describe and interpret, thereby having to actively distinguish between "real" and "unreal" aspects of instrumentally mediated perception.

\section{Empirically Studying Laboratory Practices (II): Alač’s Study of fMR}

How scientists attribute meaning to specific technologies during the observation of scientific phenomena is explored in more detail in Morana Alač's recent (2011) study on how fMRI visuals are used to make claims about the human brain. Her book can be read as a plea for a return to the laboratory studies that grounded the discipline of STS. Despite the fact that STS has grown as a scientific discipline, so she argues, the interest in actual laboratory practices has waned and largely been replaced by research on science policy, the relationship between science and media, and the political influence of scientific developments. However, according to Alač, large areas of laboratory work have remained unexplored (Ibid. 16). Building on the tradition of laboratory studies, Alač aims to show how the reality constituted in relation with fMRI scans is the product of multimodal interactions between scientists and between scientists and brain scans in the laboratory. According to Alač, among the most important things thus far neglected in laboratory studies is that the visibility of the objects that scientists investigate "is relative to the circumstance of their practical and multimodal engagement" (Ibid. 18). She specifically aims to reveal the importance of gestural interactions in the production of fMRI visuals by showing that they are grounded in the "lived world of the hands" (Ibid. 158). Drawing on video-taped material, she aims to show how human meaning making in the neurosciences is multimodal and importantly concerns gestural interactions.

Lynch's work is of specific interest to Alač, because his focus on how artifacts are eliminated in neuroscientific practices points to the assumption in neuroscientific practice that "the moving body must become invisible [...], so that the "embodied" mind (i.e., the brain) can be studied" (Ibid. 69). However, her focus is significantly different: whereas Lynch was still primarily concerned with the ethnomethodological question of order, Alač's primary focus is on how scientists ascribe meaning to the phenomena they encounter in scientific practice. She specifically zooms in on how more experienced neuroscientists teach novices to identify artifacts and how this is accompanied with a specific way of coming to ascribe a meaning to the experimental data that is deemed appropriate.

Alač's way of understanding the processes through which neuroscientists attribute meaning to visuals of the brain is loosely grounded in the semiotics of the American pragmatist Charles Sanders Peirce. Drawing on Peirce, Alač proposes understanding fMRI scans not as images of the brain but instead as diagrammatic signs that can be used to conceptualize the relation between brain areas and the cognitive performance they help to instantiate. From a Peircean perspective, images are signs that have the same simple qualities as the objects they stand proxy for (e.g., one can think of a painted picture of an apple as an image). Diagrams, on the contrary, signify relations between different aspects of objects that can be understood in a variety of manners and allow for experimentation: "Diagrammatic signs show what cannot be observed otherwise while consenting for engagement. This engagement has the potential for generating insights regarding the relationship between the represented elements" (Ibid. 43).

The object of study in the practice of cognitive neuroscientists, human cognition, is not a singular object but is constituted through how different aspects of it are actively integrated through the activity of scientists. Only when understanding fMRI visuals as diagrammatic signs allowing the conceptualization of the complex relationship between activity in the brain and human cognition does it become possible to account for the work of the practitioners that must actively establish links between the different relations signified in the diagram. Without establishing these links, human cognitive functioning cannot be observed, precisely because the "seeing of what cannot be seen relies on the human aptitude to think by exploiting our visual capacity and our skill of handling objects in the world" (Ibid. 28).

The point of Alač's book is that the seeing of cognition can be investigated by studying how cognitive neuroscientists exploit their visual capacity by combining it with gestural interactions through which the relation between the brain and cognitive functioning is made present. This is, for example, illustrated in a discussion of an excerpt of a conversation between an experienced fMRI user and an apprentice learning how the way that visual information is processed in different areas on the brain can be seen on a fMRI scan. The discussion revolves around the identification of a "phase map" of how this processing occurs, which is a visual in which the temporal relationship between the 
data and experimental stimuli can be detected, and in which the time at which neuronal activity has occurred is indicated with different colors (Ibid. 95). Being able to attribute meaning to a phase map requires observers to be able to see how these different areas in the brain are temporally linked to the stimuli present during the experiment.

In the excerpt, the experienced neuroscientist gradually attempts to teach the apprentice how the temporal relation between experimental stimuli and neuronal processes can be seen. She does so by distinguishing between "seeing" and "looking" and uses "the expression 'actually see' [...] [to] refer to the understanding of the data configuration, as opposed to just perceiving colorful images on the computer screen" (Ibid. 98). Next, the experienced neuroscientist starts to use gestures to posit a space between herself and the computer screen, indicating that attributing meaning to the data requires an active involvement of the researcher and cannot be reduced to the perceptual qualities of the fMRI scan under study. Using such gestures indicates the potential mutability of the visuals related to. Alač uses this as an argument against the Latourian idea that the inscriptions offered by technologies should be interpreted as immutable mobiles, because it shows that within laboratories, the visuals produced by technologies are treated in highly mutable terms: "As seen in the fMRI laboratory, when coordinated with gesturing hands, graphical inscriptions can be quickly transformed but often do not traverse laboratory walls" (Ibid. 10o).

In the interaction with diagrammatic signs, so Alač argues, researchers can attribute meaning to fMRI scans by experimenting with them and stipulating different relational patterns within them through processes of visual and gestural interaction. Through this embodied engagement, researchers slowly become aware of the possible patterns that can be detected in fMRI scans and becomes capable of understanding why there is a consensus that some detected patterns are more plausible for understanding the relation between neuronal processes and cognitive function than others. Because she focuses on the gestural interactions in interactions between experienced scientists and apprentices, Alač seems to uncritically assume the ongoing existence of conceptual frameworks of cognitive neuroscience that are instantiated by fMRI. My interest, however, is also in how technological mediations and how they are appropriated give rise to precisely these frameworks. On the one hand, this can be seen as an extension of Alač's study because it is also concerned with how cognitive neuroscientists make sense of the visuals of the human brain they encounter. On the other hand, it breaks with Alač's aims, because meaning making is not considered in terms of knowledge transfers between experts and novices but is rather understood in terms of how the appropriation of technological mediations can give rise to new ways of understanding human cognition and the role of the brain in its realization.

\section{§6.5 ETHNOMETHODOLOGY AND STUDYING THE APPROPRIATION OF TECHNOLOGICAL MEDIATIONS}

The proposal to study how human beings appropriate technological mediations is presented as a corrective to the almost exclusive focus on the workings of technologies in postphenomenology and the neglect of how technological mediations are treated by human beings: "In order to develop a full understanding of processes of mediation, we should not only study 'what things do' [...], but also how humans give meaning to these mediations-both empirically and conceptually" (Verbeek 2015, 190). Indeed, to strengthen the argument that technologies do not determine the constitution of reality, for example, by offering a single perspective on scientific phenomena that determines how scientists interpret the world (cf. De Boer, Te Molder, and Verbeek 2018), it is necessary to reveal the processes of appropriation through which human beings express a certain freedom of interpretation in relation to the technological mediations that they encounter.

I propose that a combination of postphenomenology and EM can help study how technological mediations are appropriated in scientific practices. In the context of scientific practice, studying appropriations of technological mediations "makes it possible to investigate how human beings who use scientific instruments give meaning to the mediating roles of technologies and to the mediated realities they help to constitute" (Verbeek 2015, 195). Focusing on how technologically mediated observations and visualizations are translated into the scientific object that is investigated in scientific practices helps to better understand not only how technological mediations co-constitute how scientists act but also how they accomplish the coming into being of a shared reality. For example, thinking of Michael Lynch's study on artifacts, how the brain tissues of dead rats must be rendered in a specific way to stand proxy for organic processes in living animals can be understood as a specific way of giving meaning to how electron micrography mediates our understanding of the brain of an animal. Accordingly, EM can help reveal not only how technologies shape how order is constituted within scientific practices but also how the object of investigation-in this case, the brain of an animal-is made present through the appropriation of a technological mediation.

Integrating what I call a conversational approach to ethnomethodology into postphenomenology introduces (at least) two possible pitfalls: (i) by focusing too much on the human interactions through which a shared reality is accomplished, the mediating role of technologies in this process might again be surpassed and (ii) by reducing scientific practices to the practical action that scientists undertake, thereby neglecting the hermeneutic processes within which the conceptual frameworks that also constitute 
the reality that scientists study. The first pitfall would entail denying what is gained by postphenomenology: taking seriously how the constitution of reality is mediated by the presence of technologies. The second pitfall would conflict with the aim of studying human appropriations to study both empirically and conceptually how humans give meaning to technological mediations and fails to take seriously that scientific practices have the explicit aim to relate to Galilean objects (i.e., to what Heidegger called the relation with the present-at-hand). The latter can only be studied when a hermeneutic perspective is also integrated into EM. By showing how these two pitfalls can be avoided, I aim to clarify how the study of the appropriation of technological mediations differs from traditional ethnomethodological approaches to scientific practices and highlight what can be understood as the hermeneutic component of the approach developed in this chapter.

\section{How to Witness the Appropriation of Technological Mediations?}

Why is there a risk of overlooking the mediating role of technologies in EM in the first place? Crucial from the perspective of EM is that practices should be explained in terms of the order that is expressed by their members from within yet can be witnessed by an ethnomethodological observer: "Enacted local practices are not texts which symbolize "meanings" or events. They are in detail identical with themselves, and not representative of something else. The witnessably recurrent details of ordinary everyday practices are constitutive of their own reality. They are studied in their unmediated details and not as signed enterprises" (Garfinkel 2002, 97, my emphasis). Order is not to be explained in terms of non-witnessable structures such as "interests," "rationality," or "power-relations" but in terms of the member's methods through which a shared reality is accomplished in concerted action (cf. Garfinkel 1967)

It was exactly at the point of witnessability that Garfinkel departed from Schütz's phenomenological approach to intersubjectivity: when taking as a starting point the interpreting individuals who must make idealizations for intersubjectivity to come into being, Schütz introduced terms that are not witnessably part of how members act in concrete practices. Because of this, Garfinkel reformulated Schütz's question of how intersubjectivity arises through how individuals interpret the world and each other into the question of how order arises within practices through the norms to which members of practices orient and hold each other accountable when acting and talking. Considering that the concept of "technological mediation" also departs from a phenomenological perspective, would that again entail dissociating the question of how individuals interpret the world from the question of how practices are ordered? Or, to put it differently, to what extent are technological mediations and how they are appropriated events that can be "witnessed?"
Let me attempt to answer this question by discussing the identified second potential pitfall-the reduction of scientific practices to the practical actions that scientists undertake, which can beillustrated byhow Garfinkelattempts to re-specify how thecoming into being of the phenomena of Galilean physics. In line with the ethnomethodological aim to re-specify the natural sciences as sciences of practical action, Garfinkel argues that the phenomena of physics are "real-world phenomena in locally witnessable, naturally accountable coherent substantive, material's details in and as of the things' generality, just in any actual case, endogenously, and that abbreviations means, without explaining their generality by introducing into the course of the work a generically theorized More that is needed of shop floor details beyond their autochthonous production and accountability" (Garfinkel 2002, 264). Accordingly, the constitution of the phenomena of physics can be investigated "from within" scientific practices by investigating how a series of localized events give rise to the "Galilean objects" of science that transcend the indexicality of local practices.

Garfinkel attempts to show that the shop floor details and their witnessable accountability constitute the phenomena of physics through a reproduction of Galilei's inclined plane demonstration of the real motion of free-falling bodies. Being able to reproduce this experiment has been crucial in the development of modern physics, because only when Galilei would be able to ensure that on every occurrence and if properly conducted by every experimenter, it would be demonstrable that the phenomena he observed transcended the particularities of its situated production. In other words, he had to demonstrate that his results applied not only to some objects in motion in certain settings but to all objects that roll (Ibid. 268). This requires the presence of a set of instructed actions describing "all objects that roll" not as Galilean objects but as objects oriented to in the lifeworld that will only behave in the desired manner if their lifeworld properties are treated in a very specific manner. ${ }^{48}$ Garfinkel takes this as evidence that the natural sciences can be re-specified as sciences of practical action, because the presence of the qualifier "all" in the laws of physics must necessarily be accompanied with its accountability and observability, which depends on a set of practical actions that must be instructably observable to everyone.

Although the reproduction of this relatively easy experiment would seem rather straightforward-in fact, it is considered standard practice in high-school physics

48 Such sets of instructed actions can still be quite easily found online, which makes it possible for everyone to experience that Galiliei's conclusions can only be supported when the lifeworld is modified through a specific set of practical actions. See, for example, https://www.education.com/science-fair/article/rolling-downhillmeasuring-acceleration/ 
education-it turned out to be not so easy to re-constitute the reality of the phenomenon Galilei observed on the basis of his own instructions. Instead of interpreting this as a deficiency of those instructions, Garfinkel argues that this is a general property of the practical realization of any set of rules: the practical actions conducted in relation to a set of rules are themselves not captured within those, but rules function rather as norms that are oriented to in the flow of practical action (Ibid. 270). The practical circumstances within which experiments are conducted are-precisely because of the generalizability of the set of instructions-not contained within the rules that are oriented to in practical action. Accordingly, the experimental realization of the phenomena of physics is not a matter of rule-following but occurs in the interaction between the situatedness of practical actions in relation to the rules that are realized within this situatedness. The reality of the objects within scientific practice is, therefore, a continuous interaction between the indexical nature of the here and now and the potential generalizability of this here and now, realized by orienting to the rules designed to realize them.

Garfinkel's idea that the phenomena realized within scientific practices are constituted through the continuous interactions between generalizable rules and practical actions already points to the fact that science cannot be reduced to practical actions. towards rules requires an understanding of the relevant concepts that are contained within them. Furthermore, the rules that are oriented to are often implicitly presented rather than made explicit in concrete manuals, indicating that a shared epistemic stance about how to realize a specific scientific object is already present before a specific experiment is conducted. Integrating the hermeneutic approach of technological mediation into EM can also help reveal these aspects of scientific practice, thereby taking into account the theoretical-interpretative way in which scientific objects are constituted (i.e., the adjective "scientific" in "scientific practice").

The relevant concepts contained within the rules that are oriented to in scientific practices have become increasingly complex (cf. Hacking 1999). As Lynch and Bogen have argued, in response to Garfinkel's program, and as continued by the conversation analyst Harvey Sacks, Galilean observation science should no longer be considered the model for studies of scientific practices (1994). As I have attempted to clarify above, through a discussion of Bachelard's concept of phenomenotechnique, the increasing complexity of scientific objects is constituted because their realization fundamentally depends on how theoretical concepts can be made empirically present by technological means. This indicates that these concepts are not fixed but rather continuously change through how technological mediations are appropriated. In ethnomethodological terms, the theoretical concepts must be made indexically present in relation to relevant technologies. Making explicit the concepts present in the rules that are oriented to and how they are made interactionally present in relation to technological mediation requires an understanding of the hermeneutics of how the "empirical" is interpreted in terms of existing theoretical concepts.

The constitution of scientific objects occurs through the continuous oscillation between existing theoretical concepts and how they are mediated by how they are made present within a phenomenotechnique. Accordingly, the appropriation of technologica mediations can be made witnessably present by revealing the relevant concepts used to interpret the phenomena that are perceptually encountered within scientific practices and how their meaning becomes either contestable or more stable in this process. Doing so requires studying not only the practical actions that scientists undertake, but also the theoretical-hermeneutical processes through which the reality that scientists study is constituted. In both cases, the constitution of this reality can be understood in terms of the norms that are oriented to in the making present of scientific objects within the relation between scientists and technologies.

\section{§6.6 CONCLUSION: THE HERMENEUTICS OF MEDIATIONS AND} THE DISCURSIVENESS OF CONVERSATIONS

In this chapter, I have developed an approach to the empirical study of the appropriation of technological mediations in scientific practices, starting with Schütz's discussion of the phenomenological experience of attempting to claim group membership, which points to the presence of a shared reality of the group one wishes to be a member of. Subsequently, we have seen how this idea was transformed within EM from reality as a stable category to a continuous practical accomplishment. In scientific practice, the accomplishment of this shared reality largely occurs through the validation of epistemic judgments in conversation. However, the world in which these judgments occur is constituted by technologies that allow scientists to establish a relation with the phenomena they study. As such, an EM of scientific practice must be complemented with a postphenomenological approach capable of revealing how technologies mediate how the phenomena that scientists study become present.

Through a combination of postphenomenology and EM, I have suggested the development of an empirical approach allowing the investigation of howscientific objects are constituted by establishing a relation with what Heidegger termed the "present-athand." More technically, I have suggested that scientific practices must be understood as practices that explicitly aim to overcome the indexicality of its situatedness through the constitution of Galilean objects. Trivially, scientists cannot perceive their objects of 
interest without the presence of technologies. However, when observation is understood in terms of the constitution of a Galilean object rather than as a single act of perception, we must attempt to understand it as a process of shaping rather than simply a process of seeing, which complicates how technologies allow scientists to relate to the objects they study. The constitution of Galilean objects requires the continuous maintenance of shared norms that allow for their transcending of indexicality. These norms are made accountably present in the discursive interactions between scientists. Accordingly, when studying the conversations between scientists, the (often tacit) norms that are oriented to in the constitution of a shared reality can be made explicit.

For example, in relation to fMRI, specific norms come into being that constitute the reality of the scientific object "human cognition." Observing "cognition" is not merely a perceptual act facilitated by the presence of fMRI that presents it visually but is the product of an epistemic negotiation that encompasses the workings of the scanner, the reliability of the analysis used to transform measurements into images, and the establishment of an explicit link between the visual object (brain scan) and an interpretation of a specific cognitive function. In this case, the practical accomplishment of a shared reality-in this case of human cognition-occurs through (i) the perceptual presentation of a visual object that is continuously (re-)appropriated by (ii) addressing the quality of its production and (iii) using a set of relevant concepts to make sense of its content. The structure of this accomplishment is not given but takes shape through how the perceptual phenomena encountered in scientific practices are interpreted. When understanding these aspects as technological mediations, it becomes possible to understand the norms that are oriented to in the constitution of human cognition in this context in terms of the hermeneutic process in which technological mediations are appropriated.

Integrating EM into postphenomenology has allowed me to overcome some of the downsides of the philosophical perspectives discussed earlier in this dissertation: (i) it overcomes the focus on individual perception often present in postphenomenology; (ii) it does not mystify a theoretical relation with the world-as was the case in Heidegger's phenomenology-because it makes researchable how technologies mediate how a relation with the present-at-hand is established; (iii) It allows to study how in relation with a specific phenomenotechnology, an epistemological rupture with everyday life is established without assuming-as Bachelard did-an already existing form of scientific rationality; and (iv) studying the norms to which scientists orient when overcoming the indexicality of scientific practice does not assume the presence of a specific scientific fact as is the case in Latour's semiotic approach. Because of this, an empirical investigation into how technological mediations are appropriated can be considered to open up a space for studying science-in-the-making.

Admittedly, my proposal that a combination of postphenomenology and EM can be used to study the appropriation of technological mediations has thus far been largely theoretical. However, the specificities of this approach are best seen when implemented. In the next two chapters, I do so by presenting two case studies in which the approach sketched in this chapter is applied. Both case studies focus on neuroscientific practices that are concerned with the study of human cognition and behavior. As is demonstrated below, the different technologies used in different neuroscientific practices give rise to different epistemic norms, thereby each constituting the reality of "human cognition" in a different manner. 


\section{CHAPTER 7:}

\section{Constituting "Visual Attention" in}

the Cognitive Neurosciences ${ }^{49}$ 


\section{INTRODUCTION: THE PROMISE OF THE “NEURO”}

The promise of cognitive neuroscience is to explain human cognition in terms of its underlying neurophysiological interactions. A driving force in the development of this scientific domain is the idea that a unified theory of the human mind can be established with the help of the neurosciences. This is reflected in proposals for projects such as Mindscope (Koch et al. 2015) and The Decade of the Mind (Albus et al. 2007). Typically, it is stressed that the neurosciences have the potential to mitigate human suffering from mental and physical neurological diseases by developing "a mathematical and predictive framework of how all elements [of the brain] fit together and act as a whole to give rise to intelligence and consciousness" (Koch et al. 2015:39).

Brosnan and Michael (2014) have argued that this promise of future merit binds different neuroscientific practices together and allows for the existence of "neuro" to endure. In this chapter, we study an important development within cognitive neuroscience that embodies such a promise: NIBS. To do so, we followed a group of cognitive neuroscientists who are among the first to combine EEG with several forms of NIBS in the study of visual attention. Our analysis focuses on how visual attention is constituted in the interaction between scientists who collectively relate to NIBS technologies through which human cognition is disclosed in terms of the human brain.

From its early use onwards, the promise of NIBS is to establish causal relationships between brain processes and cognitive processes by stimulating the brain and observing the corresponding behavioral change (Sack 2006; Walsh and Cowey 2000). In this way, it is thought that neurophysiological processes that are functionally relevant to particular cognitive processes can be identified. However, NIBS does not allow researchers to observe neurophysiological processes and must be coupled with imaging technologies, such as fMRI or EEG for the visualization of neurophysiological change (Herrmann et al., 2016; Miniussi et al., 2013).

In this chapter, I show that EEG, NIBS, and the combination of NIBS and EEG each give rise to a different constitution of visual attention, of which the reconcilability is not self-evident. The different technologies do not so much offer different perspectives on one singular object that can be identified as "visual attention" but rather make scientists relate to different provisional objects that must be actively stabilized. As we show, the relation to these objects is mediated by the specific technologies used. We argue that the norms that scientists orient to when relating to the human brain differ per technology, which undermines the idea that the use of different technologies will eventually converge into one coherent picture of cognitive phenomena, such as visual attention.
Precisely because of this lack of convergence, it seems unlikely that the neuroscientific study of human cognition will eventually give rise to a unified theory of the human mind in terms of its underlying neurophysiology.

To show this, we first introduce a framework to analyze the role of technologies in neuroscience, based on the approach of postphenomenology, arguing that the reality that scientists investigate is mediated by the technologies they use ( $\$ 7.1)$. Next, we show that postphenomenology has rightly emphasized the role of technologies in the construction of scientific objects but lacks empirical translation. To fill this lacuna, we relate postphenomenology to empirical studies of (neuro)scientific practice and suggest that a postphenomenological framework, augmented with insights from CA, provides a fruitful way to study how "visual attention" is constituted in neuroscientific practice After developing this theoretical framework, we discuss how we collected our data and the methods we use in our analysis $(\$ 7.2)$ and provide an explanation of the technica details necessary for a basic understanding of cognitive neuroscientific research into visual attention $(\$ 7 \cdot 3)$.

Our analysis shows that NIBS technologies make researchers strongly orient to a norm of causality that is weighed against the norm of "reality" (i.e., the extent to which experimental results can be extrapolated to situations outside of the laboratory). As a consequence, NIBS actively shape how visual attention is constituted in neuroscientific practice (\$7.4). We subsequently demonstrate how the underlying interpretative framework of the cognitive neurosciences calls for the combination of NIBS and EEC and argue that the combination of NIBS and EEG mediates how neuroscientists orient themselves to the norms of causality and reality. The introduction of a new technology significantly shapes how the trade-off between causality and reality is managed, thereby constituting visual attention in a different manner $(\$ 7.5)$. We conclude by suggesting that how researchers orient themselves to the norms of causality and reality during the constitution of visual attention (i) is mediated within the relations between scientists and technologies and that (ii) "causality" and "reality" are not explicit norms that are straightforwardly complied with but are implicitly oriented to when constituting visual attention as a neuroscientific phenomenon (\$7.6).

\section{\$7.1 TECHNOLOGICAL MEDIATIONS AND THEIR APPROPRIATIONS}

In modern science, objects of research typically become visible to scientists in interactions with technological instruments. For instance, observing the human brain is impossible 
without imaging technologies such as computed tomography and MRI. Similarly, observing human cognition in neuroscientific terms depends on technologies such as fMRI, EEG, and NIBS. These technologies are central in translating relevant phenomena into candidates for human interpretation. In the words of the postphenomenologist Don Ihde, a "translation is a technological transformation of a phenomenon into a readable image. This is one analog to a hermeneutic process, except in this case it is a material hermeneutic process" $(1991,56)$. These translations can be understood as technological mediations that structure how reality becomes perceptible to scientists (Ihde, 1991, 1998, 2009). Ihde suggests that, to understand modern scientific practice, we must focus on these hermeneutic processes that give rise to the existence of scientific objects.

Although technologies help shape relations between scientists and the reality they study, they do not determine the objects of research. Rather, technologies mediate the reality that scientists study: in the relation between humans and technologies, a specific knower (subject) and thing known (object) are constituted, but the structure of the relation between the two is not fixed (Verbeek 2005, 130). Different technologies disclose the reality that scientists study differently and constitute different types of scientific observers. From this perspective, understanding how scientists relate to technologies becomes a way to understand how scientists and the objects they study mutually constitute one another. Ihde emphasizes that technologies make reality perceptually present in a specific way and understands technological mediations in scientific practice in terms of the constitution of a specific perceptual object that becomes visible for an embodied observer. This has inspired postphenomenological studies showing how images condition debates in the neurosciences (Rosenberger 2011) and on how scientific observations of the surface of Mars are mediated by imaging technologies such as the Mars Orbiter Camera (Rosenberger 2008, 2013).

In emphasizing the actively mediating role of technologies, the postphenomenological approach has tended to overlook how human beings subsequently understand and act upon these mediations. Analyses of technological mediations deserve to be complemented with analyzing human appropriations in actu (Verbeek 2016, 191). The constitution of visual attention as an object of research depends not only on how brain activity becomes perceptually present through technological mediations but also on how groups of scientists collectively appropriate these mediations. As discussed in more detail below, we suggest that CA allows us to capture both the implicit and explicit ways in which technological mediations are appropriated in actu (cf. Ibid. 195).50 Thus far, the empirical study of how technological mediations are appropriated in scientific practices has not been a central concern in postphenomenology. In this article, we adopt the challenge of studying how technological mediations are appropriated by conducting an empirical study of how visual attention is constituted in neuroscientific practice.

\section{Scientific Instruments in Neuroscientific Practice}

The empirical study of laboratory practices has been a central interest of STS since its early days (e.g., Knorr-Cetina 1999; Knorr-Cetina and Mulkay 1983; Gilbert and Mulkay 1984; Latour and Woolgar 1986). Interest in neuroscientific practices increased after the designation of the Decade of the Brain (1990-1999), a large, publicly funded big science project devoted to the study of the human brain (e.g., Littlefield 2009; Littlefield and Johnson 2012; Pickersgill and Van Keulen 2012). Since the increased popularity of the neurosciences is closely related to technological developments that visualize brain processes in vivo, the role of brain imaging technologies in scientific practices has primarily been the subject of investigation (e.g., Beaulieu 2002). Critical studies have focused on how neuroscientists unjustifiably tend to reduce human beings and personalities to their underlying neurophysiology (e.g., Choudhury and Slaby 2012; Dumit 2004).

Furthermore, it has been shown that brain scansshould notbeunderstood as allowing to "peak into the human mind" but that understanding human cognition in terms of its underlying mechanisms is dependent on active processes of human interpretation (e.g., Roskies 2007). For example, it has been argued that the "seeing" of brain scans has been conceptualized as the product of organized embodied actions (Alač 2008), as the tacit knowledge needed to interpret brain scans (Gross 2009; Heiberg Engel 2008). While such analyses convincingly show that the interpretation of brain scans presupposes a specific social and embodied organization, they often surpass the question of how technologies help shape the objects of scientific research. In this study, we examine this question by investigating how visual

50 Previous empirical postphenomenological studies on scientific imaging have nicely shown how technologies mediate perception in scientific practice in the context of microscopy in a cytology laboratory (Forss 2012) and in particle physics (Hasse 2008). In the present chapter, the focus is not primarily on scientific imaging and hence is less on how visualizations of scientific phenomena become perceptually available. Accordingly, the concept of "appropriation" is used precisely to understand how technologies mediate the constitution of scientific objects beyond the perceptual-although it does not at all aim to deny the fundamental importance of perceptual observation in scientific practices. To reveal the subtleties of how technological mediations are appropriated in actu requires to engage closely with the flow of action in which scientific practice occurs. This flow of action cannot be captured by using empirical methodologies such a interviewing techniques or participant observation (e.g., Aagaard 2015; Hasse 2008), but can-so we argue-be fruitfully approached from the perspective of CA. For a more detailed discussion about postphenomenology and its relation to different empirical research methodologies, see Aagaard (2018). 
attention is shaped in the relations between humans and technologies. We focus on how brain imaging technologies constitute the scientific object "visual attention" in a very specific way and shape how it becomes a reference point of collective orientation. From this perspective, scientific objects are never fixed entities but are rather tentative objects that are subject to continuous revision. In line with recent conversation analytic studies, we show that the coming into being of such objects can be understood as practical accomplishments. In other words, scientific objects such as visual attention "emerge and [are] established, perceived and understood, from processes and trajectories of social interaction" (Nevile et al. 2014, 17). In our analysis, we show that the processes and trajectories of social interaction are mediated by the technologies that scientists use and, accordingly, mediate the epistemic norms scientists hold each other accountable for.

\section{Conversation Analysis and Normative Accountability}

We use CA to study the constitution of visual attention. Related to EM, CA (Sacks 1992; Lynch 1985, 1988; cf. Te Molder and Potter 2005) studies from a participants' perspective how people use language as a medium to construct a reality in which meaningful actions are performed. Like EM, CA is interested in the rules and norms that people use and hold each other accountable for. Both EM (Garfinkel 1967) and CA (Sacks 1992; Te Molder and Potter 2005) define everyday life as deeply and inherently normative.

According to conversation analysts, normativity is not so much the consequence of people obeying certain rules but is rather constituted by the fact that people orient themselves towards norms: actions are described in ways that display their status with regard to some rule or expectation (Heritage 1984). When categorizing events as departing from some normative order, people account for that deviation, thereby making routinely hidden norms available for inspection by researchers. By orienting themselves to these norms, participants organize their conversations around what they routinely interpret as normatively appropriate conduct (Heritage 1984, 115-120). From this perspective, the practical accomplishment of an object is simultaneously a normative accomplishment. Building on this line of research, we analyze in this chapter how visual attention is constituted within the process in which scientists make themselves accountable to specific epistemic norms, which in turn take shape in the interaction with technologies. Conversation analysis allows us to analyze interactions between scientists in real-time, which enables us to show the norms to which they orient in the active constitution of visual attention. Because these norms are constantly (re-)negotiated, visual attention is interpreted not as a rigid entity but as an accomplishment that is subject to continuous change (Koschmann and Zemel 2014; Nevile et al. 2014). Consequently, scientific objects do not appear as stable referents but are dynamically constituted in the interactions between scientists and in the relations between scientists and technologies.

\section{$\$ 7.2 \quad$ DATA AND METHODS}

For our data, we used video recordings of discussions between members of a group of researchers in the cognitive neurosciences during their weekly laboratory meetings. The material was recorded over a period of two months. We transcribed and examined the recordings with a primary focus on the verbal exchanges. A supplementary analysis of the video material was performed whenever it appeared necessary for a full understanding of what was said and done. The names of the participants have been altered, and the date and time indications have been deleted to minimize the possibility of identification. Institutional ethical approval was granted before the period of data collection. The data corpus consists of recordings of five laboratory meetings, comprising a total of approximately 500 minutes of recorded material.

The recorded meetings were transcribed using ELAN ${ }^{51}$ The primary part of the dat corpus was transcribed to a words-only level, but relevant parts were transcribed in more detail, including the pauses and overlap between speakers. The original conversations were in English, but most participants were non-native speakers. We have not translated the conversations into grammatically correct sentences, because this would undermine the objective of studying the constitution of objects in real-life conversations among participants.

In line with the principles of CA, our approach has been participant centered (i.e., we examined how participants in the conversation actively constructed a meaningful reality) (Lynch 1993). In addition, we began with the assumption of technological mediation theory that considering technologies (such as NIBS or EEG) is crucial when it comes to understanding the constitution of objects. Accordingly, our analysis has focused on those elements in the conversations where the relation between the use of a particular technology and the constitution of visual attention was subject of discussion.

\section{$\S 7.3$ NIBS, EEG, AND VISUAL ATTENTION}

NIBS includes a set of different technologies that stimulate the brain at different levels. Neuroscientists use NIBS to study the neurophysiology underlying human cognition. In the present case, they aim to establish a causal relation between neurophysiological activity and our ability to detect visual stimuli. Visual attention is typically measured

51 ELAN was developed by the Max Planck Institute for Psycholinguistics, The Language Archive, Nijmegen, The Netherlands (url: http:/|tla.mpi.nl/tools/tla-tools/elan/). For an explanation of ELAN, see Wittenburg et al. (2006) 
using an eye-tracking device. During experimental trials, participants are asked to fixate on a red cross that appears at different places on a screen. As experiments typically involve more than one participant, the relation between NIBS and visual attention is described in terms of the average of the statistical differences within a group of participants. Hence, observing visual attention requires the translation of the result of the stimulation into a graph that visualizes the average behavioral performance of the participants.

Specific to NIBS technologies is that they allow for the alteration of neurophysiological activity and that they are assumed to induce behavioral change. Depending on the location and intensity of the stimulation, researchers expect that the participant's ability to fixate on the red cross will increase or decrease. The effect of NIBS is conceptualized in terms of the statistical difference between the participant's behavioral performance without stimulation and the behavioral performance during stimulation. Actual stimulation is often compared with a so-called sham condition, in which researchers pretend to stimulate the participant's brain. A comparison between the sham condition and the actual stimulation serves to filter out the behavioral changes that are caused not by the induced stimulation but by the unusual circumstances in which experimental trials occur.

The neurophysiology underlying behavioral change cannot be observed using NIBS. Observing neurophysiological changes requires one to use NIBS in combination with imaging technologies such as EEG and fMRI. Only in this way can researchers detect the neurophysiological patterns that correlate with the behavioral changes occurring after stimulation. Successful integration of EEG and NIBS allows researchers to infer that the neurophysiological changes observed are actually caused by the NIBS technology, instead of being a random effect of other environmental stimuli.

\section{\$7.4 CONSTITUTING VISUAL ATTENTION THROUGH NIBS}

The causal reasoning instantiated by NIBS can be understood as follows: a stimulation technology (NIBS) causes behavioral change (BC) (see Figure 1). By stimulating the brain at a specific location at a specific frequency, researchers can test hypotheses on how stimulation influences behavioral performance. For example, stimulating a specific brain area might increase or decrease the participant's ability to fixate on a red cross that is shown on a screen. In this way, visual attention becomes present as an object that can be manipulated by the researcher, such that a causal relationship between the stimulation and the behavioral change can be established.

\section{NIBS}

Figure 1: Causal Reasoning in NIBS Practices

A crucial problem that the researchers face is how visual attention can appear as an object that can be causally reasoned about. This requires the careful construction of causality within a specific experimental set-up. Researchers are very much aware of their own acts of construction, which makes them constantly question the reality of their own constructions. "Too much causality" is often interpreted as an indication of a "lack of reality." Thus, creating visual attention in terms of causality requires the management of potentially conflicting normative ideals that researchers hold each other accountable for: the norm of "causality," and the norm of "reality" (i.e., the extent to which experimental results can be extrapolated to the world beyond the laboratory). In our analysis, we show how this problem develops in relation to the technologies used and how it is managed in the interactions between scientists. In doing so, we highlight that the construction of visual attention is the product of a trade-off between normative conceptions of both causality and reality. Contrary to a traditional take on science as a project that cumulatively approaches the truth about a fixed object in a stable reality, the reality of visual attention is continuously (re-)established in the negotiation between the norms of "causality" and "reality."

Consider the following fragment of a conversation between Mike, Pete, and Suzy that illustrates the pattern. Suzy has just proposed a new experimental framework for studying visual attention that would be more in accordance with reality (i.e., more "ecologically valid" [line 28]). For that purpose, Suzy proposes the integration of "distractors" into the experimental design:

Excerpt 1:

Mike: m yeah but [if=

2. Mary: [yeah

Mike: =all it means adding so::me (.) random (o.5) pictures on both sides of the visual field (.) and the (creations) still as they would were

Pete: I- I- I think that those paradigms are quite difficu::It in terms of interpretation (.) becau::se you never know whether you have an effect on the target or the distractor that leads to certain behavioral change (.) (16 lines omitted)

Pete: yea-yeah emmhe I mean distractors are interesting because the-they are ecologically valid right? They are distractors over time an- an- an-suppressing 

speaki::ng adding this makes it a less well-controlled design

The proposal to integrate distractors is positively picked up upon by Mike in lines 3-5, who treats it as a minor adjustment to the existing experimental set-up, namely, as only involving the addition of "some random pictures" (line 3). Pete, however, treats these distractors in an entirely different way when arguing that their inclusion would make the experimental set-up "quite difficult in terms of interpretation" (lines 6-7), because the source of the behavioral change can no longer be detected (lines 8-9). In other words, adding distractors complicates the "NIBS $\rightarrow$ BC" logic embodied in NIBS technologies. What Mike considers to be "some random pictures" is treated by Pete as seriously undermining the normative ideal of constructing visual attention in terms of causality. This requires a degree of precision that Pete argues to be incompatible with Suzy's proposed framework.

Pete agrees with Suzy that distractors would make the experiment "ecologically valid" (line 12) because in real life, people continuously suppress the presence of irrelevant yet potentially distractive stimuli (lines 13-14). However, adding distractions also makes the experimental set-up less well controlled (lines 17-18), which makes it no longer possible to interpret the experimental outcomes in terms of the causal relation between NIBS and BC. The experimental set-up must follow the logic instantiated by NIBS, which constitutes a norm of causality to which scientists orient in the construction of their object of research. Making the experiment more ecologically valid is not an option, because it comes at the expense of no longer being able to understand the experiment in causal terms. This implies that in the constitution of visual attention, neuroscientists hold each other normatively accountable for maintaining the causal structure of the experimental set-up, and they do so at the expense of its "realness": the extent to which experimental results can be extrapolated to conditions outside of the laboratory.

Our analysis thus suggests that the norm of causality competes with normative conceptions of the reality of a constructed object, such as its ecological validity. This indicates that when the constitution of visual attention is mediated by NIBS, (i) constituting visual attention can be seen as the interactional outcome of a trade-off between "reality" and "causality," that is, as two in practice conflicting norms to which researchers hold each other accountable; (ii) the norm of causality more strongly structures how visual attention is constituted than the norm of reality; and (iii) the norm of causality is not reflected upon, (i.e., is not the subject of any explicit deliberation) and remains unproblematized.

\section{§7.5 COMBINING NIBS AND EEG: COMPLICATING CAUSALITY}

NIBS technologies constitute visual attention in a specific manner because they embody the logic of a causal relationship between brain stimulation and behavioral change (Figure 2). When combining NIBS with EEG, the construction of visual attention becomes increasingly complex. Schematically, an element is added to the causal reasoning process that also accounts for neurophysiological change: NIBS causes neurophysiological change (NPC) which in turn causes behavioral change (BC) (Figure 2). To make the observation of neurophysiological change possible, the combination of NIBS with a brain imaging technology is required. In our case, the researchers chose to combine NIBS with EEG. The combination of these technologies requires researchers to demonstrate a more complex causal relationship between brain stimulation and neurophysiological interactions.

2.1 NIBS: Without Neuronal Activity

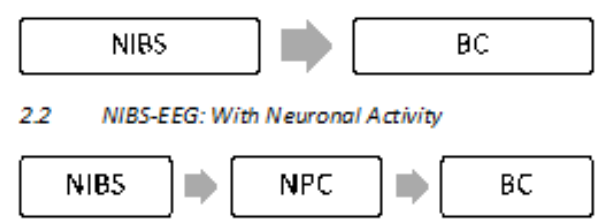

Figure 2: Causal Reasoning in NIBS-EEG Practices

In the group of researchers under study, EEG is combined with a specific form of NIBS, transcranial alternate current stimulation (TACS), which allows for the direct stimulation of oscillatory brain activity (Herrmann et al. 2016). Oscillations can be defined in terms of frequency bands and occur constantly without the presence of experimental stimuli. It is assumed that these different frequency bands correspond to specific cognitive processes (e.g., Ward 2003). The stimulation of a specific frequency band through TACS therefore opens the possibility of establishing a causal link between oscillations and specific cognitive processes.

Combining EEG and TACS constitutes a different causal logic, because now a causal relation between TACS, the neurophysiological change corresponding to the stimulation, and the corresponding behavioral change must be established. The combination of EEG and TACS gives rise to the need to understand brain stimulation in terms of 
visualizations of the underlying neurophysiology, rather than in terms of the directly visible behavioral consequences. Also, a task stimulus can no longer be understood as only producing this or that neurophysiological response that can be measured by EEG, as it must understand this response precisely to the extent that it is caused by TACS. Not only should it become possible to observe the NPC occurring during the experiment, but the NPC must be interpreted as directly caused by TACS. As a consequence, causality can no longer be thought of as an interaction between two components but should be understood as distributed through an increasingly complex chain of different elements. Constituting Visual Attention Through TACS-EEG: Reality and Causality

The novel way in which visual attention is constituted through TACS-EEG becomes clearly visible when the researchers attempt to observe relevant neurophysiological activity and link it to the induced stimulation. This process of observation already starts before a participant receives brain stimulation. Before applying TACS, the relevant oscillatory frequency band of the participant must be determined, because the breadth of frequency bands varies among individuals. For this purpose, participants are presented with a cognitive task (say, following a red dot on a screen), and it is then analyzed, using EEG, which activity in a specific frequency band corresponds with the behavior of the participant. Consider the following conversation in which Pete and Suzy attempt to determine the breadth of a frequency band

\section{Excerpt 2:}

1. Pete: I am seeing to your peak

2. Suzy: $\quad$ yeah and I mean it's like two hertz broad (.) they sa:y [hhh

3. Pete:

4. Suzy: it it's two hertz but yeah [eh

5. Pete:

6. Suzy

[mmm

7. Pete: =because that's too nice a number to be true::

8. Suzy: yea yea yeah it's too nice=

In line 1, Pete reacts to a graph shown by Suzy, in which he identifies a peak that indicates the breadth of the frequency band of a participant. Suzy responds by specifying the exact breadth, when stating that it is "like 2 hertz broad" (line 2), corresponding to what "they say" (line 2). Because "2 hertz broad" is treated by Pete as an unreliable outcome (it is "too nice a number be true" [line 9]), we take it to refer to the average in breadth across participants in general. Pete's immediate rejection of the peak being two hertz broad shows that when determining individual frequency bands, researchers do not rely on external theoretical standards but consider that, in practice, measurements do not coincide with theoretical expectations. Contrary to the "beauty" of theoretical generalizations, individual electrophysiological activity is "messy." Accordingly, the norm of "reality" introduces an expectation that the experimental results should have a certain level of "messiness," which in turn functions as a reason to question the adequacy of statistical analyses. The criteria of "messiness" and "beauty" thus co-determine the (in)adequacy of experimental results and create certain normative expectations about the reality of the observed breadth of an individual frequency band.

Identifying an individual frequency band requires the correlation of neurophysiological activity and behavioral performance. When combining TACS and EEG, it must be ensured that oscillatory change can be understood as being causally produced by TACS, that is, not dependent on other variables. This requires moving beyond the correlational logic of EEG, which cannot rule out that a change in oscillatory activity is affected by something other than the induced stimulation. Furthermore, visual attention is no longer understood as the causal relation between TACS and BC but instead as the more complex causal relation between TACS, NPC, and BC (Figure 2). As we show, the integration of NPC is not treated as a technical problem, but it spurs researchers to orient themselves to the norm of causality in a manner that narrows down how visual attention can be understood. In other words, the reality of visual attention is causally dependent on specific oscillatory patterns as shaped by the combination of TACS and EEG. Consider the following conversation between Mike, Mary, and Andrew:

\section{Excerpt 3:}

1. Mike: was there anything [that you guys have seen or not

Mary: [e:*:.:hm no I don't think that it goes that fa:::r $($. huhu so:: it was really .hh and I-I-I think even so what [colleague] said and I see the same that even (.) between the different subjects for one subject .hh the dorsal attention network is more linked toward you $\mathrm{kn}-\mathrm{mmhmmh}$ is more linked to five hertz and for the other its more ten hertz [a::nd you know so th-the

Pete: $\quad$ muh he he

Mary: [its really so we are with with the[the

o. Andrew:

11.

12. Mary:

13. Mike: I mean it [could be a variable yeah yeah th-that's the e::h good question [.hhhh ha is it just noise or is it more than noise 
that's indeed also what I mean if we wanna push it by scanning nine people it would be nice

if it is on the basis of (0.5) some let's say educated(.) guess that it works (0.3)

yea::h

that something works huhu

that TACS does anything (.) in the brain that would be nice
When discussing the outcome of the TACS-EEG experiment, Pete asks whether the effects of TACS can be "seen." Mary responds that she is not yet sure, because the analysis did not go "that far" (lines 3-4) (i.e., her analysis was unable to determine whether the oscillatory change could be causally linked to TACS). Too much difference exists between individual participants to determine whether the oscillatory change is caused by TACS (lines 7-11). This temporal understanding of seeing as a process over time instead of as an immediate act indicates that whether an object can be observed is dependent on how it is constituted. The norms of causality and reality are constitutive of both the act of seeing and the construction of the seen. This is reflected in Andrew's question of whether some type of systematics can be detected that accounts for the differences (lines 14-16). The seeing of visual attention is dependent on the extent to which it can be regarded as causally produced by TACS. Because no definite answer can be given to Andrew's questions, Mike states that at this point, he is unsure whether "something works" (lines 25) (i.e., whether the individual neurophysiological differences can be causally explained in terms of the TACS stimulation).

The conversation ends with Mike displaying insecurity regarding whether TACS has stimulated the brain at all. This statement can only be meaningfully interpreted when the behavioral change is to be understood in terms of not only TACS but also the underlying neurophysiology. Using the original NIBS logic, it would have been clear that the behavioral change was caused by TACS. Using TACS-EEG, to establish a relation between TACS and behavioral change is to understand the effect of TACS, but this understanding must be complemented with an account of the relationship between TACS and the neurophysiology. TACS-EEG research complicates the norm of causality, which must now be understood as the measurable causal relation between NIBS, NPC, and BC. Because of this change, it becomes possible to interpret the behavioral change caused by TACS as not necessarily "doing anything in the brain" (lines 26-27). The reality of visual attention becomes dependent on the causal norms that come into being in the relation between the researchers, and in the relation between the researchers and the technologies that they use.
With the introduction of EEG, the relation between TACS and behavioral change becomes increasingly complex. This complexity sparks an uncertainty in TACS-EEG research, making it not straightforward and clear how NIBS, NPC, and BC are linked. Regardless of the complexity of the interactions between these three elements, researchers remain oriented to a norm of causality in TACS-EEG research. Consider the following interaction between Suzy and Pete:

\section{Excerpt 4:}

1. Pete:

2.

3. Suzy:

4. Pete:

6. Suzy:

7. Pete:

8. Suzy:

9. Pete:

10. Suzy:

11. Pete:

12.

13. them and try to applic- apply them somehow hhh I am totally not convinced [hahaha

[no?

naaa nooo it-its its its a conflict of of research styles its its eeh (2.0) huhuhuh

tell me more about it?

no::: its its just I would always start with a proper EEG [experiment= $[\mathrm{mhmm}$

=we have behavi $[$ orally=

$$
\text { [yea yea }
$$

$=(0.3)$ things that can relate to physiological measures and and you kno:::w and then you have (.) a correlation::: (0.3) of two things and then you can (.)move on to causality with brain stimulation thats just how I feel about it
Pete indicates that he is uncertain about the approach taken in the laboratory when conducting TACS-EEG research (line 2). When identifying a "conflict of research styles" (lines 4-5), he contrasts the work in the laboratory with an approach that would "start with a proper EEG experiment” (lines 7-8). Such an experiment would establish a correlation between behavior and physiology from which, he asserts, causality could be inferred at least that is how Pete "feel[s] about it" (line 16). The use of phrases with a subjective connotation, such as "research styles" and "how I feel about it," indicates that his own approach does not provide an objective-for participants-manner to construct visua attention through the use of TACS-EEG. The constitution of visual attention in terms of TACS-EEG is dependent on the individual style of the researcher and is not treated as an "objective" solution that determines whether the neurophysiological change is caused by TACS-as would be the case if only NIBS were used to investigate the human brain Although Pete suggests that the research should "start with a proper EEG experiment" 
(lines 7-8)-indicating a clear starting point-he does not provide a justification for this idea other than to state that it would be the consequence of his preferred style of research.

The combination of intervening with NIBS, and imaging with EEG, requires the integration of the causal reasoning embodied in NIBS and the correlational reasoning embodied in EEG. In NIBS research, the construction of visual attention can best be understood as managing the trade-off between "causality" and "reality," in which causality is treated as unproblematically realized through NIBS. However, with the introduction of EEG, "seeing" visual attention is treated as problematic in this context, and the researchers cannot easily design a causal understanding of behavioral changes in terms of the relation between the induced stimulation and neurophysiological change.

In summary, the constitution of visual attention, when investigated through TACS-EEG, reintroduces a norm of causality that appears as more complex than in the case of NIBS, because a new variable-neurophysiological change-must be integrated. Through this complexity, the norm of causality can no longer be unproblematically applied but is instead treated as relative to contingent norms, such as personal research styles that "allow to move from correlation to causality" (excerpt 4, 13-14). This suggests that how causality is made normatively relevant in the constitution of visual attention is mediated by the specific technologies involved. In turn, this leads to a different way through which the trade-off between causality and reality is managed in the constitution of visual attention.

\section{\$7.6 CONCLUSION: TECHNOLOGICAL MEDIATIONS AND THE} NORMATIVE EXPECTATION OF CAUSALITY

Our analysis of how visual attention is constituted in cognitive neuroscientific research using NIBS, and combining NIBS and EEG, suggests a dominant orientation towards a cause-effect model of the relationship between brain and behavior and demonstrates how this orientation is taken for granted in the scientists' research routine. In the context of NIBS, we have argued that (i) constituting visual attention can be seen as the interactional outcome of a trade-off between "reality" and "causality"; (ii) the norm of "causality" more strongly structures how visual attention is constituted than the norm of "reality"; and (iii) the norm of causality remains unproblematized.

When NIBS is combined with EEG, the norm of "reality" suddenly becomes more complex, because reality is treated by the scientists as possessing a certain messiness that must be reflected in the observation of brain activity related to visual attention. We have demonstrated that the norm of causality can no longer be unproblematically applied in the context of NIBS-EEG. When brain activity is made visually available, researchers cannot straightforwardly assume a causal relationship between the induced stimulation and the observed behavioral change. This, however, does not make researchers refrain from normatively orienting themselves to causality, but it rather spurs them to begin orienting themselves to contingent, subjective norms, such as individual research styles, thereby safeguarding the constitution of visual attention in causal terms (cf. Gilbert and Mulkay 1984, 57). This suggests that (i) how researchers orient themselves to the norms of causality and reality during the constitution of visual attention is mediated within the relations between scientists and technologies and (ii) "causality" and "reality" function not as explicit norms but as implicit criteria, for which participants hold each other accountable, thus actively using these for the constitution of visual attention as a neuroscientific phenomenon.

Because visual attention is constituted differently in the case of combined NIBS and EEG than in the case of NIBS alone, we suggest that technologies are mediating how scientific objects come into being. Don Ihde $(2009,64)$ has argued that technologies significantly contribute to how scientists interpret the reality that they are studying and suggested understanding scientific practices as material hermeneutic practices. We have added to this work by revealing the interpretative processes through which technological mediations are appropriated (cf. Verbeek 2016), thus showing how scientists translate a phenomenon made visible by material technologies into an object of research, namely, visual attention. What it means for an object of research to be causally affected is dependent upon the particular brain stimulation technique used.

Instead of understanding technologies as possessing preferred norms constituting preferred plans of action inscribed within them (e.g., Akrich 1992), we do not assume that the norms that constitute the reality of scientific phenomena are inscribed in the technologies to which scientists relate. Our study shows how "visual attention" is created in a trade-off between what is treated by the scientists themselves as the conflicting normative pair of "reality" and "causality." By studying in actu how visual attention is constituted within this specific normative orientation, we have not only shown that normative work is involved in scientific practice but also been able to trace how these norms shape how neuroscientists understand the objects that they study.

What are the consequences of this perspective for how the brain and mind are investigated in big science projects such as the Decade of the Brain and the Decade of the Mind? Can "a mathematical and predictive framework of how all elements [of the mind] fit together 
and act as a whole to give rise to intelligence and consciousness" (Koch et al. 2015, 39) be developed? Critical approaches to the neurosciences have argued that neuroscientific research cannot be unproblematically used to solve societal problems (e.g., Dumit 2004). In their call for a Critical Neuroscience, Choudhury and Slaby advocate for critical engagement with neuroscientific research and argue that research on the impact and practices of neuroscientists should help to answer the question of "what kinds of ideas, hopes, methods, and institutions come together to produce what will count as facts about the brain" $(2012,4)$. By making explicit the role of the epistemic norms of causality and reality in the constitution of visual attention, we suggest that a specific normative framework constituting what counts as a cause-effect relationship comes into being as a consequence of how technological mediations are appropriated. Accordingly, such cause-effect relationships do not reflect an existing state of affairs external to the group of scientists but are normative accomplishments realized through how neuroscientists appropriate technological mediations.

Reflecting upon how scientists do this-that is, appropriating technological mediations-helps to reveal the interpretative-and normative-frameworks to which scientists orient themselves when constituting their objects of research. By revealing the material hermeneutic processes that structure the practices of the neuroscientists under study, we hope to have opened up a space for critical reflection on the reality that neuroscientists relate to-and the role of technologies in these processes-becomes possible. Because neuroscientists in the laboratory under study orient themselves to a linear norm of causality, other ways of understanding visual attention-and, more generally, other potentially valuable explanations of human behavior-are discarded, since these would not fit the desired causal model. Implicitly, this perspective rules out possible models in which the brain is not governing behavior and therefore becomes less central to what a human being is. Accordingly, the current popular understanding of the human brain as an autonomous agent that fully determines human behavior may not come as a surprise, as it actually reflects how neuroscientists themselves establish brainbehavior relationships in their scientific practices. By showing how the constitution of visual attention is dependent on a particular appropriation of technologies, such as NIBS and NIBS-EEG, we have shown that this understanding of human behavior is not necessarily constituted by orienting to an a priori concept of causality but is instead contingent on how a trade-off between the norms of "causality" and "reality" is managed in neuroscientific practice. 
CHAPTER 8:

"Braining” Neuropsychiatric Experiments 


\section{INTRODUCTION: THE “NEURO” IN PSYCHIATRY}

The widespread introduction of fMRI into psychology in the 1990s initiated a great optimism about the capability to finally unravel the mysteries of the human mind. Also, in psychiatry, brain imaging technologies were welcomed with great optimism as means to establish, with rigorous exactness, the cause(s) of patients' symptoms by allowing the tracing of mental disorders back to disorders in the functioning of the brain (cf. Pickersgill 2011). In the DSM-IV, for example, it was suggested that the transformation from psychiatry into neuropsychiatry would finally grant psychiatry its desired "objectivity" by making obsolete the distinction between "mental" and "physical" disorders (cf. APA 1994, xxi).

Initially, the use of brain imaging technologies in the neurosciences was guided by the assumption that specific cognitive functions could be mapped onto specific brain areas. From this perspective, the cause of a mental disorder could be found in a specific brain area that was not functioning "normally" (cf. Vidal 2009). However, the current consensus in the neurosciences leans towards the idea that human cognition is realized within large networks of neurons spread across the brain (see, for example, the Human Connectome Project), thereby generating complexity instead of the desired simplicity (cf. Buckner, Krienen, and Thomas Yeo 2013; Menon 2011; Sporns 2014). As specific cognitive functions are thought of as being realized within networks of neurons, the ways in which mental disorders can be explained are also changing. Investigating the causes of mental disorders now requires researchers to identify the complex networks responsible for specific cognitive functions and discover patterns of "aberrant" organization within these networks.

Neuropsychiatric research searches to understand mental disorders in terms of underlying brain activity (cf. Greicius 2008; Poldrack et al. 2012). At the laboratory under study, the aim is to understand mental disorders, such as attention deficit hyperactivity disorder (ADHD), in terms of the neurophysiological interactions that constitute their symptoms. The promises of neuropsychiatry are (i) to offer an objective foundation grounding diagnostic processes and (ii) to allow for the prescription of clinical (pharmacological) treatments that specifically target the symptoms of a specific mental disorder. This model of understanding mental disorders posits neurophysiological activity as an explanatory cause of specific symptoms, thereby treating (the study of) the human brain as potentially simplifying the processes of psychiatric diagnosis and treatment (cf. Insel and Cuthbert 2015). the cognitive neurosciences and show how the reality of visual attention is constituted within the technologically mediated trade-off between the norms of causality and reality. In this chapter, I show, through an analysis of conversations between scientists who interpret brain scans, how the objects oriented to in neuropsychiatry are constituted through a different trade-off: one between complexity and simplicity. The question of how the complexity of the brain shapes neuropsychiatric practices must be answered relative to the aim of neuropsychiatry, namely, to develop simple explanatory models of mental disorders that possess a clear clinical purpose. I focus on how brain scans are interpreted in light of previous diagnostic categories and subsequently treated as incentives to develop experiments that are tailormade to these categories. Through this focus on the appropriation of brain scans, I investigate how objects of neuropsychiatry are constituted within the presence of a specific phenomenotechnology.

Building upon the idea that technologies mediate scientific knowledge, this chapter departs from the idea that the use of fMRI in neuropsychiatry gives rise to a specific understanding of the brain as complex. I do so through an analysis of conversations between a group of neuropsychiatrists in which they interpret experimental data. Data was obtained in a neuropsychiatry laboratory in a university hospital in the Netherlands and consists of approximately five hours of recorded conversations between neuropsychiatrists..$^{2}$

The chapter is structured as follows: firstly, I suggest that how the human brain is understood as "complex" in neuropsychiatry is shaped through how scientists appropriate brain imaging technologies and that these appropriations can be studied from the perspective of EM (§8.1). Secondly, I briefly discuss the relation between research in neuropsychiatry and the clinical function of psychiatry, focusing specifically on the relationship between the perceived complexity of mental disorders in term of brain activity and the desired simplicity of clinical treatment (\$8.2). I subsequently demonstrate how the relationship between complexity and simplicity is actively managed by neuropsychiatrists, by showing how interpretations of experimental data are structured through an orientation to previous diagnostic labels (§8.3). I then show how the appropriation of complexity becomes an incentive to develop experiments that are tailormade to these already established diagnostic categories (\$8.4). To conclude, I suggest that ignoring the complexity introduced by network approaches to human cognition is a strategy to make relevant the work of neuropsychiatry for concrete individuals (\$8.5).

52 The term "neuropsychiatise" should not be understood as referring to a clinical psychiatrist. None of the researchers at the laboratory under study were clinical psychiatrists themselves, but the participants in their experiments were recruited from the clinical psychiatrists at the same academic hospital. 


\section{\$8.1 THE COMPLEXITY OF THE BRAIN AS TECHNOLOGICALLY} MEDIATED

Neuropsychiatrists investigate the underlying neurophysiological substrates of mental disorders, and doing so requires the presence of brain imaging technologies such as EEG or fMRI that make it possible to observe brain activity in vivo. How neuropsychiatrists relate to (symptoms of) mental disorders is therefore dependent on how they relate to the technologies that they use to investigate those disorders. In the relation between scientists and technologies, specific interpretative categories and options for action and manipulation come into being that allow scientists to understand the object under study in a variety of ways (cf. Ihde 1991,137). Accordingly, the objects of scientific knowledge are constituted not only through the technological mediations that bring them within the domain of human perception but also through how scientists actively appropriate them within particular schemes of interpretation and action (cf. Verbeek 2016).

Brain imaging technologies mediate how neuropsychiatrists understand mental disorders by making available in vivo the complex working of the human brain and its role in the development of mental disorders perceptually. However, the technologically mediated manner in which the complexity of the brain and how it helps realize specific forms of cognitive (dis)functioning does not occur in a vacuum but is relative to existing knowledge of mental disorders and brain functioning. Brain imaging technologies must be integrated into the existing goals and aims of neuropsychiatrists. In other words, when brain imaging technologies present the brain as a complex network, neuropsychiatrists are not simply confronted with a fait accompli. Rather, they must develop new interpretative strategies and plans of action against the background in which they understand mental disorders. Although the complexity of the brain cannot be simply surpassed, its role in relation to the understanding of mental disorders is not fixed. In the appropriation of the complexity of the brain, new ways appear to hypothesize how (symptoms of) mental disorders are realized and develop experimental circumstances in which such hypotheses can be tested.

The conception of the brain as a complex network is not new. Throughout history, complexity has often been singled out as a central feature of the human brain. For example, at the end of the $19^{\text {th }}$ century, the famous Spanish histologist Santiago Ramón y Cajal developed an understanding of the brain of a complex organ on the basis of microscopic observations of the neural structure of brain cells. However, as the French epistemologist George Canguilhem has argued, philosophers interested in scientific knowledge should not be "thinking that persistent use of a particular term indicates an invariant underlying concept” (Canguilhem 1994, 32 op. cit. Rees 2016, 92). The question that should be posed, because of the situated nature of complexity, is how the use of fMRI in neuropsychiatry discloses the human brain as complex.

In the context of molecular biology, Hans-Jörg Rheinberger has argued that in the history of biology, crucial experiments typically developed parameters for simplification to be explanatory successful, while simultaneously retaining the complexity of the research object (e.g., genes) (1997b). This implies a trade-off between simplicity and complexity in experimental research. Similarly, based on a critical reading of how pioneering synthetic biologists describe their work, Talia Dan-Cohen notes that researchers in synthetic biology are often trained as computer scientists and electrical engineers and deliberately ignore the biological complexity of life when developing models for designing and constructing novel organisms (2016). In this chapter, I show how a trade-off between simplicity and complexity is made in neuropsychiatric practice by exploring how neuropsychiatrists interpret experimental data. Because neuropsychiatric experiments and explanations make most of the aspects of the brain irrelevant, they do not unproblematically reflect the complexity of the brain. However, as becomes clear below, neuropsychiatrists do not so much ignore complexity as make it a workable element within the schemes through which they explain mental disorders. The chapter shows how the complexity of the brain is made workable, and the trade-off achieved, by laying bare how the specific technological mediations are appropriated by scientists on the ground.

\section{An Ethnomethodological Perspective on the Objects of Neuropsychiatry}

In Chapter 6, I argued that studying appropriations of technological mediations requires an ethnomethodological perspective on the interaction between human beings and technologies. Rather than in isolation, technological mediations should be treated as belonging to processes within which scientific objects are constituted. In line with this perspective, I understand the coming into being of the objects of research within neuropsychiatry (i.e., mental disorders) as processes occurring within the relations between scientists and between scientists and technologies.

My analysis of the data is based on recordings of conversations between people working in the neuropsychiatry laboratory in which experimental data obtained by brain imaging technologies is interpreted. These conversations were transcribed using ELAN. Inspired by $\mathrm{CA}$ and $\mathrm{EM}$, I use these real-time interactions to reveal the norms that are oriented to during these processes of interpretation (cf. Garfinkel 1967; Heritage 1984).

In line with how Michael Lynch (1985) integrates CA into the study of scientific practices, I reveal how certain interpretative acts must be performed to maintain the continuity of the epistemic themes within scientific practices. Lynch argues that it is by orienting 
to projects addressing specific epistemic themes that the actions of scientific collectives are structured and within which certain features of the obtained data stand out as relevant. However, "the relatedness of actions in a project's sequence of actions [...] was not available in the continuous monitoring of the spectacle of events which where witnessed in the lab" (Lynch 1985, 55). Accordingly, "the continuity of a project is not a 'real-time' continuity [...] but the analysis [of practical activities] need to supply [...] a way of indexing successively displayed actions to their appropriate projects" (Ibid. 68). ${ }^{53}$ The level of detail in which the fragments are transcribed reflects my focus on analyzing how neuroscientists orient themselves to specific epistemic themes: I have chosen to transcribe overlaps between speakers and pauses to be able to analyze how orienting to an epistemic theme occurs collectively. I have refrained from a more detailed transcription level often used in CA, because my intention is not to analyze the structure of conversations proper but to instead reveal how epistemic themes are interactionally oriented to and made relevant.

When the project of neuropsychiatry can be understood as establishing (causal) relationships between brain activity and specific mental disorders, it is through this lens that the appropriation of technological mediations must be addressed. Accordingly, the central epistemic theme that I focus on in this chapter is how the perceived complexity of the brain is made to match the aim of neuropsychiatry to link patterns of brain functioning to symptoms of mental disorders.

\section{\$8.2 NEUROPSYCHIATRY AND THE CLINICAL FUNCTION OF} PSYCHIATRY: COMPLEXITY AND SIMPLICITY

Before specifically turning to how neuropsychiatrists appropriate technological mediations in practice, a brief explanation is necessary regarding the promise of neuropsychiatry in relation to existing psychiatric practices. As indicated, the promise of integrating brain imaging technologies into neuropsychiatry is that they allow the measurement of brain activity, which will lead to more fine-grained diagnostic psychiatric processes in the long run. In the laboratory in which the data of this study was obtained, brain imaging technologies such as fMRI are primarily used to investigate how mental disorders such as autism spectrum disorder (ASD) or ADHD correlate with specific patterns of brain activity.

53 This already presupposes an interpretation of CA that slightly deviates from the traditional aim of CA to study in real time how conversations are ordered by focusing on phenomena such as turn-taking and further general characters of the sequential organization of conversations (cf. Lynch 1985, 6-12; Ten Have 1990).
Diagnosing someone with ADHD, obsessive-compulsive disorder (OCD), or ASD is not to point to a singular entity but to categorize a multiplicity of different symptoms under a single header. For example, the DSM-V lists the following symptoms as diagnostic criteria for ASD: (i) persistent deficits in social communication and social interaction; (ii) restricted, repetitive patterns of behavior, interest, or activities; (iii) symptoms being present in early developmental period (iv) symptoms causing clinically significant impairment; and (v) disturbances not being better explained by intellectual disability (cf. APA 2013, 49-50). This indicates that neuropsychiatric research does not explicitly target mental disorders as a whole but works on the level of the symptoms associated with them. The laboratory in which the conversations were recorded has a strong focus on "restricted, repetitive patterns of behavior, interest, or activities," which is considered a symptom of either ADHD, OCD, or ASD. Accordingly, brain imaging technologies were primarily used to target aspects of the brain that were thought to be relevant for this specific type of behavior.

One would expect that fMRI, as well as the supposed objectivity associated with it, would be foundational when arriving at exact knowledge about the brain and its relation to certain pathologies (scheme 1). However, the previous psychiatric diagnosis, often based on the intuitive expert judgment of psychiatrists when meeting a patient for the first time, is leading, according to psychiatrists, when interpreting brain scans and the results of behavioral psychiatric tests (scheme 2) (cf. Cohn 2012, 182-83). The supposed exactness of brain scans is thus rarely used to challenge previous diagnoses, but rather, the content, meaning, and relevance of brain scans in psychiatric research strongly depends on judgments made by means of the techniques of "traditional" (i.e., based on interviews and questionnaires) psychiatry. scheme 1

\section{fMRI - Test - Naked Eye}

Naked Eye - Test - fMRI Scheme 2
While both of these schemes suggest a linearity in how brain scans are interpreted in (neuro-)psychiatry, in practice, the different ways of obtaining knowledge often intermingle, and interpretative processes follow a hermeneutic, rather than linear pattern. Psychiatric tests are sometimes used to challenge brain scans; brain scans are sometimes used to challenge the expert judgments of psychiatrists; and earlier psychiatric judgments are sometimes used to challenge the authority of either psychiatric tests or brain scans. This interpretative pattern is guided by the question of whether the behavior of a patient, her brain visualized through fMRI, or certain results are indicative of (a) "normality" or "pathology" or (b) a specific type of pathology (e.g. 
ASD, ADHD). It is only in this context that the supposedly exact knowledge of brain imaging technologies becomes relevant, and thereby necessarily intertwined, with ways to gather to knowledge that is deemed "less objective."

\section{Building the Neurological Complexity of Mental Disorders}

Mental disorders are cluster concepts that encompass a range of symptoms and make a wide range of different types of behavior fit into a single diagnostic category. This points to a tension in how brain imaging technologies are treated: on the one hand, a consensus exists among researchers that the brain and how it realizes specific cognitive functions must be understood in terms of neural networks that cannot be traced back to a specific origin and should not be associated with specific brain regions. This makes it increasingly difficult to understand (symptoms of) mental disorders in terms of their underlying neurology (cf. Fitzgerald 2014; Maung 2016). This complexity is treated as objectively displaying that the complexity of the human brain is a fact of nature. On the other hand, however, at the same time as being treated as an inevitable feature of human nature, the displayed complexity is treated as a manageable and malleable phenomenon that can be simplified to conduct experiments in neuropsychiatry. The following fragment is indicative of this tension:

\section{Excerpt 1:54}

Sally it has been very helpful for my biological background of the behavior that eh we see

Mike it's not so straightforward eh

4. Sally no::

Mike and that again and that's what makes doing research e::::h terribly complex (3 lines omitted)

Sally yes and that makes that you cannot say the putamen is my region of interest and

exe it is different we understand how autism works e::h because it is so extremely interwoven

yes yes yes I mean these loops remain [important=

$$
\text { [yes }
$$

be possible that one loop gets in one way or another more attention than another loop that's possible regardless of whether they are more integrated into

54 The names of the participants have been altered, and the date and time indications have been deleted to minimize the possibility of identification.

55 Excerpts 1,2, and 3 are parts of a conversation that orighally occurred in Dutch. The excerpts are translated by the author. Original fragments can be delivered on request. nother system, it can still be the case that one gets suppressed and that has to be (o.5) otherwise the behavior can never be explained

(3 lines omitted)

yes but it gives me now primarily the feeling that e::h you get the tendency to pull in more and more and that eventually:: you end with yes the brain is a large network and everything is [connected=

$$
\begin{aligned}
& \text { [hm } \uparrow \mathrm{hm} \\
& \text { [=you need everything du:.:.: }[\text { [that's } \\
& \text { [yeah } \\
& \text { [of course true but it's }
\end{aligned}
$$

e::h incredibly difficult to e::h consider regions in isolation

t- that's simply the case

In this conversation between a postdoctoral researcher (Sally) and a senior researcher and vice-director of the laboratory (Mike), the brain is being built as a complex organ that evades simple explanatory models of mental disorders. Sally was asked to write a review of how the neural networks associated with repetitive and stereotyped behavior map onto the anatomical regions of the brain. She states that doing research for this review was a "good way to see the biological background of the observed behavior" (lines 1-2). This is treated by Mike as indicating that the origins of behavior in the brain are not "so straightforward" (line 3), which makes doing research "terribly complex" (lines 6-7). Sally responds affirmatively to Mike and treats the complexity of the brain as preventing researchers from focusing on its specific regions (the putamen, line 9) and using deviances in specific regions as explanatory for autistic behavior (lines 10-11). Instead, she orients herself to the complexity of the brain as indicative of the fact that autism is "extremely interwoven" (line 11). Accordingly, complexity is oriented to as a norm that forces moving beyond the mapping of brain functions to specific brain regions.

In response to Sally, Mike suggests that the loops of activity observed in the brain may have an important explanatory function (line 12). "Loops" are patterns of brain activity moving across different areas of the brain, and specific patterns of loops are thought to be indicative of specific cognitive functions (cf. Amso \& Scerif 2015). Mike states that thinking in terms of loops still possesses some explanatory potential, because it allows the explanation of autistic behavior as constituted by one loop suppressing another (lines 18). If not, he says, the behavior observed in autism "can never be explained" (line 19). Sally responds to this suggestion by stating that such an approach only leads to the "tendency to invoke more" and eventually leads to a view that "the brain is a large network and everything is connected" (lines 23-24). Her consecutive "you need everything du:.:.:h" 
(line 26) displays the self-evidence of such network complexity yet clearly demonstrates annoyance concerning the lack of explanatory potential of such a perspective. In this case, the desired simplicity of using the brain as an explanation of autistic behavior is oriented to as a norm conflicting with the complexity of the brain. The conversation ends by Mike saying that this complexity "is simply the case" (line 31), indicating that there is no theoretical path out of this problem.

This conversation shows that neuropsychiatrists must manage a trade-off between two theoretically conflicting norms to integrate the "neuro" into psychiatry: on the one hand, they orient themselves to the norm of (neuro)biological complexity, while on the other hand, they orient themselves to the desired simplicity of causal explanations of how symptoms of mental disorders are realized. This indicates that the complexity of the brain is not uncritically accepted but is appropriated and integrated into the existing aims of neuropsychiatry. In the next two sections, I show how this trade-off is managed by focusing on two interrelated epistemic concerns of the neuropsychiatrists under study: (i) on how brain scans are interpreted in terms of previous diagnoses and (ii) on how the brain scans are treated as an incentive to develop new ways of experimentation. This analysis reveals the sense in which the possibility of observing brain activity in vivo is made relevant for the purposes of neuropsychiatry.

\section{\$8.3 THE ROLE OF DIAGNOSTIC LABELS IN THE INTERPRETATION} OF EXPERIMENTAL DATA

The complexity of the human brain and its role in the realization of cognitive functioning is not only a matter of theoretical concern, as shown in Fragment 1, but it also affects the sense in which brain scans are treated as objective. In this section, I discuss how researchers orient themselves to brain activity visualized through fMRI by analyzing two excerpts from a conversation in which the data of an experiment that aims to target "repetitive and stereotyped behavior" in individuals diagnosed with ADHD, OCD, or ASD is discussed.

At the laboratory under study, the perceived complexity of the brain mediates what is understood by "repetitive and stereotyped behavior" as a symptom of ADHD, OCD, or ASD. The symptom "repetitive and stereotyped behavior" obviously encompasses a wide range of heterogeneous instances of behavior. For example, in the DSM-V, examples of this symptom in the context of ASD range from "extreme distress at small changes" to "greeting rituals" (APA 2013, 50). However, these different types of behavior are treated as homogeneous, in the sense that they are different instances of repetitive and/or stereotyped behavior. This type of behavior is a symptom of ADHD, OCD, and ASD; hence, neuropsychiatrists often stipulate that, in one way or another, a continuum exists between different mental disorders in terms of this symptom (e.g., Hyman 2010; Lichtenstein et al. 2010). Yet, at the same time, the different diagnostic categories constitute a normative expectation that different patterns of brain activity are underlying the behavior in the different patient groups. Researchers thus must orient themselves to the complexity of the human brain such that it becomes relevant in terms of the simplicity of existing diagnostic categories. How the complexity of the brain is oriented to in this context, as well as the extent to which it is oriented to as objectively, becomes clear from my analysis of two excerpts in which brain scans are interpreted. I believe these two excerpts are representative of how existing diagnostic categories are invoked to interpret brain scans.

The first of these excerpts is taken from a conversation between the head of the laboratory (Mary), the postdoctoral researcher also encountered in excerpt 1 (Sally), and a PhD candidate under the direct supervision of Sally (John). The conversation focuses on how to interpret the data that John obtained from a recent experiment on impulsivity. Using a "GO-NOGO" paradigm, individuals were asked to react as quickly as possible when presented with a stimulus, by either pushing on a green button (GO) or on a red button (NOGO). In doing so, the researchers aimed to study the extent to which presenting deviant stimuli influences a participant's ability to continue the task as instructed. It was hypothesized that individuals diagnosed with OCD, ASD or ADHD have increased reaction times or make mistakes when presented with a deviant stimulus.

\section{Excerpt 2:}

Mary I estimate that this will simply be (.) in terms of diagnostic differences in brain

4. Sally

Mary at this point we can no longer deny [this

6. John

Mary I would still like to know how these two groups are divided among the three diagnostic groups ADHD ASD and OCD and is this something

John yes this is the first part of the ROI analysis in which I e::.h actually these three and there are some more in the other groups that I tested but e::h in the first contrast nothing come out but I want to do it on contrast three because on a whole brain level [something

Mary [that something was there 
(4.0)

16. Mary that sounds like a good idea

17. $\quad(2.0)$

18. Mary but thus far (.) the eventual conclusion is thus [primarily

19. John [yes haha that one

20. Sally stupidly this would fit in into my impression of the literature at this point and then it is really a pity that eh yes it is not the nicest things to write a negative [study=

3. Mary [no but is not unimportant

4. Sally [=but it is not a real surprise that you do not find anything in this group with
The excerpt begins with Mary stating that a conducted experiment does not display differences in brain activation patterns across the different patient groups (lines 1-3), which makes the experiment "a negative study" (line 4). Both Sally (line 5) and John (line 7) agree with this assessment. The adjective "negative" indicates that earlier psychiatric diagnostics function as norms that the conversational participants orient themselves to when developing experimental hypotheses. This constitutes an expectation that when experimental participants demonstrate a similar task performance, the underlying patterns of brain activity would differ between different patient groups.

Later, however, in response to Mary, John says that an option may still exist where differences are visible on a whole-brain level (line 15). Again, this assumption is guided by previous diagnostic labels, because it suggests that although the analysis focusing on a particular region of interest in the brain might not display differences in brain activation, these differences may be present on the level of the brain as a whole. While Mary responds to this by saying that "that sounds like a good idea" (line 18), she continues by restating her earlier conclusion that no difference across the patient groups exists (line 20), which John affirms (lines 21-22). Even though the complex interactions on a whole-brain level might display differences across patient groups, this is not treated as potentially challenging the earlier conclusion. Hence, the complexity of brain activity on a whole-brain level is displaced as a reliable source for detecting differences between patient groups.

In the final part of the discussion, Sally states that this conclusion "stupidly fits her impression of the literature" (lines 23-24) and that while it is a pity to have to write a negative study (lines 25-26), the outcome is not "particularly strange" (line 30). During Sally's conversational turn, Mary also says that the negative outcome is "not a real surprise" (line 28). Sally states that this significance is to be found in the fact that no differences in brain activity can be found while using the "particular task" they have used and that it is worthwhile to "mention that very explicitly" (line 30). Hence, on the one hand, the observed brain activity is treated as objectively showing that no differences can be identified across patient groups, yet on the other hand, this is not necessarily treated as a feature of the participant's brain activity as such but is made relative to the experimental circumstances in which brain activity was measured. The previous diagnosis of a specific mental disorder is thus invoked as a norm for interpreting the experimental data, as the measured brain activity is not assumed to objectively indicate a similarity across mental disorders but instead prompts a discussion about whether specific experimental circumstances can still "pull out" differences in brain activity Accordingly, the complexity of the human brain must be negotiated in relation to the expectations constituted in relation with the type of mental disorder that is attributed to the brain under discussion.

This negotiation occurs in excerpt 3, where Sally and Marry continue to discuss the conceptual possibilities that might help to experimentally reveal the circumstances under which differences in brain activity can be detected:

\section{Excerpt 3:}

1. Sally e::h what what the data from America would say is that almost the only way to 
19. Sally

20. Mary

21.

22. Sally

23. Mary

24. Sally

25. Mary

26.

28. [yes

[=all the data from

questionnaires suggests that oh it seems that [actually=

[.hhhh yes:::

the three mental disorders are not really [discrete=

[no

[=but that there is a continuum but

then we do these sort of studies and take an adhd-task and we push and pull and we actually=

(all laugh)

get no movement in the ASD group that was supposed to be in the same continuum and that is just::.:

Sally suggests that on the basis of earlier obtained data, it might be helpful to include stimuli that are "incredibly salient" (lines 3-4) to show behavioral differences across patient groups in this particular experimental design (lines 2-3). Earlier experiments showed that in terms of task performance, groups diagnosed with a specific (yet until now unspecified) mental disorder had a slightly worse task performance, but Sally admits that this difference was quite minor (lines 6-8). In response, Mary states that integrating more salient stimuli causes a "little movement" but still does not display "enormous differences" between distinct mental disorders (lines 11-12). Again, previous diagnoses have a strong normative input: the expectation of the outcome of the experiment is that there are "enormous differences" that are "really clear."

In response, Sally suggests that presenting "more social stimuli" might cause some more "movement," because these might allow for investigating whether something is wrong in the "limbic system" of the individuals diagnosed with a mental disorder (line 16). She says that these different reactions to different types of stimuli are treated as new ways to understand the underlying causes of deviant behavior. They namely point to the possibility that this limbic system "brings the cognitive control system out of balance" rather than that something is wrong in the "cognitive control system itself" (lines 18-20). This indicates that different experimental circumstances reflect different hypotheses about how certain types of behavior are realized in the brain. Instead of that Sally orients herself to brain activity to find the root of deviant behavior, brain activity is treated as a malleable phenomenon reflecting the specificity of certain experimental circumstances. After Sally has proposed a difference in terms of brain activity, Mary returns to the question of how the experimental data relate to the behavioral data obtained via questionnaire (lines 21-22). Mary treats the questionnaire data as relevant because it suggests that a continuum exists between the three mental disorders that are clinically manifest (lines 29-31). However, as she points out, when conducting their studies and using an "ADHD-task" (line 31), there is no movement in the ASD group, even after they "push and pull" (line 31) the data. She suggests that this is peculiar, because on the basis of the questionnaires, ASD and ADHD would be in "the same continuum" (line 34). This is where the discussion ends, and, as suggested by the laughter displayed in line 32, all of the participants treat this conclusion as rather uncomfortable. Again, rather than treating the experimental outcome and the observed brain activity as reflecting "facts of nature," it is oriented relative to earlier clinical diagnoses.

My analysis shows that diagnostic labels have a strong normative function in processes of data interpretation. Researchers actively attempt to reconcile brain activity with existing diagnostic labels, even when this seems difficult. As such, the visualized brain activity is attributed an objective status to the extent that it can be aligned with earlier diagnoses (cf. Cohn 2012). The absence of relevant differences in brain activity in different diagnostic groups is not treated as an "objective" fact but rather functions as an initiative for researchers to develop new experiments that allow for aligning the observed brain activity with previous diagnostic labels. In the next section, I explore how the relation between these two aspects is managed in the development of new experiments.

\section{§8.4 “BRAINING” PSYCHIATRIC EXPERIMENTS}

In the previous section, I showed that researchers orient themselves to the complexity of the human brain in term of previous diagnostics processes that have already classified the participants in the experiments as having a certain mental disorder. Only in light of previous diagnoses does it become possible to interpret the observed brain activity. In other words, the researchers must develop experiments that can tie neurophysiological activity to specific symptoms of mental disorders. As this section demonstrates, researchers develop a practice of "braining" psychiatric experiments to do so (i.e., they develop experimental set-ups in which brain imaging technologies are appropriated in such a way that they can be understood in terms of earlier psychiatric diagnoses). In doing so, the complex structure through which cognitive functions are realized is neglected and fMRI is treated as allowing the linkage of symptoms of mental disordersin this case, impulsivity-to specific brain regions. Orienting to fMRI in this way assumes that human cognitive functions originate from particular brain areas and that fMR allows the objective localization of specific cognitive acts in the brain in vivo.

In the excerpts analyzed in this section, how "repetitive and stereotyped behavior" can 
be experimentally investigated at the laboratory by linking it to the impulsive reactions of individuals when being confronted with something that is of their central interest is discussed. In a presentation on the experimental study of repetitive patterns of behavior in children diagnosed with ASD, a researcher at the laboratory explains why she makes this specific link along the following lines:

\section{Excerpt 4:}

1. Mary so e::h everyone has an interest or a hobby could be sportcars

(5 lines omitted)

but in any case usually you should be able to function around that interest so it should not impairing your daily life you should be able to function at a job without being busy with sport cars all the time e::h but this is different in

autism

(4 lines omitted)

and that interest e::h may be so intense that it does impair them in their daily lives so:: e::h

(5 lines omitted)

they are rather all consuming and they do limit social interactions when they interfere with daily activities

(3 lines omitted)

so: e:h what we wanted to know is the behavioral and neural pattern of impulse control to preferred interest first in healthy adults that is a pilot study we did and then we wanted to know whether children with autism would demonstrate a bias towards their restricted interests compared to typically developing control children

Repetitive and stereotyped behavior is, in this experimental context, understood in terms of the specific interest of an individual with autism that "may be so intense that it does impair them in their daily lives" (lines 10-11). To a certain extent, the relation between individuals with autism and their interest is treated as being continuous with the hobbies and interests of healthy individuals (lines 1-2). However, the behavior that individuals diagnosed with autism display in relation to those interests is treated as marking a difference, because they "are rather all consuming $[. .$.$] and interfere with daily activities"$ (lines 13-14). This behavioral difference is oriented to as a norm that constitutes a break in the continuum between "healthy" individuals and individuals diagnosed with autism: children with autism "demonstrate a bias towards their restricted interests" (line 20-21), which makes them "deviate from the behavioral and neural pattern of impulse control'
[...] in healthy adults" (lines 16-18). What is treated as the most relevant question in this context is how this hypothesis can be tested in terms of both the behavioral and neural differences between healthy individuals and individuals diagnosed with ASD. Hence, the difference between "healthy individuals" and "individuals with ASD" is already assumed by orienting to how individuals have been classified through earlier diagnostic processes.

Because how scientific experiments are materialized is mediated by fMRI, the difference between healthy individuals and individuals who are diagnosed with ASD must be reflected on a neurological level. Given the complexity of neuronal interactions and their relation to cognitive and emotional functioning, experiments must be designed to specifically target the neurological underpinnings of the "impairment" in the brain that constitutes the deviant behavior in individuals diagnosed with ASD. Accordingly, the complexity of the human brain is made relative to specific interests of individuals and the associated impulsivity that is the consequence of them. Only when this situation is realized can the brain have an explanatory function within this type of neuropsychiatric research. Ironically, this requires researchers to align the perceived "objectivity" of the human brain as revealed through fMRI with the "subjective" interests of individuals to become relevant as objective knowledge. Accordingly, "braining” psychiatric experiments simultaneously requires the researchers to personalize psychiatric experiments.

As explained during the presentation, because the impairments that are observable in individuals with ASD are relative to the behavior of "healthy people," it is first necessary to find a way to study impulsivity in this latter group. Prior to the experiment, individuals were asked to choose from 22 different potential interests (ranging from trains to SpongeBob Squarepants) the three interests most to their liking. Subsequently, these "healthy" individuals performed a GO-NOGO task and were asked to refrain from pushing a button when confronted with one of the interests of their choosing. As a control condition, participants were asked to perform the same task but were instead confronted with different facial expressions and colors. Behaviorally speaking, these healthy individuals were equally good in performing this task under the three different conditions. However, the researcher argues that in terms of brain activity, a difference can be detected. Excerpt 5 demonstrates how the objectivity of fMRI is oriented to when substantiating this claim:

\section{Excerpt 5:}

1. Mary e::.:.:.h it was an fmri study so::: basically the take away message here is that e:h areas were activated that you 
Interestingly, the fMRI results are treated as relevant not because they display something new and/or exciting but because they show that the "areas [of the brain] were activated that you would expect during this type of task" (lines 4-5), which is further specified in lines 4-9. Only the potential reason for the "interior frontal gyrus cognitive control activation" (lines 10-11) is explicitly explained, indicating the presumed relevance of this brain area for this specific task. Activity in the insula makes sense because it "is activated when seeing things that are salient to you" (line 14) yet is not constitutive of deviant behavior because "healthy individuals are just able to inhibit themselves regardless" (lines 19-20). Instead of providing new information on how behavior is neurologically constituted, fMRI is used in this experiment to validate whether the stimuli used in the experiment trigger activity in the brain areas they are supposed to trigger. fMRI is thus treated as offering objective certainty in the sense that it allows the validation of whether the experimental stimuli can be mapped onto brain regions associated with certain cognitive functions (e.g., looking is linked to the visual cortex, etc.). Thus, rather than being invoked as introducing complexity, fMRI is oriented to as allowing the causal linkage of specific brain areas to specific cognitive functions.

A similar function is ascribed to fMRI when the researcher discusses how the supposed "impairments" of individuals diagnosed with ASD can be made present experimentally:

\section{Excerpt 6:}

1. Mary e::h these sort of relatively neutral stimuli or stimuli that are just not of interest to an individual with autism e:h do not capture that change in impulse contro e::-h what does capture in individuals with autism's interest is what they like (3 lines omitted)
Sally identifies as a potential problem that "relatively neutral stimuli [...] do not capture the change in impulse control” (lines 1-3). Rather, experimental stimuli should reflect "what they like" (line 5) (i.e., target impulsivity in relation to the specific restricted interests of the participants). She refers to other studies that showed evidence that "increased activity in left insula" was shown "when viewing images of their special interests" (lines 8-9). This resonates with the activation in healthy individuals when confronted with images of their interest (cf. excerpt 5 , lines 13-15). However, in addition, they display "increased activation in the fusiform area," which is traditionally associated with face recognition, and indicates high visual expertise (because healthy individuals are relatively good in recognizing faces). Accordingly, a parallel is drawn between the visual expertise that healthy individuals display in face recognition and the visual expertise of individuals with ASD "when watching what they like" (line 18). This suggests that if a GO-NOGO paradigm were used for investigation, the stimuli used in it should at least trigger brain activity in the "left insula" and "fusiform area." So, by linking specific cognitive functions to specific brain regions, fMRI is treated as introducing a norm to which experimental stimuli must conform: only when activity is present in the identified brain areas is the development of experimental stimuli treated as successful.

fMRI thus introduces a normative framework against which experimental stimuli are evaluated, eventually giving rise to the idea that these stimuli must be "tailormade" relative to the subjective personal interests of individuals. Only in this way can prior distinctions between "healthy" individuals and individuals diagnosed with a mental disorder be maintained. The human brain is not oriented to in terms of its complexity in this context (as we would, for example, expect on the basis of excerpt 1). Instead, fMRI is treated as an incentive to develop experiments that are tailormade to (confirm) previously established diagnostic categories. 


\section{$\S 8.5$ CONCLUSION: THE OBJECTIVITY OF FMRI IN THE CONTEXT OF THE TRADE-OFF BETWEEN COMPLEXITY AND SIMPLICITY}

By attempting to understand the perceived complexity of the human brain in terms of how mediating technologies such as fMRI are appropriated in neuropsychiatric practice, I have attempted to show how the possibility to visualize brain activity in vivo mediates how the brain is understood as complex. This has revealed, firstly, that visualizations of the brain are not treated as offering a straightforward form of objectivity, or as finally allowing the unraveling of the mysteries of the human psyche and the origins of mental disorders. Nor was fMRI treated as unproblematically allowing the interpretation of the human brain in terms of a complex network. A sharp contrast thus exists between the rhetoric that brain imaging technologies reveal regarding the enormous complexity of the human brain and the actual practice of neuropsychiatry: complexity is managed to suit the pragmatic goals and aims at stake. This study highlighted two ways in which this can be done. Firstly, diagnostic labels are oriented to as norms that structure how visualizations of brain activity are (to be) interpreted. A prior difference between "healthy" individuals and individuals diagnosed with certain mental disorders is thus presupposed for brain scans to become interpretable. Secondly, this prior difference informs how neuropsychiatric experiments are "brained": fMRI is treated an incentive to develop scientific experiments that are specifically tailored to confirm earlier established diagnostic differences

The relevance of observing brain activity for the purposes of psychiatry, as well as how the fMRI is treated as offering objective knowledge, must be considered relative to how the trade-off between complexity and simplicity is managed in practice. As such, fMRI should not be considered a technique that allows psychiatrists to perceive brain activity but rather as belonging to the phenomenotechnology within which the objects of neuropsychiatry (i.e., [symptoms] of mental disorders) are constituted. While theoretically, the brain is oriented to as a complex organ (see excerpt 1 ), in their daily routines, researchers manage this complexity vis-à-vis the pragmatic aims of (i) distinguishing between the "normal" and the "pathological" and (ii) making this different neurologically present in scientific experiments. Inevitably, a trade-off between the organic complexity of the human brain and the desired simplicity of explanations of (symptoms of) mental disorders must be managed. Accordingly, the technological mediation of scientific knowledge should be understood in terms of how mediating technologies function against an existing background of pragmatic aims and existing theoretical knowledge. Acknowledging this helps to clarify the problematics that neuropsychiatry faces when the brain is to be understood as a complex network. The analysis shows that the complexity of the brain must be understood not in isolation but rather in terms of how it is managed and made relevant in the daily routines of neuropsychiatrists.

Currently, neuroscientists are confronted with the ideal that unraveling the complexity of the brain will help mitigate the sufferings of people with mental disorders. However, at the same time, whether this ideal has a biological or cultural origin is unclear. For example, Cornelius Borck has shown that "the complexity so easily assumed to apply to the brain is very much an attributed quality, reflecting a cultural expectation and a desire to invest the brain with the elevated status of delivering compelling answers about human nature and intelligence" $(2012,118)$. The unproblematic nature of this ideal is reflected in Des Fitzgerald's study of autism research. Fitzgerald suggests that the complexity attributed to the brain prevents neuroscientists from developing straightforward explanations of mental disorders yet simultaneously puts them into a position in which they cannot deny the biological evidence that suggests a difference between "normal" and "pathological" brains. They are in an "awkward place: unable to tack autism to an emerging project of 'neuroreductive' certainty [...] neuroscientists are equally unable to simply ignore both the evidence and the desire for a neurogenetic basis to the disorder" (Fitzgerald 2014, 247). In one way or another, the complexity attributed to the human brain must be dealt with within neuropsychiatry to reach explanations of mental disorders. My analysis of how diagnostic labels normatively structure how brain scans are interpreted, as well as how the fMRI is treated as allowing to map cognitive functions onto brain areas, can be considered an instance of how this "awkward place" is managed in practice. A large part of the work in neuropsychiatric practice seems precisely to handle being in this awkward place pragmatically.

One of the questions arising-precisely because of how brain imaging technologies are appropriated-when neuropsychiatric experiments become entangled with the behavior and interests of specific individuals is the extent to which such personalized "brained" experiments can be extrapolated beyond the medical biographies of specific individuals. In other words, a potential conflict seems to exist between the attempt to tailor scientific experiments to the mental disorders that individuals are diagnosed with and the desire to produce generalizable experimental results. This is a problem that Sally (the researcher discussing her experimental approach in excerpts 4-6) claims to have often encountered when presenting her research: aligning experiments to personal interests has often been treated as making the experiments "highly subjective" and hence "difficult to interpret." This indicates that the practice in which neuropsychiatric experiments are "brained" in the site under study is not necessarily representative of the research domain of neuropsychiatry at large. However, what the present study points to is that the promise of objectivity associated with the introduction of brain imaging technologies in psychiatry constitutes an uneasy relationship between the complexity 
of the brain and the desired simplicity of psychiatric explanatory models. Rather than choosing between either a neuroreductionism or the means of traditional psychiatry, how brain imaging technologies are appropriated reveals a new dimension: (neuro-) biological evidence of mental disorders gives rise to a specific form of experimenting that highlights the inevitable subjectivity of mental disorders. In this sense, the (supposed) objectivity of scientific knowledge can be considered constitutive of how the human subject who is diagnosed with a certain mental disorder is understood.

In her discussion of how complexity is dealt with in synthetic biology, Talia DanCohen distinguishes between neglect and (purposive) ignorance. She argues that in cases of "neglect," the complexity of biological systems is entirely removed from view, while ignorance "requires a carefully blinkered view and the ability to bide one's time, something that engineers, many of whom tethered their funding to technological promises, didn't build into their research programs" (Dan-Cohen 2016, 918). When applied to neuropsychiatry, the following can be said: in cases of neglect, it seems that neuropsychiatrists lose what has been gained through developments in brain science. In the case of ignorance, the complexity of the human brain becomes present as manageable and as something of which researchers acknowledge cannot be experimentally present as a whole.

The integration of fMRI in neuropsychiatry does make it less likely that the complexity of the brain is neglected, because complexity becomes perceptually available. However, this does not imply that a networked understanding of the human brain is straightforwardly applied to the explanation of mental disorders. Rather, fMRI can be understood as changing the hermeneutic process through which mental disorders are interpreted by adding a biological layer of interpretation that cannot be neglected. This hermeneutics is visible, for example, in how the development of experimental stimuli takes a different shape when mediated through fMRI. This can be considered a critical appropriation of complexity, such that it can be made to fit in-and made relative to-the aims of neuropsychiatric research and the promise neuropsychiatry bears for improving individual treatments in clinical practices. Against this background, how neuropsychiatric experiments are developed in this laboratory appears not as a case of straightforward neglect but rather as a form of ignorance that allows for managing the trade-off between the desired simplicity of neuropsychiatric explanations and the understanding of the brain as a complex organ stemming from the biological and neurological sciences.

In this chapter, I have conceptualized the constitution of the objects of neuropsychiatry in terms of how brain imaging technologies mediate the trade-off between complexity and simplicity. The epistemic concerns considered in the appropriation of technological mediation in neuropsychiatry are thus very different from those discussed in the previous chapter, which focused on the use of NIBS and NIBS-EEG in cognitive neuroscience. This suggests that how scientists appropriate technological mediations is contingent upon both the technologies used (e.g., NIBS vs. fMRI) and the pragmatic concerns at stake (e.g., cognitive neuroscience vs. neuropsychiatry). Accordingly, it does not make much sense at this point to say that brain imaging and brain stimulation technologies mediate the reality of "the brain," thereby giving rise to a specific way of understanding human behavior. Rather, brain imaging and brain stimulation technologies figure within broader processes of object constitution particular to the concerns of scientists who appropriate technological mediations in a specific practical setting. The novel ways in which these technologies disclose human behavior should, therefore, be understood in terms of how they allow the objectification of (aspects of) human behavior in cognition such that they become candidates for scientific investigation. This points to the postphenomenological approach of technological mediation being as much as a philosophy of practice as a philosophy of technologies. 
CONCLUSION:

A Philosophy of Technological Mediation as a Philosophy of Scientific Practice 
A question that has been lurking in the background of this dissertation-but that is centered in the conclusion-is what is meant by the concept "scientific practice," as well as how scientific practices are to be studied. The adjective "scientific" suggests that there is something specific and distinctive about "scientific practices," while the noun "practice" indicates that there is, in one way or another, a continuity between scientific practices and other practices. How must we understand the relationship between "scientific" and "practice" such that we can understand what a "scientific practice" is? To address this problematic, the chapters in the first part of this dissertation were also concerned with the extent to which a phenomenological analysis of the role of technologies in everyday life can be extended to the practices of science.

The research in dissertation has been guided by two questions. The first part explored the question of "How to understand the mediating role of technologies in scientific practice?," while the second part was concerned with the question of "How do technologies mediate the reality that collectives of neuroscientists investigate in neuroscientific practice?" As stated in the introduction, posing these specific questions implies a pre-existing adherence to two interrelated assumptions:(i) an analysis of technologies (i.e., scientific instruments) should be a central aspect of a philosophy of science and (ii) a philosophy of science should focus on the practice of science rather than on scientific theorizing. In this conclusion, I show how the concepts of "mediating technologies" and "scientific practice" have been shaped in such a way that the questions posed in the introduction can be answered. Furthermore, I show the specific way in which the technologies used in neuroscientific practice shape the reality of the objects of the neurosciences.

\section{The Mediating Role of Technologies in Scientific Practice}

Postphenomenological studies of scientific practice have been developed specifically in opposition to a theory-based understanding of science; instead, the development of a technology-driven account of science grounded in the practical interactions between scientists and technologies has been proposed (cf. Ihde 1991, 100). Postphenomenologists begin from the Heideggerian idea that our primary relation with the world is always a practical one with the tools and technologies around us, rather than one in which the entities around us appear as objects that are foreign to us. Building upon this perspective, empirical studies in postphenomenology attempt to reveal how a meaningful reality is constituted within the practical relations between individuals and technologies.

When centralizing the role of technologies in scientific practice, postphenomenology importantly counterbalances overly theoretically oriented philosophies of scientific instruments. When closely studying how scientists interact with technologies, it becomes clear that scientific instruments do not embody a univocal perspective (cf. Giere 2006) that scientists can be acquainted with when having the correct training (cf. Hacking 1983). Nor can it be said that scientific instruments embody specific knowledge claims that are waiting to be "found" by the scientists who use them (cf. Baird 2004). Precisely what is at stake in a philosophy of scientific instruments-understood as mediating technologies-is the development of a collective epistemic stance towards what they do allow to be observed and how these observations become meaningful in relation to the theoretical and practical concerns of scientific practices.

Postphenomenology, however, as I have argued in this dissertation, sufficiently recognizes neither the importance of the theoretical aspects of science nor the collectivity of science. One aim of this dissertation was to show not only the relevance of the philosophy of technology for the philosophy of science but also the shortcomings arising when a philosophy of technological mediation enters the domain of science. I have done so by reevaluating the insights of "classical philosophers," which posited a divide between philosophy and scientific research. Specifically, I have showed the ongoing relevance of the philosophy of Martin Heidegger and Gaston Bachelard by integrating their theoretical work into an empirical philosophy of technoscience. For example, by taking seriously Heidegger's suggestion that science intends to develop a relation with the world in terms of the present-at-hand, it has become possible to ask what is specific to scientific practices, in contrast with other practices that do not hold this explicit aim. Accordingly, I have identified as a central concern of scientific investigations precisely how this relation is to be established.

With the introduction of the epistemology of Gaston Bachelard and his notion of phenomenotechnique, the question of whether a philosophy of science should focus on either theories or practices is replaced with the question of how scientific instruments coconstitute the concepts that scientists employ when understanding the reality that they study. This insight is relevant for a philosophy of technological mediation: technologies not only mediate the practical interactions with the things around us but also shape the terms that scientists use when attributing meaning to the reality that they investigate. I have argued that this indicates the necessity of studying the hermeneutic work arising within relations between scientists and scientific instruments, hermeneutic work that cannot be captured within ANT, which approaches scientific instruments semiotically and interprets them as inscription devices. This shift from a semiotic to a hermeneutic approach to the study of scientific practices is thus a consequence what were identified as crucial insights of the philosophies of Heidegger and Bachelard.

Through this philosophical exploration, the scientific practices in which technologies play a mediating role are not solely understood in terms of the practical relations between 
scientists and technologies but are also extended in terms of the concepts and norms to which scientists orient (i.e., the empirical hermeneutics at work) when appropriating technological mediations. As such, an empirical philosophy of technoscience is necessary that is capable of revealing not only how scientists act in relation with technologies but also how technologies mediate how scientists think. When the latter is considered, it becomes possible to reveal which mode of thinking constitutes the specificity of a practice that can be characterized as "scientific." It is in this sense that a philosophy of technological mediation develops a specific concept of "scientific practice." Yet, how can one make researchable the ways in which technologies mediate our understanding of reality on both a practical-perceptual and a theoretical-conceptual level?

To answer this question, it is necessary to not treat human-technology relations in isolation but to instead explicitly situate them in the practices within which they are constituted. Let me illustrate this by briefly reflecting on the case study on neuropsychiatry discussed in Chapter 8: when beginning with the idea that scientific instruments mediate how and which scientific objects come into being, one is tempted to think that the cognitive neuroscientists working with fMRI and NIBS herald such technologies for their revolutionary potential. Furthermore, when considering the public enthusiasm and optimism about the cognitive neurosciences as a source to describe the workings of the mind with scientific certainty by reducing it to the brain, one expects that this idea has its roots in the practical ways in which scientists engage with brain scans. When clinging to this perspective, it is equally tempting to expect that, if the optimism about the possibility to objectify the human mind is not explicitly present, as an analyst, one should attempt to unmask cognitive neuroscientists as secret reductionists..$^{6}$ In one way or another, fMRI and NIBS should do something new, must give rise to the unexpected, must change the worldview of the researchers. The microscope revolutionized biology; the telescope revolutionized astronomy; and now, fMRI and NIBS revolutionize the study of the human being. Beginning with this idea, it might come as a surprise that the actual practical routine of cognitive neuroscience does not match such-of course, highly exaggerated-expectations.

For example, when entering the neuropsychiatry laboratory in the case study discussed in Chapter 8 for the first time, the principal investigator told me that the ultimate aim of the research conducted in the laboratory was to "show the inadequacy of the diagnostic categories in the DSM, and to develop a new model for psychiatry". Of course, this

56 Engaging in this project of unmasking might be triggered by recent developments in philosophy that aim to naturalize several branches of philosophy with reference to developments in neuroscientific research. For a prominent attempt to do so in the case of ethics, see, for example, Churchland (1986, 2018). For a criticism of such endeavors, see, for example, Choudhury and Slaby (2011), Vrecko (2010). might have only been a casual remark, quickly uttered in between two more importan meetings, but yet this was the type of revolutionary language one expects and deems important when attributing great significance to technological mediations. Surprisingly, from this perspective, the DSM and the categories within it did not seem to play any significant role in the practical routine of the laboratory, nor was the possibility of visualizing brain activity in vivo considered as a fundamental source of novel insights. Of course, the practical routine was simply there, and was-at least not visible to the novice observer-not ordered in relation to brain scans. The reality built in neuropsychiatric practice, accordingly, did not entirely coincide with the reality one would expect to find. When specifically examining diagnostic categories and brain scans, technological mediations seem difficult to detect. This suggests that-if existing-these mediations often are not explicitly foregrounded but lurk in the background. Accordingly, the reality that one is engaged in building in a philosophy of technological mediation is one in which the background is explicitly foregrounded. The relevant questions then become which aspects of the background are to be foregrounded (i.e., cede from being background), and for what purposes is this done? Posing these questions already shows that from the start, the reality that is built within neuroscientific collectives cannot be cut loose from the broader practical aims and theoretical presuppositions (i.e., the phenomenotechnology) of the scientific practice under study.

A Philosophy of Scientific Instruments as a Philosophy of Scientific Practice: Technological Mediation as Reality Building

In the first chapter of this dissertation, I argue that scientific practices are collective activities through and through and that understanding how technological mediations are appropriations by scientific collectives requires understanding how a shared epistemic stance with regard to specific technological mediations comes into being, which is why I suggest that if we wish to study empirically the hermeneutics at work through which the reality that scientists study is constituted, we should integrate (elements of) EM and CA into a philosophy of technological mediation. The hermeneutic work to be studied-the practice under investigation-is, then, a study of the activities through which a shared reality is built in scientific practice and the meaning that is attributed to the objects appearing in it. The activity of reality building cannot be cut loose from human-technology relations but can be neither exhausted by them nor reduced to them This endeavor marks the second augmentation of postphenomenology, which morphs a philosophy of technological mediation from a philosophy of scientific instruments into one of scientific practice.

How is the activity of reality building in scientific practice reflected in the empirica studies discussed in this dissertation, and how does it enlarge our understanding of 
technological mediations? Applying philosophical concepts to concrete case studies helps to better understand not only the domain under investigation but also the philosophical concepts applied. In his essay The Stranger, Alfred Schütz describes this in terms of how a newcomer becomes acquainted with the customs of a group that (s)he desires to become part of. The process of learning can only continue to the extent to which the concepts and explanations of the newcomer do not coincide with those of the group. If the integration were complete, nothing would remain that could be explained or reflected upon. In Schütz's words, "[I]f [the] process of inquiry succeeds, then [the group's] pattern and its elements will become to the newcomer a matter of course, an unquestionable way of life, a shelter, and a protection. But then the stranger is no stranger anymore, and his specific problems have been solved" (1944, 507). My suggestion is that something similar holds for the relation between the philosopher and the practices (s) he investigates: a divide always exists between the reality of the practice itself and the one ascribed to it by the analyzing philosopher.

Also, from a (post-)phenomenological point of view, we cannot assume a position of a value-free, disinterested observer, who gives a neutral description of the practice (s)he engages with. In one way or another, the intentional relation with the practice under study is both already constituted by the prior interest in this practice and changes when the analyst immerses in this practice. Both the studying subject and the studied object are mutually shaped during the process of investigation. Hence, investigating a practice implies engaging with it, and the level of engagement shapes how the practice under study is described. As such, Schütz's words can serve as a cautionary remark that imposes a limit on our engagement with scientific practices: to some extent, we must remain strange to them to be able to lay bare the unquestioned schemes of reference of their members. Studying specific processes of reality building, after all, does not coincide with the building of this specific reality.

In EM, the purpose of the foregrounding of the background is directed at "the reform of technical reason" (Garfinkel 2002, 93). According to Garfinkel, the social sciences movement falsely assumes that no order exists in the activities of everyday life and that it is the task of sociology to create this order through developing formal rational procedures. He derives from this that the specific technical reasoning of the social and natural sciences is necessary to establish order into an otherwise disassociated and disordered set of practices. Ethnomethodological studies, however, "specifly] the work of the social sciences and the natural sciences as naturally accountable sciences of practical action and practical reason" (Ibid. 93). This indicates that an order already exists prior to the intervention of technical reason. However, this pre-existing order is not independent of technical reason: the specific way in which practices are ordered "includes the incarnate work by formal analysts [scientists]" (Ibid. 96). Thus, when foregrounding the practical actions in social science, the purpose of EM is to reveal a form of practical reason that precedes technical reason. The re-specification of the social and natural sciences, then, is an attempt to reveal the order already implied and accounted for in scientific practices and to make this order available for critical reflection.

Would pointing to scientific practices being structured around the appropriation of technological mediations, similar to the purpose of EM, be to point to something prior to the technical vocabulary of the science? Recent criticism of postphenomenological analyses suggests that this is not the case and argues that the predominantly descriptive character tacitly instantiates an overly optimistic stance towards technoscientific developments (e.g., Bantwal Rao et al. 2015; Feenberg 2015; Romele 2017). Focusing too strongly on conducting empirical studies of technoscientific practices is then considered to undermine the potential of philosophy to develop a genuine critical position (cf. Rao et al. 2015; Smith 2018).

\section{Towards a Broader Understanding of Technological Mediations: Developing a} Phenomenology of Technicity

How "scientific practice" is understood in the philosophy of technological mediation developed in this dissertation does allow for developing a critical position towards the technoscience in terms of what I call a phenomenology of technicity and therefore evades the abovementioned criticism. Let me explain how.

The concept of technicity ${ }^{57}$ I borrow from the French philosopher Gilbert Simondon, who extensively discussed the ontology of technological objects and why these demand philosophical reflection..$^{8}$ In this section, I suggest a phenomenological understanding of this concept and show how it culminates into the possibility for analyzing scientific practices beyond a descriptive level.

57 This notion of "technicity" differs significantly from Don Ihde's use of the concept of technics (cf. Ihde 1979, 1990). For Ihde, technics is embodied in scientific instruments that might instantiate specific trajectories of observation. In my account, "technicity" refers not so much to the specific characteristics of scientific instruments but rather to the technical mode of thinking within which scientific objects are constituted. Precisely because of this difference, I hold that a hermeneutics of scientific practice cannot be reduced to a material hermeneutics of human-technology relations.

58 My discussion of Simondon's concept of technicity is not an exegesis of its function within his oeuvre but specifically concerns itself to the extent that Simondon helps developing a phenomenology of technicity within scientific practice. For example, I leave out here a discussion of other important concepts in simondon's work that are specific to the ontology of technological artefacts, such as the notions of concretization, individuation, and transduction. For a detailed discussion of these concepts, see, for example, Mills (2016). For an application of these concepts within current philosophy of technology, see Feenberg (2017 Chapter 3). 
Simondon's philosophy of technology calls for an engagement with our technical relation with the world as a necessary part of how the world appears to us. In 1958, when Simondon's central work On the Mode of Existence of Technical Objects was published, technics was often opposed to culture and reduced to its functionality. To counter this view, Simondon attempted to develop a philosophy capable of recognizing how a technical mode of thinking is not opposite to human engagement with the world but forms an essential part of it (cf. Bontems 2018). Understanding how the world does appear thus requires understanding technics from within its process of appearing.

Simondon's analysis of technicity begins with an analysis of the coming into being of technical objects, which he terms the study of the ontogenesis of technical objects (cf. Simondon 2016, 255). Importantly, for Simondon, technical objects must not be understood as "things" or "artifacts" but rather as functioning within existing milieus and as exercising forces on other beings, thereby potentially bringing new realities into being (cf. Hoel and Van der Tuin 2013). However, as Simondon argues, the notion of technicity cannot be reduced to constituted technical objects, nor can it be fully understood through an analysis of these; the mode of technicity is prior to the technical object:

"It is insufficient, for understanding technics, to start from constituted technical objects; objects appear at a certain moment, but technicity precedes them and goes beyond them; technical objects results from an objectivation of technicity; they are produced by it, but technicity does not exhaust itself in the objects and is not entirely contained within them" (Simondon 2016, 176).

Technicity thus has the potential of becoming objectified, of giving rise to an object that appears stable. This stability presupposes the existence of technicity, because without it, there would be no operation available through which stabilization could occur. In other words, the constitution of technical objects presupposes a technical mode of thinking. With the introduction of technicity in the domain of science, how the objects of the sciences come into being must be understood in terms of "the appearance of a chain of successive and elementary mediations" (Ibid. 187). Only through these mediations can a unified scientific object come into being. However, this unification cannot be conceived of by technics alone, as the concepts that scientists use are explanatory of what occurs within the chains of mediations and are therefore not identical with them.

Technicity should then be considered the introduction of a technical mode of thinking: "In science, technicity introduces the search for a how through the decomposition of an overall phenomenon into elementary operations" (Ibid. 243). When these elementary operations are conducted appropriately, they can be productively unified through the use of scientific concepts. For example, one can think of concepts such as "visual attention" and "impulsivity" in the neurosciences as such productive unifications. However, these productive unifications can only be made insofar as they are mediated by a technical mode of action: "Technics intervenes between perception and science [...] it provides the schemas, the representations, and the means of control of the mediations between man and nature" (Ibid. 251). The norms that a philosophy of technological mediation have brought to the fore can be considered an empirical specification of this technical mode of action. Therefore, these norms explicate how scientists relate to the reality that they study and which unifications scientists deem productive. Thus, these norms are simultaneously indicative of technics and of the relation between scientist and the world through technicity.

Although Simondon remains silent about the nature of the objects that science produces (e.g., microbes, ADHD), I see no reason not to consider them in terms of how he uses "object" when speaking of "technical object." Since-as I have shown-the objects of science are not mere reflections of natural processes but are instead constituted within a phenomenotechnology, their existence is a technical existence. That is, I suggest thinking of them as objects that come into existence in specific milieus and that in such a milieu, they exercise force on other beings, thereby potentially bringing new realities into being. Conceived in this way, Simondon's concept of technicity can be a welcome addition to a postphenomenological approach to technological mediations, because it does not limit the notion of "mediation" to the relation between scientists and concrete artifacts. Importantly, the need for this addition stems not just from an isolated philosophical concern but from the often-non-direct ways in which the work of scientists is mediated by scientific instruments. This empirical observation points to the fact that the dialogue between material and immaterial hermeneutics in scientific practice can be understood as the mediation of science by technics (in a Simondonian sense).

Apart from allowing the more apt conceptualization of what scientific instruments do in scientific practice, integrating the notion of technics has another advantage that reaches beyond the particularities of specific empirical studies. This second advantage is that Simondon's analysis of technicity introduces a specific role for the philosopher, who-by laying bare the genesis of technical objects-can help create new forms of experience, by bringing technicity back within the sphere of the subject.

With regard to how the task of the philosopher should be executed is where the philosophy of technological mediation sketched in this dissertation and Simondon's approach to technical objects in terms of an ontogenesis diverge: Simondon stands in an encyclopedic 
tradition and conceives of his ontogenetic project in terms of transferring discursive knowledge about how technological objects come into being such that their mode of existence can be grasped cognitively (cf. Loeve, Guchet, and Bensaude-Vincent 2018, 5-8). A philosophy of technology mediation, however, emphasizes how a phenomenology of technicity helps develop new forms of practical engagement (cf. Kiran, Verbeek, and Oudshoorn 2015; Verbeek 2011). These two approaches are not mutually exclusive per se, but the divergence is rather a matter of focus: whereas Simondon attempts to describe the interaction between different elements such that certain technical objects come in to being, I focus-inspired by postphenomenology-on technical objects sparking specific forms of human engagement within a concrete practical setting.

When considering this difference, Simondon remains instructive regarding what can be an ambition of philosophy of technoscience. ${ }^{59}$ Crucial in this respect is the idea that we encounter technical objects never in isolation but always within larger technical ensembles:

"The tool, instruments, or isolated machine can be perceived by a subject who remains detached from them. But the technical ensemble cannot be grasped by intuition, for it cannot be considered a detached, abstract, or manipulable object at man's disposal. It corresponds to an experience of existence and a situation, it is tied by reciprocal action with the subject" (Ibid. 235).

Just as technical objects cannot be isolated from technical ensembles, the human subject also always finds himself within a technical ensemble that structures its experience and possibilities to act. As an example of a technical ensemble, Simondon uses the conditions necessary to build a boat: "a fairly flat ground, yet close to the water, sheltered yet luminous, with supports and wedges to keep the ship standing while it is being built" (Ibid. 76-77). This also presupposes the participation in this ensemble of the shipbuilder, who relates to the elements through which the ship is built. Not only regarding such a small microcosmos can we speak of a technical ensemble; one can also conceive of factories (cf. Ibid. 163) or, indeed, the scientific laboratory (Ibid. 65) as examples of technical ensembles. What these examples have in common is that in such situations, objects come into being that generate a specific coupling of man and world.

The task of the philosopher in Simondon's view then is to "help raising awareness of

59 Simondon's theory of concretization plays an important role in Andrew Feenberg's approach of critical constructivism within philosophy of technology (cf. Feenberg 2017, Chapter 4). A comparison between Feenberg's use of Simondon and the present is beyond the scope the present discussion but does deserve attention in light of discussing the relation between critical constructivism and postphenomenology. the situation within the technical ensemble, by reflecting it within himself and by expressing it; but [...] all he can do is be the one who solicits an intuition in others" (Ibid. 236, my emphasis). Describing one's situation in a technical ensemble presupposes a reflection on what this situation is, and through communication, others can similarly intuit their situations within the technical ensemble. By expressing the situation within the technical ensemble, the place of others within a technical ensemble also becomes available for reflection to them; it allows the development of new intuitions about situation that is occasionally taken for granted. Linking a philosophy of technological mediation to a phenomenology of technicity therefore brings to the fore how a technical ensemble is realized through a specific mode of thinking and how this mode of thinking is mediated through technologies. Doing so occurs not merely to describe an existing situation but also to open up the possibility of explicitly restructuring the technical ensemble(s) in which one finds oneself.

It is important to emphasize what it means to solicit an intuition-instead of convincing one, either by rational or by rhetorical means-to fully grasp what a philosophy of technological mediations is capable of communicating. For Simondon, "intuition is neither sensible nor intellectual; it is the analogy between the come-into-being of known being and the coming-into-being of the subject, the coincidence of two comingsinto-being" (Ibid. 242). Intuition thus mediates between the already constituted subject and the already constituted object, such that new and different forms of constitution can come into being.

\section{The Mediated Reality of Neuroscientific Collectives and the Critical Potential of a} Philosophy of Technological Mediation

How then, can a philosophy of technological mediation solicit relevant intuitions? The point of invoking the concept of technicity is not to give Simondon the final say in what a philosophy of instruments in scientific practices should look like but rather to identify how the mode of thinking present in science can be understood as being constitutive of its objects. Laying bare this mode of this thinking-as I attempt to do in this dissertationallows for developing a critical relation to scientific practices and the objects constituted within them. This can be exemplified when applied to the neurosciences: departing from an ethnomethodological perspective, the neurosciences can be regarded as executing a form of technical reason, for example, by arguing for a change in educational programs (e.g., Carew and Magsamen 2010), psychiatric treatments (e.g., Insel and Cuthbert 2015) legal arrangements (cf. Meynen 2014), or marketing (cf. Ariely and Berns 2010). This is done with reference to a neurological order that is said to be constitutive of how human beings experience and act upon the world. The technical vocabulary of the neurosciences is, according to optimistic neuroscientists, necessary to show how the world is actually 
ordered, regardless of existing sociological and personal accounts of it (e.g., Lamme 2006; Soon et al. 2008).

Revealing something that is prior to technical or scientific reason can be a purpose of conducting laboratory studies. For example, Morana Alač's study on how neuroscientists interpret brain scans shows that interpretations multimodal engagement enacted within a specific social setting. She uses this finding to critically relate to how fMRI is generally perceived:

"Whereas fMRI technology presupposes that our cognitive processes can be reduced to the workings of an individual's brain, I argue for a view of cognition that is distributed between people and rooted not only in mental processes and computational inferences but also in a culturally shaped and socially enacted world" (Alač 2011, 20).

In this case, the empirical study of neuroscientific practice functions to counter a specific neuroscientific paradigm that accompanies the introduction of fMRI. Showing how the interpretation of brain scans presupposes the existence of a form of cognition that does not fit into the existing the paradigm is, in Alač's work, a way to reveal the limits of a specific scientific paradigm. Revealing the human work involved in neuroscientific practice can-in line with Garfinkel's description of EM-be considered a re-specification of the neurosciences that allows to reveal an already existing form of reason.

What, then, is specific to focusing on the role of technologies in scientific practices and singling them out as doing something specific that must be acknowledged? Don Ihde has, as mentioned several times throughout this dissertation, argued that any study of scientific practice should focus on material technologies, because these structure the interpretative processes at work. In his view, studying scientific practice therefore requires developing a material hermeneutics that focuses on the work of concrete technologies: besides human work and human reason, room should also be made for the work of nonhumans and how these help disclosing reality. This shift of focus does not eliminate the importance of human work in scientific practice. However, it reconceptualizes the human work explicitly involved in terms of the appropriation of technological mediations (cf. Verbeek 2016). As stated, I was inspired by this work to begin examining the hermeneutic processes that technologies instantiate and attempt to identify technological mediations and how these are appropriated.

In the two empirical studies discussed in this dissertation, I have framed the appropriation of technological mediations in terms of the epistemic norms that neuroscientists orient themselves to when investigating the brain. Considering these norms points to scientists' relating to scientific objects through not only technologies but also collective epistemic judgments. Although these norms can be conceptualized as appropriations of technological mediations, they only become visible in conversations between scientists in which experimental data is interpreted. Placing the appropriation of technological mediations at the center of scientific practice effectively counters the idea that technologies determine how scientific objects are constituted through a causal interaction of natural and material elements. On the contrary, by pointing to the contingencies involved during the appropriation of technological mediations, the human work involved in the constitution of scientific objects is rehabilitated, yet in a way that does not make them independent of the phenomenotechnological circumstances within which their actions occur.

What follows from a focus on the human appropriation of technological mediations is that the investigations conducted in this dissertation do not, strictly speaking, belong to a material hermeneutics (cf. Ihde 2009; Verbeek 2003)-at least not if we assume "material" to refer to the material presence of concrete technologies. Rather, the "material" should be understood in terms of what I call a phenomenotechnology, consisting of both material technologies and immaterial norms and concepts. Foregrounding the epistemic norms that structure the reality of scientific objects in the cognitive neurosciences thus has consequences on how technological mediations are to be understood. We must focus not only on how the physical characteristics of technologies shape how phenomena are perceived but also on how appropriations of technological mediations structure how the realities of these observed phenomena are conceived.

Let meclarify this with an examplefrom thecase study focusing on the constitution of visual attention. I argued that NIBS technologies-or, brain stimulation-mediate the reality of visual attention because they embody a strong causal norm towards which scientists orient themselves. Furthermore, I showed that the constitution of visual attention as an object that can be related to is the outcome of a trade-off between the norms of "causality" and "reality." The specific manner in which this trade-off was managed revealed that only when researchers can interpret their observations in terms of a recognizable causality does visual attention become real. ${ }^{60}$ That scientists orient themselves to these norm indicates that their intentionality is hermeneutically structured not just by the material technologies but also by the normative expectations and goals of their investigations. To understand how technologies mediate the reality that scientists study, it is therefore

60 Now, of course, the fact that "reality" and "causality" normatively structure scientific investigations is unsurprising: the expectation of science is that it reveals causal relations between real objects. What is surprising is how these norms attain a specific meaning as appropriations of technological mediations. 
necessary to focus on how these normative expectations manifest in relation with technologies and how the use of technologies takes shape in relation to the normative expectations. The constitution of visual attention is, accordingly, accomplished within a dialogue between material and immaterial hermeneutics. Through this dialogue, an intentional relation between scientists and visual attention comes into being-and it is within this intentional relation that NIBS becomes meaningful as causal.

Foregrounding this dialogue is not so much a re-specification of neuroscientific practice as it is a specification of the technical reasoning that actually occurs in scientific practice. A philosophy of technological mediation-by foregrounding the dialogue between material and immaterial hermeneutic processes-is an explication of the technicity of scientific practice. Because of its focus on technological mediations and their appropriations, a philosophy of technological mediation can be considered a phenomenology of technicity. Conceived in this manner, a conceptualization of the role of technologies in scientific practices reaches beyond the domain of embodied perception and shows how the constitution of scientific objects occurs within a specific of mode thought. Accordingly, laying bare the appropriation of technological mediations is done to point not to something prior-be it practical reasoning or multimodal engagement-to the technical reasoning within the cognitive neurosciences but rather to how scientists engage in technical thinking. Doing so allows to give both empirical and philosophical body to the claim that science is to be understood as technoscience (cf. Ihde 2009; Latour 1987; Nordmann 2012)

This dissertation has attempted to solicit an intuition in others regarding what it means to be alive with the neurosciences (i.e., to make it intuitively intelligible how man is today coupled to the world through the objects of the neurosciences). I have done this by illuminating the processes within which these objects come into being within scientific laboratories and identifying which structuring roles epistemic norms have in this process. Intuitively grasping the normative contingencies involved in the constitution of neuroscientific objects helps neuroscientists reflect on their place in the technical ensemble that the laboratory comprises. Furthermore, this opens up the possibility to reflect on the relation between the technicification of human psychology and the specific conception of the human subject that accompanies it. An explication of the constitution of neuroscientific objects is, from this perspective, an explication of how it is to live with the cognitive neurosciences. 


\section{BIBLIOGRAPHY}




\section{BIBLIOGRAPHY}

- Aagaard, J. (2015). Media Multitasking, Attention, and Distraction: A Critical Discussion. Phenomenology and the Cognitive Sciences 14(4), 885-896.

- Aagaard, J. (2018). An Introduction to Postphenomenological Methodologies. In J. Aagaard, J.K.B. Friis, J. Sorenson, O. Tafdrup, and C. Hasse (eds), Postphenomenological Methodologies: New Ways in Mediating Techno-Human Relationships (pp. xi-xxx). London: Lexington Books.

- Achterhuis, H. (ed.) (2001). American Philosophy of Technology: The Empirical Turn (translated by R. Crease). Bloomington: Indiana University Press.

- Akrich, M. (1992). The De-scription of Technical Objects. In W. Bijker, and J. Law (eds), Shaping Technology/ Building Society: Studies in Sociotechnical Change (pp. 205-224). Cambridge: MIT Press.

- Alač, M. (2008). Working with Brain Scans: Digital images and Gestural Interaction in fMRI Laboratory. Social Studies of Science 38(4), 483-508.

- Alač, M. (2011). Handling Digital Brains: A Laboratory Study of Multimodal Semiotic Interaction in the Age of Computers. Cambridge: MIT Press.

- Albus, J.S. et al. (2007). A Proposal for a Decade of the Mind Initiative. Science 317(5843), 1321.

- Ali, S.S., Lifshitz, M., and Raz, A. (2014). Empirical Neuroenchantment: From Reading Minds to Thinking Critically. Frontier in Human Neuroscience 8(357), 1-4.

- Amso, D., and Scerif, G. (2015).The Attentive Brain:Insights from Developmental Cognitive Neuroscience. Nature Reviews Neuroscience 16(10), 606-619.

- Ankeny, R., et al. (2011). Introduction: Philosophy of Science in Practice. European Journal for Philosophy of Science 1,303-307

- APA (1994).Diagnostic and Statistical Manual of Mental Disorders, $4^{\text {th }}$ Edition: DSM-IV. Washington: American Psychiatric Association.

- APA (2013). Diagnostic and Statistical Manual of Mental Disorders, $5^{\text {th }}$ Edition: DSM-5. Arlington: American Psychiatric Association

- Ariely, D., and Berns, G.S. (2010). Neuromarketing: The Hope and Hype of Neuroimaging in Business. Nature Reviews Neuroscience 11, 284-292.

- Bachelard, G. (1949a). Le Rationalisme Applique. Paris: PUF.

- Bachelard, G. (1949b). The Philosophic Dialectic of the Concepts of Relativity (translated byF.W. Williams). In P. A. Schlipp (ed.), Albert Einstein: Philosopher Scientist (pp. 563-580). New York: MJF Books.

- Bachelard, G. (1951). L'Activité Rationaliste de la Physique Contemporaine. Paris: PUF.

- Bachelard, G. (1964). The Psychoanalysis of Fire (translated by A.C.M. Ross). London: Routledge.

- Bachelard, G. (1968). The Philosophy of No (translated by G.C. Waterson). New York: Orion Pres

- Bachelard, G. (1970). Épistémologie: Textes Choisis Par Dominique Lecourt. Paris: PUF.

Bachelard, G. (1984). The New Scientific Spirit (translated by A. Goldhammer). Boston: Beacon Press.

Bachelard, G. (1997). Fragments of a Poetics of Fire (translated by K. Haltman). Dallas: The Pegasus Foundation.

- Bachelard, G. (1999). Water and Dreams: An Essay on the Imagination of Matter (translated by E.R. Farrell).
Dallas: The Pegasus Foundation

- Bachelard, G. (2002). The Formation of the Scientific Mind: A Contribution to a Psychoanalysis of Objective Knowledge (translated by M. McAllester Jones). Manchester: Clinamen Press.

- Bachelard, G. (2005a). From La Essai Sur la Connaissance Approchée (translated by M. Tiles). In G. Gutting (ed.), Continental Philosophy of Science (pp. 176-183). Oxford: Blackwell.

- Bachelard, G. (2005b). Noumena and Microphysics (translated by D. Reggio). Angelaki, 10(2), 73-78.

- Bachelard, G. (2012). The Flame of a Candle (translated by J. Caldwell). Dallas: The Pegasus Foundation.

- Baird, D. (2003). Thing Knowledge: Outline of a Materialist Theory of Knowledge. In: H. Radder (ed.), The Philosophy of Scientific Experimentation (pp. 39-67). Pittsburgh: The University of Pittsburgh Press.

- Baird, D. (2004). Thing Knowledge: A Philosophy of Scientific Instruments. Berkeley: University of California Press.

- Beaulieu, A. (2002). Images Are Not the (Only) Truth: Brain Mapping, Visual Knowledge, and Iconoclasm. Science, Technology, \& Human Values 27(1), 53-86.

- Bischur, D. (2014). Scientific Practice and the World of Working. Beyond Schutz's Wirkwelt. In M. Staudigl, and G. Berguno (eds), Schutzian Phenomenology and Hermeneutic Traditions (pp. 127-147). Dordrecht: Kluwer.

- Blok, V. (2011). An Indication of Being - Reflections on Heidegger's Engagement with Ernst Jünger Journal of the British Society for Phenomenology 42(2), 194-208.

- Bloor, D. (1976). Knowledge and Social Imagery. London: Routledge.

- Bontems, V. (2018). On the Current Uses of Simondon's Philosophy of Technology. In S. Loeve, X. Guchet, and B. Bensaude-Vincent (eds), French Philosophy of Technology: Classical Readings and Contemporary Approaches (pp. 37-50). Dordrecht: Springer.

- Boon. M. (2015). The Scientific Use of Technological Instruments. In S. Ove Hansson (ed.), The Role of Technology in Science: Philosophical Perspectives (pp. 55-79). Dordrecht: Springer.

- Borck, C. (2012). Toys are Us: Models and Metaphors in Brain Research. In S. Choudhury, and J. Slaby (eds), Critical Neuroscience: A Handbook of the Social and Cultural Contexts of Neuroscience (pp. 113-133). Oxford: Wiley-Blackwell.

- Borck, C. (2016). How We Way Think: Imaging and Writing Technologies across the History of the Neurosciences. Studies in History and Philosophy of Science Part C: Studies in History and Philosophy of Biological and Biomedical Sciences 57, 112-120.

- Brosnan, C., and Michael, M. (2014). Enacting the 'Neuro' in Practice: Translational Research, Adhesion and the Promise of Porosity. Social Studies of Science 44(5), 680-700.

- Buckner, R.L., Krienen, F.M., and Thomas Yeo, B.T. (2013). Opportunities and Limitations of Intrinsic Functional Connectivity MRI. Nature Neuroscience 16(7), 832-837.

- Canales, J. (2015). The Physicist and the Philosopher: Einstein, Bergson, and the Debate That Changed Our Understanding of Time. Oxford: Princeton University Press.

- Canguilhem, G. (1991). The Normal and the Pathological (translated by C. R. Fawcett). New York: ZONE.

- Canguilhem, G. (1994). Etudes d'Histoire et de Philosophie des Sciences Concernant les Vivant et la Vie. Paris Vrin 
- Canguilhem, G. (2008). Knowledge of Life (translated by S. Geroulanos, \& D. Ginsburg). New York: Fordham University Press.

- Caputo, J. D. (2012). Heidegger's Philosophy of Science: The Two Essences of Science. In T. Glazebrook (ed.), Heidegger on Science (pp. 261-279). New York: SUNY Press.

- Carew, T.J., and Magsamen, S.H. (2010). Neuroscience and Education: An Ideal Partnership for Producing Evidence-Based Solutions to Guide $21^{\text {st }}$ Century Learning. Neuron 67(5), 685-688.

- Carusi, A., and Sissel Hoel, A. (2014). Towards a New Ontology of Vision. In C. Coopmans, J. Vertesi, M.E. Lynch, and S. Woolgar (eds), Representation in Scientific Practice Revisited (pp. 201-222). London: The MIT Press.

- Chang, H. (2014). Epistemic Activities and Systems of Practice: Units of Analysis in Philosophy of Science after the Practice Turn. In L. Soler, S. Zwart, M. Lynch, and V. Israel Jost (eds), Science After the Practice Turn in the Philosophy, History and Social Studies of Science (pp. 67-79). New York: Routledge.

- Chimisso, C. (2001). Gaston Bachelard: Critic of Science and Imagination. London: Routledge.

- Chimisso, C. (2008a). From Phenomenology to Phenomenotechnique: The Role of Early TwentiethCentury Physics in Gaston Bachelard's Philosophy. Studies in History and Philosophy of Science Part A 39(3), 384-392.

- Chimisso, C. (2008b). Writing the History of the Mind: Philosophy and Science in France, 19oos to 1960 . Hampshire: Ashgate Publisihing.

- Chimisso, C. (2013). The Life Sciences and French Philosophy of Science: Georges Canguilhem on Norms. In H. Andersen, D. Dieks, W.J. Gonzalez, T. Uebel, and G. Wheeler (eds), New Challenges to Philosophy of Science (pp. 399-410). Dordrecht: Springer.

- Chimisso, C. (2015). Narrative and Epistemology: Georges Canguilhem's Concept of Scientific Ideology. Studies in History and Philosophy of Science 54, 64-73.

- Choudhury, S., and Slaby, J. (2012). Introduction: Critical Neuroscience-Between Lifeworld and Laboratory. In S. Choudhury, and J. Slaby (eds), Critical Neuroscience: A Handbook of the Social and Cultural Contexts of Neuroscience. Oxford: Wiley-Blackwell.

- Churchland, P.S. (1986). Neurophilosophy: Towards a Unified Science of the Mind-Brain. Cambridge: The MIT Press.

- Churchland, P.S. (2018). Braintrust: What Neuroscience Tells us about Morality. New York: Princeton University Press.

- Cohn, S. (2012). Disrupting Images: Neuroscientific Representations in the Lives of Psychiatric Patients. In S. Choudhury, and J. Slaby (eds), Critical Neuroscience: A Handbook of the Social and Cultural Contexts of Neuroscience (pp. 179-193). Oxford: Wiley-Blackwell.

- Coopmans, C., Vertesi, J., Lynch, M.E., and Woolgar, S. (eds) (2014). Representation in Scientific Practice Revisited. London: The MIT Press.

- Cox, R. (1978). Schütz's Theory of Relevance: A Phenomenological Critique. The Hague: Springer.

- Dan-Cohen, T. (2016). Ignoring Complexity: Epistemic Wagers and Knowledge Practices among Synthetic Biologists. Science, Technology, \& Human Values 41(5), 899-921.

- Daston, L. and Galison, P. (2010). Objectivity $2^{\text {nd }}$ ed. New York: ZONE Books.
- De Boer, B., Te Molder, H., and Verbeek, P.P-. (2018). The Perspective of the Instruments: Mediating Collectivity. Foundations of Science 23(4), 739-755.

- De Vries, G. (2016). Bruno Latour. Cambridge: Polity Press.

- Deleuze, G., and Guattari, F. (1987). A Thousand Plateaus: Capitalism and Schizophrenia (translated by B. Massumi). Minneapolis: The University of Minnesota Press.

- Descartes, R. (1993). Meditations on First Philosophy $3^{\text {rd }}$ edition (translated by D. A. Cress). Indianapolis: Hackett Publishing Company.

- Dumit, J.(2004).Picturing Personhood: Brain Scans and Biomedical America. Princeton: Princeton University Press.

- Edwards, D., Ashmore, M. \& Potter, J. (1995). Death and Furniture: The Rhetoric, Politics, and Theology of Bottom Line Arguments against Relativism. History of the Human Sciences 8(2), 25-49.

- Ellul, J. (1964). The Technological Society (translated by J. Wilkinson). New York: Knopf.

- Feenberg, A. (1999). Questioning Technology. London: Routledge.

- Feenberg, A. (2015). Making the Gestalt Switch. In R. Rosenberger, and P.P-. Verbeek (eds), Postphenomenological Investigations: Essays on Human-Technology Relations (pp. 229-237). New York: Lexington Books.

- Feenberg, A. (2017). Technosystem: The Social Life of Reason. Cambridge: Harvard University Press.

- Fitzgerald, D. (2014). The Trouble with Brain Imaging: Hope, Uncertainty and Ambivalence in the Neuroscience of Autism. BioSocieties 9(3), 241-261.

- Forss, A. (2012). Cells and the (Imaginary) Patient:The Multistable Practitioner-Technology-Cell Interface in the Cytology Laboratory. Medicine, Health Care and Philosophy 15(3), 295-308.

- Foucault, M. (1989). Introduction. In G. Canguilhem. The Normal and the Pathological (translated by C.R. Fawcett) (pp. 7-24). New York: ZONE Books.

- Franssen, M., et al. (eds). (2016). Philosophy of Technology after the Empirical Turn. Dordrecht: Springer.

- Friis, J.K.B.O. (2012). Perception: Embodiment and Beyond. Foundations of Science 17(4),363-367.

- Garfinkel, H. (1952). The Perception of the Other: A Study in Social Order. Unpublished Ph.D. dissertation, Harvard University.

- Garfinkel, H.(1967). Studies in Ethnomethodology. New Jersey: Prentice-Hall.

- Garfinkel, H. (2002). Ethnomethodology's Program: Working Out Durkheim's Aphorism (ed. A.W. Rawls). New York: Rowman \& Littlefield Publishers.

- Garfinkel, H., Lynch, M., and Livingston, E. (1981). The Work of a Discovering Science Construed with Materials from the Optically Discovered Pulsar. Philosophy of Social Science 11(2), 131-158.

- Garfinkel, H., and Sacks, H. (1986). On Formal Structures of Practical Actions. In H. Garfinkel (ed.), Ethnomethodological Studies of Work (pp. 160-193). London: Routledge.

- Gaukroger, S. W. (1976). Bachelard and the Problem of Epistemological Analysis. Studies in History and Philosophy of Science 7(3), 189-244

- Gayon, J. (1998). The Concept of Individuality in Canguilhem's Philosophy of Biology. Journal of the History of Biology 31, 305-325

- Gest, H. (2004). The Discovery of Microorganisms by Robert Hooke and Antoni van Leeuwenhoek, 
Fellows of the Royal Society. Notes and Records of the Royal Society $58(2), 187-201$.

- Giere, R. (2002). Discussion Note: Distributed Cognition in Epistemic Cultures. Philosophy of Science $69(4), 637-644$.

- Giere, R. (2006). Scientific Perspectivism. Chicago: University of Chicago Press.

- Giere, R., and Moffatt, B. (2003). Distributed Cognition: Where the Cognitive and the Social Merge. Social Studies of Science 33(2), 301-310.

- Gilbert, G.N., and Mulkay, M. (1984). Opening Pandora's Box: A Sociological Analysis of Scientist's Discourse. Cambridge: Cambridge University Press.

- Glazebrook, T. (200oa). From to Nature, to Technology: Heidegger on Aristotle, Galileo, and Newton. The Southern Journal of Philosophy 38, 95-118.

- Glazebrook, T. (20oob). Heidegger's Philosophy of Science. New York: Fordham University Press.

- Greco, M. (2005). On the Vitality of Vitalism. Theory, Culture and Society 22(1), 15-27.

- Greicius, M. (2008). Resting-State Functional Connectivity in Neuropsychiatric Disorders. Current Opinion in Neurology 21(4), 424-430

- Gross, S. (2009). Experts and'Knowledge that Counts': A Study into the World of Brain Cancer Diagnosis. Social Science \& Medicine 69, 1819-1826.

- Hacking, I. (1983). Representing and Intervening: Introductory Topics in the Philosophy of Natural Science. Cambridge: Cambridge University Press.

- Hacking, I. (1999). The Social Construction of What? Cambridge: Harvard University Press.

- Harman, G. (2004). Prince of Networks: Bruno Latour and Metaphysics. Melbourne: Re.press.

- Hasse, C. (2008). Postphenomenology: Learning Cultural Perception in Science. Human Studies 31, 43-61.

- Heiberg Engel, P.J. (2008). Tacit Knowledge and Visual Expertise in Medical Diagnostic Reasoning: Implications for Medical Education. Medical Teacher 3o(7), 184-188

- Heidegger, M. (1977a). The Question Concerning Technology (translated by W. Lovitt). In W. Lovitt (ed.), The Question Concerning Technology and Other Essays (pp. 3-35). London: Garland Publishing.

- Heidegger, M. (1977b). The Age of the World Picture (translated by W. Lovitt). In W. Lovitt (ed.), The Question Concerning Technology and Other Essays (pp. 115-154). London: Garland Publishing.

- Heidegger, M. (1977c). Science and Reflection (translated by W. Lovitt). In W. Lovitt (ed.), The Question Concerning Technology and Other Essays (pp. 155-182). London: Garland Publishing.

- Heidegger, M. (1985). Being and Time (translated by J. Macquarrie, and E. Robinson). Oxford: Basil Blackwell.

- Heidegger, M. (2004). Die Grundbegriffe der Metaphysik. Welt - Endlichkeit - Einsamkeit. Frankfurt am Main: Klostermann.

- Heritage, J. (1984). Garfinkel and Ethnomethodology. Cambridge: Polity Press.

- Herrman, C.S., Strüber, D., Helfrich, R.F., and Engel, A.K. (2016). EEG Oscillations: From Correlation to Causality. International Journal of Psychophysiology 103, 12-21.

Hertogh, C.M.P.M. (1986). Bachelard en Canguilhem: Epistemologische Discontinuïteit en het Medisch Normbegrip. Amsterdam: VU Uitgeverij.

- Hoel, A.S., and Van der Tuin, I. (2013). The Ontological Force of Technicity: Reading Cassirer and
Simondon Diffractively. Philosophy and Technology 26(2), 187-202.

- Holton, G. (1969). Einstein, Michelson, and the “Crucial” Experiment. Isis 6o(2), 132-197.

- Hooke, R. (1665). Micrographia: Or Some Physiological Description of Minute Bodies Made by Magnifying Glasses. With Observations and Inquiries Thereupon. London: J. Martyn and J. Allestry.

- Horkheimer, M. \& Adorno, T. (1969). Dialektik der Aufklärung: Philosophische Fragmente. Frankfurt: Fischer

- Høstaker, R. (2005). Latour-Semiotics and Science Studies. Science Studies 18(2), 2-25.

- Hutchins, E. (1995). Cognition in the Wild. Cambridge: MIT Press.

- Hyder, D. (2003). Foucault, Cavaillès, and Husserl on the Historical Epistemology of the Sciences. Perspectives on Science 10(4), 107-129.

- Hyman, S.E. (2010). The Diagnosis of Mental Disorders: The Problem of Reification. Annual Review of Clinical Psychology 6, 155-179.

- Ihde, D. (1979). Technics and Praxis. Dordrecht: D. Reidel Publishing Company.

- Ihde, D. (1990). Technology and the Lifeworld: From Garden to Earth. Indianapolis: Indiana University Press.

- Ihde, D. (1991). Instrumental Realism: The Interface between Philosophy of Science and Philosophy of Technology. Indianapolis: Indiana University Press.

- Ihde, D. (1993). Postphenomenology: Essays in the Postmodern Context. Evanston: Northwestern University Press.

- Ihde, D. (1997). The Structure of Technology Knowledge. International Journal of Technology Design Education 7, 73-79.

- Ihde, D. (1998). Expanding Hermeneutics: Visualism in Science. Evanston: Northwestern University Press.

- Ihde, D. (2009). Postphenomenology and Technoscience: The Peking Lectures. New York: The State University of New York Press.

- Ihde, D. (2010). Heidegger's Technologies: Postphenomenological Perspectives. New York: Fordham University Press.

- Ihde, D., and Selinger, E. (2004). Merleau-Ponty and Epistemology Engines. Human Studies 27(4),361-376.

- Insel, T.R., and Cuthbert, B.N. (2015). Brain Disorders? Precisely. Science 348(6234), 499-500.

- Jaspers, K. (1951). Man in the Modern Age (translated by C. Paul, \& E. Paul). London: Routledge \& Kegan Paul.

- Kaplan, E. K. (1972). Gaston Bachelard's Philosophy of Imagination: An Introduction. Philosophy and Phenomenological Research 33(1), 1-24

- Kiran, A.H., Verbeek, P.P-., and Oudshoorn, N. (2015). Beyond Checklists: Towards an Ethical-Constructive Technology Assessment. Journal of Responsible Innovation 2(1), 5-19.

- Kletzl, S. (2014). Scrutinizing Thing Knowledge. Studies in History and Philosophy of Science Part A 47, 118-123.

- Knorr-Cetina, K. (1999). Epistemic Cultures: How the Sciences Make Knowledge. London: Harvard University Press.

- Knorr-Cetina, K., and Mulkay, M. (eds). (1983). Science Observed: Perspectives on the Social Study of Science. London: SAGE

- Koch, C. et al. (2015). Project Mindscope. In G. Marcus, and J. Freeman (eds), The Future of the Brain: Essays by the World's Leading Neuroscientists (pp. 25-39). Princeton: Princeton University Press. 
- Kochan, J. (2010). Latour's Heidegger. Social Studies of Science 40(4), 579-598.

Koschmann, T., and Zemel, A. (2014). Instructed Objects. In M. Nevile, P. Haddington. T. Heinemann, and M. Rauniomaa (eds), Interacting with Objects: Language, Materiality, and Social Activity (pp. 357-377). Amsterdam: John Benjamins.

- Kroes, P.A., and Meijers, A. (eds) (200o). The Empirical Turn in the Philosophy of Technology. Amsterdam: JAI.

- Kuhn, T. S. (1962). The Structure of Scientific Revolutions. Chicago: University of Chicago Press.

- Lamme, V. (2006). Towards a True Neural Stance on Consciousness. Trends in Cognitive Sciences 10(11), 494501.

- Latour, B. (1983). Give me a Laboratory and I will Raise the World. In K. Knorr-Cetina, and M. Mulkay (eds), Science Observed (pp. 141-170). London: SAGE.

- Latour, B. (1986). Visualization and Cognition: Thinking with Eyes and Hands, Knowledge and Society 6, $1-40$.

- Latour, B. (1987). Science in Action: How to Follow Scientists and Engineers through Society. Cambridge: Harvard University Press.

- Latour, B. (1988a). The Enlightenment without the Critique: A Word on Michel Serres' Philosophy. In J. Griffith (ed.), Contemporary French Philosophy (pp. 83-98). Cambridge: Cambridge University Press.

- Latour, B. (1988b). The Pasteurization of France (translated by A. Sheridan, and J. Law). Cambridge: Harvard University Press.

- Latour, B. (1993a). Pasteur on Lactic Acid Yeast: A Partial Semiotic Analysis. Configurations 1(1), 129-146.

- Latour, B. (1993b). We have Never been Modern (translated by C. Porter). Cambridge: Harvard University Press.

- Latour, B. (1994). On Technical Mediation - Philosophy, Sociology, Genealogy. Common Knowledge 3(2), 29-64.

- Latour, B. (1996). On Actor-Network Theory. A Few Clarifications plus More than a Few Complications. Soziale Welt 47, 369-381.

- Latour, B. (1999a). Pandora's Hope - Essays in the Reality of Science Studies. Cambridge: Harvard University Press.

- Latour, B. (1999b). On Recalling ANT. In J. Law, and J. Hassard (eds), Actor Network and After (pp. 15-25). Oxford: Blackwell.

- Latour, B. (2004). Why has Critique Run out of Steam? From Matters of Fact to Matters of Concern. Critical Inquiry 30, 225-248.

- Latour, B. (2005).Reassembling the Social:An Introduction to Actor-Network Theory. Oxford: Oxford University Press.

- Latour, B. (2008). What is the Style of Matters of Concern? Assen: Van Gorcum.

- Latour, B., and Woolgar, S. (1986). Laboratory Life: The Construction of Scientific Facts $2^{\text {nd }}$ ed. Princeton: Princeton University Press.

- Law, J. (2007). Actor Network Theory and Material Semiotics. In B. Turner (ed.), The New Blackwell Companion to Social Theory, $3^{\text {rd }}$ Edition (pp. 141-158). Oxford: Blackwell.

- Lecourt, D. (1975). Marxism and Epistemology: Bachelard, Canguilhem and Foucault. London: NLB.
- L Lichtenstein, P., Carlström, E., Rastam, M., Gillberg, C., and Anckarsäter, H. (2010). The Genetics of Autism Spectrum Disorders and Neuropsychiatric Disorders in Childhood. American Journal of Psychiatry 67 1357-1363.

- Littlefield, M. (2009). Constructing the Organ of Deceit: The Rhetoric of fMRI and Brain Fingerprinting in Post-9/11 America. Science, Technology, \& Human Values 34(3), 365-392.

- Littlefield, M., and Johnson, J.J. (eds) (2012). The Neuroscientific Turn: Transdisciplinarity in the Age of the Brain. Michigan: The University of Michigan Press.

- Loever, S., Guchet, X., and Bensaude-Vincent, B. (2018). Is There a French Philosophy of Technology? General Introudction. In S. Loeve, X. Guchet, and B. Bensaude-Vincent (eds), French Philosophy of Technology: Classical Readings and Contemporary Approaches (pp. 1-20). Dordrecht: Springer.

- Loscerbo, J.(1981). Being and Technology:A Study in the Philosophy of Martin Heidegger. The Hague: Martinus Nijhoff Publishers.

- Lynch, M. (1985). Art and Artifact in Laboratory Science: A Study of Shop Work and Shop Talk in a Research Laboratory. London: Routledge \& Kegan Pau

- Lynch, M. (1988). The Externalized Retina: Selection and Mathematization in the Visual Documentation of Objects in the Life Sciences. Human Studies 11(2), 201-234.

- Lynch, M. (1993). Scientific Practice and Ordinary Action: Ethnomethodology and Social Studies of Science. Cambridge: Cambridge University Press

- Lynch, M. (1994). Representation is Overrated: Some Critical Remarks About the Use of the Concept of Representation in Science Studies. Configurations 2(1), 137-149.

- $\quad$ Lynch, M., and Bogen, D. (1994). Harvey Sacks's Primitive Natural Science. Theory, Culture \& Society 11, 65-104.

- Maung, H.H. (2016). Diagnosis and Causal Explanation in Psychiatry. Studies in History and Philosophy of Biological and Biomedical Sciences 60, $15-24$

- McManus, D. (2012). Heidegger $\&$ the Measure of Truth. Oxford: Oxford University Press.

- Menon, V. (2011). Large-scale Brain Networks and Psychopathology: A Unifying Triple Network Model. Trends in Cognitive Sciences 15(1), 483-506.

- Merleau-Ponty, M. (2005). Phenomenology of Perception (translated by Colin Smith). London: Routledge.

- Meynen, G. (2014). Neurolaw: Neuroscience, Ethics, and Law. Review Essay. Ethical Theory and Moral Practice $17(4), 819-829$.

- Mills, S. (2016). Gilbert Simondon: Information, Technology and Media. London: Rowman \& Littlefield

- Miniussi, C., Harris, J.A., and Ruzzoli, M. (2013). Modelling Non-Invasive Brain Stimulation in Cognitive Neuroscience. Neuroscience and Biobehavioral Reviews 37(8), 1702-1712.

- Nevile, M., Haddington, P., Heinemann, T. \& Rauniomaa, M. (eds) (2014), Interacting with Objects: Language, Materiality, and Social Activity. Amsterdam: John Benjamins.

- Nordmann, A. (2012). Another parting of the ways: Intersubjectivity and the Objectivity of Science. Studies in History and Philosophy of Science 43, 38-46.

- Ogawa, S., Lee, T.M., Kay, A.R., and Tank, D.W. (1990) Brain Magnetic Resonance Imaging with Contrast Dependent Blood Oxygenation. Proceedings of the National Academy of Sciences 87(24), 9868-9872 
- Olesen, F. (2012). Scientific Objectivity and Postphenomenological Perception. Foundations of Science, $17(4), 357-362$.

- Pickersgill, M. (2011). 'Promising' Therapies: Neuroscience, Clinical Practice, and the Treatment of Psychopathy. Sociology of Health \& Illness 33(3), 448-464.

- Pickersgill, M., and Van Keulen, I. (eds) (2012). Sociological Reflections on the Neurosciences. Bingley: Emerald.

- Pitt, J. (2007). Speak to Me: Essay Review of Thing knowledge: A Philosophy of Scientific Instruments by Davis Baird. Metascience 16(1), 51-59.

- Poldrack, R.A., Mumford, J.A., Schonberg, T., Kalar. D., Barman, B., and Yarkoni, T. (2012). Discovering Relations Between Mind, Brain, and Mental Disorders Using Topic Mapping. PLOS Computational Biology 8(10), e1002707.

- Popper, K. (1959). The Logic of Scientific Discovery. London: Hutchinson \& Co.

Potter, J. (1996). Representing Reality: Discourse, Rhetoric and Social Construction. London: SAGE.

- Rabinow, P. (1994). Introduction: A Vital Rationalist. In F. Delaporte (ed.), A Vital Rationalist: Selected Writings from Georges Canguilhem (pp. 11-22). New York: ZONE Books.

- Rao, M.B., Jongerden, J., Lemmens, P., and Ruivenkamp, G. (2015). Technological Mediation and Power: Postphenomenology, Critical Theory, and Autonomist Marxism. Philosophy and Technology 28(3), 449-474.

- Rees, T. (2016). Plastic Reason: An Anthropology of Brain Science in Embryogenetic Terms. Oakland: University of California Press.

- Rheinberger, H.J.- (1997a). Toward a History of Epistemic Things. Synthesizing Proteins in the Test Tube. Stanford: Stanford University Press.

- Rheinberger, H.J-- (1997b). Experimental Complexity in Biology: Some Epistemological and Historical Remarks. Philosophy of Science 64(4), S245-254.

- Rheinberger, H.J. (2005). Gaston Bachelard and the Notion of "Phenomenotechnique." Perspectives on Science 13(3), 313-328.

- Rheinberger, H.J. (2010).An Epistemology of the Concrete: Twentieth-Century Histories of Life. Durham: Duke University Press.

- Romele, A. (2017). Entangled in Digital Media. Techné: Research in Philosophy and Technology 21(1), 106-113.

- Rosenberger, R. (2008). Perceiving other planets: Bodily experience, interpretation, and the Mars Orbiter Camera. Human Studies 31, 63-75.

- Rosenberger, R. (2011). A Case Study in Applied Philosophy of Imaging: The Synaptic Vesicle Debate. Science, Technology, \& Human Values 36(1), 6-32.

- Rosenberger, R. (2013). Mediating Mars: Perceptual Experience and Scientific Imaging Technologies. Foundations of Science 18, 75-91.

- Rosenberger, R. (2016). Notes on a nonfoundational phenomenology of technology. Foundations of Science. DOI: 10.1007 / 1 10699-015-9480-5.

- Rosenberger, R., and Verbeek, P.P. (eds) (2015). Postphenomenological Investigations: Essays on HumanTechnology Relations. London: Lexington Books.

- Roskies, A. (2007). Are Neuroimages like Photographs of the Brain? Philosophy of Science 74(5), 860-872.
- Rouse, J. (1996). Engaging Science: How to Understand its Practices Philosophically. New York: Cornell University Press.

- Sack, A. (2006). Transcranial Magnetic Stimulation, Causal-Structure-Function Mapping and Networks of Functional Relevance. Current Opinion in Neurobiology 16(5), 593-599.

- Sacks, H. (1992). Lectures on Conversation Volumes I \& II (ed. G. Jefferson). Oxford: Blackwell.

- Schmidgen, H. (2014). Bruno Latour in Pieces: An Intellectual Biography (translated by G. Custance). New York: Fordham University Press.

- Schaffer, S. (1992). Essay Review: The Eighteenth Brumaire of Bruno Latour. Studies in History and Philosophy of Science 22(1), 174-192

- Science Project: Acceleration on an Inclined Plane. Retrieved from https://www.education.com/sciencefair/article/rolling-downhill-measuring-acceleration/ (Accessed 26-07-2018).

- Schütz, A. (1944). The Stranger: An Essay in Social Psychology. American Journal of Sociology 49(4), 499-507

- Schütz, A. (1945). On Multiple Realities. Philosophy and Phenomenological Research 5(4), 533-576.

- Schütz, A. (1953). Common-Sense and Scientific Interpretation of Human Action. Philosophy and Phenomenological Research 14(1), 1-38

- Schütz, A. (1962). Concept and Theory Formation in the Social Sciences. In Alfred Schütz: Collected Papers, Volume I (pp. 48-66). The Hague: Martinus Nijhoff.

- Serres, M., and Latour, B. (1995). Conversations on Science, Culture, and Time (translated by R. Lapidus). Michigan: The University of Michigan Press.

- Shapin, S. and Schaffer, S. (2011). Leviathan and the Air-Pump: Hobbes, Boyle, and the Experimental Life $2^{\text {nd }}$ edition. Princeton: Princeton University Press.

- Simondon, G. (2016). On the Mode of Existence of Technical Objects (translated by C. Malaspina, and J. Rogove). Minneapolis: Univocal,

- Smith, D. (2018). Exceptional Technologies: A Continental Philosophy of Technology. London: Bloomsbury.

- Soon, C.S., Brass, M., Heinze, H.J.-, and Haynes, J.D-. (2008). Unconscious Determinants of Free Decisions in the Human Brain. Nature Neuroscience 11, 543-545

- Sporns, O. (2014). Contributions and Challenges for Network Models in Cognitive Neuroscience. Nature Neuroscience 17(2), 652-660.

- Suárez, M. (2004). An Inferential Conception of Scientific Representation. Philosophy of Science 71(5), 767779 .

- Svenaeus, F. (2013). The Relevance of Heidegger's Philosophy of Technology for Biomedical Ethics. Theory of Medicine and Bioethics 34, 1-15.

- Te Molder, H. (2015). What Happened to Post-Cognitive Psychology? In: Tileaga, C., and Stokoe, E. (eds), Discursive Psychology: Classic and Contemporary Issues. Explorations in Social Psychology (pp. 87-100). New York: Routledge.

- Te Molder, H., and Potter, J. (eds) (2005). Conversation and Cognition. Cambridge: Cambridge University Press.

- Ten Have, P. (1990). Methodological Issues in Conversation Analysis. Bulletin de Methodologie Sociologie $27,23-51$. 
- Tiles, M. (1984). Bachelard: Science and Objectivity. Cambridge: Cambridge University Press.

- Van Dongen, J. (2009). On the Role of the Michelson-Morley Experiment: Einstein in Chicago. Archive for the History of Exact Sciences 63, 655-663.

- Van Fraassen, B.C. (1980). The Scientific Image. Oxford: Clarendon Press

- Van Fraassen, B.C. (2008). Scientific Representation: Paradox of Perspective. Oxford: Clarendon Press.

- Verbeek, P.P. (2003). Material Hermeneutics. Techné 6(3), 181-184.

- Verbeek, P.P. (2005). What Things Do. Pennsylvania: Pennsylvania University Press.

- Verbeek, P.P-. (2011). Moralizing Technology: Understanding and Designing the Morality of Things. Chicago: The University of Chicago Press.

- Verbeek, P.P. (2016). Toward a Theory of Technological Mediation:A Program for Postphenomenological Research. In Friis, J., and Crease, R. (eds), Technoscience and Postphenomenology: The Manhattan Papers (pp. 189-204). London: Lexington Books.

- Vertesi, J. (2012). Seeing Like a Rover: Visualization, Embodiment, and Interaction on the Mars Exploration Rover Mission. Social Studies of Science 42(3), 393-414.

- Vidal, F.(2009). Brainhood, Anthropological Figure of Modernity. History of the Human Sciences 22(1), 5-36.

Visser, G. (2014). Heideggers Vraag naar de Techniek. Nijmegen: Uitgeverij Vantilt.

- Vrecko, S. (2010). Neuroscience, Power and Culture: An Introduction. History of the Human Sciences 23(1), $1-10$

- Walsh, V., and Cowey, A. (2000). Transcranial Magnetic Stimulation and Cognitive Neuroscience. Nature Reviews Neuroscience 1(1), 73-79

- Ward, L.M. (2003). Synchronous Neural Oscillations and Cognitive Processes. Trends in Cognitive Science $7(12), 553-559$

- Whitehead, A.N. (1920). The Concept of Nature. Cambridge: Cambridge University Press.

- Wittenburg, P. et al. (2006). ELAN: A Professional Framework for Multimodality Research. In Proceedings of LREC 2006, Fifth International Conference on Language Resources and Evaluation (pp. 1556-1559).

- Wolf, T. (2003). Konstitution und Kritik der Wissenschaften bei Heidegger. Zeitschrift für Philosophische Forschung 57(1), 94-110.

- Wolf, T. (2005). Hermeneutik und Technik: Martin Heideggers Auslegung des Lebens und der Wissenschaft als Answort auf die Krise der Moderne. Würzburg: Königshausen \& Neumann. 
APPENDIX:

Summary

Samenvatting

Acknowledgements

Publications 


\section{SUMMARY}

In my dissertation, I develop a philosophical account of the role of scientific instruments in scientific practice with a specific focus on the neurosciences. I conceptualize scientific instruments as mediating technologies, a notion derived from the approach of postphenomenology developed in current philosophy of technology. In this specific understanding, scientific instruments are not understood as mute instruments that allow to better realize pre-existing human goals and projects, but as mediating how human beings relate to the world, thereby shaping their experience and understanding of reality. Based on this conceptualization, I develop an account of mediating technologies that is specific to the practice of science.

Investigating the role of mediating technologies in scientific practice requires a focus on a specific type of practice. In my case, the focus will be on an area of science that has been rapidly growing in the last decades: the (cognitive) neurosciences. I have two main reasons for focusing on this specific area. Firstly, the development of the neurosciences into a 'Big Science' ran parallel with the development of advanced imaging technologies allowing to visualize brain activity. This makes it an excellent area to study how the neurosciences and the objects that neuroscientists speak about are shaped in relation with technologies. Secondly, the neurosciences currently draw a lot of public attention and media coverage, often conveying the message that increasingly mental phenomena are demystified by the neurosciences and can be explained purely in materialist terms. The enormous public interest in scientific explanations of the mind make some suggest that we currently witness a 'neurohype'. This makes it pivotal to understand how the objects that neuroscientists investigate and make claims about are shaped by the technologies they use.

The goal of my dissertation is twofold: on the one hand, it aims to-building on the work of Don Ihde, Martin Heidegger, Gaston Bachelard, and Bruno Latour-develop a systematic account of the mediating role of technologies in scientific practice. On the other hand, this account will be used to study how brain imaging and brain stimulation technologies shape the reality that neuroscientists investigate through an analysis of two case-studies: one in cognitive neuroscience, and one in neuropsychiatry.

A postphenomenological approach on the mediating role of scientific instruments, so I argue in this dissertation insufficiently recognizes both the importance of the theoretical aspects of science and the collectivity of science. The former, I tried to integrate by reevaluating the insights of 'classical philosophers' that posited a divided between philosophy and scientific research. Specifically, I showed the ongoing relevance of the philosophy of Martin Heidegger and Gaston Bachelard by integrating their theoretical work into an empirical philosophy of technoscience. By taking seriously 
Heidegger's suggestion that science intends to develop a relation with the world in terms of the present-at-hand, it became possible to ask what is specific to scientific practice in contrast with other practices that do not have this explicit aim. Accordingly, I identified as one of the central concerns of scientific investigation precisely how this relation is to be established.

With the introduction of the epistemology of Gaston Bachelard and his notion of phenomenotechnique, postphenomenology was augmented with the concepts that scientists use when understanding the phenomena that they study. When the objects of science are approached as coming into being in a phenomenotechnique, the question whether a philosophy of science should focus on either theories or practices is replaced with the question how scientific instruments co-constitute the concepts that scientists employ when understanding the reality they study. This insight is relevant for a philosophy of technological mediation: technologies not only mediate the practical interactions with the things around us, but also shape the terms that scientists use when attributing meaning to the reality of the objects they investigate. Understanding this process requires to study the hermeneutic work arising within relations between scientists and scientific instruments.

I develop an ethnomethodological approach to scientific practices that allows to study this hermeneutic work. This approach allows to analyze how scientists appropriate technological mediations in terms of the epistemic norms that neuroscientists orient in the building of a shared reality. In my first case-study, I use this approach to study empirically how the scientific object 'visual attention' in the cognitive neurosciences is shaped through appropriations of technological mediations. I show that the constitution of visual attention is managed in terms of a tradeoff between the epistemic norms of 'causality' and 'reality', and that the way in which researchers orient to these norms is mediated by the different technologies used. In my second case-study, I study how brain imaging technologies mediate how the objects of neuropsychiatry (i.e., mental disorders) are constituted. I argue that the constitution of mental disorders in neuropsychiatric practice takes place through a trade-off of the epistemic norms of complexity and simplicity, and show that the way this trade-off is managed mediates how the adequacy of earlier psychiatric diagnoses is evaluated, and how experiments in neuropsychiatry are designed.

By analyzing the mediating role of technologies in scientific practice, this dissertation has attempted to make it intelligible how man is today coupled to the world through scientific objects (of the neurosciences). This I have done by showing the processes within which these objects come into being within scientific laboratories and which structuring role epistemic norms have in this process. Intuitively grasping the normative contingencies involved in the constitution of scientific objects helps neuroscientists to reflect on its place in the technical ensemble that the laboratory is. Applied to the neurosciences, it opens up the possibility to reflect on the relation between the technicification of human psychology and the specific conception of the human subject that it is accompanied with. An explication of the constitution of neuroscientific objects is, from this perspective, an explication of how it is to live with the neurosciences. 


\section{SAMENVATTING}

HOE WETENSCHAPPELIJKE INSTRUMENTEN SPREKEN: EEN HERMENEUTIEK VAN TECHNOLOGISCHE MEDIATIES IN DE (NEURO-)WETENSCHAPPELIJKE PRAKTIJK

In dit proefschrift ontwikkel ik een filosofische benadering om de rol van wetenschappelijke instrumenten in de wetenschappelijke praktijk beter te begrijpen, en focus in het bijzonder op de rol van instrumenten in de neurowetenschappen. Om dit te bewerkstelligen stel ik voor om wetenschappelijke instrumenten te begrijpen als mediërende technologieën, een term die ik overneem uit de postfenomenologie. Deze term duidt aan dat wetenschappelijke instrumenten geen neutrale of stemloze objecten zijn die in staat stellen tot het steeds beter uitvoeren van vooraf bepaalde doelen en activiteiten. In tegendeel, als mediërende technologieën begrepen, vormen wetenschappelijke instrumenten de ervaring en het begrip dat we van de werkelijkheid hebben. In lijn met deze gedachte ontwikkel ik een benadering die zich specifiek richt op hoe technologieën de werkelijkheid mediëren binnen het domein van de wetenschappelijke praktijk. Bijgevolg wordt de vraag gesteld of er iets specifiek iets aan de wetenschappelijke praktijk dat in ogenschouw moet worden genomen wanneer we de mediërende rol van technologieën in de wetenschap willen analyseren.

De rol van mediërende technologieën in de wetenschappelijke praktijk kan niet in zijn algemeenheid onderzocht worden, maar vergt te focussen op een specifieke wetenschapsgebied.In dit proefschrift focusikopeen wetenschapsgebied dat de afgelopen decennia is opgekomen en momenteel veel publieke aandacht genereert: de (cognitieve) neurowetenschappen. De twee belangrijkste redenen om op dit gebied te focussen zijn de volgende: ten eerste is de ontwikkeling van de cognitieve neurowetenschappen niet los te zien van het toenemende gebruik van geavanceerde beeldvormende technologieën die het mogelijk maken om hersenactiviteit te visualiseren. Om deze reden zijn de cognitieve neurowetenschappen bij uitstek geschikt om te onderzoeken hoe de werkelijkheid waarover zij spreekt vorm krijgt door de gebruikte technologieën. Ten tweede krijgen de cognitieve neurowetenschappen veel aandacht in media en maatschappij, vaak in de vorm van het idee dat zij mentale en cognitieve fenomenen demystificeren door deze te verklaren middels een materialistisch vocabulaire. Onderzoekers karakteriseren deze ontwikkeling als een 'neurohype'. Om deze hype en haar relatie tot de objecten waarover neurowetenschappers spreken te begrijpen, is het nodig om aandacht te besteden aan de manier waarop wetenschappelijke instrumenten de werkelijkheid die neurowetenschappers onderzoeken vormgeven.

Het doel van dit proefschrift is tweeledig: enerzijds tracht ik-gebruik makend van het werk van filosofen als Don Ihde, Martin Heidegger, Gaston Bachelard, en Bruno Latour- 
een systematisch benadering te ontwikkelen om de mediërende rol van technologieën in de wetenschappelijke praktijk te onderzoeken. Anderzijds zet ik deze benadering om duidelijk te maken hoe technologieën die in staat stellen om het brein te visualiseren en te stimuleren de werkelijkheid van de neurowetenschappen op een specifieke manier vormgeven. Dit zal gedaan worden door twee casussen te analyseren waarin technologieën een centrale rol spelen: de eerste in de cognitieve neurowetenschap, en de tweede in het gebied van de neuropsychiatrie.

In het eerste deel van het proefschrift laat ik zien dat de postfenomenologische analyses de mediërende rol van wetenschappelijke instrumenten zowel het theoretische als het collectieve karakter van de wetenschap onvoldoende in ogenschouw nemen. Dit eerste aspect probeer ik te integreren in de postfenomenologie door het werk van Martin Heidegger en Gaston Bachelard te bediscussiëren in de context van de hedendaagse techniekfilosofie. Beide filosofen laten zien dat de wetenschap een speciaal karakter heeft waaraan niet voorbij gegaan dient te worden wanneer we de rol van technologie in de wetenschap trachten te begrijpen. Het is mijn doel de inzichten van beide denkers vruchtbaar te maken voor een empirische filosofie van techniek en wetenschap.

Heidegger stel voor om wetenschap te begrijpen als een praktijk die zich expliciet ten doel stelt om de wereld te doen verschijnen als een verzameling objecten extern aan het observerende individu. Hij noemt dit het doen verschijnen van de wereld als voorhanden. Wanneer dit doel specifiek tot de wetenschappelijke praktijk behoort, wordt het mogelijk deze praktijk te onderscheiden van andere praktijken die niet dit expliciete doel hebben. De centrale vraag die ik vanuit Heidegger stel is hoe de wereld als voorhanden verschijnt in de wetenschappelijke praktijk. Het theoretische karakter van de wetenschap onderzoek verder aan de hand van de epistemologie van Gaston Bachelard. Gebruikmakend van zijn notie 'fenomenotechniek' laat ik zien hoe de objecten van wetenschap tot stand komen in de interrelaties tussen instrumenten, bestaande concepten, en wetenschappelijke experimenten. Dit is een relevant inzicht voor een filosofie van technologische mediatie, omdat het laat zien dat technologieën niet alleen vormgeven hoe we praktische relateren aan de wereld, maar ook de manier waarop we middels concepten betekenis toekennen aan deze wereld. De vraag die ik vanuit dit perspectief stel is hoe de concepten die wetenschappers gebruiken om de fenomenen die ze aanschouwen te duiden worden medevormgeven door wetenschappelijke instrumenten. Technologieën zetten dus aan tot specifieke vormen van hermeneutiek in de wetenschappelijke praktijk. Ik betoog dat een filosofie van wetenschappelijke instrumenten zich ten doel dient te stellen deze hermeneutische processen bloot te leggen en te analyseren.

Ik ontwikkel een etnomethodologische benadering ten aanzien van wetenschappelijke praktijken die in staat stelt om de hermeneutiek van de wetenschappelijke praktijk te koppelen aan het collectieve karakter van wetenschapsbeoefening. Deze benadering stelt in staat om de manier waarop wetenschappers collectief betekenis geven aan technologische mediaties te analyseren. Ik gebruik de term appropriatie om dit proces te vatten. Dit appropriëren doen wetenschappers door de epistemische normen waaraan wetenschappers oriënteren gedurende de totstandkoming van een gemeenschappelijke wereld expliciet te maken.

Deze benadering pas ik toe op twee casussen. In de eerste casus gebruik ik haar om empirisch te bestuderen hoe het wetenschappelijke object 'visuele attentie' in de cognitieve neurowetenschappen vorm krijgt door de manier waarop wetenschappers technologische mediaties appropriëren. Ik laat zien dat de constitutie van 'visuele attentie' afhangt van de manier waarop de epistemische normen 'causaliteit' en 'realiteit' tegen elkaar worden afgewogen, en dat de manier waarop wetenschappers aan deze normen oriënteren gemedieerd wordt door de gebruikte technologieën. In de tweede casus bestudeer ik hoe beeldvormende technologieën de objecten van de neuropsychiatrie (d.i., mentale stoornissen) helpen te constitueren. Ik betoog dat mentale stoornissen in de neuropsychiatrische praktijk vorm krijgen door de manier waarop de epistemische normen van 'complexiteit' en 'simpelheid' worden afgewogen. Verder laat ik zien hoe de manier waarop deze afweging plaatsvindt de veronderstelde betrouwbaarheid van eerdere psychiatrische diagnoses medieert, wat zijn neerslag vindt in het ontwerp van neuropsychiatrische experimenten.

In conclusie, betoog ik dat een analyse van de mediërende rol van technologieën in de wetenschappelijke praktijk in staat stelt inzicht te bieden in de manier waarop wetenschappers gekoppeld worden aan de wereld door de manier waarop wetenschappelijke objecten tot stand komen (in de neurowetenschappen). Dit stelt (neuro-)wetenschappers in staat te reflecteren op de normen die ze gebruiken in de manier waarop technologische mediaties geapproprieerd zichtbaar te maken, en daarbij inzicht te krijgen in de contingentie van hun eigen praktijk. Het doel hiervan is om nieuwe intuities te ontwikkelen over wat het betekent om wetenschap te bedrijven. Meer specifiek hoop ik een ruimte te hebben gecreëerd waarin het mogelijk wordt te reflecteren op de manier waarop de menselijke psychologie tot technisch object gemaakt wordt in de wetenschappelijke praktijk, en het specifieke begrip van het menselijke subject tot hieraan ten grondslag ligt. Wanneer de filosofie van wetenschap en technologie op deze manier begrepen wordt, is zij niet louter een manier om te analyseren hoe wetenschappelijke objecten tot stand komen, maar ook een manier om inzicht te bieden om wat het betekent te leven met de (neuro-)wetenschappen. 


\section{ACKNOWLEDGEMENTS}

First, I would like to thank my supervisors Peter-Paul Verbeek and Hedwig te Molder for providing me the opportunity to embark on this project, and for their on-going stimulation when writing, thinking, observing, seeing, thinking, and writing again. PeterPaul, your enthusiasm has been an ongoing source of inspiration during the writing of this dissertation. You showed me that philosophy should not be an exercise that is to be reserved to a group of serious-looking individuals, but instead is found everywhere and should be accessible to everyone. Hedwig, thank you for allowing me to enter a new world by introducing me to work in conversation analysis and ethnomethodology. You helped constantly reminding me that if the empirical reality seemed incomprehensible, this would be a problem for me, and not for this reality. Thank you both for your guidance.

I also want to thank my colleagues at the philosophy department for creating a stimulating working environment. The members of the "human-technology relations" group, I want to thank specifically for the many interesting discussions and the feedback on my work Jonne and Olya, without having you as office mates, writing my dissertation would not be the same. I have great memories of the projects we have worked on together, and for the many conversations we had on what would be the purpose of doing philosophy.

The research in this dissertation would have not been possible without the willingness of two laboratories to function as an object of study. I want to thank everyone involved in these laboratories, for allowing an individual weirdly calling himself a "philosopheranthropologist" to peak into the daily activity of producing scientific knowledge.

Luckily, there are forces and sources outside of academia that allow for putting the importance of writing a $\mathrm{PhD}$ in the right perspective. Being with my friends showed me every time again, that there is more to the world than reading and writing. When I was worried about my dissertation, they helped reminding me that a head is cleared rather effectively with a couple of beers. Thanks for that. In similar vein, I thank the existence of football for allowing to forget about writing every week. Marleen, I am really glad that you have been there during the last steps of my dissertation, and for providing love and warmth during what would otherwise undoubtedly be a stressful period.

Finally, I want to thank my parents. Pa en ma, I am glad that I can celebrate this moment with you. I would not be here without you. 


\section{ABOUT THE AUTHOR}

After obtaining a bachelor's degree in philosophy at the Radboud University Nijmegen and a master's degree in history and philosophy of science at Utrecht University, Bas de Boer became a PhD student at the University of Twente. Within the project Theorizing Technological Mediation led by prof.dr.ir. Peter-Paul Verbeek and funded by the Dutch Research Council (NWO), he explored the mediating role of technologies in scientific practice with a focus on the neurosciences. This exploration that was supervised by Peter-Paul Verbeek and Hedwig te Molder resulted in this PhD dissertation.

Bas presented his work at various international conferences such as the (bi-)annual meetings of the Society for Social Studies of Science, the Society for Philosophy and Technology, as well as at workshops on the philosophy of Gaston Bachelard, and on causality in the neurosciences. Furthermore, he published in journals such as Techné: Research in Philosophy of Technology and Foundations of Science.

Bas's research interests are in (continental) philosophy of science and technology, phenomenology, hermeneutics, and philosophy of health. Currently, he is working as a post-doctoral researcher at the University of Twente on the 4TU funded project Pride and Prejudice, where he investigates how health monitoring technologies give rise to new conceptions of health. 


\section{PUBLICATIONS}

De Boer, B., \& Hoek J. (forthcoming). The Advance of Technoscience and the Problem of Death Determination: A Promethean Puzzle. Techné: Research in Philosophy of Technology

2. De Boer, B. (2019). Gaston Bachelard's Philosophy of Science: Between Project and Practice. Parrhesia: A Journal for Critical Philosophy 31, 154-173.

3. De Boer, B., Hoek, J., \& Kudina, O. (2018). Can the Technological Mediation Approach Improve Technology Assessment? A Critical View from 'Within'.Journal of Responsible Innovation 5(3), 299-315.

4. De Boer, B., Te Molder, H., \& Verbeek, P.P-. (2018). The Perspective of the Instruments: Mediating Collectivity. Foundations of Science 23(4), 739-755.

5. De Boer, B., Edens, S., \& Hoek, J. (2017). Introduction: Mediated Imaginations: Technologies Touching upon Art. Kunstlicht 38(4), 6-11.

6. De Boer, B. (2015). Jacob Colyer: Mediating Between the European and the Ottoman World. Belgrade: Embassy of the Kingdom of the Netherlands. 
